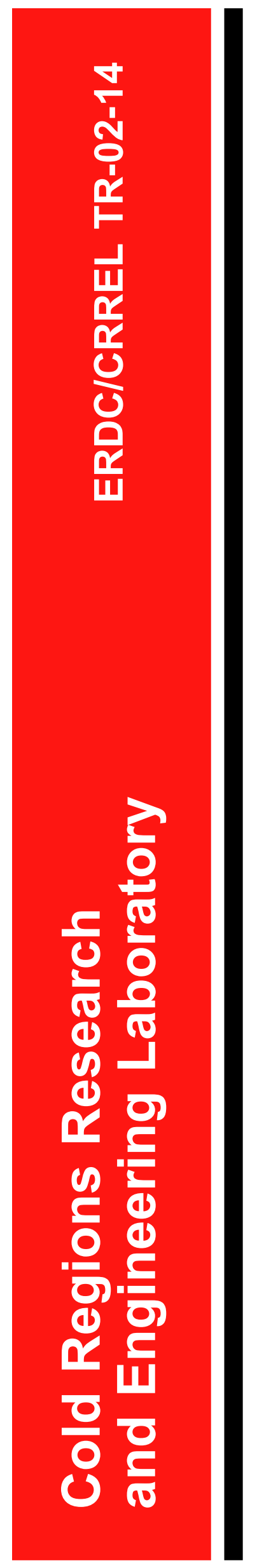

\title{
Survey of River Ice Influences on Channel Bathymetry Along the Fort Peck Reach of the Missouri River, Winter 1998-1999
}

Leonard J. Zabilansky, Robert Ettema, James Wuebben, and

Norbert Yankielun

September 2002 US Army Corps of Engineers ${ }_{\circledast}$ Engineer Research and Development Center 
Abstract: This report documents the findings of a comprehensive survey that investigated the extent to which river ice influences channel bathymetry along the Fort Peck reach of the Missouri River. The Fort Peck reach stretches about 170 miles from Fort Peck Dam, Montana, to Lake Sakakawea, North Dakota. The reach comprises a channel of alluvial sinuous-braided morphology historically known for its shifting thalweg and erosion-prone banks. The survey, which entailed extensive monitoring and detailed measurements of channel bathymetry, ice conditions, and flow velocity distribution, was conducted at five sites during the winter of 1998-99. The observations and data, though still preliminary and incomplete, indicate fundamental processes whereby river ice formation may influence channel bathymetry along the Fort Peck reach, as well as other flow-regulated, alluvial-channel rivers. Prior to the survey, the river ice processes had only been conceptualized but not documented. The results provide evidence that ice cover formation can trigger shifts in the channel thalweg location and can exacerbate riverbank erosion. The observations and data provide insights for operating Fort Peck Reservoir, as well as for engineering activities in the Fort Peck reach of the Missouri River. More generally, they indicate which riverbank stabilization structures likely work better in winter conditions, where riverside water intakes might best be located, and the effects of ice formation on local channel morphology at bridge crossings. The information also has significance for dredging work. The conclusions are based on measurements made during the 199899 winter season on the Fort Peck reach, when the hydraulic and ice conditions were unique during the time of the measurements. Further work is needed to confirm the processes and to understand the short- and long-term interactions between the variables influencing the bank-ice-sediment system.

How to get copies of ERDC technical publications:

Department of Defense personnel and contractors may order reports through the Defense Technical Information Center:

DTIC-BR SUITE 0944

8725 JOHN J KINGMAN RD

FT BELVOIR VA 22060-6218

Telephone (800) 225-3842

E-mail help@dtic.mil msorders@dtic.mil

WWW http://www.dtic.mil/

All others may order reports through the National Technical Information Service:

NTIS

5285 PORT ROYAL RD

SPRINGFIELD VA 22161

Telephone (703) 487-4650

(703) 487-4639 (TDD for the hearing-impaired)

E-mail_orders@ntis.fedworld.gov

WWW http://www.ntis.gov/index.html

For information on all aspects of the Engineer Research and Development Center, visit our World

Wide Web site:

http://www.erdc.usace.army.mil 


\section{Technical Report}

ERDC/CRREL TR-02-14

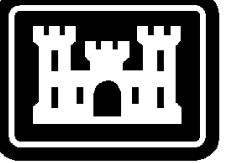

US Army Corps

of Engineers ${ }_{\circledast}$

Engineer Research and

Development Center

\section{Survey of River Ice Influences on}

Channel Bathymetry Along the Fort Peck

Reach of the Missouri River, Winter 1998-1999

Leonard J. Zabilansky, Robert Ettema, James Wuebben, and

September 2002

Norbert E. Yankielun 


\section{PREFACE}

This report was prepared by Leonard J. Zabilansky, Research Civil Engineer, U.S. Army Engineer Research and Development Center, Cold Regions Research and Engineering Laboratory (CRREL), Hanover, New Hampshire; Dr. Robert Ettema, Professor, Iowa Institute of Hydraulic Research, The University of Iowa; James Wuebben, Director, CRREL; and Dr. Norbert E. Yankielun, Research Electrical Engineer, CRREL. The work was funded by the Omaha District of the U.S. Army Corp of Engineers under contract number W59XQG82641142. Technical reviewers of the report were Dr. Jon Zufelt and Andrew Tuthill of CRREL.

The novelty of a field investigation of this magnitude and complexity required a team of unique individuals. Special thanks go to the staff of the Natural Resources Conservation Service's Montana Division and Culbertson office for their invaluable assistance in executing the field measurements. Keenan Engelke was a local resource for equipment, assisted in a multitude of tasks in the study, and provided anecdotal information on the river. Contributions from CRREL include John Gagnon with support for the web cam, Chris Donnelly for the fabrication of the TDR, and Charles Clark for electronic support of the instrumentation.

The authors express their appreciation to John Remus, Laura Timp, and William Miller of the Omaha District of the U.S. Army Corps of Engineers. Throughout its course, the project was supported in various practical ways by the Coordinated Resource Management Group of Culbertson.

This publication reflects the personal views of the authors and does not suggest or reflect the policy, practices, programs, or doctrine of the U.S. Army or Government of the United States. The contents of this report are not to be used for advertising or promotional purposes. Citation of brand names does not constitute an official endorsement or approval of the use of such commercial products. 


\section{CONTENTS}

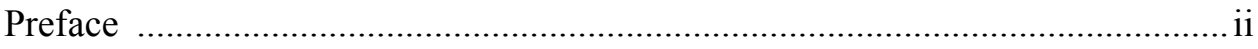

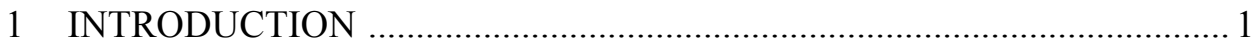

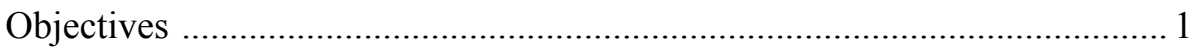

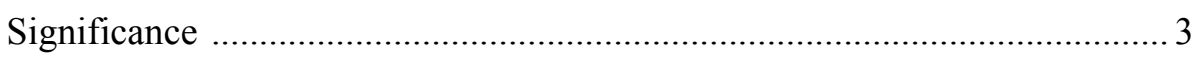

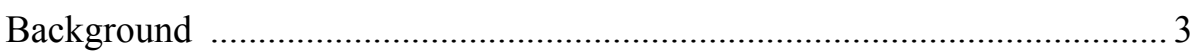

2 PHYSICAL SETTING OF THE FORT PECK REACH …............................ 5

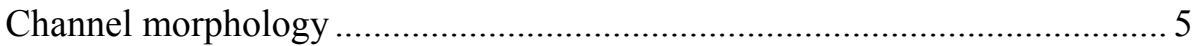

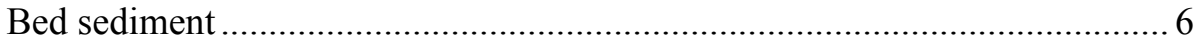

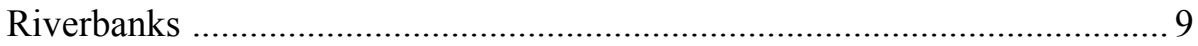

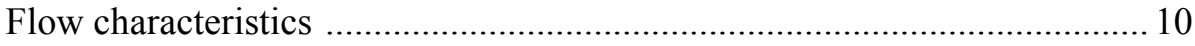

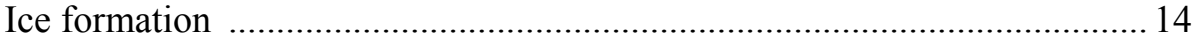

3 REVIEW OF RIVER ICE INFLUENCES ON

CHANNEL MORPHOLOGY …................................................... 15

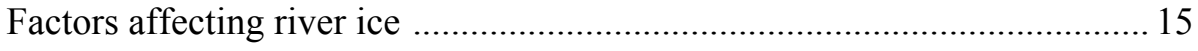

Ice cover influence on the local cross section of flow ................................ 17

Channel anabranching and avulsion ......................................................... 19

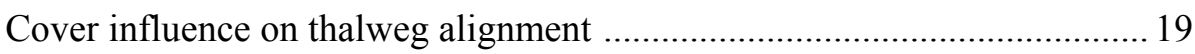

Ice cover influence on channel bed elevation ............................................... 22

4 REVIEW OF RIVER ICE INFLUENCES ON RIVERBANKS ................. 24

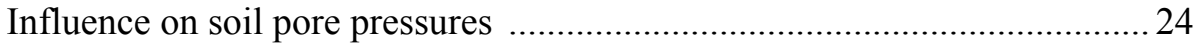

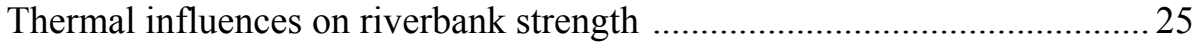

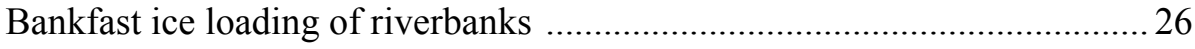

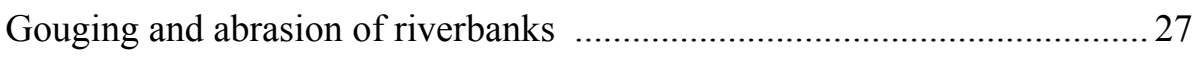

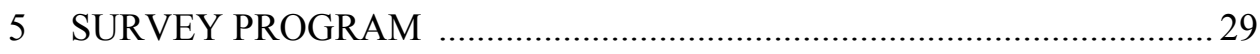

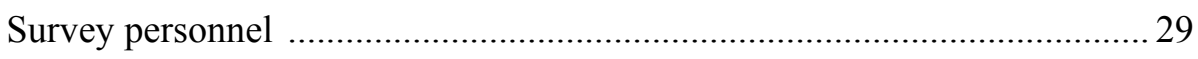

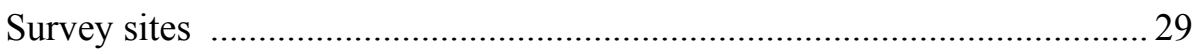

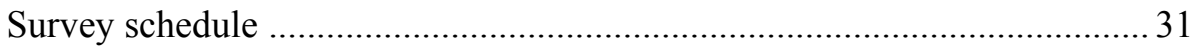

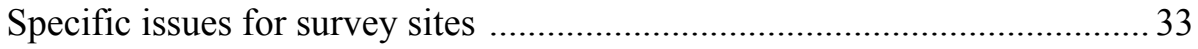

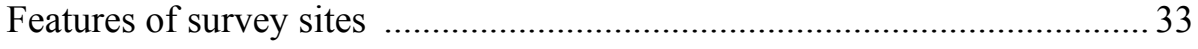

Summary of measurements and observations .......................................... 41 


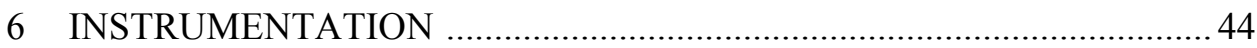

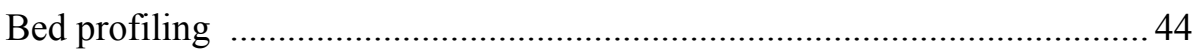

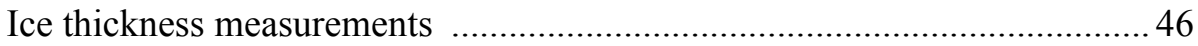

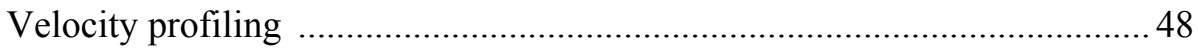

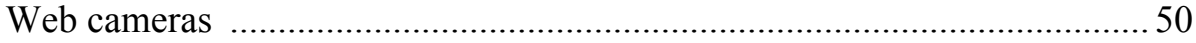

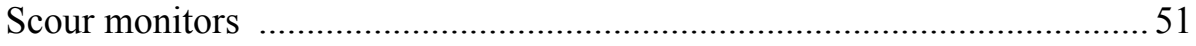

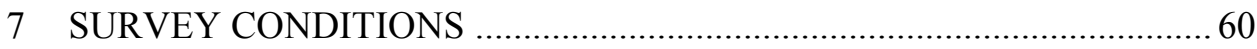

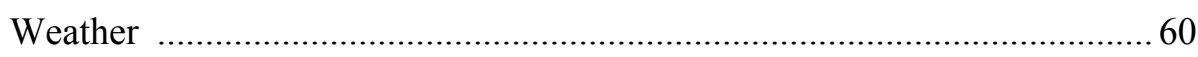

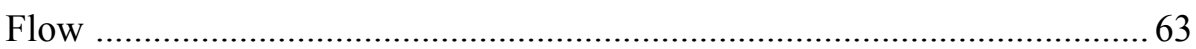

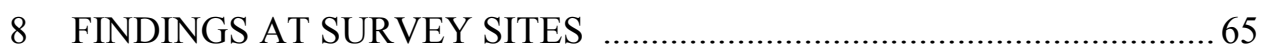

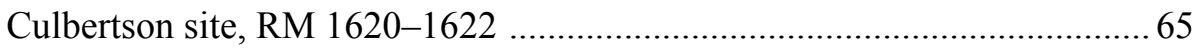

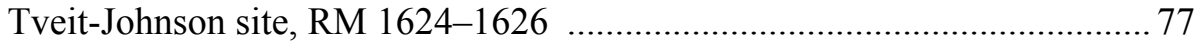

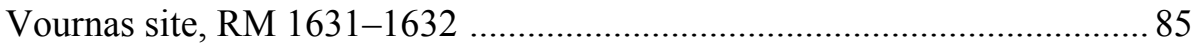

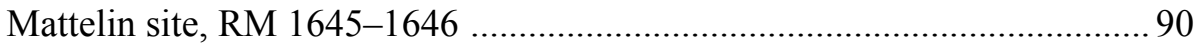

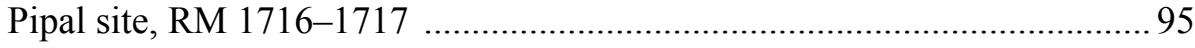

Observations on riverbank erosion at the survey sites .............................. 101

9 PERFORMANCE OF RIVERBANK STABILIZATION METHODS ..... 108

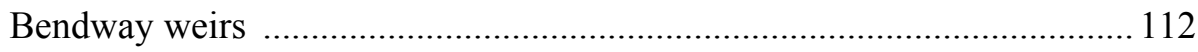

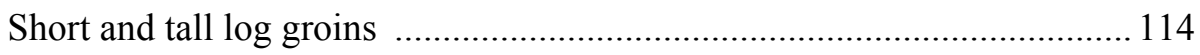

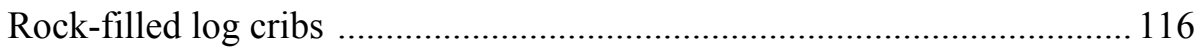

Hay bale revetments on riprap toe …....................................................... 119

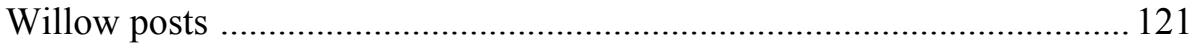

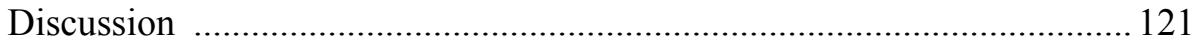

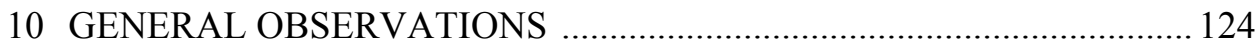

Hydraulic influences of river ice ........................................................... 124

Geotechnical influences of river ice ......................................................... 127

Combined impact of hydraulic and geotechnical influences ...................... 128

11 CONCLUSIONS AND FURTHER ISSUES ......................................... 130

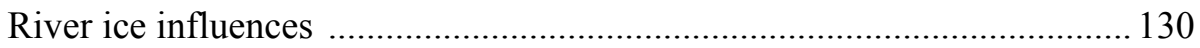

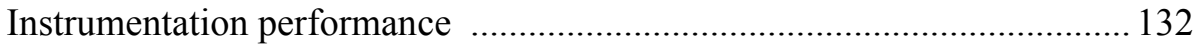

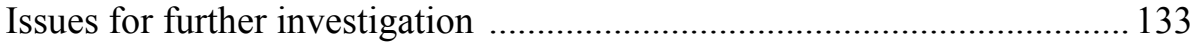

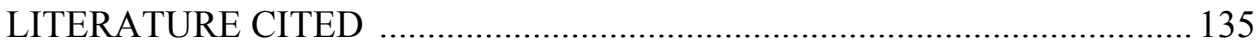




\section{LIST OF ILLUSTRATIONS}

Figure 1. Fort Peck reach of the Missouri River ................................................ 2

Figure 2. Typical subreachs in the Fort Peck reach ............................................. 8

Figure 3. Missouri River between RM 1621 and 1620, near Culbertson, Montana ....................................................................... 8

Figure 4. Median diameter of bed sediment along the Fort Peck reach ................ 8

Figure 5. Riverbank along the reach .......................................................... 9

Figure 6. Hydrographs for water years 1930 and 1987, before and after construction of the Fort Peck Dam .......................................................... 11

Figure 7. Mean daily flow rates indicated by the USGS gage at Fort Peck ........ 12

Figure 8. Flow frequency curves for the Current Water Control Plan (CWCP) and the Preferred Alternative (PA) schedules for water release from Fort Peck Dam

Figure 9. Effect of ice cover on flow conveyance in lateral segments of a two-part, compound channel ....................................................... 18

Figure 10. Effect of an ice cover on flow depth and velocity ..........................20

Figure 11. Variation of channel and thalweg sinuosity with channel slope ........20

Figure 12. Influence of an ice cover on a meandering channel

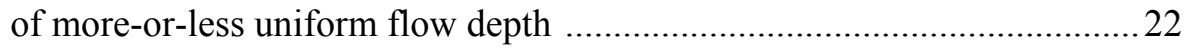

Figure 13. River ice impact on the thalweg of a sinuous-braided channel .........23

Figure 14. Collapse of shorefast ice, and possibly bank material,

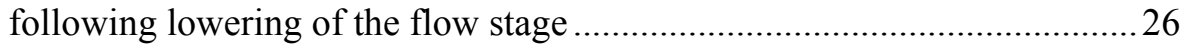

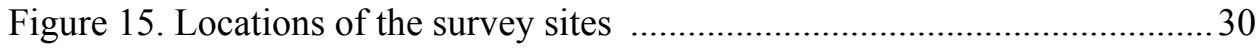

Figure 16. Aerial view of RM 1620-1621, Culbertson site ............................... 33

Figure 17. Survey cross sections near RM 1620-1621, Culbertson site ............. 34

Figure 18. Aerial view of RM 1623-1624, Tveit-Johnson site ......................... 35

Figure 19. Survey cross sections near RM 1623-1624, Tveit-Johnson site ....... 36

Figure 20. Aerial view of RM 1631-1632, Vournas site .................................. 37

Figure 21. Survey cross sections near RM 1631-1632, Vournas site .................. 37

Figure 22. RM 1646, Mattelin site ............................................................. 38

Figure 23. Survey cross sections near RM 1645-1646, Mattelin site ................ 39

Figure 24. Sediment accumulation at an irrigation pump site near RM 1687,

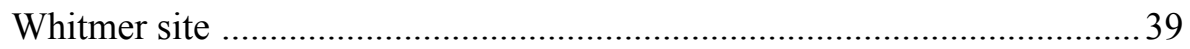

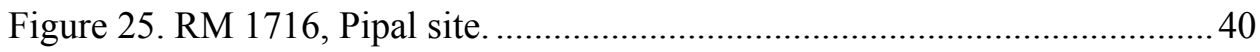

Figure 26. Survey cross sections near RM 1715-1716, Pipal site ..................... 41

Figure 27. Sled with microwave radar towed by an all-terrain vehicle .............. 46

Figure 28. Typical radar profile of ice cover thickness ..................................... 47

Figure 29. Processed radar profile of ice cover thickness ................................. 47

Figure 30. Marsh-McBirney velocity meter with extension pole ....................... 49

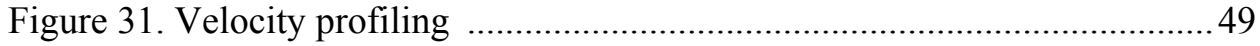




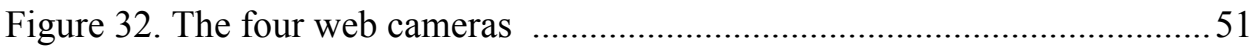

Figure 33. Simulated TDR signal and schematic of probe …...........................53

Figure 34. Locations of TDR bed-level monitors ..............................................5

Figure 35. Schematic of the on-shore data acquisition system ...........................55

Figure 36. Comparison between the reflected signals using a Tektronics 1502

step pulse and a Tektronics 1503 using the impulse signal ........................56

Figure 37. Hydrostatic water pressure at the Culbertson site

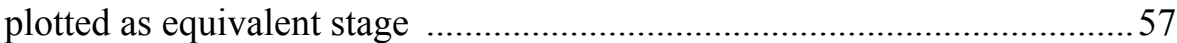

Figure 38. Air and water temperatures at the Culbertson site ...........................57

Figure 39. Waterfall plot of images from TDR 1 captured using the 1503 ........59

Figure 40. Discharge from the Fort Peck Dam,

1 October 1998 to 1 May 1999

Figure 41. Average precipitation for the fall period of 1970 to 1999 and

precipitation for January 1997 to January 1999 .............................................61 61

Figure 42. Early stage of breakup in the downstream reach of the Pipal site ..... 62

Figure 43. Ice conditions at the Culbertson site in the early stages of breakup ..63

Figure 44. Discharge from the Fort Peck Dam with measurements

from the Wolf Point and Culbertson gages ...................................................... 64

Figure 45. Culbertson site during freeze-up prior to the ice

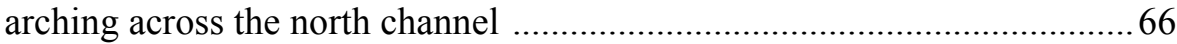

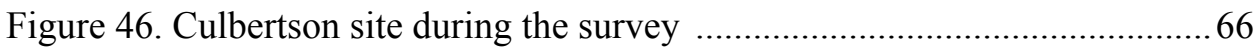

Figure 47. Bed profiles of cross sections at RM 1620.4 ...................................69

Figure 48. Velocity distributions at approximately the middle of the north

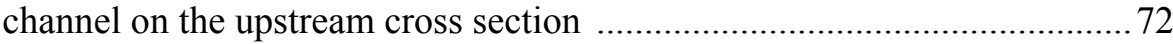

Figure 49. Bed elevation on the north bank of the north channel

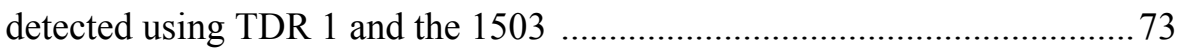

Figure 50. Bed elevations from the TDRs using the 1503 ............................... 74

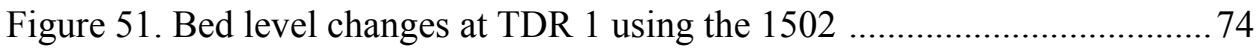

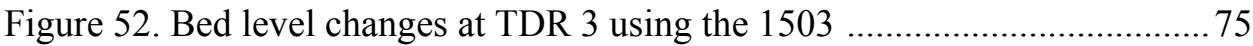

Figure 53. Bed level changes at TDR 6 using the 1503 ................................... 76

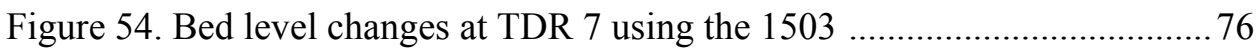

Figure 55. Tveit-Johnson site (RM 1623-1624) during the survey ................... 78

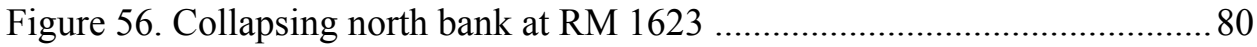

Figure 57. Change in the north bank position following breakup ....................... 81

Figure 58. Crack and ultimate riverbank failure above bankfast ice,

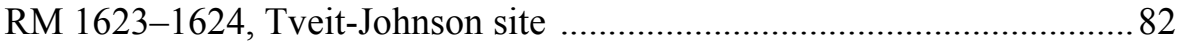

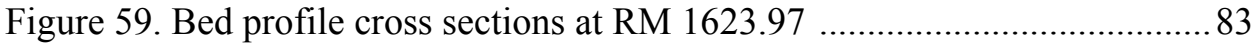

Figure 60. Velocity distributions at approximately mid-channel at RM 1624.02 .84

Figure 61. North riverbank gradually tilting and failing, RM 1623................... 85

Figure 62. Vournas site (RM 1631-1632) during the survey ............................ 86

Figure 63. Crack development in the south riverbank at RM 1632.55 ..............88 
Figure 64. Bed profile cross sections at RM 1632.55

Figure 65. Velocity distributions about mid-channel downstream at cross section RM 1632.55 at approximately $200 \mathrm{ft}$ from the right bank ..... 90

Figure 66. Mattelin site (RM 1645-1647) during the survey ........................... 91

Figure 67. Bed profile cross sections at RM 1646.9 …...................................... 94

Figure 68. Velocity distributions at RM 1649.9 station $5+00 \quad$........................... 95

Figure 69. Soil spalling from the face of the north riverbank at RM 1646 ........ 95

Figure 70. Open water area in the lee of a bar at RM 1716 .............................. 96

Figure 71. Pipal site (RM 1715-1716) during the survey ................................. 97

Figure 72. Bed profile cross sections at RM 1715.58 ...................................... 99

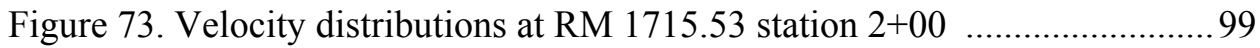

Figure 74. Water on ice at the Pipal site during the winter of 1994-95 ............ 100

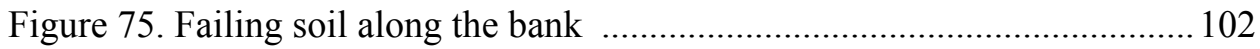

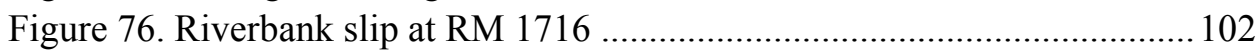

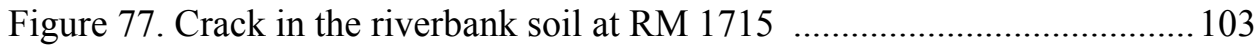

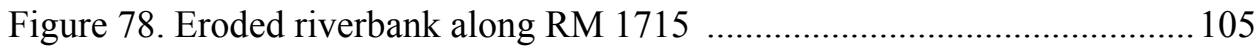

Figure 79. Fallen block of bank material at the riverbank toe .......................... 105

Figure 80. Extensive undercutting of the riverbank at RM 1632 ......................... 106

Figure 81. Toppling at the Tveit-Johnson site ...............................................106

Figure 82. Bank collapse following the formation of horizontal cracks .......... 107

Figure 83. Locations of bank stabilization methods used at

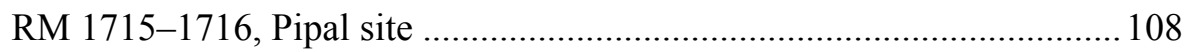

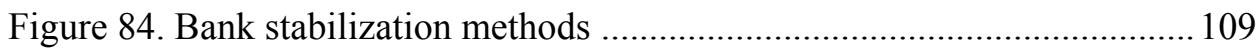

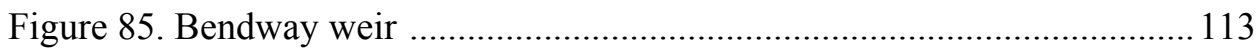

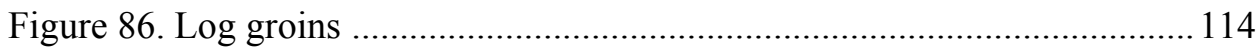

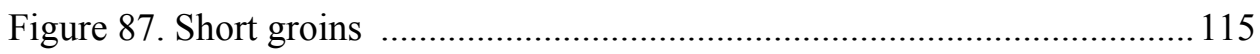

Figure 88. Short groin with relocated shoreline crack ................................... 116

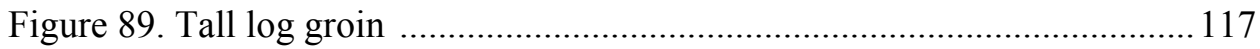

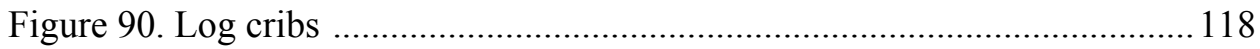

Figure 91. Hay bale revetment frozen into the ice cover ................................. 119

Figure 92. Collapsed section of bank near the hay bale revetment

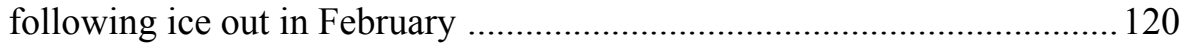

Figure 93. Riprap being plucked by bankfast ice ........................................... 120

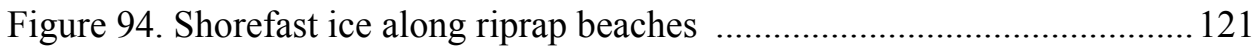

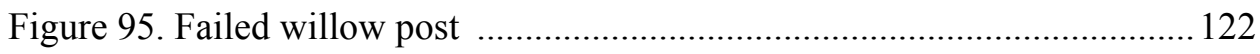

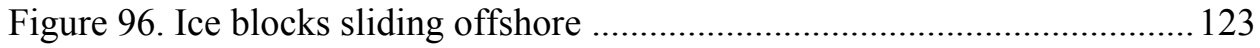

Figure 97. Ice cover concentration of flow toward the outer bank of a bend ...125

Figure 98. Two scenarios for how ice cover formation in a sinuous-braided

channel may alter the location of the major subchannel ...........................126

Figure 99. Methods by which hydraulic influences, together with geomechanical influences, may weaken and erode channel banks 


\section{LIST OF TABLES}

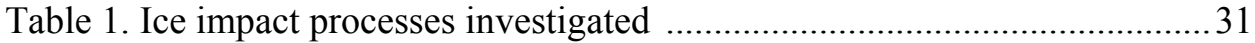

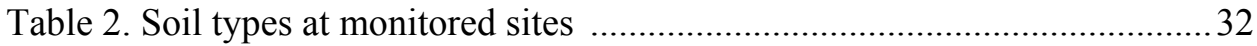

Table 3. Site monitoring and survey alignments ................................................ 45

\section{CONVERSION FACTORS: NON-SI UNITS TO SI UNITS OF MEASUREMENT}

These conversion factors include all the significant digits given in the conversion tables in the ASTM Metric Practice Guide (E 380-93), which has been approved for use by the Department of Defense. Converted values should be rounded to have the same precision as the original (see E 380-93).

\begin{tabular}{|lcl|}
\hline \multicolumn{1}{|c}{ Multiply } & By & \multicolumn{1}{c|}{ To obtain } \\
\hline inch & 25.4 & millimeter \\
foot & 0.3048 & meter \\
mile & 1609.347 & meter \\
foot ${ }^{3} /$ second & 0.0004719474 & meter 3 second \\
degrees Fahrenheit & $t_{C}=\left(t_{F}-32\right) / 1.8$ & degrees Celsius \\
\hline
\end{tabular}




\title{
SURVEY OF RIVER ICE INFLUENCES ON CHANNEL BATHYMETRY ALONG THE FORT PECK REACH OF THE MISSOURI RIVER, WINTER 1998-1999
}

\author{
LEONARD J. ZABILANSKY, ROBERT ETTEMA, JAMES WUEBBEN, AND \\ NORBERT E. YANKIELUN
}

\section{INTRODUCTION}

It is well known that alluvial channel bathymetry adjusts in accordance with prevailing conditions of water flow, alluvial sediment availability, and channel bank conditions. Because river ice affects these conditions, it potentially influences alluvial channel morphology. It may do so over a range of scales in space and time. The extent and full nature of river ice influences, however, have yet to be determined. Some influences are reasonably well understood and some barely recognized; few have been investigated rigorously. It is well known, for instance, that an ice cover affects the vertical and lateral distributions of flow in a channel. Less well known are how river ice influences the flow's capacity to entrain and transport alluvial sediment and the geotechnical stability of channel banks flanking the flow. To a large extent the influences likely are seasonal, coming and going with the annual occurrence of winter weather. They also may have an enduring impact, such as reducing riparian vegetation growth along a channel. In overall terms, river ice influences on alluvial channel morphology are not well known.

Numerous studies have focused on the channel morphology, flow, and sediment transport conditions along the Missouri River. Several studies have investigated conditions of ice formation along the river. Only a few studies have been conducted to determine the relationships between flow, channel conditions, and ice.

\section{Objectives}

This study comprises a comprehensive survey conducted with the primary objective of determining if and how river ice influences channel bathymetry along the Fort Peck reach of the Missouri River (Fig. 1). The river along this reach is long known for its wandering thalweg and eroding riverbank propensi- 


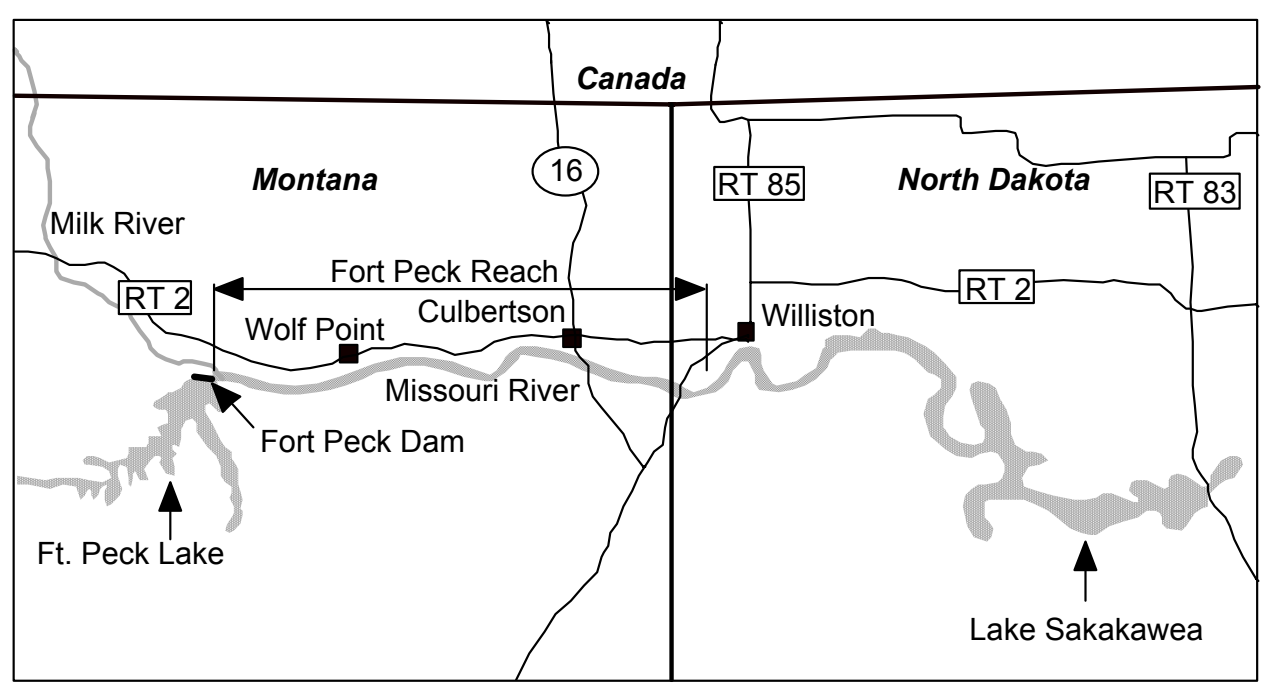

Figure 1. Fort Peck reach of the Missouri River.

ties (e.g., Haydon 1931, USACE 1933, USACE-Omaha 1998a). The reach extends about 170 miles from Fort Peck Dam to Lake Sakakawea and includes the river's confluence with the Yellowstone River. The study reach covered 97 miles in the central portion of the Fort Peck reach.

The survey entailed extensive monitoring and detailed measurements of channel bathymetry, ice conditions, and flow velocity distribution. It was conducted at five sites during the winter of 1998-99. A useful feature of the reach, for survey purposes, is that the river's flow discharge is known, because Fort Peck Dam regulates winter flow through the reach with little contribution by tributaries within the reach. Further useful features are the accessibility of the survey sites and the logistical support provided by the communities along the reach.

An important additional objective of the survey was to evaluate the performance of the various instrumentation techniques for measuring flow velocity, bathymetry, and ice thickness in ice-covered rivers. Several of the techniques used were inventive, such as the use of ground-penetrating radar for measuring bathymetry through an ice cover, microwave radar for ice-thickness profiling, time-domain reflectometer (TDR) scour monitors for real-time monitoring of bed elevation, and video cameras for remote monitoring of survey sites. Information on instrumentation performance will be useful for possible future monitoring of the Missouri and other alluvial channel rivers under winter conditions. 


\section{Significance}

The observations and data produced in this study reveal how river ice formation processes may adversely affect the stability of the Fort Peck reach of the Missouri River, as well as other flow-regulated, alluvial channel rivers. Prior to the survey these processes either had not been identified or had not been documented. The observations and data show how ice cover formation can trigger shifts in channel location, which can accelerate bank erosion. Active movement and switching of thalweg position and extensive bank erosion were observed during the six-month survey.

The observations and data are of direct significance for engineering activities along the Fort Peck reach of the Missouri River and along similar alluvial rivers subject to frigid winters. They reveal how ice-induced channel changes may adversely affect the functioning of channel and bank stabilization structures, water intakes, and bridge crossings, as well as potentially interfering with dredging work. In general terms, the observations and data are of use for identifying and mitigating problems caused by regulated flow releases from reservoirs during frigid winter conditions. Although a small amount of information is available on the winter conditions along the river between its confluence with the Yellowstone River and Lake Sakakawea (Wuebben and Gagnon 1995), few aspects of winter conditions have been documented for the Fort Peck reach.

Since this survey was exploratory, unique, and planned with an imprecise knowledge of the processes whereby ice influences alluvial channel morphology, it was not complete. Some key aspects of the processes were not fully detected during the survey and had to be inferred from survey observations and data. Those aspects need further investigation.

\section{Background}

Several concerns prompted the need for the survey. The Omaha District of the U. S. Army Corps of Engineers (USACE-Omaha), which has long-term interests in the overall behavior and stability of the Missouri River, wished to determine whether and how channels along the Fort Peck reach of the Missouri River altered during winter. The insights obtained would assist USACE-Omaha in mitigating possible adverse effects of flow releases from Fort Peck Reservoir during winter. USACE-Omaha is considering enhancements to the Corps' Current Water Control Plan (CWCP) for the river. The preferred alternative to the CWCP apparently may entail increasing flow releases from Fort Peck Dam during winter (Pokrefke et al. 1998). River ice formation seems not to have figured prominently in evaluating the alternative schedule. 
Moreover, the survey would help USACE-Omaha to better understand the wintertime performance of riverbank stabilization structures that it recently installed at a site in the Fort Peck reach and at other sites along downstream reaches of the Missouri River. The insights would be of use in further design and deployment of the methods.

The impetus for the survey also was provided by immediate concerns facing farmers and small communities along the Fort Peck reach. Extensive riverbank erosion along several portions of the reach continues to diminish productive irrigated cropland along the river, and a high proportion of pump sites along the reach experience sedimentation difficulties. A frequent remark by people living along the reach is that the bank erosion and pump site sedimentation processes are especially apparent in early spring when ice departs the reach. The survey was an opportunity for USACE-Omaha to investigate the processes contributing to these concerns. 


\section{PHYSICAL SETTING OF THE FORT PECK REACH}

Much has been written about the physical setting of the Missouri River, including the Fort Peck reach of the river. Numerous publications document the reach's flow and channel characteristics, especially in the years following the closure of Fort Peck Dam, when flow in the reach began to be regulated by the dam. Several investigations address concerns about channel bed degradation along the upper half of the river, subsequent to the river's closure in 1940 by Fort Peck Dam (notably, USACE-Omaha 1945, 1952, Williams and Wolman 1984, Pokrefke et al. 1998). Several recent publications (e.g., Simon et al. 1999, Pokrefke et al. 1998, Wei 1997) describe and discuss channel stability concerns as well as concerns about riverbank erosion along the reach. To date, no study has investigated the interactive influences of river ice formation and channel morphology along the reach, though Simon et al. (1999) include a general review of river ice concerns for alluvial channels, such as the Fort Peck reach.

\section{Channel morphology}

The Fort Peck reach of the Missouri River begins at the tailwaters of Fort Peck Dam, Montana. It ends at the headwaters of Lake Sakakawea, which is retained by Oahe Dam, in North Dakota. The river channel itself is approximately 170 miles long and 800-1200 ft wide along the reach. The channel's average slope over this distance is about $1.6 \times 10^{-4}$ to $1.8 \times 10^{-4}$.

The closure of Fort Peck Dam in 1940 affected peak flow rates, sediment supply, and channel bed elevations along the reach. It thereby also affected ice formation along the reach. Studies of changes in bed elevation along the reach (notably, USACE-Omaha 1945, 1952, Williams and Wolman 1984, Wei 1997, Pokrefke et al. 1998) show that the channel bed degraded over a distance of about 70 river miles immediately downstream of the dam. Near the dam the average bed level dropped about $6 \mathrm{ft}$, with drops in bed elevation of as much as $11 \mathrm{ft}$ occurring at some locations along the primary channel, or thalweg. The consensus opinion is that the dam is not likely to further degrade the channel bed significantly (e.g., Pokrefke et al. 1998, Simon et al. 1999).

The channel morphology of the Missouri River along the Fort Peck reach can be described as sinuous braided. Its characteristics are transitional between those of meandering channels and braided channels. The channel's planform is sinuous, but the channel width fluctuates substantially, ranging from 800 to $1200 \mathrm{ft}$. At its wider sections the river normally flows in several subchannels. A common feature throughout the reach begins where the river narrows to a single channel bend with a point bar, followed by a wider subreach that contains one or more 
midchannel bars that divide the flow into several subchannels under normal flow conditions. At flood flow and sometimes under ice-covered flow, the bars are under water. The wider subreach is followed by another narrower and curved subreach. Figure 2 illustrates typical subreaches. The narrower subreaches commonly occur where a bluff deflects the flow, as in Figure 2a. In these subreaches the river is similar in morphology to a sinuous point-bar channel. In other subreaches (Fig. 2b), the river begins to assume the characteristics of a braided channel. Figure 3 illustrates how two subreaches typically merge. The river is constrained at its upstream and downstream ends by bluffs, while over the middle subreach the river widens and flows in several subchannels around a vegetated island and bars.

A feature of the wider subreaches is the switching of the thalweg position between subchannels. Such switches can be triggered by several factors, including a large change in flow magnitude, a change in orientation of flow entering the subreach, and (as revealed in this study) ice cover formation.

The variability of the river's channel morphology between two subreach types makes channel morphology unstable where the two subreaches merge. Usually at those locations the river's thalweg alignment does not coincide with the alignment of riverbanks. Instead, it practically impinges against a riverbank. Those locations are especially vulnerable to riverbank erosion.

\section{Bed sediment}

The sediments comprising the channel bed of the Fort Peck reach are mainly sands with zones of gravel deposits, exposed clays, and silts. USACE-Omaha (1986), among other reports, describes the nature and disposition of bed sediment along the reach.

In the subreach immediately downstream of Fort Peck Dam the bed sediments are coarser than farther downstream, and they reflect the overall degradation in the upstream portion of the reach. The subreach evidently exhibits bed armoring, where the upper surface of the bed is armored with coarser sediment less readily entrained by flow. For the extent of the Fort Peck reach encompassed by the survey (RM 1717 to RM 1620), the riverbed is formed mainly of fine to medium-size sand, with the median particle diameter in the range of $0.2-0.3 \mathrm{~mm}$. Occasional patches of coarser sediment occur along the reach. Also, zones of silts and clay sediments are exposed along the riverbanks. Figure 4 indicates the trend in median diameter of bed sediments (USACE-Omaha 1986).

The sediment load conveyed by the river comprises bedload sediment whose source is the eroding riverbanks and shifts in the channel bed. The average 


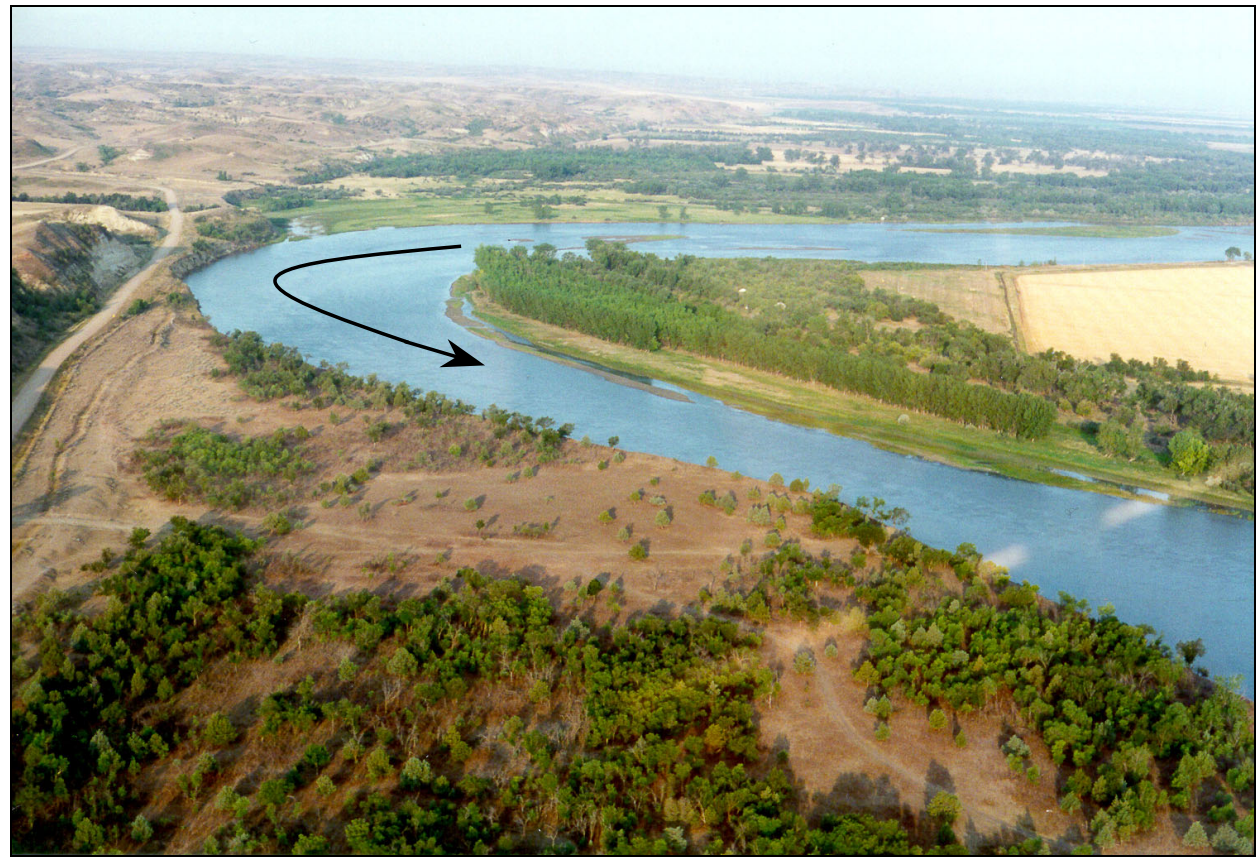

a. A typical subreach in which the river narrows to a single channel bend. (From CRM 1996.)

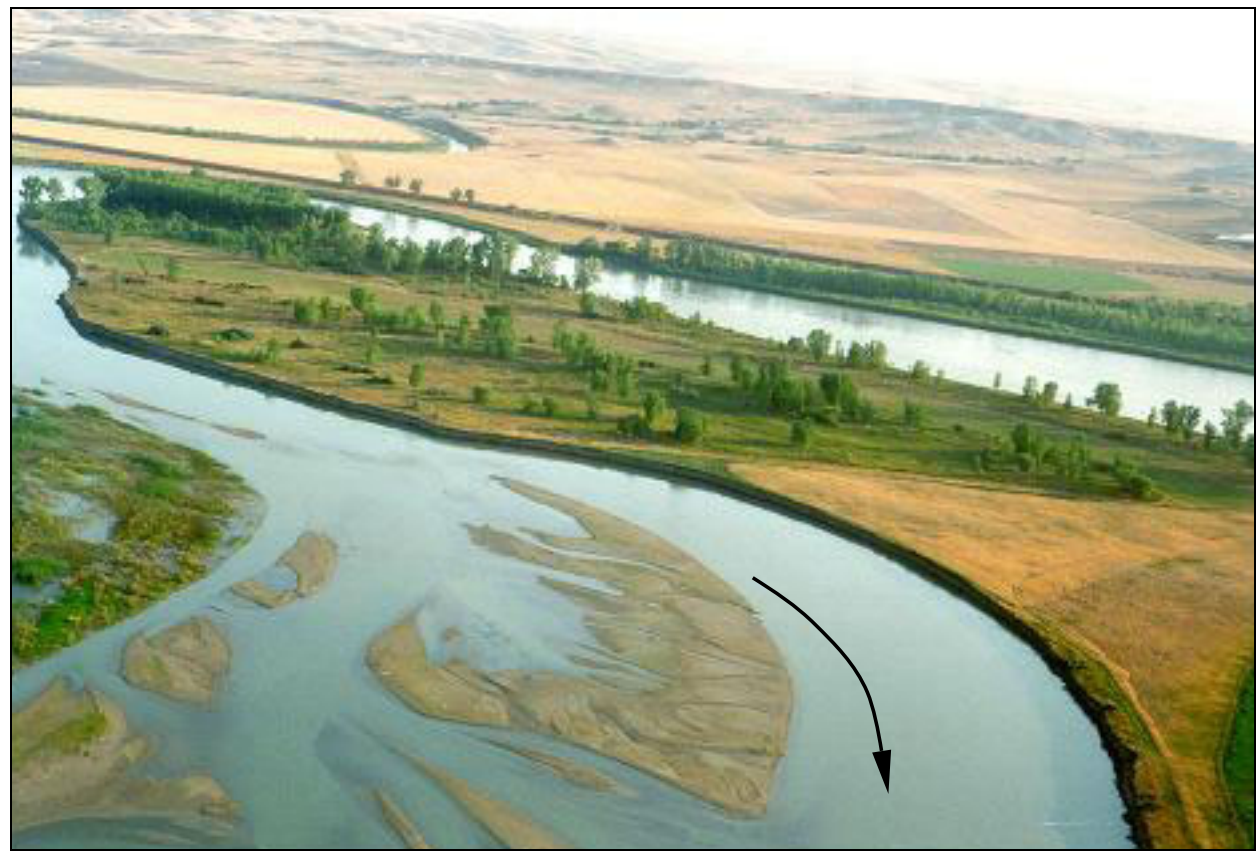

b. A typical subreach in which the river widens and flows in two or more subchannels. (From CRM 1996.) 
Figure 2. Typical subreachs in the Fort Peck reach.

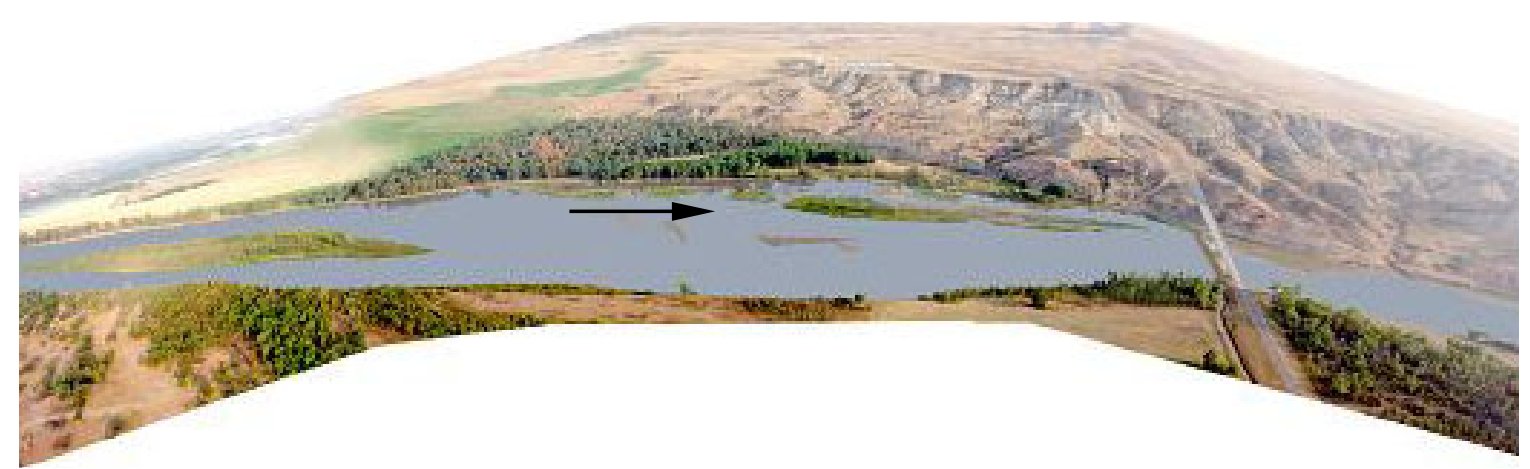

Figure 3. Missouri River between RM 1621 and 1620, near Culbertson, Montana. (From CRM 1996.)

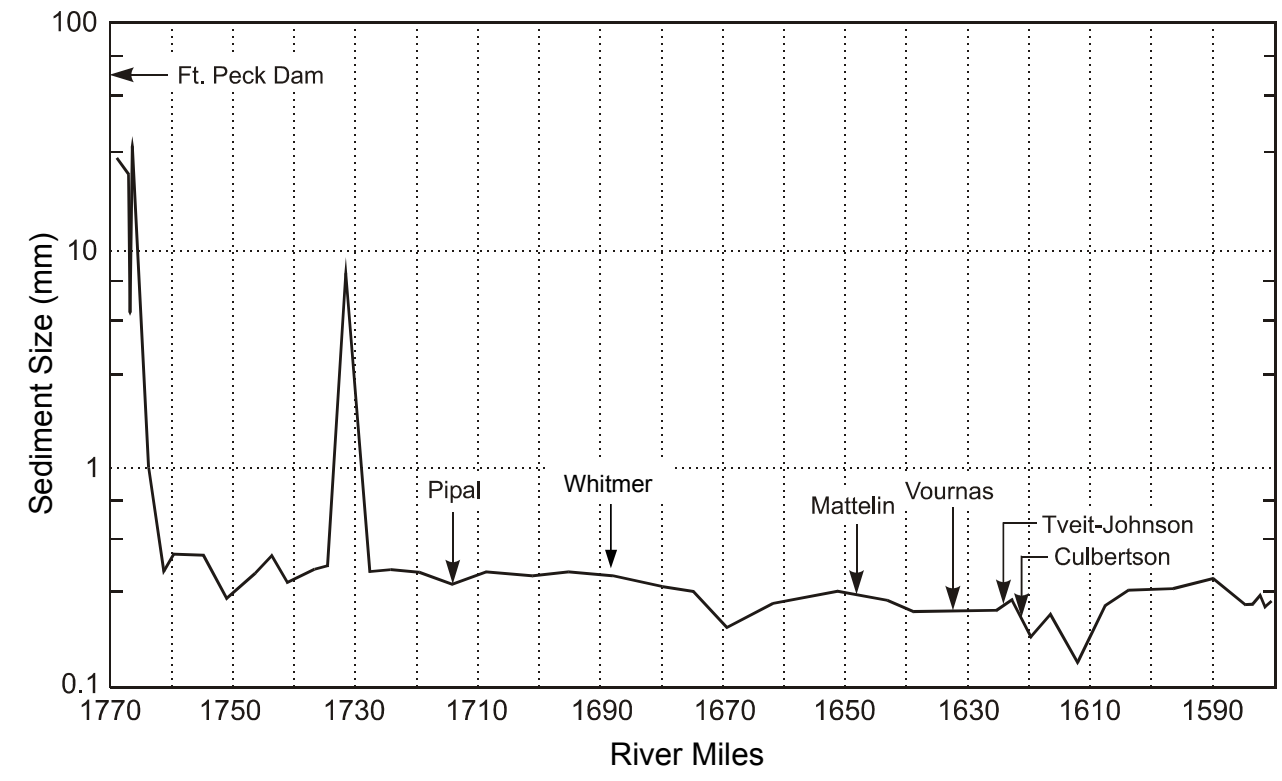

Figure 4. Median diameter of bed sediment along the Fort Peck reach. Locations of monitoring sites: Culbertson (RM 1620), Tveit-Johnson (RM 1624), Vournas (RM 1633), Mattelin (RM 1647), Whitmer (RM 1687), Pipal (RM 1716), Fort Peck Dam (RM 1771). (From USACE-Omaha 1986.)

annual sediment load is estimated to be about $5 \times 10^{6}$ tons, based on a continuous record of suspended sediment load recorded from 1958 to 1972 at a sedimentmeasuring station located just downstream of the Highway 16 bridge at Culbertson (RM 1620) and shown on the right side of Figure 3 (USACE-Omaha 1986). About $35 \%$ of the suspended load consists of silt and clay originating from 
riverbank erosion as well as from tributary inflow; the remainder is sand entrained from the channel bed. The sediment load is close to zero immediately downstream of Fort Peck Dam.

\section{Riverbanks}

The stability of the riverbanks along the Fort Peck reach of the Missouri River is a longstanding concern (e.g., Haydon 1931, Pokrefke et al. 1998). Only a few studies have investigated the geotechnical aspects of riverbank stability concerns along the reach (e.g., Simon et al. 1999). Also, a few studies have assessed the extent of riverbank erosion along the reach, as well as other reaches along the Missouri River (e.g., Pokrefke et al. 1998). To date, only one study considered aspects of winter effects on bank stability along the Missouri River (Lawson 1983, 1985). That study, however, focused mainly on banks around reservoirs such as Lake Sakakawea.

At some locations along the Fort Peck reach, especially in channel bends, the river has cut quite steep riverbanks (Fig. 5). The riverbanks typically are formed of soils having relatively low shear strength, especially low cohesive strength (Simon et al. 1999), and typically consisting of silty and sandy layers interspersed with clay or silty clay layers. The occurrence of a layer of sandy or silty soil at the base of a riverbank makes it prone to erosion. This feature is common at the sites selected for this survey.

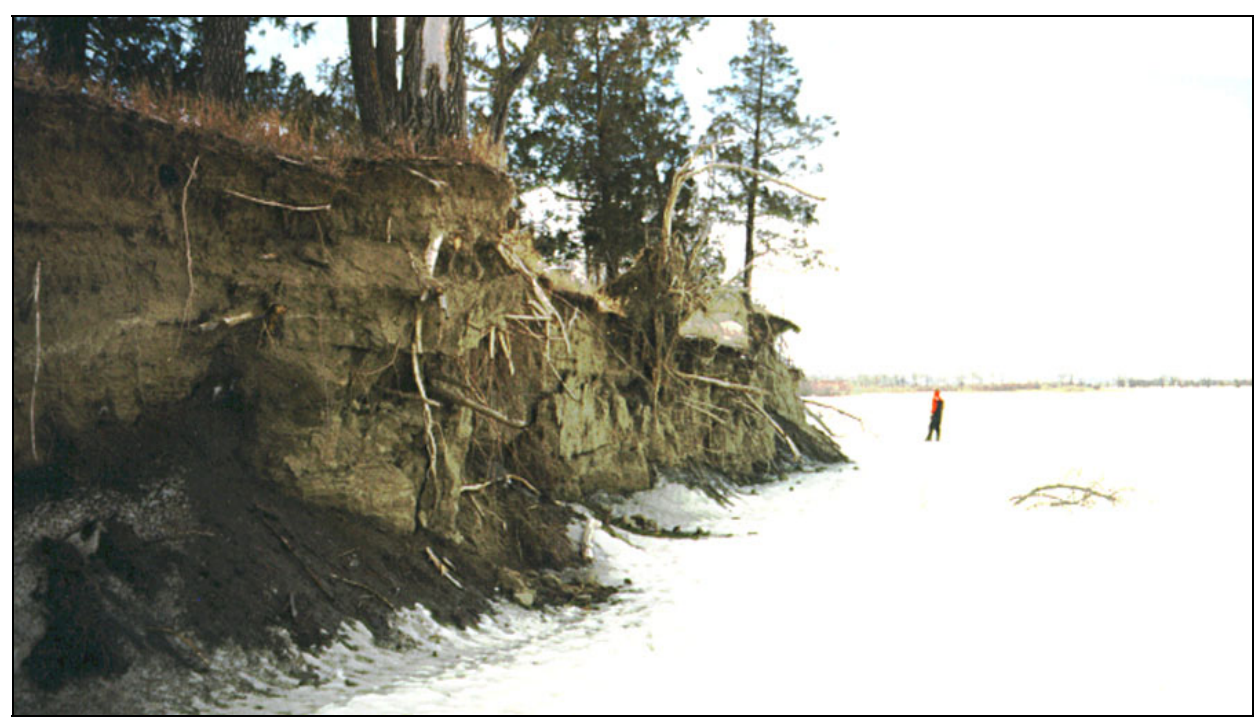

Figure 5. Riverbank along the reach. 
As with any river in cold regions, the riverbanks of the lower Missouri River are subject to freeze-thaw and freeze-sublimation weakening. Freeze-thaw weakening potentially influences riverbank erosion significantly and perhaps channel morphology as well. Freeze-sublimation weakening is likely at work deteriorating the exposed faces of riverbanks. The soils comprising the riverbanks contain enough silts and fine sands to make them prone to freeze-thaw and sublimation weakening. The east-west orientation of the average axis of the reach may create differences in erosion rates, because riverbanks facing south receive greater insolation than do north-facing banks. The extent to which the ice-related weakening influences rates of riverbank recession has yet to be determined, however.

\section{Flow characteristics}

The flow rate through the reach is monitored continuously by several stage gages operated by the USACE and U.S. Geological Survey (USGS). The provisional gage data referred to in this report are from the Fort Peck Dam (USGS station number 06132000), near Wolf Point (USGS station number 06177000), and near Culbertson, Montana (USGS station number 06185500). The Fort Peck gage was immediately downstream of the dam, and the warmer water released from the reservoir keeps the gage ice-free; the open water stage-discharge correlation was valid. As the water progressed downstream, it cooled, and the other gages may have been affected by ice.

Winter flow rates typically have varied within the range of about 2,500$22,500 \mathrm{cfs}$ since the closure of Fort Peck Dam. The maximum flow into the reservoir is reported to be 135,000 cfs (USACE-Omaha 1990), which occurred in June 1953. As extensively documented in several reports (e.g., USACE-Omaha 1986, Simon et al. 1999), the dam significantly altered the annual distribution of flow through the reach. Yet to be investigated are the effects on river ice formation on the flow released from the dam.

Before the dam was built, flows through the reach were at their lowest stage throughout the winter, the lowest stage usually occurring early in the winter (Haydon 1931). It was usual for the reach to convey two annual flood flows: one in April attributable to snowmelt augmented by rainfall and ice cover breakup throughout the lower elevations of the river's watershed, and a second, called a "June rise," caused by snowmelt in the mountains. A further flow increase, of lesser magnitude, regularly occurred during October or November.

Once the dam began significantly regulating flow releases in 1941, it reduced the temporal variability of flows in the reach, and it altered the distribution of peak or flood flows in the reach. For the period 1970-1995, peak flows usually 
occurred during the winter months. The average peak winter flows increased from about 5,000 cfs to about 14,000 cfs. Figure 6 compares the pre-dam and post-dam mean daily flows at the Wolf Point gage (RM 1700) for the water years 1930 and 1987. However, in the past two years, flow releases have varied substantially from the discharge for water year 1987 shown in Figure 6. Figure 7

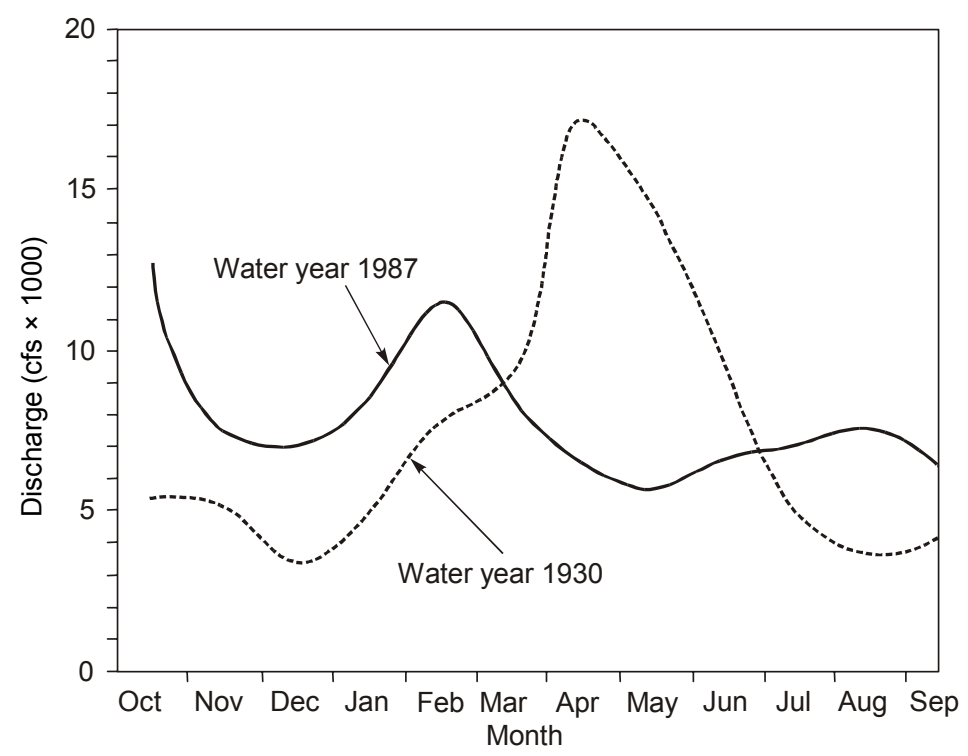

Figure 6. Hydrographs for water years 1930 and 1987, before and after construction of the Fort Peck Dam.

shows the continuous records of discharge for water years 1970-1993, 19941996, and 1997-1999. Though the records differ for these periods, for all periods the reach conveyed the largest flow rates during open water conditions.

Flow releases from Fort Peck Dam generally conform to a water management schedule for the main stem dams on the Missouri River. The schedule, called the Current Water Control Plan (CWCP), is under reconsideration by USACE-Omaha. An alternate schedule, called the Preferred Alternative (PA), is favored. The PA schedule would move the peak discharges into the spring, rather than having them occur later in the year (Pokrefke et al. 1998). The variations in flow rates between the PA and CWCP schedules are small compared to actual variations in annual river flows; Figure 8 compares the annual flow-frequency curves for the two schedules. It is thought that implementation of the PA schedule would not substantially alter the behavior of the Fort Peck reach (Pokrefke et al. 1998). The consequences for river ice formation, however, are unclear, as river ice seems not to have been included in the evaluation of the possible effects 
resulting from the PA schedule. If the PA implies reduced winter flow rates, river ice may form faster and thicker, as flows would be shallower and convey less heat. On the other hand, ice covers would form at lower stage elevations in the river channel, exposing more of the banks to freeze-thaw. This conjecture needs further consideration, possibly by means of numerical or physical modeling.

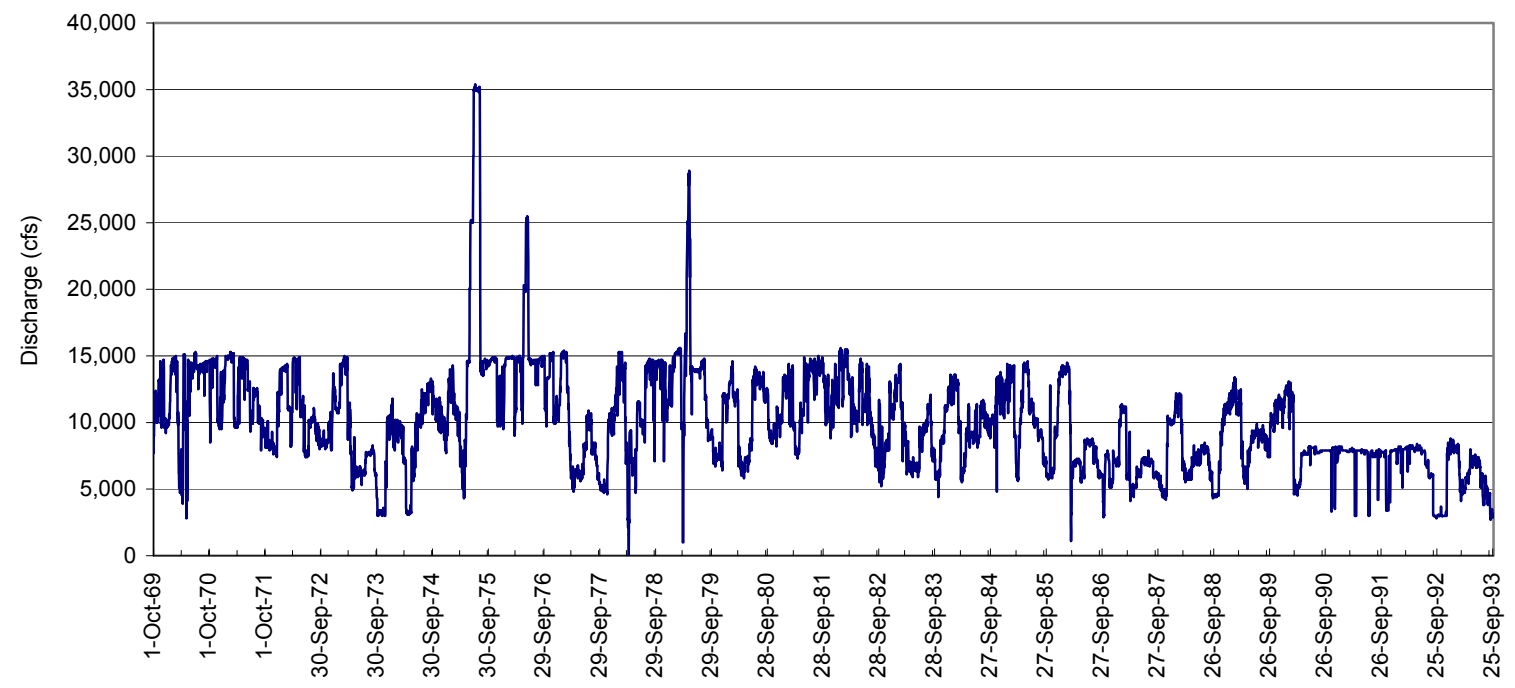

a. Water years 1970 through 1993.

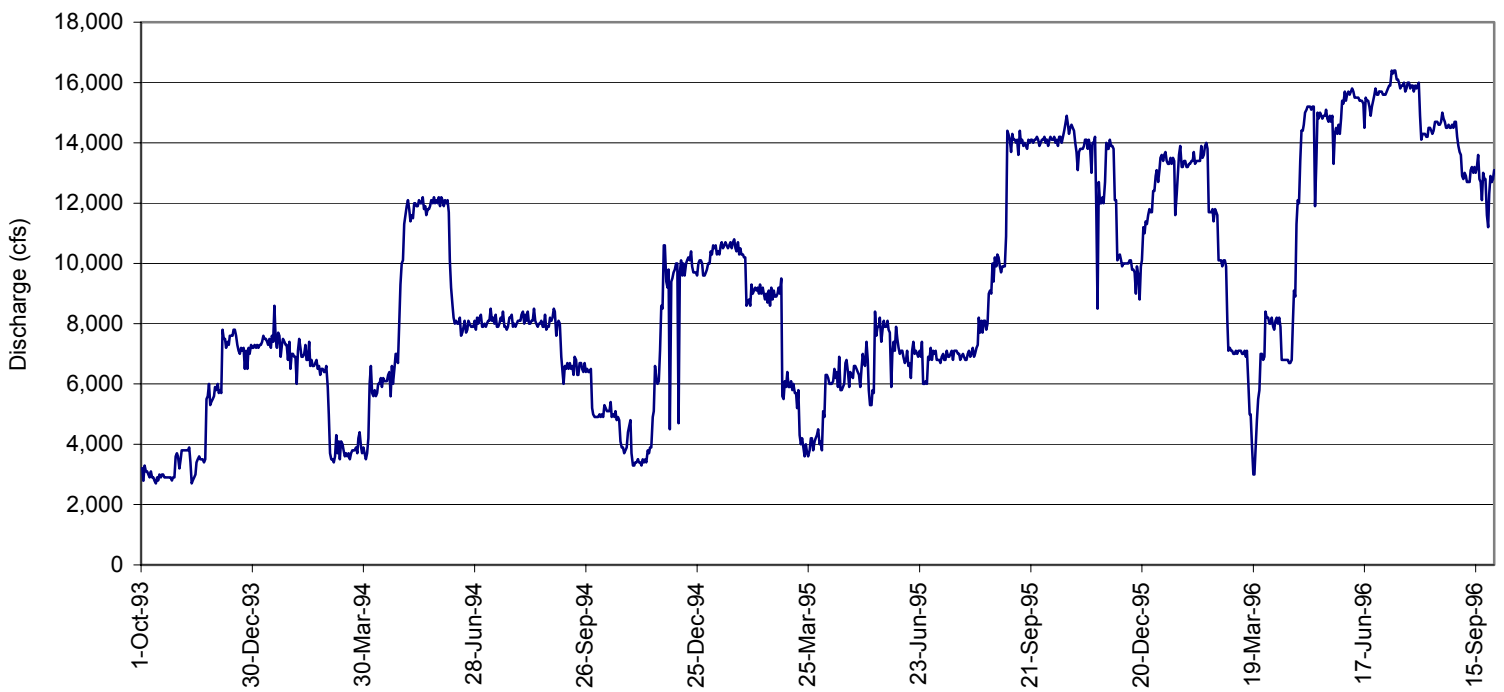

b. Water years 1994 through 1996.

Figure 7. Mean daily flow rates indicated by the USGS gage at Fort Peck. 


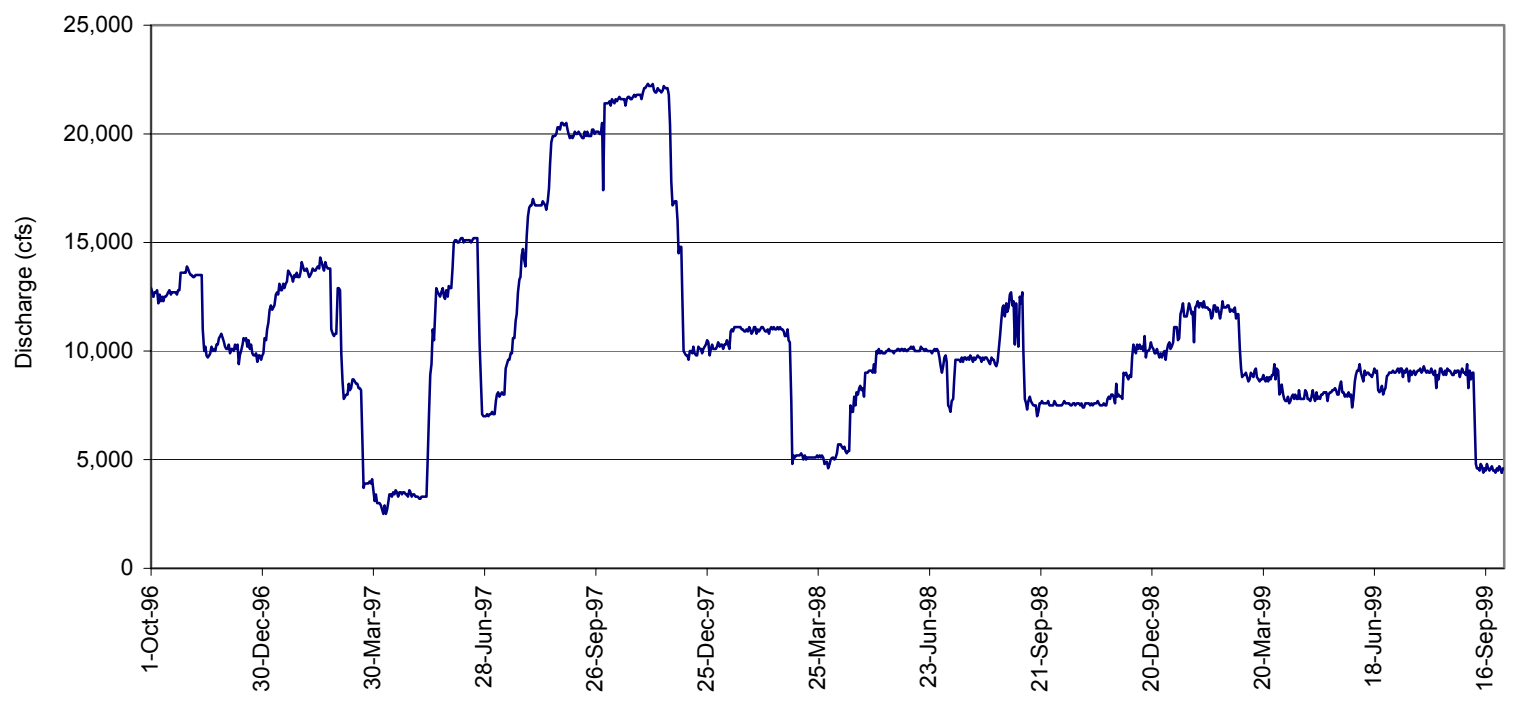

c. Water years 1997 through 1999.

Figure 7 (cont.).

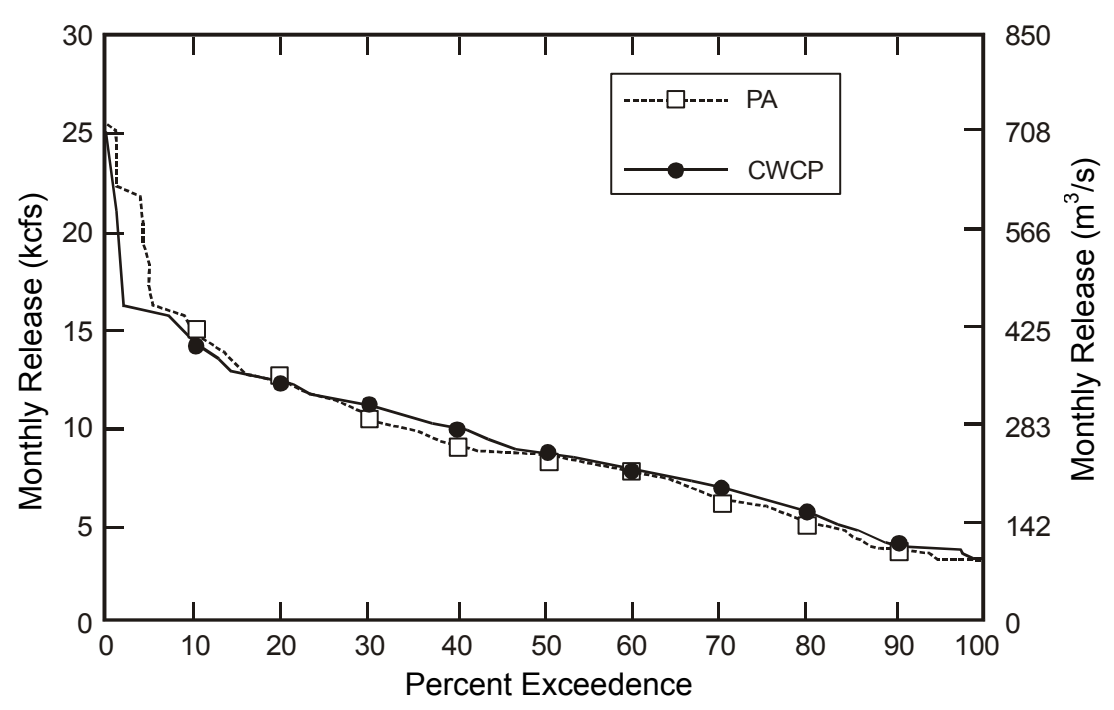

Figure 8. Flow frequency curves for the Current Water Control Plan (CWCP) and the Preferred Alternative (PA) schedules for water release from Fort Peck Dam. (From Pokrefke et al. 1998.) 


\section{Ice formation}

With Fort Peck Reservoir as the source of flow, the river begins forming its ice cover at several locations well downstream of the dam. The flow rate and temperature of the water released from the reservoir influence where and how ice covers form on the lower Missouri. The river's sinuous-point-bar and sinuousbraided morphologies ensure that the flow through the Fort Peck reach is well mixed over the flow depth, so its temperature and thermal energy are practically homogeneous over its depth. Those morphologies also produce substantial variations in flow velocity within reaches, and they provide numerous locations where frazil ice slush and pans can congest and form an ice cover or initiate an ice jam as thin, unstable ice covers break up. Once a cover is initiated, it propagates upstream.

The flow rate and temperature of the water influence where ice first appears. The higher the flow rate and temperature of the flow released into the river, the greater the distance of flow before ice cover formation begins. The local channel morphology influences where the river actually begins forming its ice cover. The river's mild slope (about $1.6 \times 10^{-4}$ to $1.8 \times 10^{-4}$ ) and moderate average velocities facilitate the formation of an initial cover of juxtaposed ice pans and floes over most reaches. Average velocities at Wolf Point and Culbertson are about 2.3 and $2.0 \mathrm{ft} / \mathrm{s}$, respectively (Pokrefke et al. 1998). At some sections and flow rates, velocities may be high enough (nominally in excess of $6 \mathrm{ft} / \mathrm{s}$ ) that ice pans get subducted under the ice cover front, causing a thickened accumulation to develop. The average flow velocities seem to remain low enough that a severe freeze-up jam does not occur. The velocities are such that frazil slush may accumulate under the cover. On the whole, bulk flow velocities increase upstream, with the likely consequence that cover formation becomes progressively more difficult at upstream locations. 


\section{REVIEW OF RIVER ICE INFLUENCES ON CHANNEL MORPHOLOGY}

Currently it is possible to describe only in conceptual terms how ice might influence alluvial channel bathymetry. No quantitative evidence exists that ice hastens or slows large-scale changes, such as the migration of a series of meander loops. Such evidence would be hard to obtain, since ice is only one of several factors that influence the dynamic balance between flow, slope, and sediment in an alluvial channel. It is useful, nonetheless, to consider the possible ways in which river ice may influence alluvial channel bathymetry.

Changes in channel geometry (e.g., width, statistical properties of meander wavelengths, and radii) may occur in response to diverse changes in flow rate and sediment supply. Some evidence exists that ice may influence midscale features of alluvial channels. For example, ice jams may lead to meander loop cutoffs. However, at this scale, ice effects are still largely unknown. At the local (or site) scale, it is possible to identify several mechanisms by which ice may hasten bank erosion and channel shifting. Two such mechanisms are flow concentration beneath an ice cover and bank or bed gouging by an ice run. Yet questions remain as to whether these mechanisms prevail over other processes and conditions and exactly how they work.

No prior study seems to have examined the full extent to which the seasonal appearance and disappearance of river ice perturbs the bathymetry, and thereby the stability, of alluvial channels subject to frigid winters. The literature regarding ice impacts on alluvial channels is sparse and inconclusive.

\section{Factors affecting river ice}

Several factors enable river ice to influence alluvial channel bathymetry. Most of them are explainable in terms of a functional relationship between a dependent variable, such as hydraulic radius of flow $R$, and the typical set of independent variables for alluvial channels:

$$
R=\mathrm{f}_{\mathrm{R}}\left(Q, Q_{\mathrm{s}}, \rho, v, d, \sigma_{\mathrm{g}}, \rho_{\mathrm{s}}, \mathrm{g} \Delta \rho, B, S_{\mathrm{o}}\right)
$$

where

$$
\begin{aligned}
Q & =\text { inflow rate of water } \\
Q_{\mathrm{s}} & =\text { inflow rate of bed sediment } \\
\rho & =\text { water density } \\
v & =\text { kinematic viscosity } \\
d & =\text { bed sediment diameter }
\end{aligned}
$$




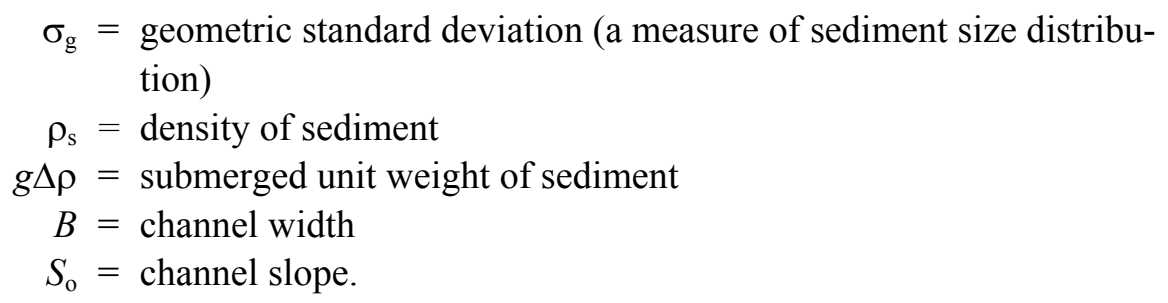

Other dependent variables of practical interest are channel width, average depth, shape, sinuosity $(\zeta)$, flow energy gradient $(S)$, and sediment transport capacity $\left(Q_{\mathrm{sc}}\right)$. Significant changes in any of the independent variables in eq 1 may alter $R, \zeta$, or $Q_{\mathrm{sc}}$ and may destabilize the alluvial reach. The greatest natural disturbances typically result from changes in $Q$ or $Q_{\mathrm{s}}$, which usually vary seasonally.

The seasonal appearance and disappearance of river ice expands and modifies the set of hydraulic variables in eq 1 in a periodic manner. The extent to which it affects important dependent variables, such as $R, \zeta$, or $Q_{\mathrm{sc}}$, is unclear for alluvial channels. Several qualitative aspects of river ice are clear, however. River ice modifies flow resistance. It exerts hydraulic and geomechanical influences that act over a range of scales in space and time. And, not surprisingly, its influence increases as channel stability under open water conditions decreases.

A relatively long, level floating ice cover, for instance, practically doubles the wetted perimeter of flow in a channel and thereby significantly increases the boundary resistance exerted on the flow. Ice accumulated as an ice jam increases the flow resistance by locally constricting flow. Increased flow resistance typically results in increased flow depth, altered flow distribution, and reduced flow drag on the bed-at least for fixed-bed channels. For a given channel, ice impacts on the channel bed and banks increase in significance as water discharge, $Q$, increases. Sediment entrainment and transport increase with increased flow in an ice-covered channel as with open water flow. Increased flow also increases the velocity of moving ice and increases the possibility of overbank flow. River ice influences likely become more significant when the water discharge fluctuates appreciably; then the prospects for other ice influences increase, such as ice cover breakup followed by ice jamming.

Through its effects on the lateral distribution of flow resistance, and, thereby flow and boundary drag, river ice may modify channel cross-sectional shape developed under open water flow conditions. By imposing additional flow resistance, river ice diminishes the effective gradient of flow energy available for sediment transport and alluvial channel shaping. It may consequently alter channel-thalweg alignment. 
By reducing the sediment transport capacity of a reach, river ice redistributes bed sediment along the channel. Whatever local-scale effects river ice may exert in accentuating erosion, river ice reduces the channel's overall capacity to convey the eroded sediment away from the erosion location. Consequently bars may develop in response to flow conditions under river ice but be washed out shortly after the cover breaks up. In situations where a significant load of bed sediment enters a long reach, river ice may tend to cause mild aggradation of the channel it covers.

Congestion or jamming of river ice at one channel (or subchannel) location may divert flow either into an adjoining channel, which then enlarges (channel anabranching and thalweg avulsion), or over the bank, which may result in a channel cutoff (avulsion).

\section{Ice cover influence on the local cross section of flow}

An ice cover imposes an additional flow-retarding boundary that decreases the flow-conveyance capacity of a channel and redistributes flow vertically and laterally. The vertical redistribution of flow is marked by flow depth increase (usually) and by a flow velocity of zero at the cover underside. The lateral redistribution of flow, though, depends on how the ice cover forms, is attached to the channel banks, and thickens. It can be explained using a flow resistance equation, such as the Darcy-Weisbach equation, that combines the appropriate variables:

$$
Q_{\mathrm{o}}=Y_{\mathrm{o}} B\left(8 g R_{0} S_{\mathrm{o}} / f_{\mathrm{o}}\right)^{1 / 2}=K_{\mathrm{o}} S_{\mathrm{o}}^{1 / 2}
$$

where $Q_{\mathrm{o}}=$ flow rate per unit width of channel

$Y_{\mathrm{o}}=$ flow depth

$B=$ flow width

$f_{\mathrm{o}}=$ Darcy-Weisbach resistance coefficient

$K_{\mathrm{o}}=$ conveyance per unit width.

The subscript "o" refers to open water flow. The presence of an ice cover may redistribute the flow laterally or concentrate it in accordance with lateral variations in flow depth and/or ice cover thickness. This influence can be illustrated using a simple, idealized channel comprising two bottom elevations of equal width (Fig. 9). It can be described approximately in terms of two conveyance components, $K_{1 \mathrm{o}}$ and $K_{2 \mathrm{o}}$, where $K_{1 \mathrm{o}}$ is associated with the deeper water.

For constant flow, a free-floating, uniformly thick ice cover reduces the magnitudes of the two conveyance components. It smears flow over the full channel width, as $K_{1 \mathrm{i}} / K_{2 \mathrm{i}}<K_{1 \mathrm{o}} / K_{2 \mathrm{o}}$ (Fig. 9b), where the subscript "i" denotes ice- 


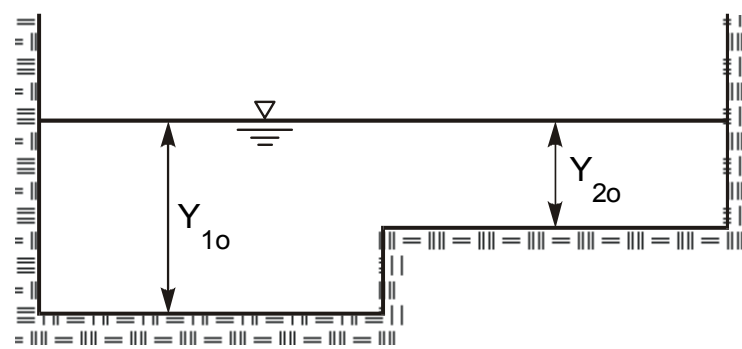

a. Open water.

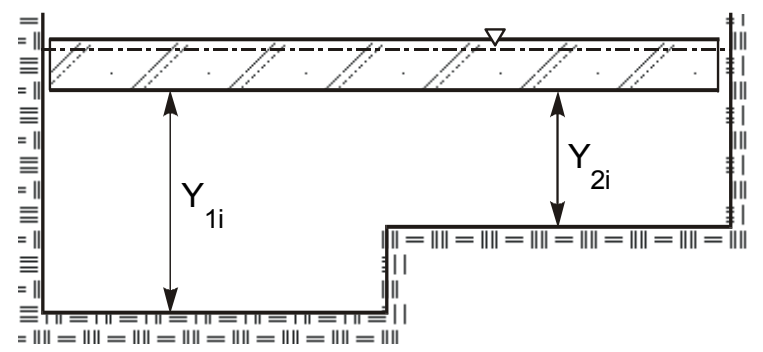

b. Reduced flow when the cover is level and free floating.

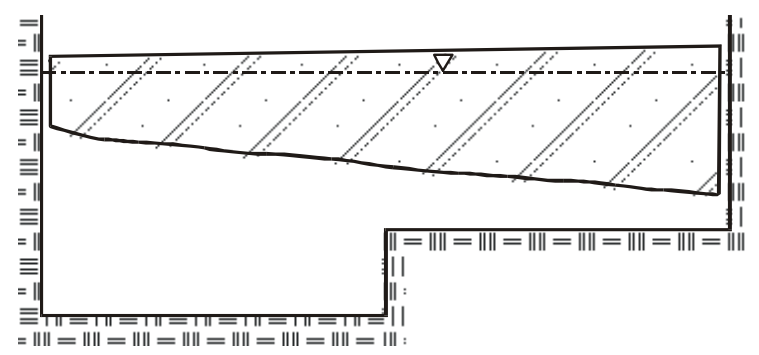

d. Increased flow when the cover is not level.

\section{c. Increased flow when the cover is fixed and thickening.}

Figure 9. Effect of ice cover on flow conveyance in lateral segments of a two-part, compound channel.

covered. However, if the ice cover were fixed to the channel banks and thickened, the reverse occurs: $K_{1 \mathrm{i}} / K_{2 \mathrm{i}}>K_{1 \mathrm{o}} / K_{2 \mathrm{o}}$ (Fig. 9c), because the reduction in flow depth represents a higher percentage of the overall depth for the shallower portion. Under this condition, the cover squeezes or concentrates flow along a thalweg, where the flow is deeper. If the thalweg lies close to one side of a channel (e.g., near the outer bank of a bend), such a concentration of flow may cause the thalweg to shift position and then deepen. On the other hand, if the thalweg were located more centrally in a channel, a fixed cover may deepen the thalweg in the same position. Also, the cover, by reducing flow through the shallow portion, may trigger further reductions in conveyance through the shallower portion by promoting ice accumulation (frazil slush or pans) and/or bed sediment deposition there. Additional flow concentration is possible if the cover is not uniformly thick (Fig. 9d), if ice grounds on the channel bed, or if shorefast or accumulated ice develops from one or both banks. 


\section{Channel anabranching and avulsion}

Channels with tight loops or with subchannels around numerous bars and islands are liable to accumulate drifting ice and precipitate ice jam formation, because their capacities are typically insufficient to convey the amount of incoming ice. They may be too curved, narrow, or shallow to enable large quantities of drifting ice pieces to pass. Jam formation may greatly constrict flow, causing it to discharge along an alternate, less-resistant course. Prowse (1998) and Dupre and Thompson (1979) suggested that ice-jam-induced avulsion plays a major role in shifting the distributary subchannels of river deltas.

When an ice jam forms at a channel loop, upstream water levels may rise enough to force the flow over the banks and across the neck of a meander loop. If the meander neck is made of erodible sediment and the flow is of sufficient scouring magnitude, a new channel can form through the neck, leaving the former channel largely cut off. A meander cutoff shortens and steepens a channel reach, affecting the river both upstream and downstream from the cutoff reach. The net effect of ice jams is to reduce channel sinuosity. Mackay et al. (1974) cited examples of such events. For the Fort Peck reach, anecdotal accounts describe a loop cutoff that occurred in 1979 at RM1603 after an ice jam.

If, on the other hand, the channel loop is wide and not easily eroded, an ice jam may have the reverse effect. Rather than causing erosion through the meander loop, the overbank flow may deposit sediment, raising the bank height and reinforcing the meander loop. Eardly (1938) reported that ice jams caused substantial sediment deposition on the floodplain of the Yukon River. Anecdotal accounts also described a similar event that occurred in the Fort Peck reach in the early 1980s at RM 1632 (Vournas site).

\section{Cover influence on thalweg alignment}

An ice cover reduces the effective energy gradient of the flow, and it reduces the flow's capacity to move sediment, which can alter the channel's shape. Consequently ice cover formation can, over time, re-orient the thalweg

Figure 10 depicts the effect that the flow drag of a free-floating ice cover has on water depth at a given discharge; in effect the ice-covered flow is equivalent to a deeper and slower open water flow. For a constant flow rate, this influence is equivalent to reducing the channel slope (or reducing the stream power). Figure 11 relates thalweg and channel sinuosity to channel slope (in effect, to energy gradient and stream power). It suggests that thalweg sinuosity is relatively sensitive to changes in the energy gradient, much more so than the overall channel sinuosity is. For a given flow rate, sediment provenance, and bed sediment com- 


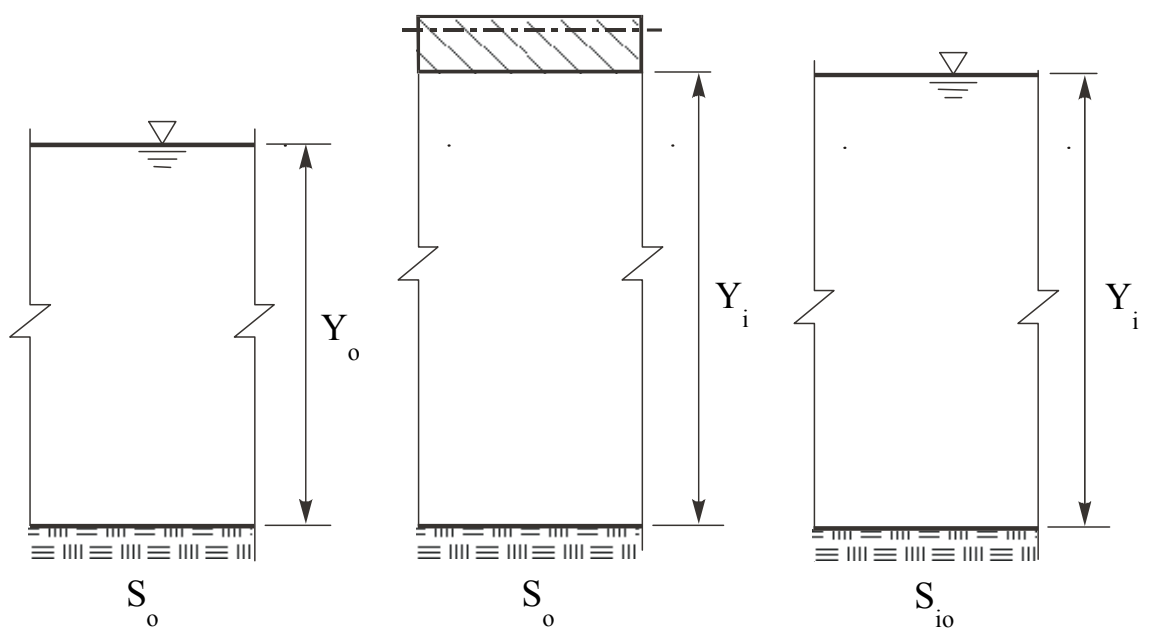

a. Initial open water

b. Flow deepened by an ice cover for the same flow rate.

c. Increased depth and reduced average velocity; that is, a reduced slope (or energy gradient, $S_{i_{0}}$ ).

Figure 10. Effect of an ice cover on flow depth and velocity.

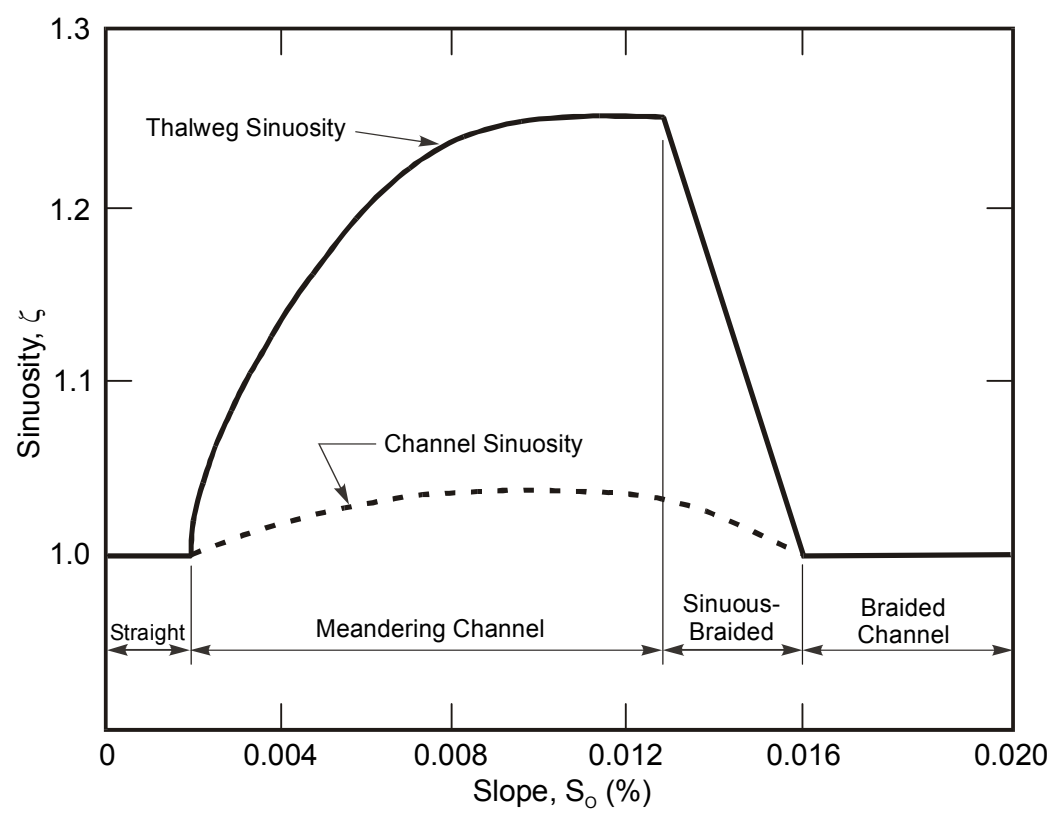

Figure 11. Variation of channel and thalweg sinuosity, $\zeta$, with channel slope, $S_{0}$. (After Schumm and Khan 1972.) 
position, thalweg sinuosity and channel planform change as the channel slope changes. Figure 11 indicates that, for a given flow rate and bed sediment size, channels lengthen or branch into subchannels as the channel slope increases.

Channel lengthening and branching are mechanisms that increase the flow resistance (and thereby the rate of energy use) in an alluvial channel to offset increased flow energy associated with an increase in channel slope. An ice cover imposes additional flow resistance, which increases the depth while decreasing the average flow velocity. The channel effectively conveys a deeper, slower flow requiring a slower rate of energy dissipation.

When the channel has a free-floating ice cover (Fig. 10b) and $Q$ is constant, the flow resistance imparted by the cover deepens the flow to $Y_{\mathrm{i}}$. The unit discharge may be written as

$$
Q_{\mathrm{i}}=Q_{\mathrm{o}}=Y_{\mathrm{i}} B\left(8 g R_{\mathrm{i}} S_{\mathrm{o}} / f_{\mathrm{i}}\right)^{1 / 2}
$$

where $R_{\mathrm{i}}$ is the hydraulic radius for the covered flow and $f_{\mathrm{i}}$ is a composite resistance coefficient for the covered channel. Channel width, $B$, is taken to be constant. It is assumed here that the overall reach slope, $S_{\mathrm{o}}$, does not change. The ice cover, by reducing the flow velocity, reduces the portion of the flow energy gradient (or stream power) expended as flow drag along the channel's bed.

For an alluvial channel, a reduction in energy gradient usually implies an adjustment in planform geometry. Since an ice cover deepens and slows the flow in a channel, the channel responds as if it were set at a flatter slope. In effect, the channel responds as if it were conveying an equivalent open water flow whose cross-sectional area is as shown in Figure 10c but whose energy gradient is reduced. The effective hydraulic radius, resistance coefficient, and energy gradient of the equivalent flow are $R_{\mathrm{io}}, f_{\mathrm{io}}$, and $S_{\mathrm{io}}$, respectively, with $R_{\mathrm{io}} \approx 2 R_{\mathrm{i}}$ and $S_{\mathrm{io}}<$ $S_{\mathrm{o}}$. For this equivalent open water flow,

$$
Q_{\mathrm{i}}=Q_{\mathrm{o}}=Y_{\mathrm{i}} B\left(8 g R_{\mathrm{io}} S_{\mathrm{io}} / f_{\mathrm{io}}\right)^{1 / 2}
$$

Equation 3 and 4 give

$$
\frac{S_{\mathrm{io}}}{S_{\mathrm{o}}}=\left(\frac{f_{\mathrm{io}}}{f_{\mathrm{o}}}\right)\left(\frac{Y_{\mathrm{o}}}{Y_{\mathrm{io}}}\right)^{2}\left(\frac{R_{\mathrm{o}}}{R_{\mathrm{io}}}\right) \approx\left(\frac{f_{\mathrm{io}}}{f_{\mathrm{o}}}\right)\left(\frac{Y_{\mathrm{o}}}{Y_{\mathrm{io}}}\right)^{3} \approx\left(\frac{Y_{\mathrm{o}}}{Y_{\mathrm{io}}}\right)^{3} .
$$

Equation 5 assumes the wide-channel approximation $R_{\mathrm{o}} \approx Y_{\mathrm{o}}$ and $R_{\mathrm{io}} \approx Y_{\mathrm{io}}$, and, because the bed sediment does not change and if the ice cover is fairly level, the ratio $f_{\mathrm{io}} / f_{\mathrm{o}} \approx 1$. 
Eq 3-5, though entailing simplifying assumptions, lead to a clear result. As the covered flow depth $Y_{\mathrm{i}}$ usually exceeds the open water depth $Y_{\mathrm{o}}$, the ratio $S_{\mathrm{i} d} / S_{\mathrm{o}}$ is less than 1 . Therefore, the energy gradient (and stream power) available for sediment transport and channel forming decreases when a channel has a freefloating ice cover. For a typical value of, say, $Y_{\mathrm{o}} / Y_{\mathrm{i}} \approx 0.8, S_{\mathrm{io}} / S_{\mathrm{o}} \approx 0.5$; in other words, for a given flow rate in a channel of given length, approximately half the energy expenditure is available for sediment transport and channel forming. The effect of an ice cover, therefore, is to trigger a shift in thalweg sinuosity and alignment so as to balance flow-energy availability and use. Figure 11 suggests, for instance, that halving the slope of a meandering channel (say, from $0.008 \%$ to $0.004 \%$ ) will reduce thalweg sinuosity; i.e., the thalweg attempts to straighten and the meander wavelengths shorten, as sketched in Figure 12.

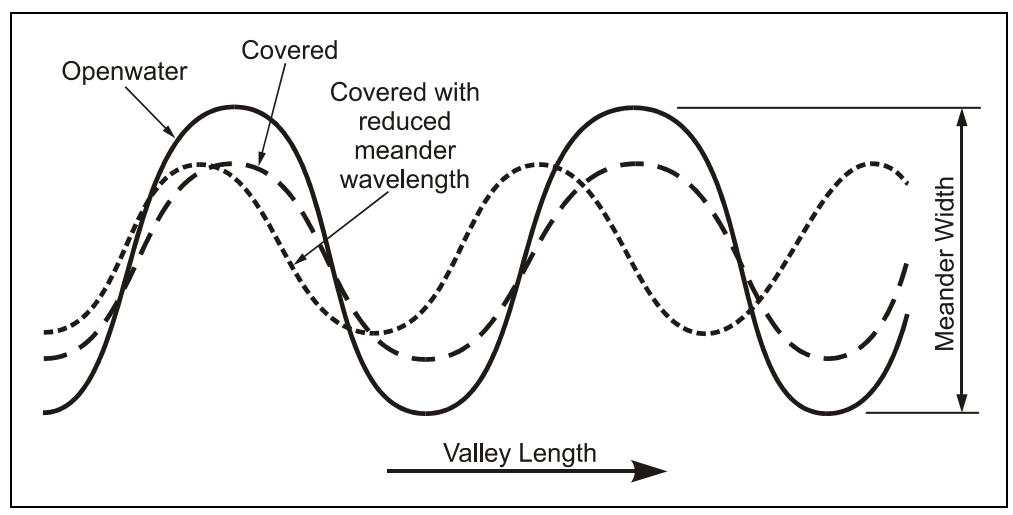
Figure 12. Influence of an ice cover on a meandering channel of more-or-less uniform flow depth. The cover may cause the thalweg to straighten and meander loops to shorten.

For sinuous-braided channels, as in Figure 13, ice cover formation and the associated decrease in the energy gradient may cause flow to concentrate in a single thalweg of greater sinuosity than the open water thalweg. For braided channels an ice cover may concentrate the flow into the larger subchannels.

If the ice cover is rigid and attached to the shore or channel structures, the cross section is constant. An increase in discharge causes a flow regime akin to pressure flow, with an increase in bulk velocity and shear stresses along the bed.

\section{Ice cover influence on channel bed elevation}

A basic issue is an imbalance between the rate of sediment supply to an icecovered reach $Q_{\mathrm{s}}$ and the sediment transport capacity of that reach $Q_{\mathrm{sc}}$. This issue involves the complex problem of spatially varied flow and sediment transport, 


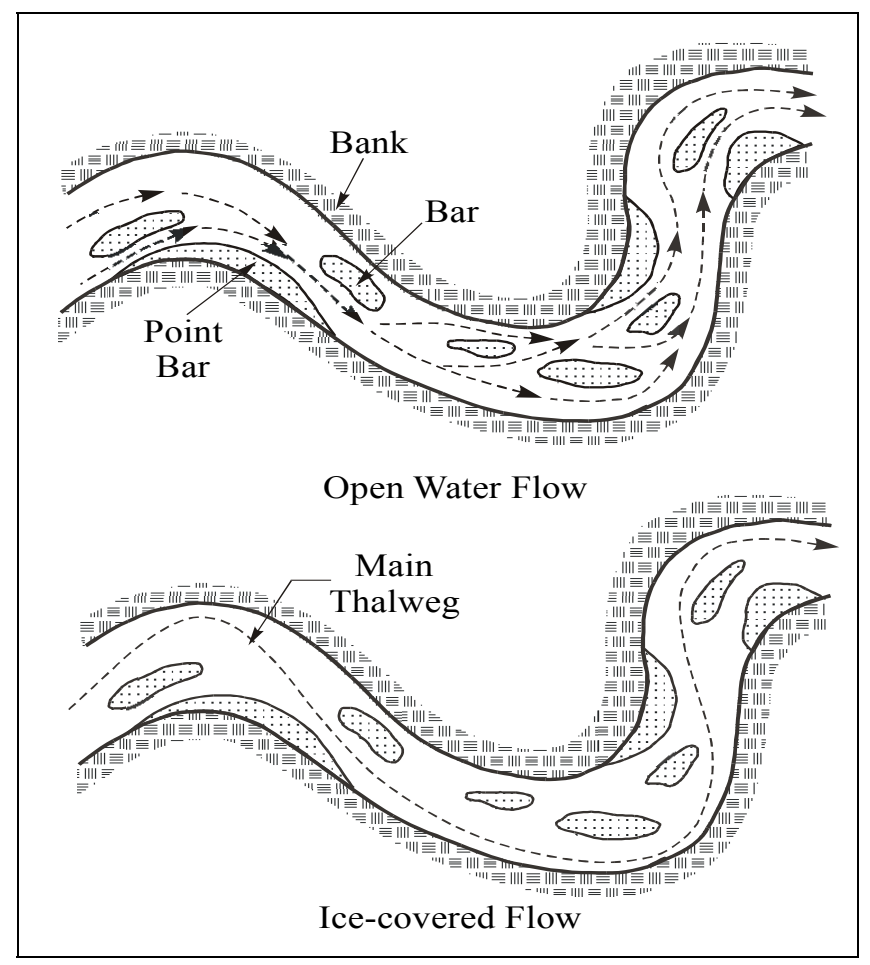

Figure 13. River ice impact on the thalweg of a sinuous-braided channel. An ice cover causes the main thalweg to become more sinuous.

with all its repercussions for local channel slope and morphology. When $Q_{\mathrm{sc}}$ is less than $Q_{\mathrm{s}}$, the bed elevation must rise locally. Conversely, if $Q_{\mathrm{sc}}$ is greater than $Q_{\mathrm{s}}$, the bed elevation must drop locally. The former condition usually would prevail for a free-floating cover, because the bulk velocity of the flow decreases. The latter condition may occur beneath an ice jam (Wuebben 1988, Neill 1976) or when the cover is fixed and rigid, because the bulk velocity of the flow is forced to increase substantially under the ice. 


\section{REVIEW OF RIVER ICE INFLUENCES ON RIVERBANKS}

River ice may influence channel bathymetry through several processes that affect channel riverbanks:

- Reduction of riverbank strength by increasing pore water pressure or by producing rapid drawdown of the riverbank water table during dynamic ice cover or ice jam breakup;

- Thermal weakening of riverbank soils;

- Tearing and dislodging of riverbank material and vegetation during the collapse of bankfast ice; and

- Gouging and abrasion of riverbank material and vegetation during an ice run.

These influences reduce the riverbank resistance to scour, increase the local supply of sediment, and promote lateral shifting of the channel. The first two influences are not well studied. The third and fourth have received a little attention, but the extents to which they affect channel morphology are unclear.

\section{Influence on soil pore pressures}

Flow stage and stage fluctuations influence seepage pressures and the freezethaw behavior of channel riverbanks. A higher flow stage raises the water table in a riverbank. A rapid drop in flow stage may quickly reduce the riverbank stability by increasing seepage pressures, thereby reducing the shearing resistance of the material comprising the riverbank. Ice cover formation raises the flow stage, whereas cover breakup may abruptly lower it. River ice formation, therefore, can weaken riverbanks.

Riverbank freezing is closely linked to bankfast ice formation along a channel. The details of the relationship between them are unclear, however. They depend on the condition of the riverbank (material, vegetation, snow, etc.), the relative elevations of the water table and the flow stage, and the temperatures of the groundwater and river water. The strength of the attachment of bankfast ice to a riverbank depends on the relative elevations of the water table and flow stage and on the water temperatures. A flow of relatively warm groundwater (i.e., several degrees above the freezing temperature) into a river will retard border ice growth and weaken its hold on the riverbank. The growth of a thick fringe of bankfast ice, on the other hand, may affect seepage flow through the riverbank, possibly constricting it and slightly raising the water table. This is especially significant for regulated rivers, for which flows do not diminish during winter. 


\section{Thermal influences on riverbank strength}

It is well known that the freezing and thawing of soil affect the erosion of riverbanks adjoining rivers and lakes. Lawson $(1983,1985)$ and Gatto (1988, 1995), among others, provided extensive reviews of the subject. In short, because frozen soil is more resistant to erosion than is unfrozen soil, riverbanks are less erodible while frozen. Freezing and thawing, however, usually weaken soils, making thawed (or thawing) riverbanks more susceptible to erosion. The net consequence on the overall rate of riverbank erosion, therefore, remains a matter of debate but most likely varies regionally and from site to site.

Freeze-thaw cycles affect the soil structure, porosity, permeability, and density. These changes in soil properties can substantially reduce soil shear strength and bearing capacity; strength reductions can be as much as 95\% (Andersland and Anderson 1990). Such adverse effects on soil strength depend on the soil particle size and gradation, the moisture content, the number and duration of freeze-thaw cycles, and several other factors. Though there is no single, standard test to determine whether a soil is prone to significant weakening due to freezethaw (Chamberlain 1981), particle size is commonly used to indicate a soil's sensitivity to freeze-thaw weakening. Soils containing fine sands and silts are especially sensitive because they are permeable and susceptible to change in soil structure. By virtue of their particle size (about $0.1-0.06 \mathrm{~mm}$ ) and the surfacetension property of water, fine sandy and silty soils absorb moisture more readily than do coarser or fine sediments. Clayey soils are less sensitive because of their low permeability. The variability of soil properties along a riverbank and within a specific riverbank location causes the effects of riverbank freezing to differ along a reach.

Gatto (1995) suggested that eroding riverbanks are especially subject to deep penetration of freezing, making more of the riverbank prone to freeze-thaw weakening and erosion. The absent or stunted vegetation on many eroding riverbanks results in diminished insulation of the riverbank and increased heat loss to air. The heat loss is greatest at the crest of a riverbank because it is exposed to air on at least two surfaces. It is also more exposed to wind, so it may accumulate less snow, which means deeper frost penetration during the winter and faster thaw in the spring. However, if the top portion of the riverbank and upland were dry, the riverbank crest might be the zone of least heat loss, as the distance between the air and the water table is greatest there.

Spring is when the riverbank is most susceptible to erosion. As the upper zone of frozen ground thaws, meltwater drains down over the surface of the still frozen ground. The riverbank, weakened by thaw expansion of the ground and subject to seepage pressures, is at its least stable annual condition. 
Several studies (Harlan and Nixon 1978, Reid 1985) have found that southfacing riverbanks do not freeze as deeply, all else being equal, as north-facing riverbanks do. South-facing riverbanks (in the northern hemisphere) receive more insolation (energy in the form of short-wave radiation from the sun) and may undergo more diurnal freeze-thaw cycles (Gatto 1995). The result has yet to be determined, but the effect may be important here because of the east-west orientation of the Fort Peck reach.

\section{Bankfast ice loading of riverbanks}

Figure 14 illustrates ways in which bankfast ice might weaken a riverbank. The ice cover freezes into the riverbank. The size of the ice root is limited by the groundwater elevation and temperature and by the nature of the riverbank material. When the water level in the channel drops and the ice cover breaks up, ice that remains attached to the riverbank rotates and tears a portion of the riverbank as it drops. It is difficult to get direct field observations of this mechanism for bankfast ice attached to vertical riverbanks. There is evidence for a related mechanism commonly termed plucking, which is used with regard to the loss of riprap stones frozen to an ice sheet. Wuebben (1995), for instance, discussed plucking concerns in the design of riprap for riverbank protection.

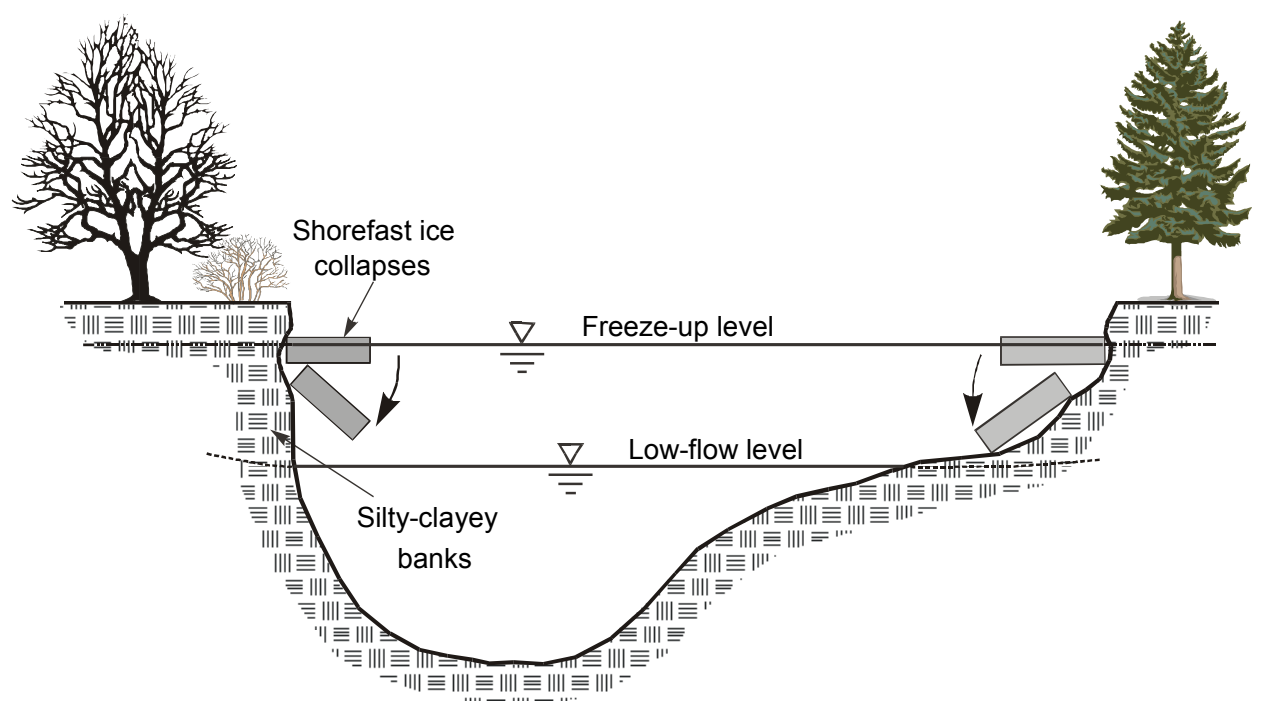

Figure 14. Collapse of shorefast ice, and possibly bank material, following lowering of the flow stage. At present, shorefast ice effects on bank erosion are not well known. 
Bankfast ice weakening of riverbanks likely is significant for steep riverbanks, especially those riverbanks containing enough clay to be termed cohesive. It also likely is significant for riverbanks where the water table declines in elevation away from the flow elevation in a channel, because the bankfast ice is less securely anchored into the riverbank. This erosion mechanism seems not to have been investigated but had been observed along the Fort Peck reach (e.g., Simon et al. 1999).

\section{Gouging and abrasion of riverbanks}

During heavy ice runs resulting from ice cover breakup or ice jam release, large pieces of ice may gouge and abrade channel riverbanks, substantially affecting the channel riverbank morphology (Marusenko 1956, Smith 1979, Hamelin 1979, Uunila 1997, Doyle 1988, Wuebben 1995). The affected channels are usually relatively steep and convey high-velocity flows. Their ice covers typically break up dramatically in concert with a sudden rise in flow, as might be caused by rapid snowmelt and/or rain. The resulting ice rubble comprises hard, angular blocks of ice.

One study of 24 rivers in Alberta (Smith 1979) led to the intriguing hypothesis that ice runs enlarge channel cross sections at riverbank-full stage by as much as 2.6-3 times those of rivers of comparable flow but not subject to ice runs. The hypothesis is based on a comparison of the recurrence interval of riverbank-full flows in the 24 rivers and an empirical relationship between the cross-section area and flow rate for riverbank-full flow. The concept is plausible, but the extent of widening seems overly large and requires confirmation. Kellerhals and Church (1980) argued against Smith's hypothesis, suggesting that other factors led to the apparent widening of the channels analyzed by Smith, including recent entrenchment of major rivers in Alberta and ice-jam effects of flow levels. Moreover, it is possible that the riverbanks are somewhat protected by a band of ice that forms a shear wall flanking the riverbanks. It is interesting to contrast Smith's hypothesis with the idea that ice jams may promote channel narrowing by causing overbank flow (e.g., Uunila 1997). For channels with the dominant channel-forming flow coinciding with ice cover breakup, the overbank loss of flow reduces the flow rate that has to be accommodated by the channel.

In many situations, notably those in which an ice run is sluggish, a shear wall of broken ice may prevent moving ice from contacting the riverbank. The shear wall usually is smooth-faced and helps the river pass the ice. Running ice, if sufficiently thick, may still gouge the lower portion of a riverbank.

Ice gouging and abrasion, though, can be severe for channel features and riverbank stabilization structures protruding into the flow. In addition, channel 
locations with substantial changes in alignment, such as sharp bends, point bars, and portions of a channel confluence, are especially prone to ice run gouging and abrasion. There is a little information on how ice runs affect the morphology of these sites.

Ice run gouging and abrasion have an important, though not yet quantified, effect on riparian vegetation that, in turn, may affect riverbank erosion and channel shifting. Where ice runs occur nearly every year, riparian vegetation communities have difficulty getting established. Ice abrasion and ice jam flooding may also suppress certain vegetation types along riverbanks. 


\section{SURVEY PROGRAM}

The survey program first entailed identifying sites where river ice likely would significantly affect the flow distribution and, thereby, the bathymetry in the river. A schedule of bathymetric surveys then was coordinated for the sites. The surveys concentrated especially on determining how ice cover formation, presence, and breakup might locally alter channel bathymetry and aggravate riverbank erosion.

\section{Survey personnel}

The survey involved a team of personnel from several organizations: the U.S. Army Corps of Engineers Cold Regions Research and Engineering Laboratory (CRREL); the Corps' Omaha District (USACE-Omaha); the Iowa Institute of Hydraulic Research (IIHR); Eisenbraun and Associates Inc., a civil-engineering company based in Yankton, South Dakota; the U.S. Department of Agriculture, National Resource Conservation Service's (NRCS) Culbertson Office; and local logistic support from the town of Culbertson. The survey interacted closely with the Coordinated Resource Management (CRM) Group, an organization of farmers who live and work along the Fort Peck reach.

\section{Survey sites}

As surveys under winter conditions are expensive, an initial issue to be resolved was the number of survey sites and the extent of measuring and monitoring to be conducted at each site. Sites were selected where bank- and channelchange concerns are most acute and where ice is perceived to be a significant factor contributing to the concerns. The eventual selection relied mainly on informal observations made during a visit in October 1998 and on anecdotal accounts of ice-related changes in channel thalweg alignment, bank erosion, and pump site sedimentation during prior winters. There was also interest in monitoring river ice influences on bank stabilization methods installed at RM 1716 (Pipal site). A further consideration was site accessibility.

Five sites were selected for monitoring:

- RM 1620-1621, a multi-thalweg channel (Culbertson site) (three cross sections between 1620.35 and 1620.45);

- RM 1623-1624, a complex bend (Tveit-Johnson site) (four cross sections between 1623.97 and 1624.11);

- $\quad$ RM 1632-1633, a bend (Vournas site) (three cross sections between 1632.55 and 1632.68); 
- RM 1646-1647, a multi-thalweg channel (Mattelin site) (three cross sections between 1646.72 and 1646.9); and

- RM 1715-1716, a bend, where the upstream half has bank protection (Pipal site) (three cross sections between 1715.53 and 1715.74).

The site locations are indicated in Figure 15. Each site is approximately 1 mile long, though the area actually surveyed was about 0.25 mile in length with survey lines approximately 300 feet apart. The monitoring of ice-related processes at these sites included overall descriptions of ice formation, extent of coverage, and breakup on the river. Several other sites were observed, but not surveyed, during the winter of 1998-99 (e.g., RM 1687, the Whitmer site).

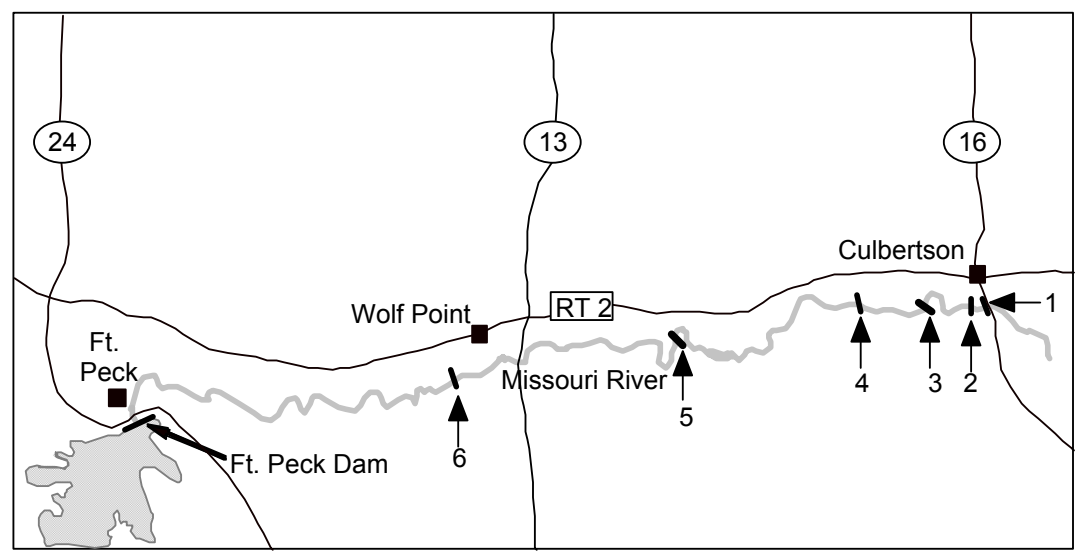

Figure 15. Locations of the survey sites.

1. Culbertson, RM 1621.

2. Tveit-Johnson, RM 1624.

3. Vournas, RM 1631.

4. Mattelin, RM 1646.
5. Whitmer, RM 1687.

6. Pipal, RM 1716.

7. Fort Peck Dam, RM 1771.

The objective of the investigation was to assess the influence an ice cover had on shifting of the main thalweg of the river, bank erosion, pump site sedimentation, and potential cutoff of meander loops by ice jams. Measurements that were made to document these concerns are listed in Table 1, along with the sites where the process was suspected to be occurring. Impaired riparian vegetation and river habitat are also important concerns, but the survey did not document them.

Table 1 also summarizes the information sought in evaluating erosion mechanisms. The Tveit-Johnson, Vournas, and Pipal sites are representative locations of bank erosion. Anecdotal evidence exists of thalweg switching from one subchannel to another in the multi-thalweg channels at the Mattelin and 


\begin{tabular}{|c|c|c|}
\hline Ice influence & Documenting measurements & Sites of special interest \\
\hline $\begin{array}{l}\text { Elevated freeze- } \\
\text { up and breakup }\end{array}$ & $\begin{array}{l}\text { Border ice collapse process: } \\
\text { Size of border ice pieces } \\
\text { Failure process } \\
\text { Disturbance of bank soil }\end{array}$ & $\begin{array}{l}\text { Pipal, RM 1716, } \\
\text { Vournas, RM } 1632 \\
\text { Tveit-Johnson, RM } 1624\end{array}$ \\
\hline $\begin{array}{l}\text { Flow distribution } \\
\text { in reaches with } \\
\text { multiple } \\
\text { subchannels }\end{array}$ & $\begin{array}{l}\text { Bathymetry: } \\
\text { Open water before winter (early } \\
\text { November) } \\
\text { Ice-covered water in early and } \\
\text { mid-winter (January, February) } \\
\text { Open water in early spring (April) } \\
\text { Ice cover: } \\
\text { Thickness distribution } \\
\text { Flow distribution: } \\
\text { For open water } \\
\text { For ice cover }\end{array}$ & $\begin{array}{l}\text { Mattelin, RM } 1646 \\
\text { Culbertson, RM } 1620\end{array}$ \\
\hline $\begin{array}{l}\text { Local scour of } \\
\text { channel bed and } \\
\text { bank toe }\end{array}$ & $\begin{array}{l}\text { Bathymetry: } \\
\text { Open water before winter (early } \\
\text { November) } \\
\text { Ice-covered water in early and } \\
\text { mid-winter (January, February) } \\
\text { Open water in early spring (April) } \\
\text { Flow distribution: } \\
\text { For open water } \\
\text { For ice cover }\end{array}$ & $\begin{array}{l}\text { Tveit-Johnson, RM } 1624 \\
\text { Vournas, RM } 1632 \\
\text { Pipal, RM } 1716\end{array}$ \\
\hline $\begin{array}{l}\text { Ice gouging and } \\
\text { abrasion during } \\
\text { an ice run }\end{array}$ & $\begin{array}{l}\text { Date of ice run } \\
\text { Photo series of ice run } \\
\text { Flow record } \\
\text { Ice thickness }\end{array}$ & All sites \\
\hline Ice jam & $\begin{array}{l}\text { Date } \\
\text { Bathymetry of jam location } \\
\text { Photos of ice movement } \\
\text { Flow record } \\
\text { Flow stages at site }\end{array}$ & Vournas, RM 1632 \\
\hline
\end{tabular}

Culbertson sites. A jam occurs on occasional years at the Vournas Farm. Three of the sites - the Pipal, Mattelin, and Tveit-Johnson sites - appear most prone to the adverse effects of elevated freeze-up, thalweg shifting, and freeze-thaw weakening of bank soil. Table 2, taken from Simon et al. (1999), lists the soil types for the banks at the sites.

\section{Survey schedule}

Six site visits were conducted in the course of the survey. Four bathymetric surveys were conducted over approximately a four-month period: October 1998 


\begin{tabular}{|c|c|c|}
\hline Site & $\begin{array}{l}\text { Major soil } \\
\text { series }\end{array}$ & $\begin{array}{l}\text { Riverbank toe } \\
\text { sediment }\end{array}$ \\
\hline Culbertson, RM 1621 & Havrelon & Sandy silt \\
\hline Tveit-Johnson, RM 1624 & Lohler & Clay \\
\hline Vournas, RM 1632 & Banks & Sandy silt \\
\hline Mattelin, RM 1646 & Trembles & Sandy silt \\
\hline Pipal, RM 1716 & Havre & Sandy silt \\
\hline
\end{tabular}

through mid-April 1999. One bathymetric survey was completed before the ice cover formed over the river. Two were conducted when the river was ice covered. A final bathymetric survey was carried out shortly after ice departed the river in early spring. Two additional site visits were carried out to observe channel conditions before and after the river became ice covered. The survey dates were as follows:

- Fall observation of channel conditions and site selection (October 14-17, 1998);

- Early winter, open water channel bathymetric survey (October 16-22, 1998);

- Early winter observation of ice formation at RM 1621, Culbertson (December 20-23, 1998);

- Early winter covered-channel bathymetric survey (January 26-28, 1999);

- Mid-winter covered-channel bathymetric survey (February 21-23, 1999); and,

- Early spring open water bathymetric survey and observations (April 4-7, 1999).

The bathymetric surveys before freeze-up (cover formation) and shortly after breakup (cover departure) revealed the extent to which ice affects channel bathymetry. The two bathymetric surveys during winter provide insights as to when and how the channel changes occurred. It was desirable, but not critical, that the surveys be conducted when the river conveyed approximately the same flow rate. 


\section{Specific issues for survey sites}

The survey necessitated sets of activities aimed at determining if and how the ice-related erosion mechanisms discussed above affect bank and channel conditions at the sites. Each site was monitored with the following questions in mind:

- What evidence exists that the ice-related channel change or erosion mechanisms are active at the site?

- How do the erosion mechanisms affect the site?

- If the mechanisms appear significant, what structural or bathymetric methods would mitigate them?

- What further investigation would be needed to confirm the mechanisms and establish the methods identified to mitigate them?

\section{Features of survey sites}

\section{Culbertson, RM 1620-1621}

This site is representative of river reaches with upstream and downstream ends that are constrained and narrowed to a single channel by a bluff located along one side of the river. Figure 3 shows the site in the summer of 1996 and Figure 2a shows the reach immediately upstream of the Culbertson site.

Between these two constrictions, the channel widens along the greater portion of the reach and initially divides into two subchannels around a vegetated bar as illustrated by Figure 16. Then, it further subdivides into as many as three subchannels. The channel subsequently narrows as the river becomes constrained

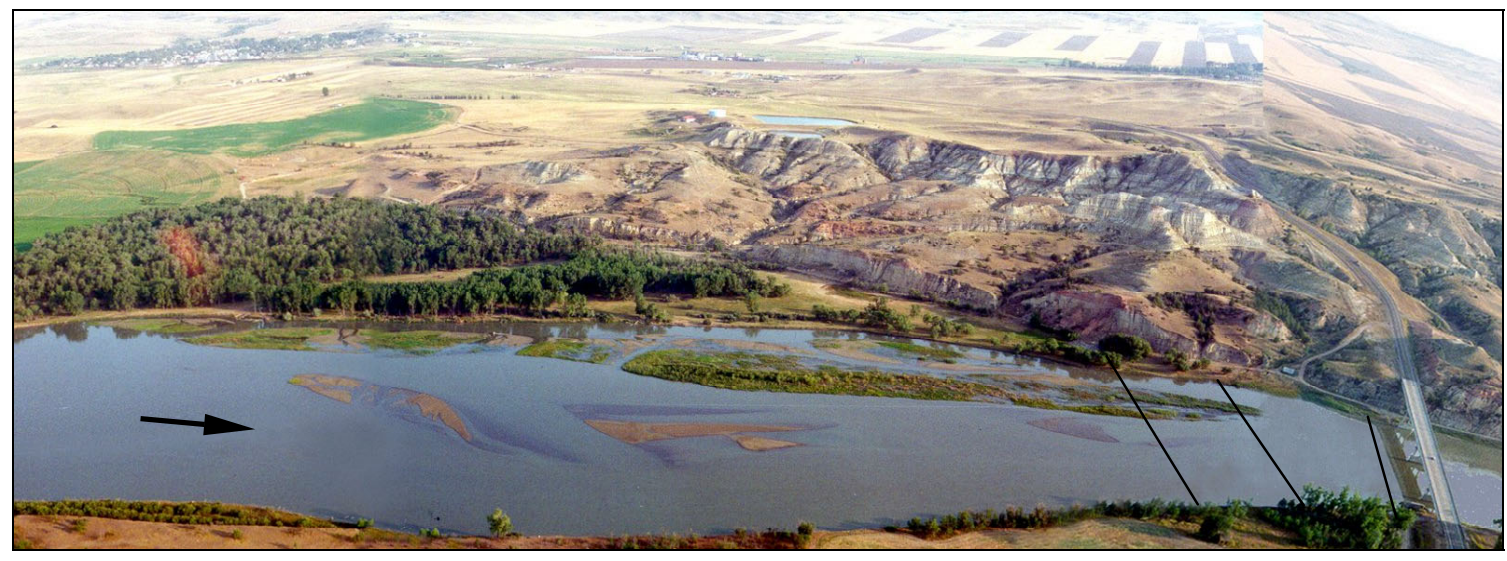

Figure 16. Aerial view of RM 1620-1621, Culbertson site. The arrow shows the direction of flow, and the lines show the approximate locations of the surveys. (From CRM 1996.) 


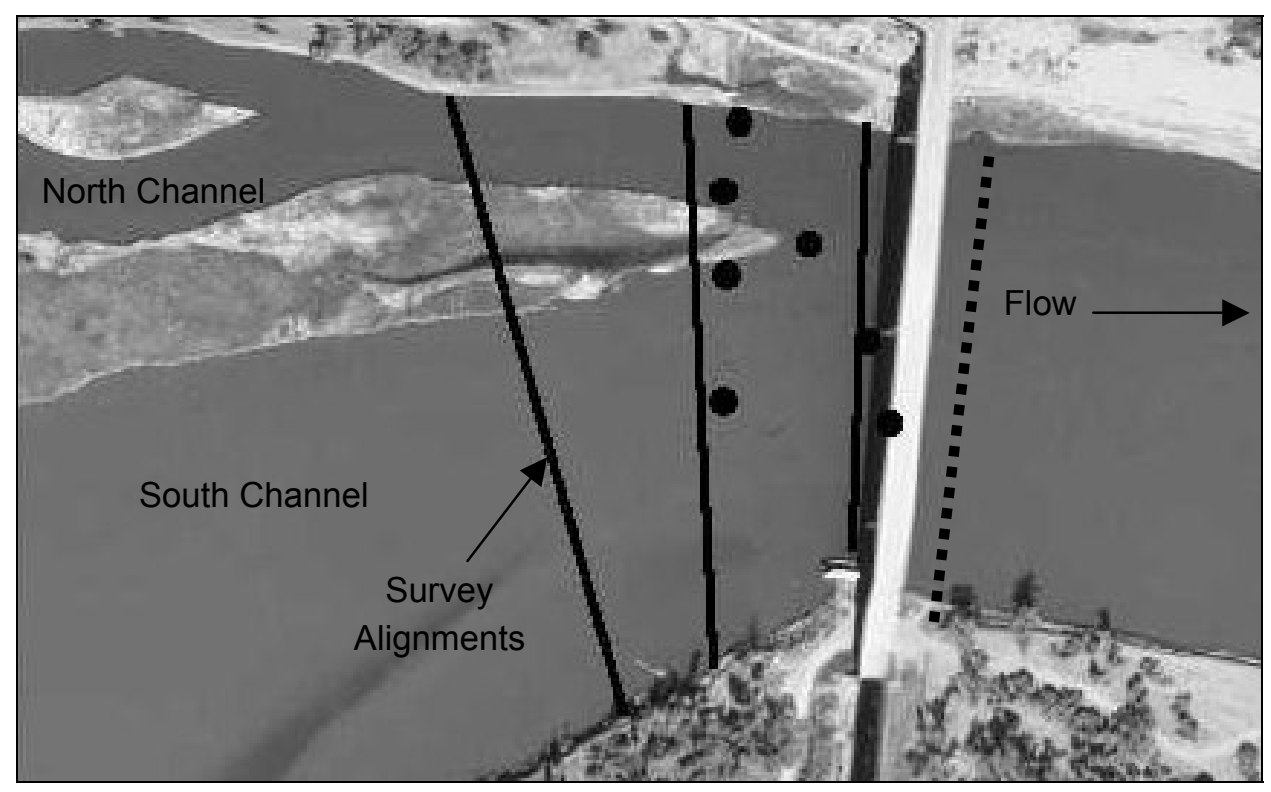

Figure 17. Survey cross sections near RM 1620-1621, Culbertson site. (From USACE-Omaha 1996.)

by the bluff at the downstream end of the reach. The subchannels align around medial bars formed of alluvial sediment deposited by the river as its crosssectional area of flow widens. Three cross sections were selected for monitoring. The general locations and orientations of the survey lines are indicated in Figure 17. A fourth cross section, under the Route 16 Bridge, was added for the ice surveys to document the influence of the bridge piers.

Of particular interest in the monitoring of this site was the likely influence of ice cover formation on the alignment of the main thalweg. Aerial photographs and map overlays (CRM 1996) indicate that the alignment has shifted several times over the past few decades. Shifting of a main thalweg is not uncommon for sinuous-braided channels, but anecdotal accounts suggest that ice cover formation may play a role at this site. Over time the main thalweg through the site has shifted from one subchannel to the other. In 1996, as depicted in Figure 3, the main thalweg at RM 1620 lay along a central subchannel. Flow in a subchannel to the north of the central subchannel had become significantly shallower because of deposition of sediment. Unfortunately the municipal water supply for the town of Culbertson draws water from an intake adjoining that subchannel, and sediment deposition has impaired the operation of the water intake. 
Tveit-Johnson site, RM 1623-1624

The river at this site narrows to a single channel near the apex of a gradual bend flanked by a high bank (approximately $15 \mathrm{ft}$ high) along its north side. Upstream, the river flows in two subchannels around medial bars. Figure 18 shows how the flow impinges against the steep north bank of the river. The four cross sections selected for monitoring are indicated in Figure 19, an aerial view taken in 1983 (USACE-Omaha 1983).

At RM 1623.5 the channel's thalweg impinges along the base of the channel's north bank and actively erodes a 3000-ft-long portion of the bank. The exact rates of bank recession have not been determined, but the erosion is causing significant loss of prime irrigated cropland. As the bank has receded, the thalweg has shifted accordingly. In addition, the shifting thalweg has caused a sediment deposition problem at a downstream location where a small irrigation pump draws water for the croplands.

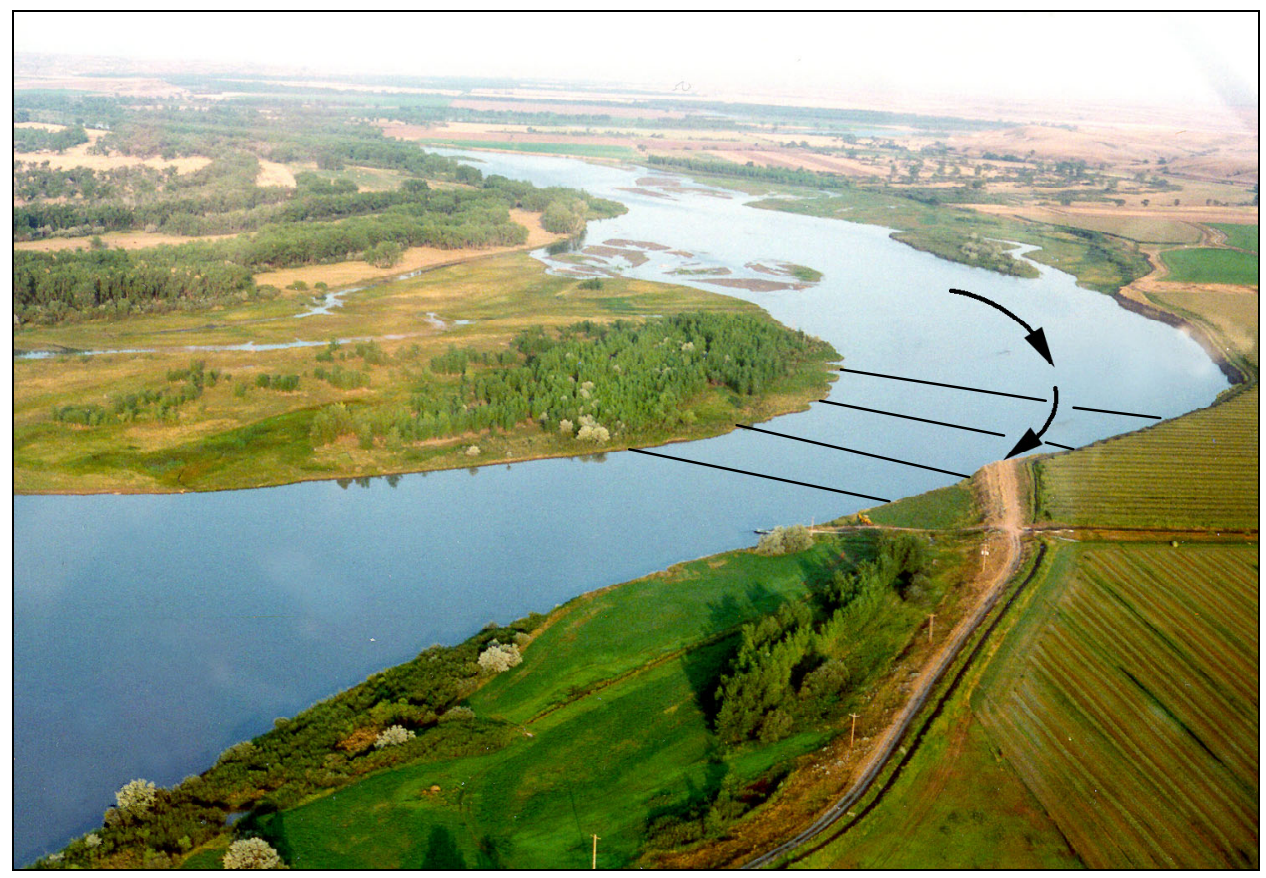

Figure 18. Aerial view of RM 1623-1624, Tveit-Johnson site. The arrows show the direction of flow, and the lines show the approximate locations of the surveys. (From CRM 1996.) 


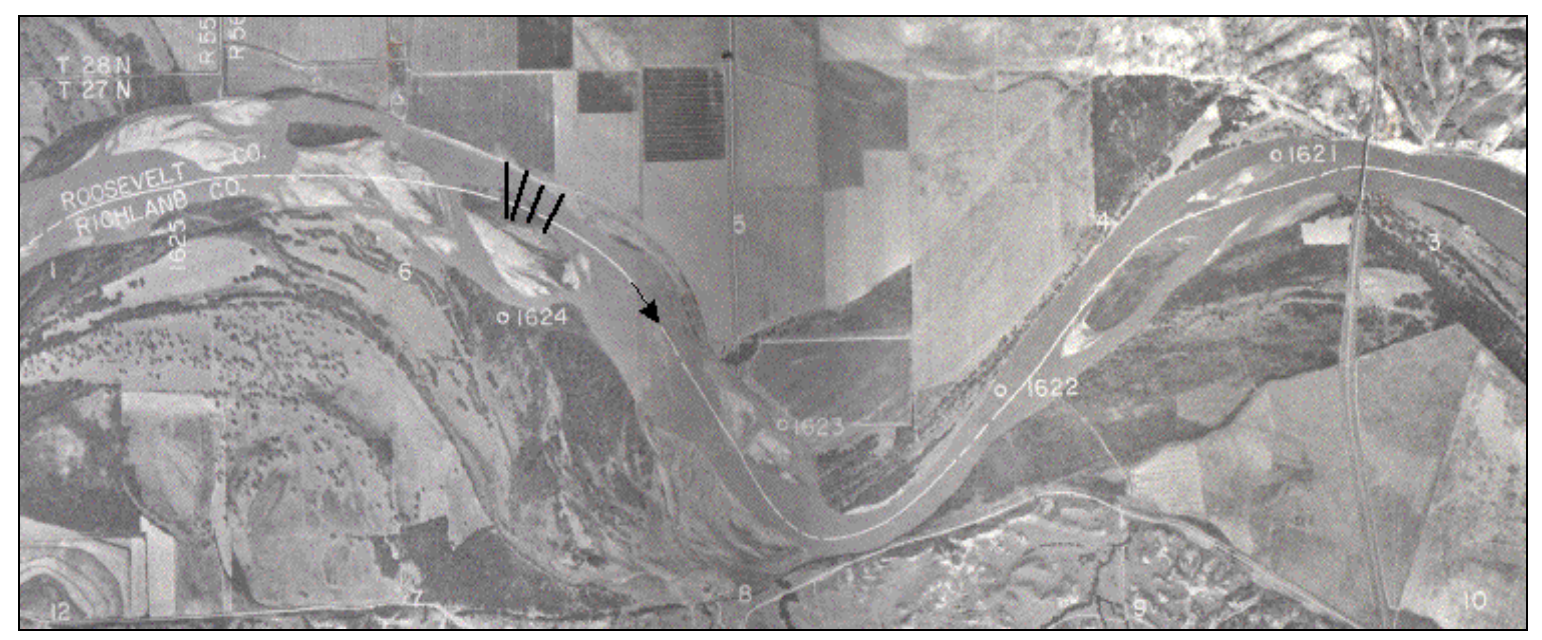

Figure 19. Survey cross sections near RM 1623-1624, Tveit-Johnson site. (From USACEOmaha 1983.)

Vournas site, RM 1631-1632

The site lies along the upstream flank of a large, irregular loop of the Missouri River, with the river flowing in a single, curved channel constrained by an outer bank that is about 10-15 ft high (Fig. 20). Immediately upstream of the site the river is constrained by a bluff. Downstream of the site the channel widens, developing an irregular bend that has a secondary subchannel. The outer bank constraining the channel is being severely eroded by flow, and the bank erosion is encroaching on the operation of a rotating irrigation pivot and cropland serviced by the pivot. Three cross sections were selected for monitoring (Fig. 21).

This site was selected for monitoring because it likely would be useful for determining how an ice cover influences flow distribution and loose-bed bathymetry in a channel bend. In particular, survey information from the site would be of use in assessing whether and how an ice cover may shift the channel thalweg. A further ice process of interest at the Vournas site is the occasional formation of an ice jam. The frequency of jamming is not known precisely, because jam occurrence has not been recorded routinely. However, anecdotal accounts indicate that the ice jams here approximately every ten years. When a jam develops, it backs up flow and causes it to spill overland until it enters the river at the downstream side of the meander loop. As the neck of the meander loop is relatively wide and overland flow velocities small, jam-induced flooding apparently deposits sediment on the flooded land.

\footnotetext{
* Personal communication with Dick Iverson, Director, Culbertson Office, U.S. National Resources Conservation Service (NRCS).
} 


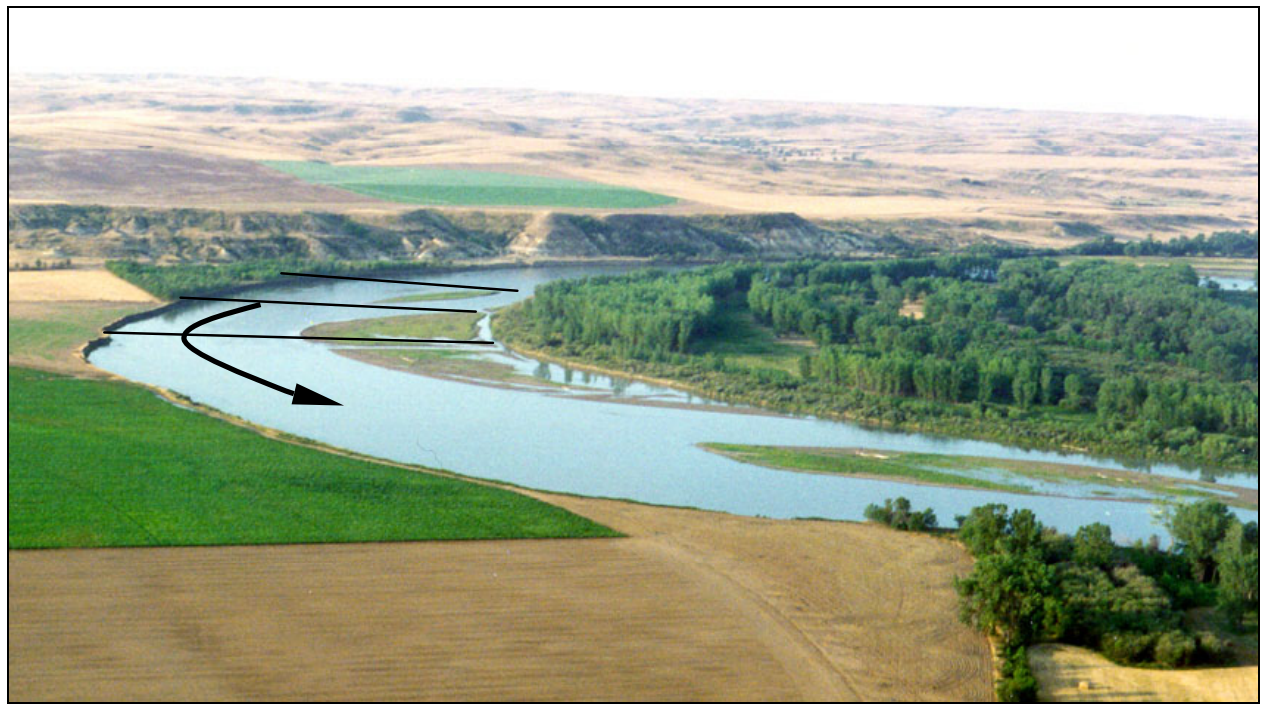

Figure 20. Aerial view of RM 1631-1632, Vournas site. The arrow shows the direction of flow, and the lines show the approximate locations of the surveys. (From CRM 1996.)

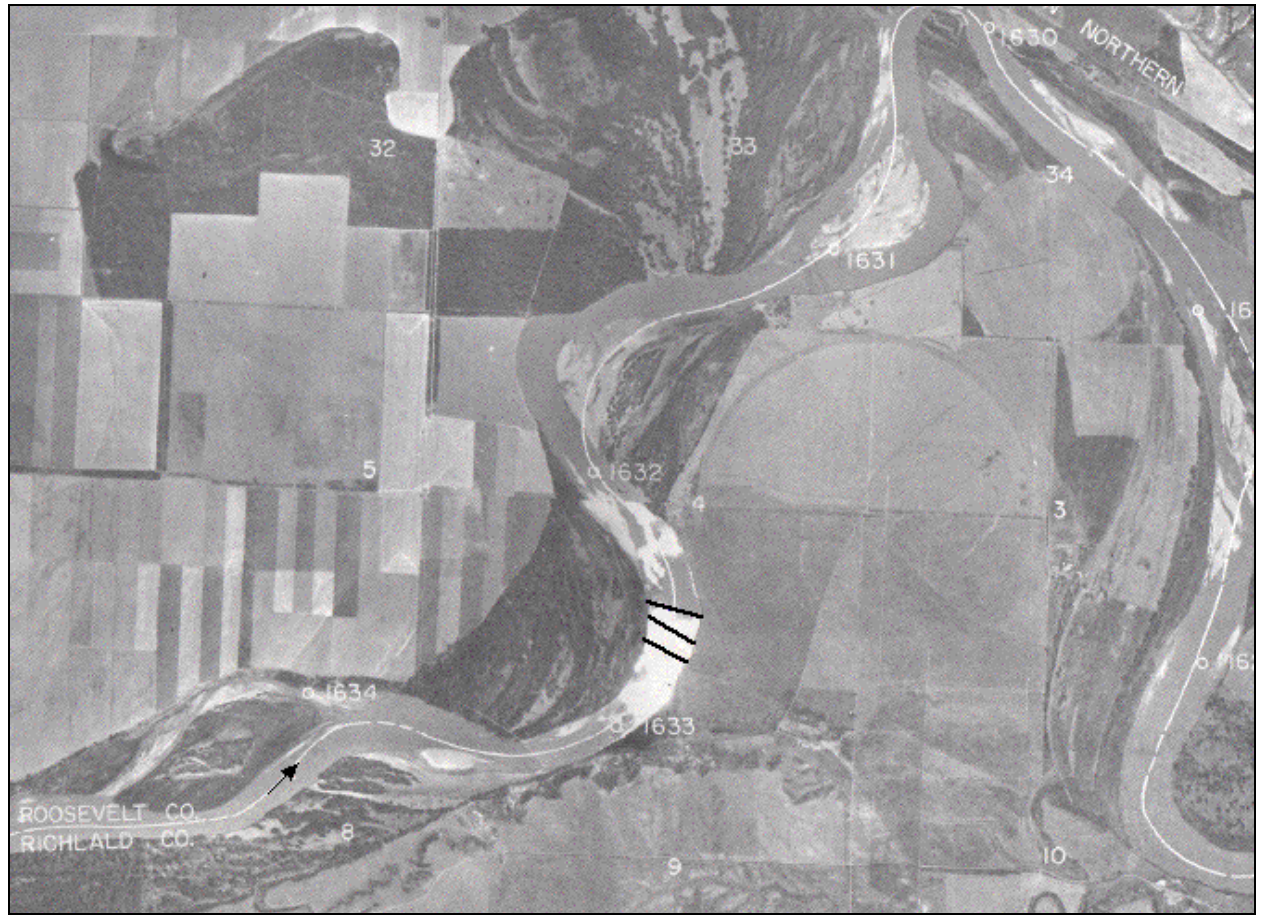

Figure 21. Survey cross sections near RM 1631-1632, Vournas site. (From USACE-Omaha 1996.) 


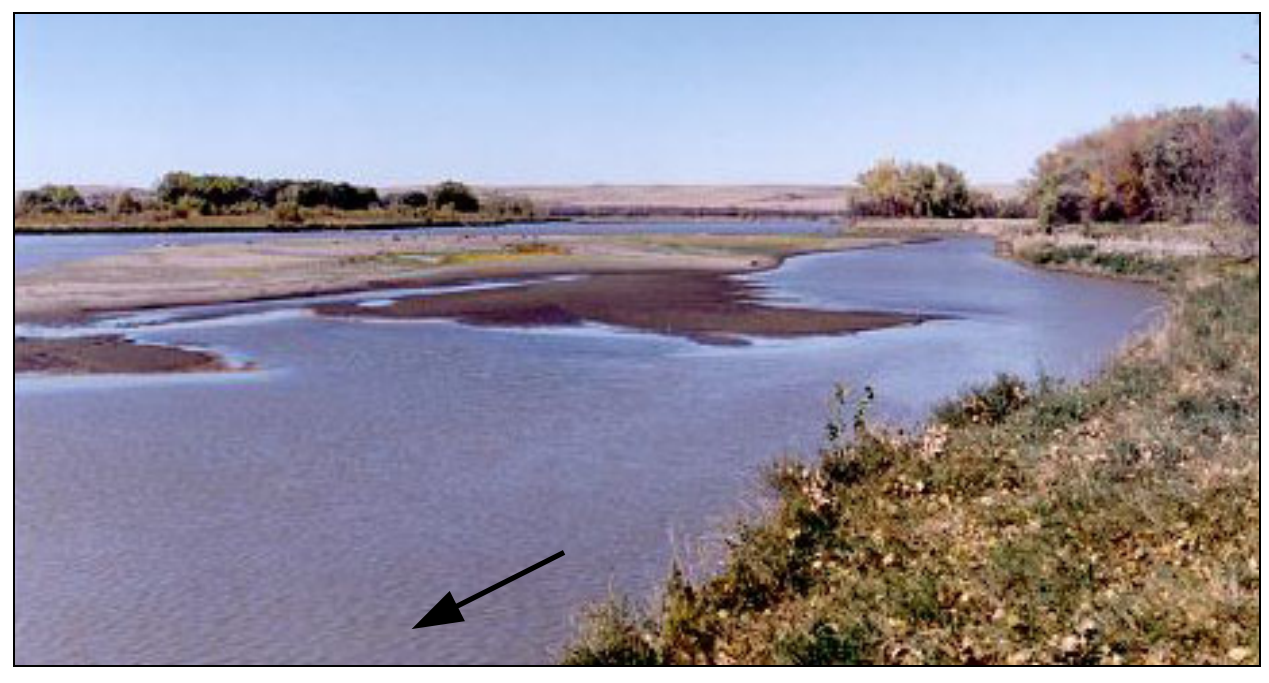

Figure 22. RM 1646, Mattelin site.

\section{Mattelin site, RM 1645-1646}

This site comprises a comparatively straight segment of river with two subchannels around several medial bars (Fig. 22). The subchannels converge at the downstream end of a large medial bar, then divide into two subchannels a short distance downstream. The north bank of the river is about 10-15 ft high and has been subject to extensive erosion. Four cross sections were selected for monitoring. The general locations and orientations of the cross sections are indicated in Figure 23, an aerial photograph taken in 1983 (USACE-Omaha 1983).

The multiple subchannels make this site similar to the Culbertson site. Like the Culbertson site, the main thalweg at this site apparently switches from one subchannel to the other, causing sedimentation of an irrigation pump site and bank erosion. This site was selected because monitoring would help determine how ice cover formation and presence may cause the flow capacity of one subchannel to reduce relative to that of the other subchannel. Additionally, the site would yield further information on how ice affects bank erosion.

\section{Whitmer site, RM 1687}

This site was observed, but no bathymetry measurements were made. The morphology of the site is similar to the Mattelin and Culbertson sites. As with those sites, an irrigation pump location is being affected by sedimentation (Fig. 24). 


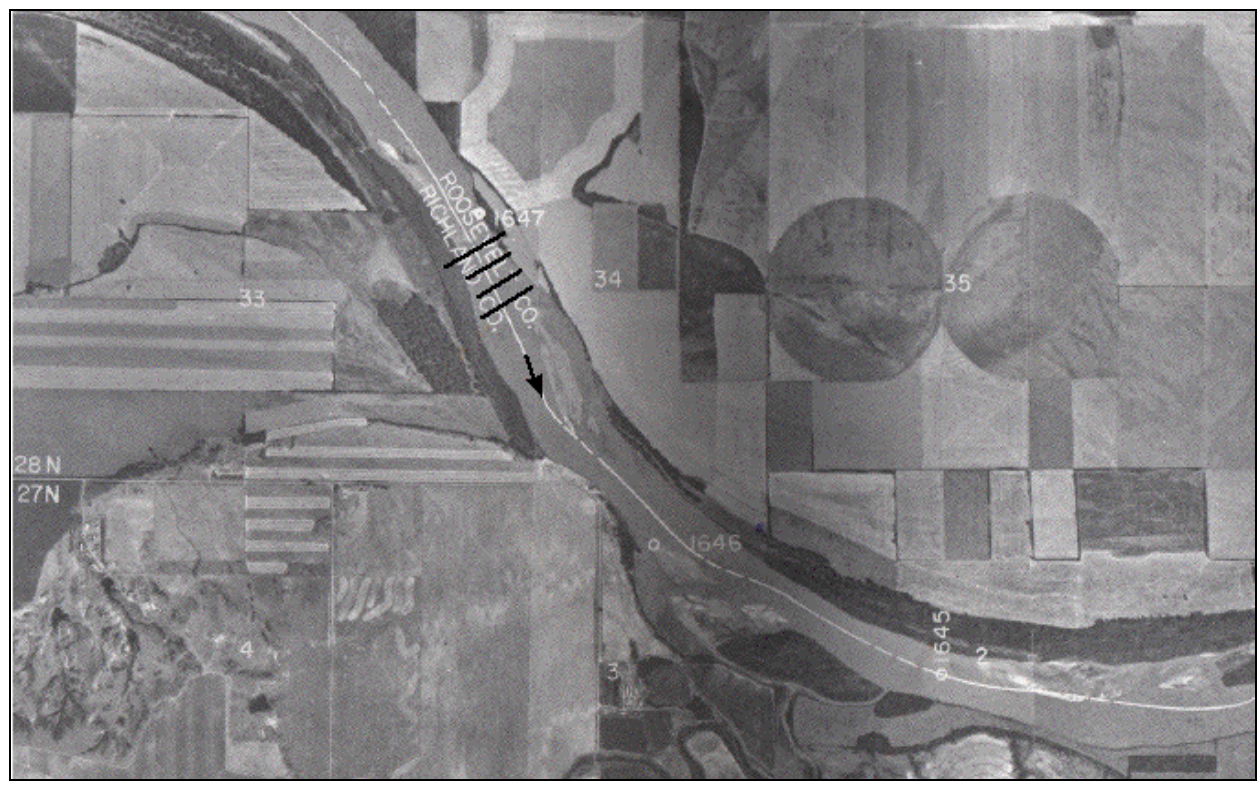

Figure 23. Survey cross sections near RM 1645-1646, Mattelin site. (From USACE-Omaha 1996.)

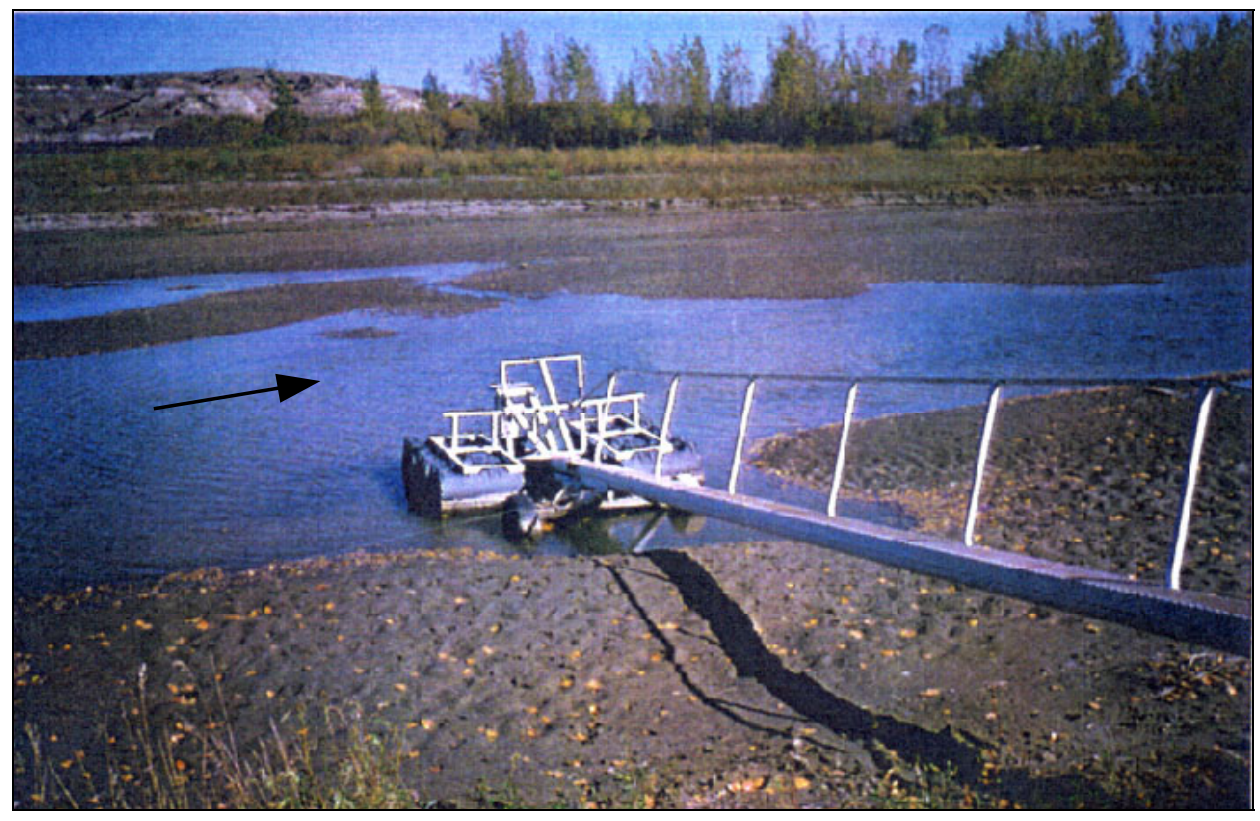

Figure 24. Sediment accumulation at an irrigation pump site near RM 1687, Whitmer site. 


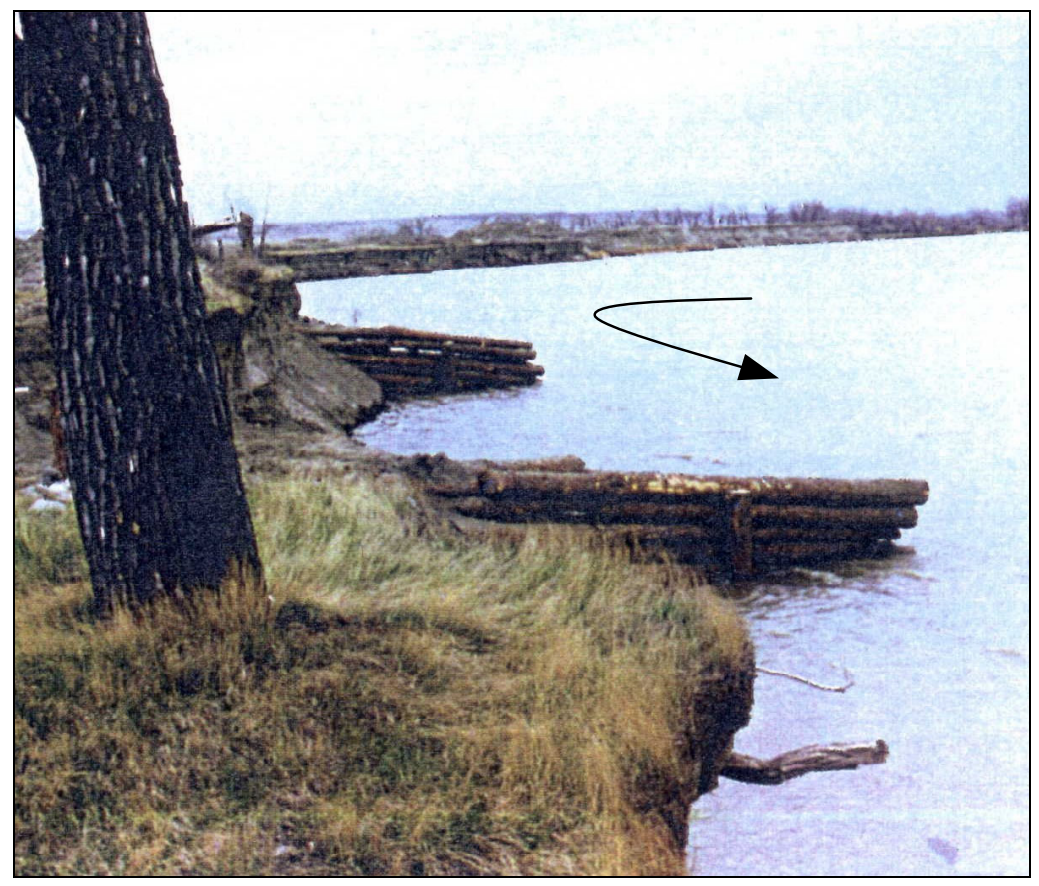

Figure 25. RM 1716, Pipal site.

Pipal site, RM 1715-1716

Flow entering this site passes around a large medial bar at the upstream end of the site. The flow then moves in a single channel that curves to form the upstream bend of a meander loop (Fig. 25). The outer bank of the channel bend is about 15-20 ft high and is subject to extensive erosion, with the consequent loss of cropland. The bend's inner bank is lower and, typical of bends in the river, slopes gradually into the river. Four cross sections were selected for monitoring (Fig. 26).

Several forms of bank stabilization have been placed along the outer bank extending $1000 \mathrm{ft}$ downstream from the upstream end of the site. LaGrone and Remus (1998) and Mellema (1997) described the methods. The remaining portion of the outer bank is unprotected and has been subject to severe bank erosion. The bank stabilization methods used include two bendway weirs built from gravel and rock, four upstream-inclined groins built from logs (two short, two tall), two short rock-filled cribs built from logs, and riprap together with a revetment of cable-anchored hay bales. The structures are discussed further later in this report. 


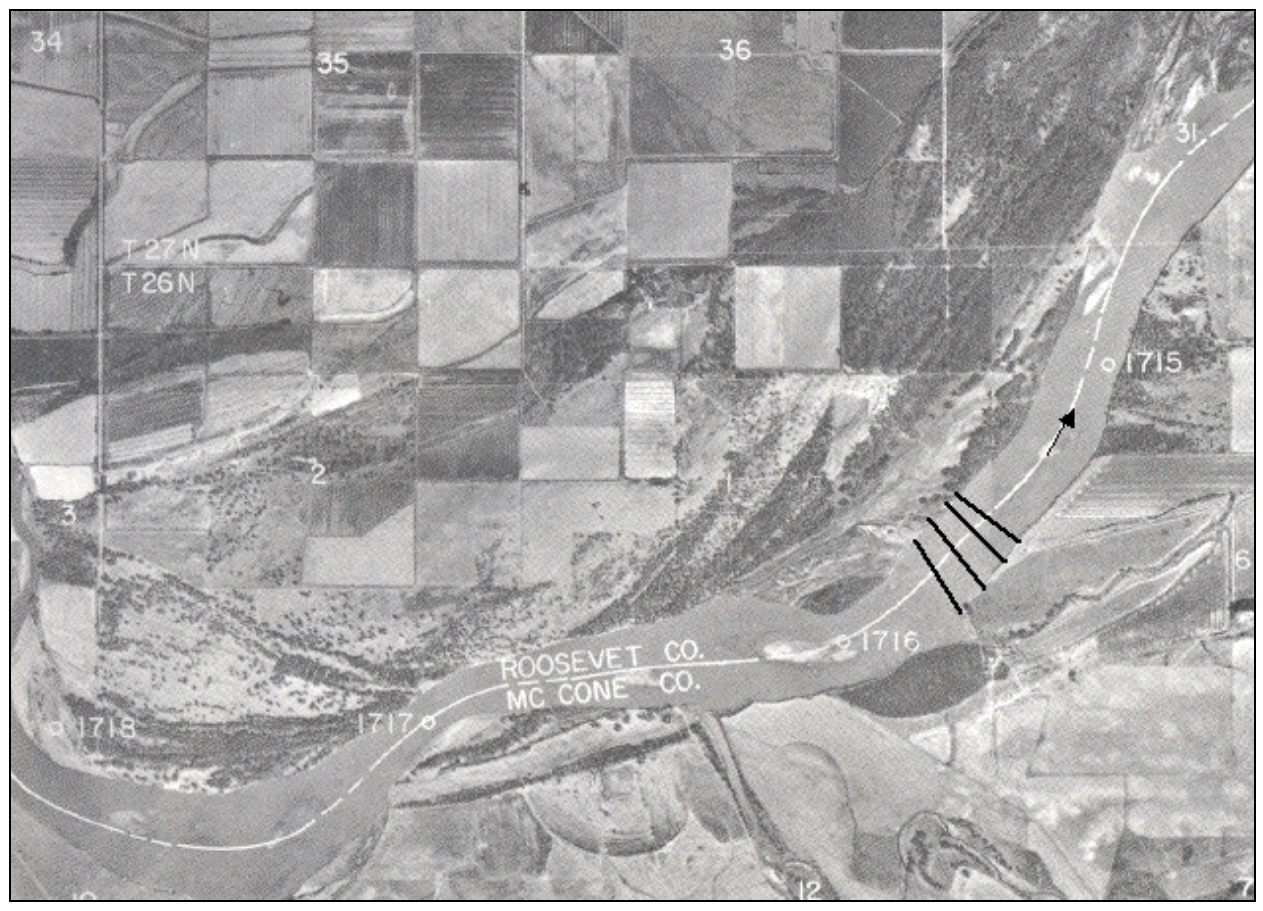

Figure 26. Survey cross sections near RM 1715-1716, Pipal site. (From USACE-Omaha 1983.)

This site was selected for monitoring because it would yield insights into ice cover influences on flow distribution and loose-bed bathymetry in a channel bend. As with the Tveit-Johnson and Vournas sites, the Pipal site would be of use in assessing whether and how an ice cover may shift the channel thalweg. Two additional purposes motivated monitoring of this site: the site was well suited for examining how river ice affects bank erosion, and it provided an opportunity to observe how several forms of bank stabilization structures perform in ice-covered flow.

\section{Summary of measurements and observations}

The following survey measurements were periodically taken at all sites:

- Channel cross-section bathymetry;

- Ice cover thickness; and

- Vertical distribution of streamwise and transverse components of flow velocity.

Eisenbraun and Associates conducted the open water bathometric survey prior to ice formation and following breakup using a differential GPS system. 
Elevation measurements (NVD 29) were reported using Montana State plane (NAD 27) coordinates. Water velocity measurements were obtained at all the sites in the fall, but Vournas and Mattelin were excluded from the spring measurements. Velocity measurements were taken at various points from a boat anchored along the cross section alignment at water depths corresponding to 0.2 and 0.6 of the total water depth The reported location was relative to the benchmark pin on the right bank and assumed to be along the alignment. Using these assumptions the $\mathrm{X}-\mathrm{Y}$ coordinates of the measurement location were calculated using linear interpolation along the alignment.

For the ice surveys, personnel from the NRSC Culbertson office used one of the open water survey pins as a benchmark. At the Culbertson, Tveit-Johnson, and Mattelin sites a pin on the elevated right bank was used as the benchmark. At the Vournas and Pipal sites the right bank is a flood plain, and the pins were submerged as the stage increased as the ice cover formed. From the available survey pins and triangulation, the submerged survey pins were re-established. To avoid the question of whether or not the pin was disturbed by the water and subsequent ice, the left-bank pin was used as the benchmark. After the survey alignment was defined, measurement stations were established at 100-ft increments across the river. Additional stations at 50-ft increments were used in the vicinity of the thalweg. Supplemental stations were also established at locations where large gradients in water depth or flow velocity were noticed.

The overall dispositions of banks, ice formation features, and flow peculiarities were noted for all sites. At three sites, video cameras were used to monitor ice cover formation, breakup, and departure. Fixed-view video cameras were mounted on poles at the Tveit-Johnson and Pipal sites and under the bridge at the Culbertson site to facilitate continuous observation of flow, ice, and bank conditions. At the Pipal site, one camera viewed the bank-protected upstream half of the site, while a second camera viewed a shore protection system and unprotected area farther downstream. The video cameras proved very useful for gaining an overall record of ice formation conditions. For instance, the images taken by the camera at the Tveit-Johnson site were assembled into animations showing a dramatic sequence of bank failure. Images from the video-camera views were accessible near-real time via an Internet web site (http://www.crrel.usace.army. $\mathrm{mil} /$ ierd/scour).

At the Culbertson pump site, seven scour probes were placed in the riverbed upstream of the Highway 16 bridge, located at the downstream end of the site. The probes provided continuous records of vertical changes in bed level throughout the winter. The bed elevation data were augmented with water pressure, water temperature, and air temperature measurements. Microwave and groundpenetrating radar were tested for use during the first winter survey. However, the 
ground-penetrating radar was found to be unsuitable for measuring channel bathymetry at the sites, because the salinity (conductivity) level of the river water was sufficiently high to dissipate the radar's signal. The microwave radar used during the January survey characterized the ice along the cross section as relatively uniform in thickness. Flow velocities were measured using a twocomponent electromagnetic velocity probe attached to a shaft that was extended by incrementally adding $3.3-\mathrm{ft}$ sections. 


\section{INSTRUMENTATION}

The survey involved a comprehensive set of instrumentation for measuring bed bathymetry, flow velocity, and ice thickness.

\section{Bed profiling}

Bed profiling was the principal approach taken to determine how the formation, presence, and breakup of river ice might influence alluvial channel bathymetry along the Fort Peck reach. Three or four cross sections were used to characterize the channel bathymetry at each site. The cross section locations established during the first survey were used for the subsequent surveys. The river mile locations for the respective cross sections appear in Table 3.

During open water the bed elevations were measured at discrete points using a conventional differential GPS survey system either by wading in the river or working from a boat. For the winter survey, we initially planned on using a ground-penetrating radar (GPR) antenna towed behind an all-terrain vehicle to continuously profile along the survey alignments and parallel with the channel. It was thought that GPR could provide detailed bottom and sub-bottom profiles of the channel. Sellman et al. (1992), for example, described the use of GPR for this purpose. GPR radar transmits a pulse through the ice into the water and propagates through the water until encountering the bed sediment. In terms of finding the bathymetric bottom profile, the profile of the ice is not of interest and can be ignored when attempting to optimize signal processing to best determine the river bottom profile. At the interface between the water and the bed sediment, a portion of the transmitted energy is reflected back to the water surface. The travel time for the pulse is directly proportional to the distance from the water surface to the bed. The portion of the transmitted energy penetrating the bed sediment propagates through the sediment until it encounters another boundary, such as a bedrock layer. There the energy again is reflected back towards the radar at the water surface. The travel time of the radar signal is proportional to the depth to this interface. The radar transmits thousands of pulses during a traverse, and the resulting reflected waveforms are used to produce a bed profile along the traverse line. Profiles along and orthogonal to the survey line could be used to generate a detail contour plot of the bathymetry in the region of the survey.

For riverbed profiling in open water conditions, an acoustic depth sounder could be used as an alternative to GPR. However, for bed profiling in ice-covered conditions, GPR has an advantage since its radio signal can penetrate the ice cover into the underlying water. Acoustic signals have difficulty penetrating through an ice cover. The difficulty is especially severe when attempting to 


\begin{tabular}{|c|c|c|c|c|c|c|c|}
\hline Site & $\begin{array}{c}\text { River } \\
\text { mile }\end{array}$ & Range & $\begin{array}{l}\text { Location of } \\
\text { survey lines }\end{array}$ & Fall & Early winter & $\begin{array}{l}\text { Prior to } \\
\text { breakup }\end{array}$ & $\begin{array}{c}\text { Following } \\
\text { breakup }\end{array}$ \\
\hline \multirow[t]{5}{*}{ Culbertson } & & 4 & \multicolumn{2}{|l|}{ Under bridge } & 30-Jan-99 & \multicolumn{2}{|l|}{ 24-Feb-99 } \\
\hline & 1620.35 & 3 & \multirow[t]{3}{*}{ Downstream of island } & Oct-98 & 30-Jan-99 & 24-Feb-99 & Apr-99 \\
\hline & 1620.40 & 2 & & Oct-98 & 29-Jan-99 & 24-Feb-99 & Apr-99 \\
\hline & 1620.45 & 1 & & Oct-98 & 30-Jan-99 & 24-Feb-99 & Apr-99 \\
\hline & Monitoring & \multicolumn{6}{|c|}{$\begin{array}{l}\text { Periodic: bed profiling, ice thickness profiling, velocity profile } \\
\text { Continuous: visual with web cam, bed elevations, water pressure, water and air } \\
\text { temperature }\end{array}$} \\
\hline \multirow{5}{*}{$\begin{array}{l}\text { Tveit- } \\
\text { Johnson }\end{array}$} & 1623.97 & 1 & Downstream of camera & Oct-98 & 25-Jan-99 & 22-Feb-99 & Apr-99 \\
\hline & 1624.02 & 2 & Perpendicular to camera & Oct-98 & 26-Jan-99 & 22-Feb-99 & Apr-99 \\
\hline & 1624.07 & 3 & In camera view & Oct-98 & 26-Jan-99 & 22-Feb-99 & Apr-99 \\
\hline & 1624.11 & 4 & upstream range & Oct-98 & 26-Jan-99 & 22-Feb-99 & Apr-99 \\
\hline & Monitoring & \multicolumn{6}{|c|}{$\begin{array}{l}\text { Periodic: bed profiling, ice thickness profiling, velocity profile } \\
\text { Continuous: visual with web cam }\end{array}$} \\
\hline \multirow[t]{4}{*}{ Vornus } & 1632.55 & 1 & \multirow[t]{2}{*}{ Downstream range } & Oct-98 & 25-Jan-99 & 23-Feb-99 & Apr-99 \\
\hline & 1632.62 & 2 & & Oct-98 & 25-Jan-99 & 23-Feb-99 & Apr-99 \\
\hline & 1632.68 & 3 & Upstream range & Oct-98 & 26-Jan-99 & 23-Feb-99 & Apr-99 \\
\hline & Monitoring & \multicolumn{6}{|c|}{$\begin{array}{l}\text { Periodic: bed profiling, ice thickness profiling, velocity profile except April } \\
\text { Continuous: none }\end{array}$} \\
\hline \multirow[t]{5}{*}{ Mattelin } & 1646.72 & 1 & \multirow[t]{3}{*}{ Downstream range } & Oct-98 & 27-Jan-99 & 23-Feb-99 & Apr-99 \\
\hline & 1646.78 & 2 & & Oct-98 & 27-Jan-99 & 23-Feb-99 & Apr-99 \\
\hline & 1646.84 & 3 & & Oct-98 & 27-Jan-99 & 23-Feb-99 & Apr-99 \\
\hline & 1646.90 & 4 & $\begin{array}{l}\text { Upstream across tip of } \\
\text { island }\end{array}$ & Oct-98 & 27-Jan-99 & 23-Feb-99 & Apr-99 \\
\hline & Monitoring & \multicolumn{6}{|c|}{$\begin{array}{l}\text { Periodic: bed profiling, ice thickness profiling, velocity profile except April } \\
\text { Continuous: none }\end{array}$} \\
\hline \multirow[t]{5}{*}{ Pipal } & 1715.53 & 4 & Downstream & Oct-98 & 28-Jan-99 & $\begin{array}{l}\text { Open } \\
\text { water }\end{array}$ & Apr-99 \\
\hline & 1715.58 & 3 & & Oct-98 & 28-Jan-99 & $\begin{array}{l}\text { Open } \\
\text { water }\end{array}$ & Apr-99 \\
\hline & 1715.66 & 2 & $\begin{array}{l}\text { Perpendicular to DS } \\
\text { camera }\end{array}$ & Oct-98 & 28-Jan-99 & $\begin{array}{l}\text { Open } \\
\text { water }\end{array}$ & Apr-99 \\
\hline & 1715.74 & 1 & Upstream of DS camera & Oct-98 & 28-Jan-99 & $\begin{array}{l}\text { Open } \\
\text { water }\end{array}$ & Apr-99 \\
\hline & Monitoring & \multicolumn{6}{|c|}{$\begin{array}{l}\text { Periodic: bed profiling, ice thickness profiling, velocity profile } \\
\text { Continuous: visual with web cam }\end{array}$} \\
\hline
\end{tabular}


obtain a continuous profile of the bed, because a solid mechanical coupling must be kept between the acoustic transducer and the ice surface. This constraint is not a problem with GPR, but GPR has other drawbacks.

Successful bed and sub-bed profiling with GPR depends on the water's conductivity. The lower the conductivity, the greater the possibility of successful radar profiling. With higher levels of water conductivity, the radar signal energy is attenuated to levels below the resolution of the radar receiver. The water in this reach has a high conductivity; at the Vournas site, water conductivity measured $714 \mathrm{mmhos} / \mathrm{cm}$, and at the Tveit-Johnson site, it measured $602 \mathrm{mmhos} / \mathrm{cm}$. These values are consistent with published values (e.g., Hopkins and Tilstra 1966). Unfortunately these high levels made continuous bed profiling using radar infeasible, and the technique was abandoned during the January survey. We resorted to measuring the bed elevation at discrete points along the cross section in conjunction with the velocity measurements described below.

\section{Ice thickness measurements}

During the January survey, ice cover thickness along each cross section was profiled using microwave FM-CW radar. This technique has been successfully used for measuring the thicknesses of freshwater ice sheets on rivers and lakes from ground and airborne platforms (e.g., Yankielun et al. 1993).

At the survey cross sections, a Ku-band radar $(18-26.5 \mathrm{GHz})$ was towed across the ice by an all-terrain vehicle. The radar antenna was mounted on a sled, with the antenna approximately $6 \mathrm{ft}$ above the ice cover (Fig. 27). Radar profiles were made of the ice cover, and the cross-section stations were marked on the

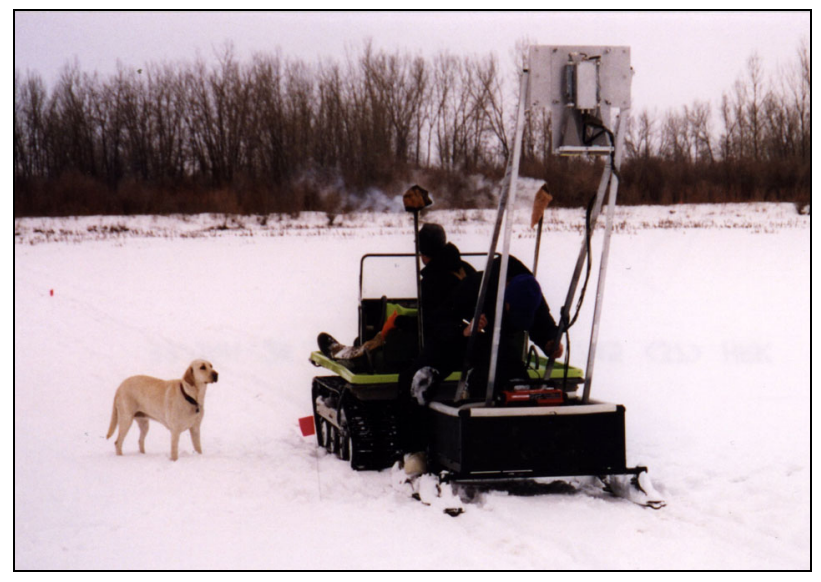

Figure 27. Sled with microwave radar towed by an all-terrain vehicle. 
trace for latter verification using ground-truth measurements. The ice cover generally ranged from 8 to 25 in. thick. Adjacent to the bridge piers at the Culbertson site the ice was up to 40 in. thick.

Figure 28 shows a typical radar profile for the 275 -ft-wide section of the river between the two piers of the northern bridge span. It also shows the largest variation in ice thickness within a short distance. The top band represents radar reflections from the air-ice interface (the top of the ice sheet). The lower band represents the radar reflection from the ice-water interface (the bottom of ice sheet). Figure 29 is the result of processing the middle $250 \mathrm{ft}$ of the radar data

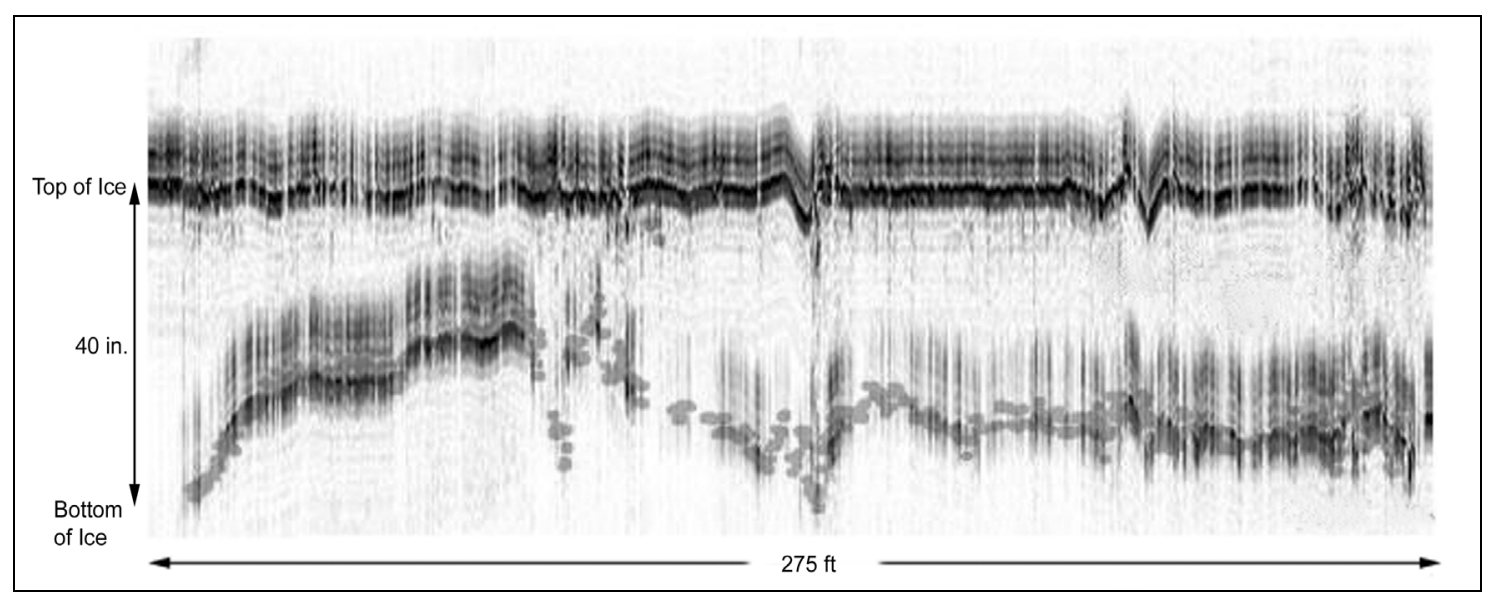

Figure 28. Typical radar profile of ice cover thickness.

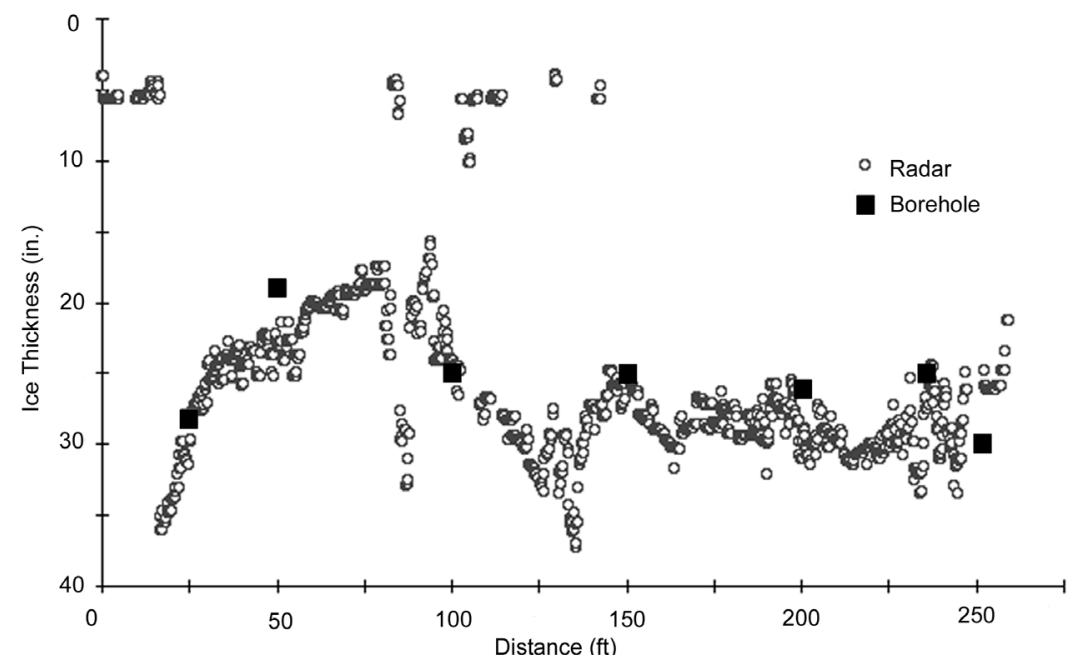

Figure 29. Processed radar profile of ice cover thickness. 
shown as Figure 28 using a depth-conversion algorithm that locates the top and bottom interface reflections and calculates the ice thickness. Physical measurements of ice cover thickness provided ground truth verification of the radar data; the radar data indicated slightly thicker ice than the physical measurements. The bias in the radar-calculated ice thickness data is caused by the variations in ice thickness due to the surface roughness of the refrozen rubble ice sheet or the thermal effect of the bridge pier.

The difference between the radar data and the measured data is attributable to the borehole drilling technique. Boreholes were drilled using an 8-in.-diameter, gasoline-powered ice auger. When the auger broke through the bottom of the ice sheet, some ice may have spalled from the underside of the ice cover, thinning the cover immediately adjacent to the borehole. This would have biased the measurements.

The radar measurements indicated that the ice thickness was relatively uniform along the respective cross sections and that the physical measurements were representative of the region. The only exceptions were adjacent to the bridge piers and over the land-fast ice, i.e. shorelines and island where the cyclic flooding and freezing thickened the ice or where higher surface velocity suppressed ice growth, i.e. thalweg areas. Therefore, it was decided not to include radar profiling of the ice thickness for the February survey.

\section{Velocity profiling}

For each survey cross section, once the radar profiling of ice thickness was completed, boreholes were drilled using the 8 -in. auger at premeasured crosssection stations. The boreholes were used for measuring the water velocity, water depth, and ice thickness.

Flow velocity was measured using the two-component electromagnetic (Marsh-McBirney Model 511) velocity meter attached to an extendable pole (Fig. 30). Velocity measurements were taken at 19.5-in. incremental flow depths, with the sensor probe oriented such that its $\mathrm{X}$-velocity component was aligned with the survey line. The velocity probe was attached to a series of 3.3-ft-long extension rods that combined to a maximum length of $18.05 \mathrm{ft}$. For the January survey, 1-in.-diameter fiberglass rods were used, but the assembled rod was too flexible and bent excessively in high-velocity zones. For the February survey, a 1.25-in.-diameter aluminum rod was used; it was considerably more rigid. The rod's maximum length was increased to $21.3 \mathrm{ft}$, requiring a team to launch the probe for each measurement (Fig. 31). 


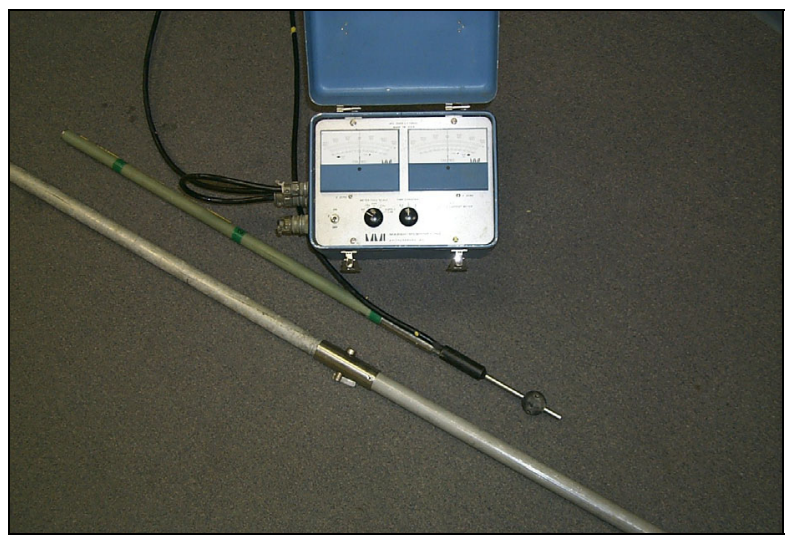

Figure 30. Marsh-McBirney velocity meter with extension pole.

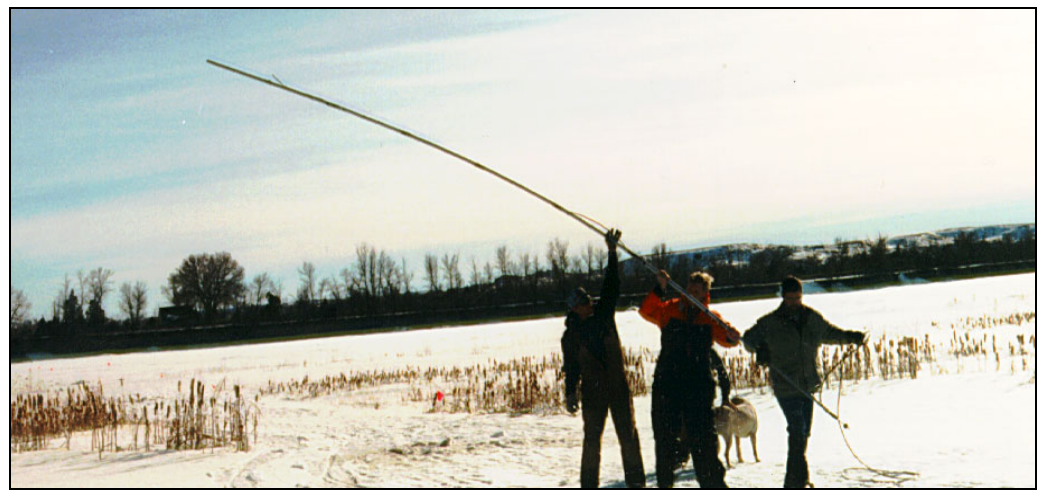

Figure 31. Velocity profiling.

Water depths were obtained in conjunction with water velocity measurements, providing the depth was less than the rod length and the velocity made it possible to maintain a nearly vertical rod. For deeper water a sonar system with a $10^{\circ}$ radar cone angle was used to measure the depth (Model LFP-300 by Electronic Mfg., Tulsa Oklahoma). To document the accuracy for the sonar system, water depths were verified using a rod when possible. The agreement was very good in clear, relatively calm water but not in areas with high concentrations of sediment or frazil. The discrepancy may be attributed to the coarseness in the scale indicated on the sonar's display screen, the integration of flow depth over the radar cone area, interference from particulates in the water column, or a combination of these factors. In some instances the sonar head was attached to an extension rod and pushed through frazil ice accumulated immediately under the ice cover. In channel areas where the water depth or velocity changed abruptly, supplemental cross-section stations were established to provide more detail. 
Contour plots were generated by entering a file with XYZ survey coordinates into Surface-Water Modeling System (SMS) software package and creating a finite element mesh. The mesh geometry was incorporated into the coordinate file, with the resulting file used as an input file to Techplot (Amtec Engineering) visualization software. The vectors representing the average velocity vectors were overlain on the elevation contour plots.

Velocity profiles were generated using open water velocity measurements that were as close as possible to a station used in the ice survey. The coordinates for the open water measurements were calculated by linear interpolation along the cross section alignment using the reported offset from shore. If the boat used to obtain the velocity measurement or the bottom elevation were out of alignment, an error could be introduced. Without repeatability in location, comparison between the open water and the ice cover velocity profiles is difficult. Given these limitations the comparisons are helpful in showing the shift in the velocity profile.

In the plots the velocity was set to 0 at the water-ice and water-sediment interfaces. To represent the open water depth, the surface velocity was set was equal to the velocity measured at 0.2 of the flow depth .

\section{Web cameras}

Visual documentation of the ice conditions was important for identifying changes in ice conditions that may have contributed to local changes in the river channel, as well as for monitoring interactions between ice floes and channel banks during ice cover breakup. Digital video cameras linked to a web site, or web cameras, proved to be invaluable for these purposes.

The digital cameras and environmental housings were installed under the bridge at the Culbertson site and attached to power poles at the Tveit-Johnson and upstream and downstream areas at the Pipal sites (Fig. 32). Digitized images were uploaded to CRREL via phone modems using a hardwired phone line at all the sites, except at the remote Tveit-Johnson site, where a cellular phone had to be used. The cameras and associated hardware were connected to 120-VAC. power. Images were automatically displayed on the web site (www.crrel.usace. army.mil/ierd/scour).

A further benefit of the web cameras was that the images could be assembled to form a movie that animated the processes being monitored. A movie sequence was developed for the Tveit-Johnson camera immediately following ice cover breakup, showing the unstable bank collapsing into the river. 


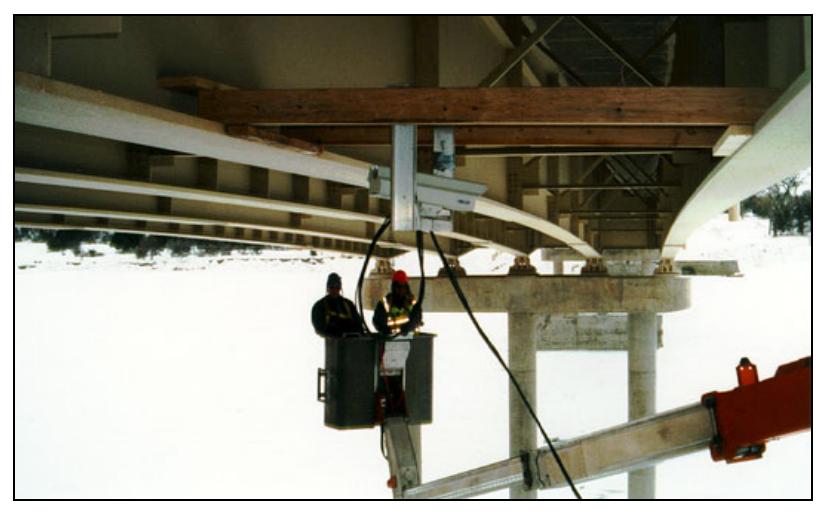

a. Culbertson.

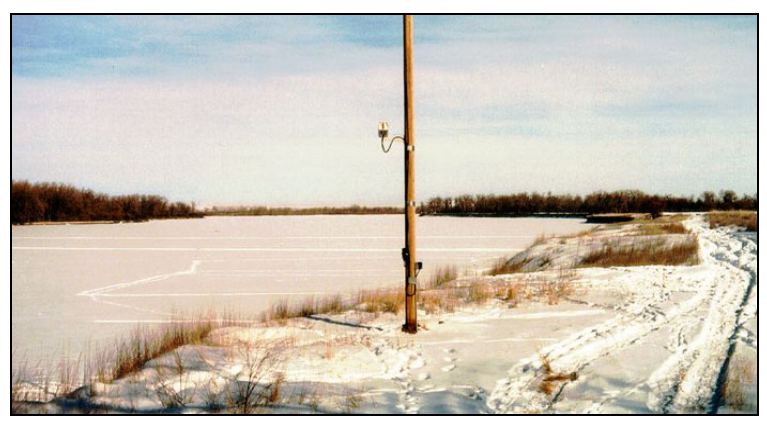

c. Pipal upstream.

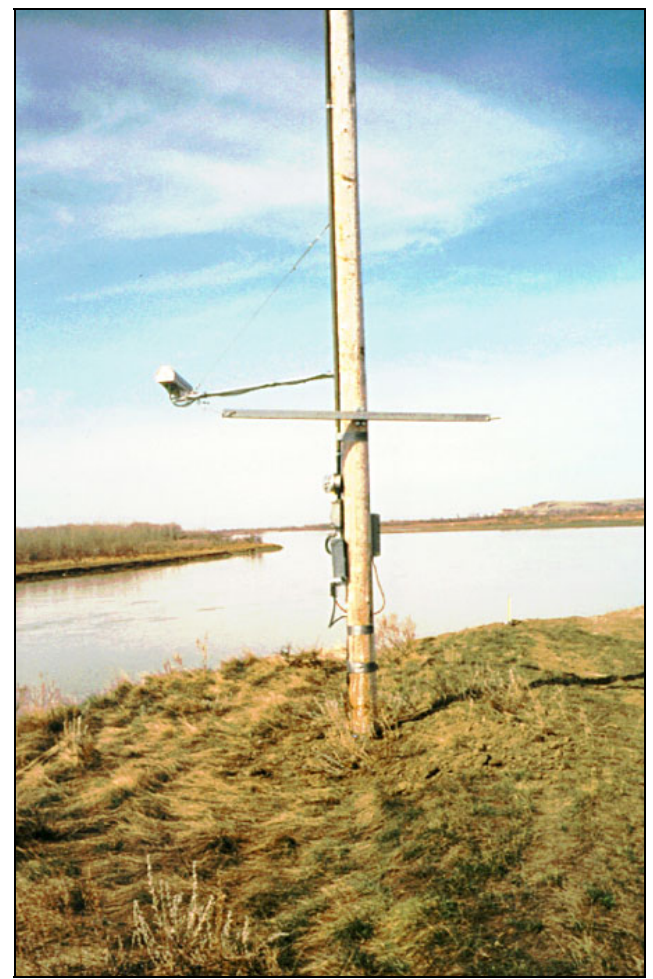

b. Tveit-Johnson.

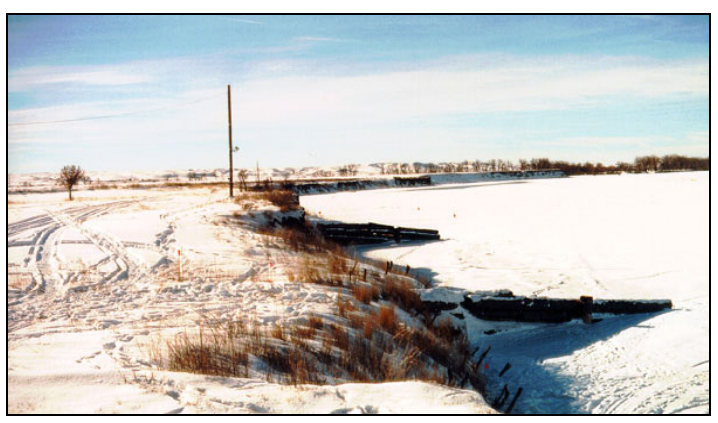

d. Pipal downstream.

Figure 32. The four web cameras.

\section{Scour monitors}

Scour monitors were used to continuously monitor channel changes associated with river ice formation and breakup, as well as with flow rate changes. This instrument is capable of tracking, in real time, changes in channel bed elevation through the winter. 
The scour monitor system, developed at CRREL, is based on time-domain reflectometry (TDR). This technology lends itself to use as a robust instrument capable of surviving ice and debris accumulations. A scour monitor is installed in the riverbed and is nonintrusive because it need not be inserted in the flow (or through the ice) to measure the local bed elevation nor will its presence have a significant effect on the depth of scour. Being inserted into the bed also reduces the risk of instrument damage, as it is sheltered from the floating ice and debris.

The TDR technology operates by generating an electromagnetic pulse (or a fast rise-time step) and coupling the pulse to a transmission line. The pulse propagates down the transmission line at a fixed and known velocity. When the pulse encounters a change in boundary conditions, a portion of the pulse's energy is reflected back to the source from the boundary. The remainder of the pulse's energy continues to propagate through the boundary until another boundary condition (or the end of the transmission line probe) causes part or all of that energy to be reflected back towards the pulse source. The round-trip travel time of a pulse and the dielectric medium through which the pulse travels enables calculation of the physical distance from the TDR source to the level of each dielectric-interface boundary encountered. A simulated reflected TDR signal is shown on the left side of Figure 33. The first boundary indicated is the electrical connection to the transmission line. It is followed by a water-sediment interface, with the remaining wave energy reflected from the end of the transmission line.

Functionally the probe has two parts: the upper sensor and the lower anchoring section. Two parallel pipes, serving as a transmission line, are welded to a lower anchoring section, as shown in right side of Figure 33. For this study the sensor section was fabricated using 1.25-in.-diameter pipes at 3.0-in. centers. The probe's sensing length was $5 \mathrm{ft}$. A plastic block on the top of the probe was used to mechanically connect, but electrically isolate, the two parallel pipes. The plastic block also served as a protective junction box for connecting the coax cable from the on-shore instrumentation to the top of the probe. Introducing the electromagnetic pulse at the top of the probe avoids the undesired effect on pulse propagation time caused by the variations in dielectric constant associated with various sediment layers surrounding the probe. The top-connection approach also makes the system suitable for use in conductive cohesive soils. The probe's sensing length is selected in accordance with the desired measurement resolution. The instrumentation uses 251 points to digitize the reflected wave and corresponding travel distance.

The lower anchoring section laterally stabilizes the probe when bed sediment is eroded, exposing the probe to impacts from bed load material and water pressure. The length of the anchoring section is a function of the requisite lateral resistance of the bed material; it is typically on the order of $7 \mathrm{ft}$. The coax cable 


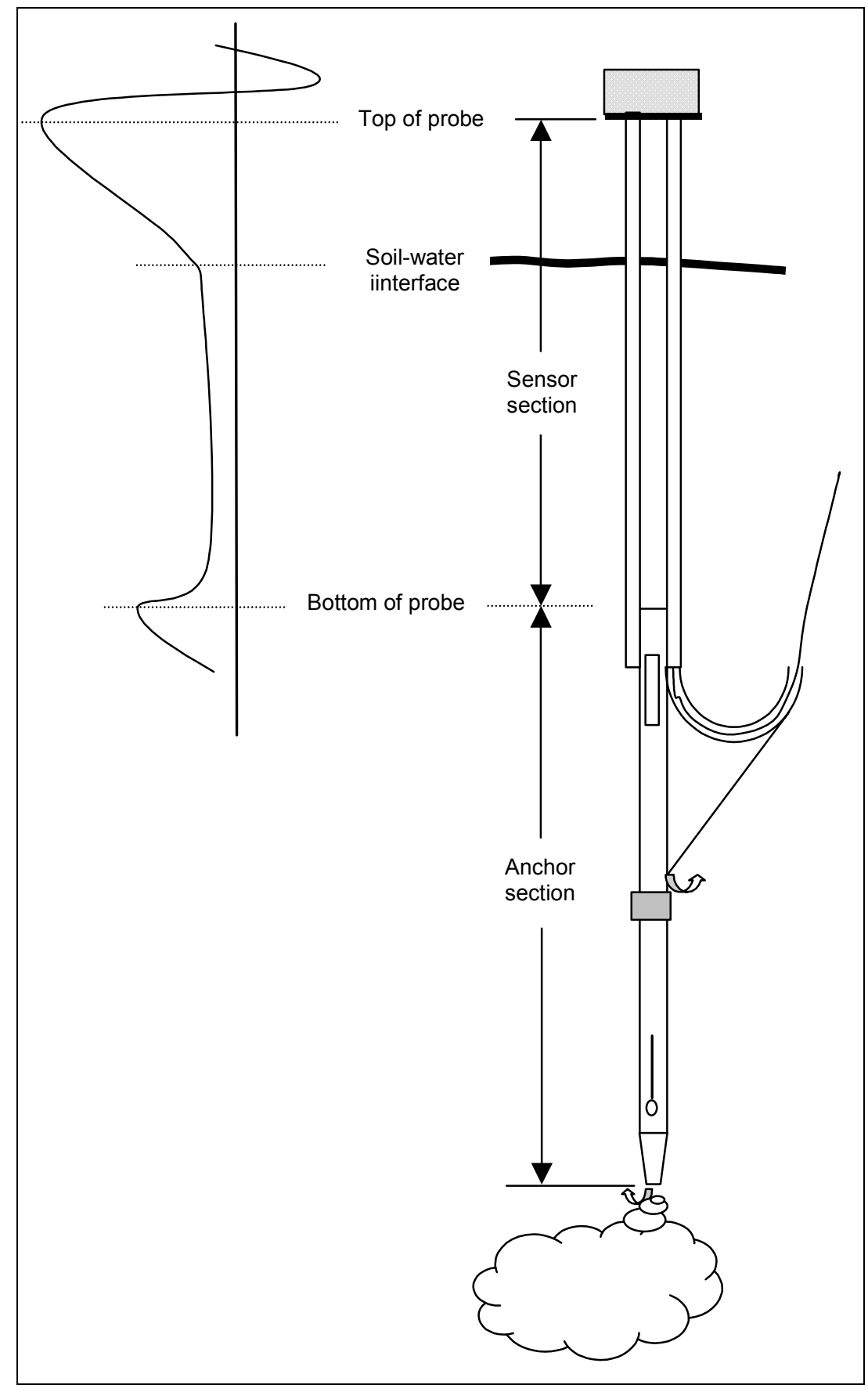

Figure 33. Simulated TDR signal and schematic of probe. 
connected at the top of the probe passes down one of the pipes and is mechanically attached to the anchoring section of the probe. The coax cable was weighted to promote its burial in bed sediment. Self-burial reduces the probability of the cable being snagged by debris and the unnecessary loading. Because of attenuation and dispersion of the TDR signal as it propagates along the coax cable, the signal's accuracy diminishes with increasing cable length. To minimize these effects on the signal, the maximum length of cable used during this study was $700 \mathrm{ft}$.

Seven TDR probes were installed during December 1998 at the Culbertson site, immediately upstream of the Route 16 bridge. The probes were jetted into the riverbed using compressed air so that the tops of the probes just protruded above the bed for situations of anticipated bed scour or at the maximum level of anticipated sediment deposition. Bedrock was approximately $10 \mathrm{ft}$ below the surface; in some areas, though, the channel had scoured to bedrock. The depth to bedrock presented a challenge in locating areas with sufficient sediment to laterally support the probes while the bed was being eroded. In some instances the anchoring section was shortened to ensure that the sensing section of the probe would be in an active erosion zone. The probes were installed on the banks of both subchannels, at the downstream tip island, between two bridge piers, and upstream of a midchannel bridge pier. The locations of the scour probes are shown in Figure 34, a plan view of the site.

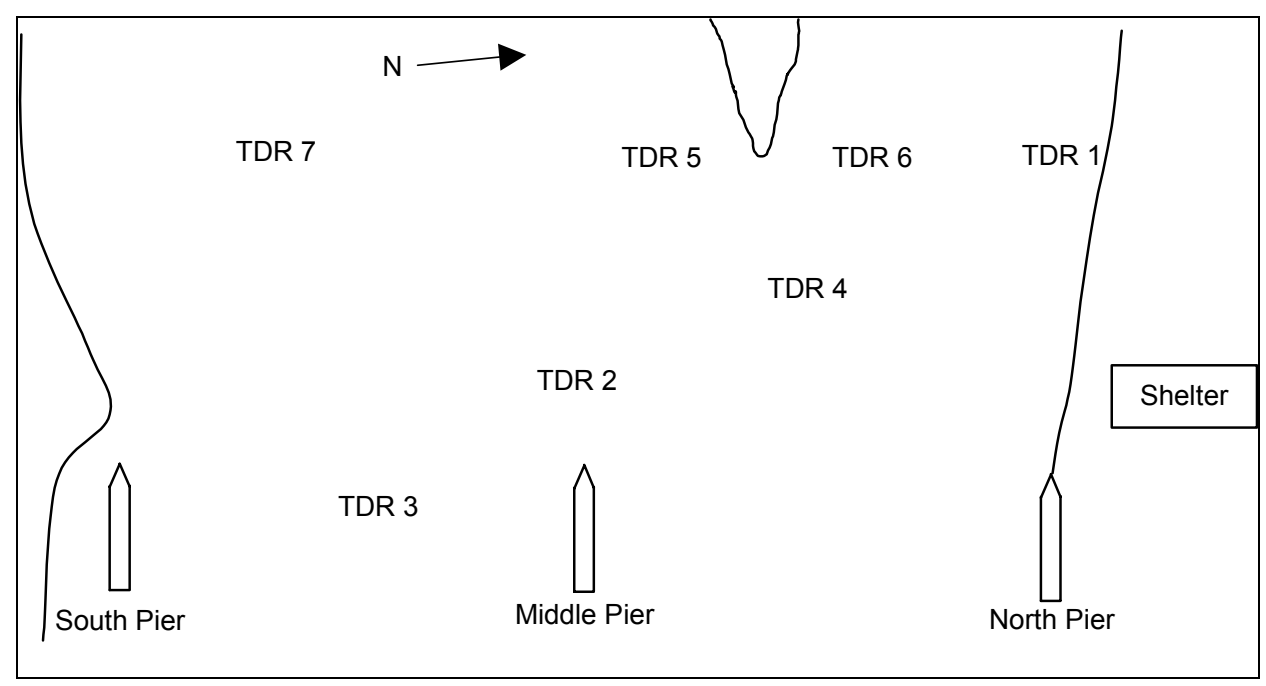

Figure 34. Locations of TDR bed-level monitors. TDR numbers and the respective cable lengths: TDR 1 (400 ft); TDR 2, 4, 5, and 6 (500 ft); and TDR 7 (700 ft). 
Bed elevations were recorded using the on-shore data collection system shown in Figure 35. The coax cable from each probe was connected to one of eight channels on a multiplexer board. A Campbell Scientific Inc. (CSI) CR10 data acquisition system configured the multiplexer to the desired channel. A Tektronics 1502 generated the electromagnetic pulse, captured the return signal, and used 251 points to digitized the reflected image. The digitized image was read and stored by the CR10 in a local storage module. A computer at CRREL recovered the data daily using a modem integrated into the DAC package.

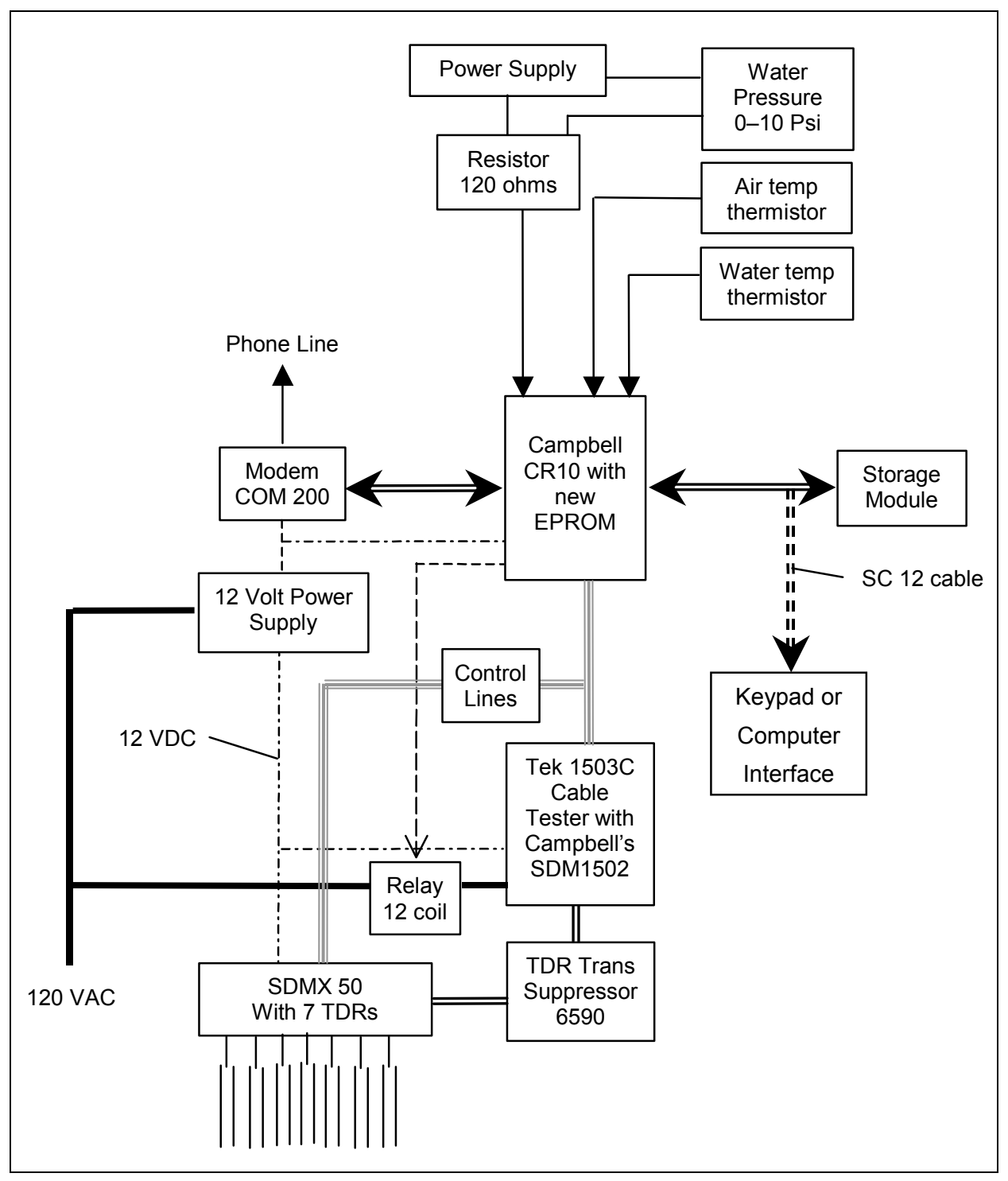

Figure 35. Schematic of the on-shore data acquisition system. 
As a periodic performance check, a portable TDR system (consisting of a Tektronics 1503 TDR) was connected to each probe, and the image was recorded on a laptop computer. The 1503 TDR generated an impulse signal rather than the step signal of the 1502 TDR. The change in pulse characteristic altered the response. A dielectric interface (a new sediment layer) appears as an inflection point in the image from the $1503 \mathrm{TDR}$, whereas it appears as a slight change in slope in the image from a 1502 TDR (Fig. 36).

In conjunction with daily TDR monitoring of bed elevations, the data acquisition system recorded 15-min-interval values of water depth (hydrostatically), water temperature, and ambient air temperature. A 6-psi Druck pressure transducer with a 4-20 mA output was installed in a standpipe immediately adjacent to the river and coupled to the river's water level. The resulting water pressure converted to equivalent stage data is plotted in Figure 37. For instrument redundancy a pair of thermistors was used to monitor the water temperature. The thermistors were housed in a robust container placed below the water level at the riverbank. An air temperature thermistor was placed in a housing attached to the shaded side of the instrumentation shelter located on the site's north bank. The water and air temperature data are plotted in Figure 38.

Determination of the distance between the probe top to the water-soil interface at the bed is based on the propagation velocity of the TDR pulse in water.

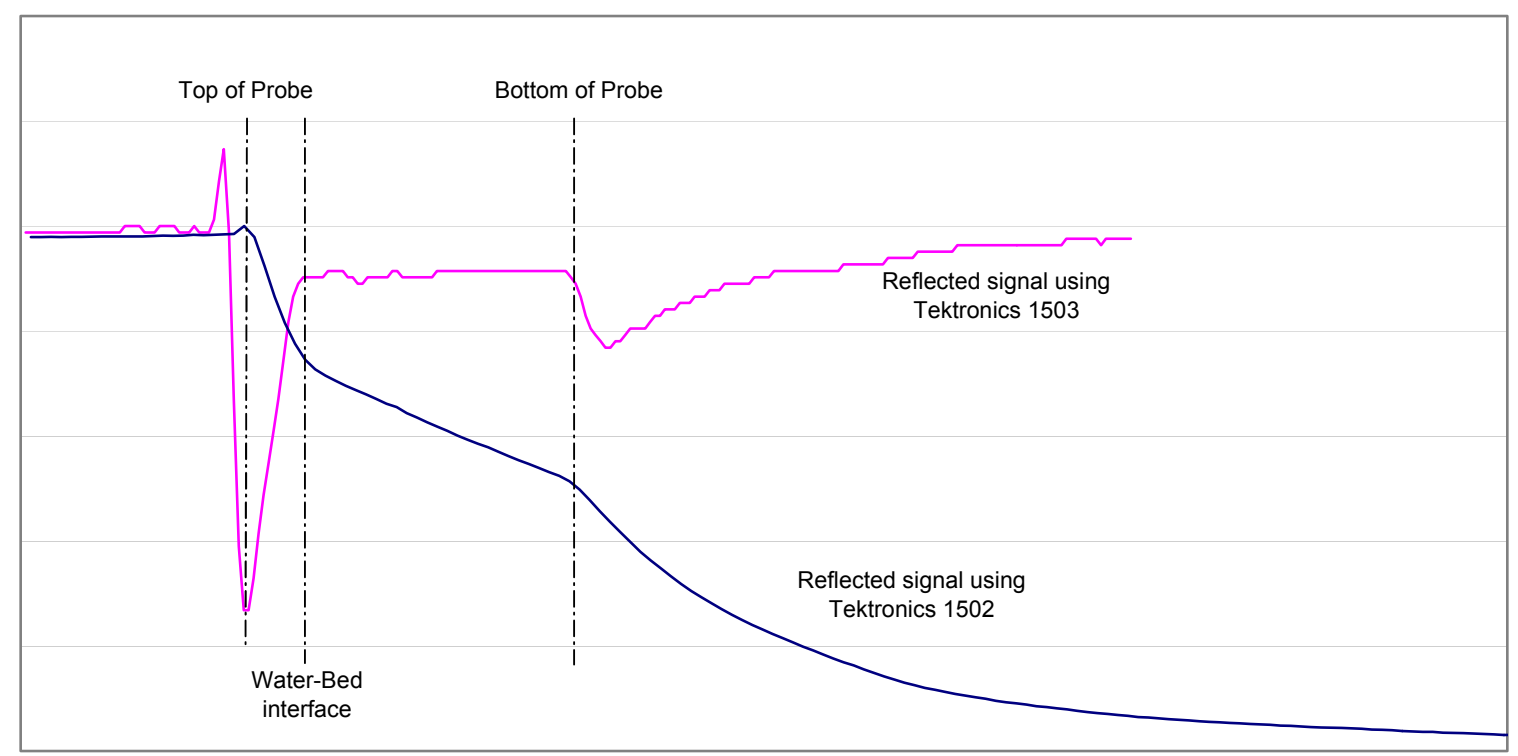

Propagation Time

Figure 36. Comparison between the reflected signals using a Tektronics 1502 step pulse and a Tektronics 1503 using the impulse signal. 


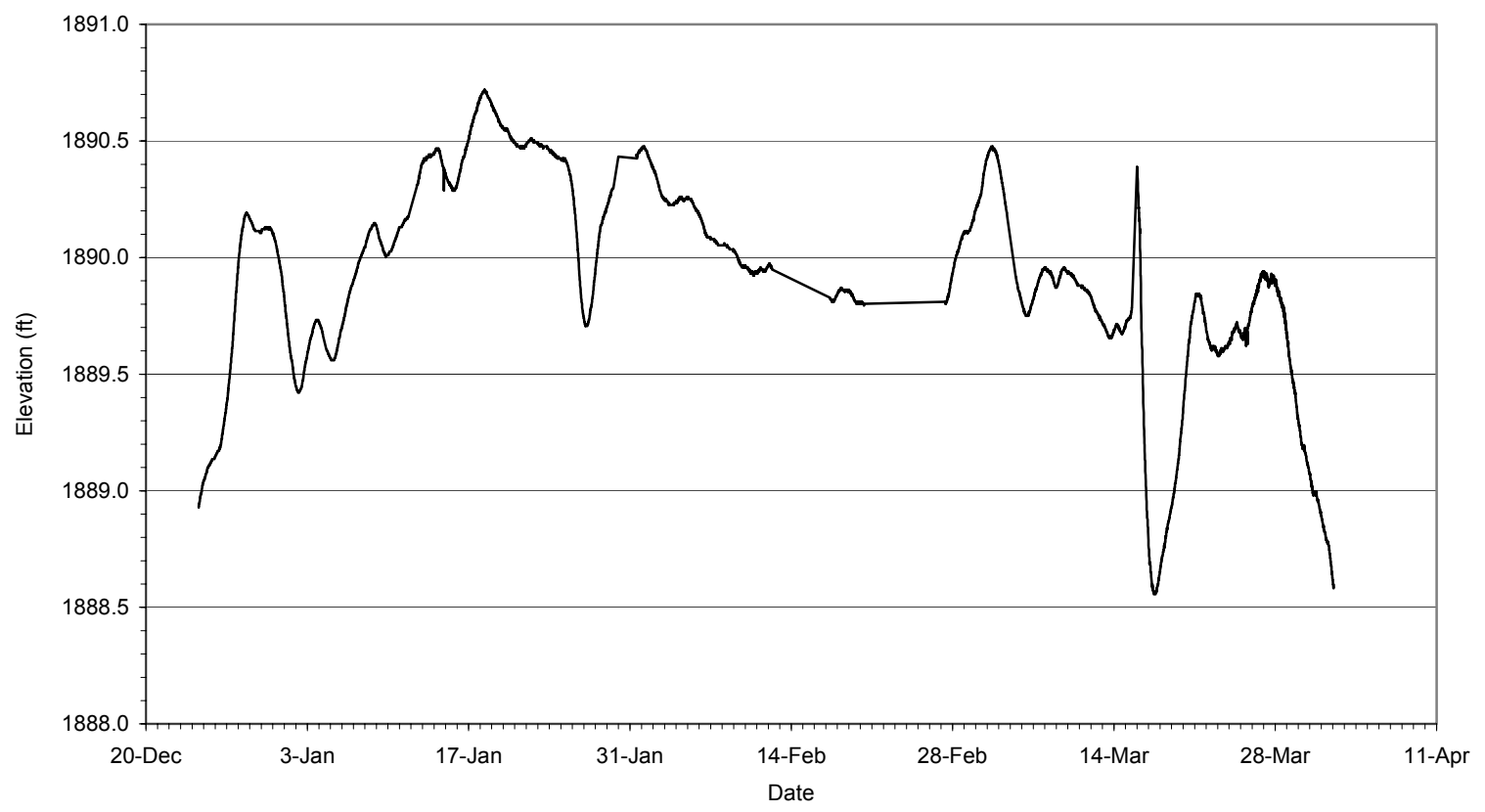

Figure 37. Hydrostatic water pressure at the Culbertson site plotted as equivalent stage.

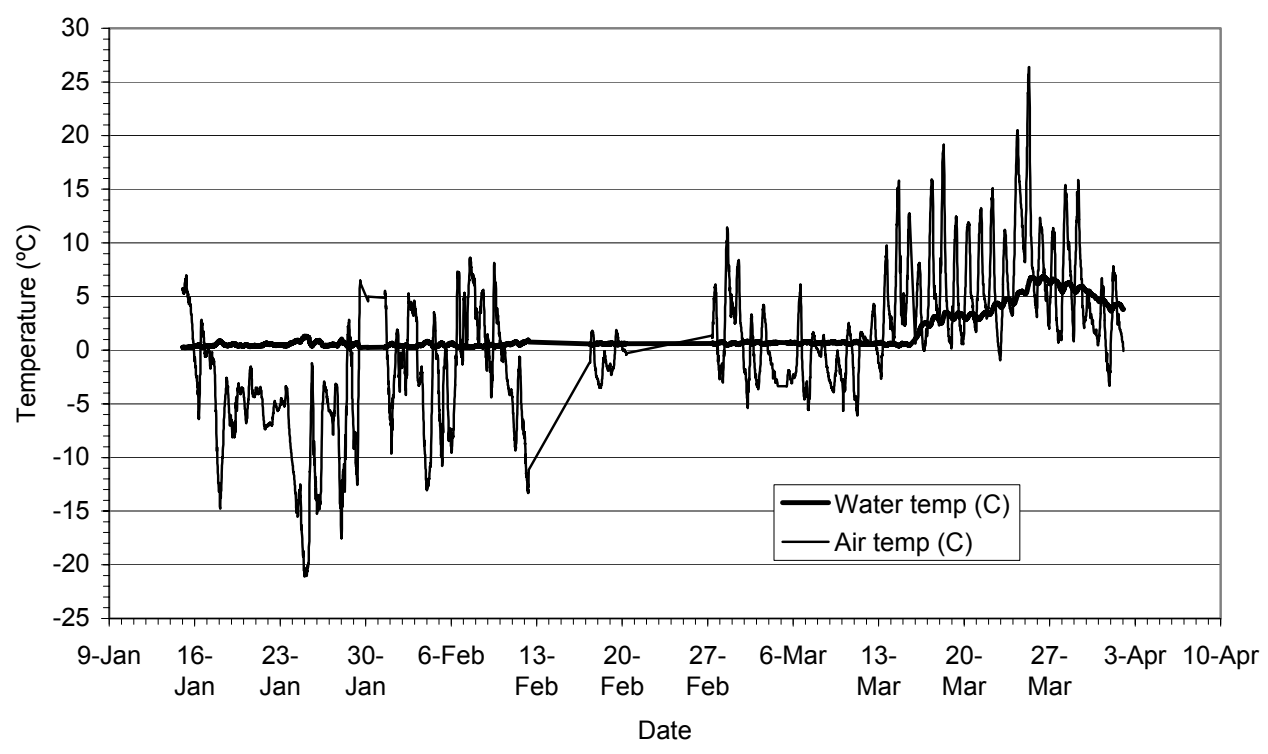

Figure 38. Air and water temperatures at the Culbertson site. 
The velocity is practically constant, compared to the variation of the velocity of propagation in the mixed soil medium surrounding the buried portion of the probe. The TDR data were analyzed in the manner described below.

Depth of scour, $d_{\mathrm{s}}$, in meters is calculated from the TDR measurement as

$$
d_{\mathrm{s}}=R \times \Delta p t \times v_{\mathrm{f}}
$$

where $R=$ spatial distance (in meters) represented by each discrete point on the TDR display. It is calculated by dividing the full-screen spatial distance by 251 , the number of discrete points used to digitize the full-screen image.

$\Delta p t=$ number of points between the reflection from the top of the probe and the reflection from the water-soil interface at the bed.

$v_{\mathrm{f}}=$ velocity of propagation or ratio of the electrical length of the probe in $\operatorname{air}\left(l_{\mathrm{e}(\mathrm{a})}\right)$ to the electrical length of the probe in water $\left(l_{\mathrm{e}(\mathrm{w})}\right)$, or $v_{\mathrm{f}}=l_{\mathrm{e}(\mathrm{a})} / l_{\mathrm{e}(\mathrm{w})}$.

Images from TDR 1, on the north bank of the north channel, using the 1503 for the period 11 January and 7 April are shown in Figure 39. The top of the probe is indicated by the signal fluctuation at the top. The water-sediment interface appears as a change in slope, with the end of the probe appearing where the signal returns to its nominal value. The upper shaded area on Figure 39 represents the distance between the top of the probe and the water-sediment interface, or the riverbed. The depths of erosion and redeposition were computed using the propagation velocity in water, which is slower compared to that of the sediment. Consequently, as more of the probe becomes exposed to the water, the round-trip travel time of the signal also increases. This increase makes the probe "electrically longer," causing the inflection representing the bottom of the probe to shift down. Because of the differences of the velocity of propagation, the implied scale in the exposed region of the probe cannot be used for determining the depth of sediment around the probe. The exposed/buried length of the probe has to be calculated using eq 6 . The accuracy of the TDR in various media is described by Yankielun and Zabilansky (1999). 


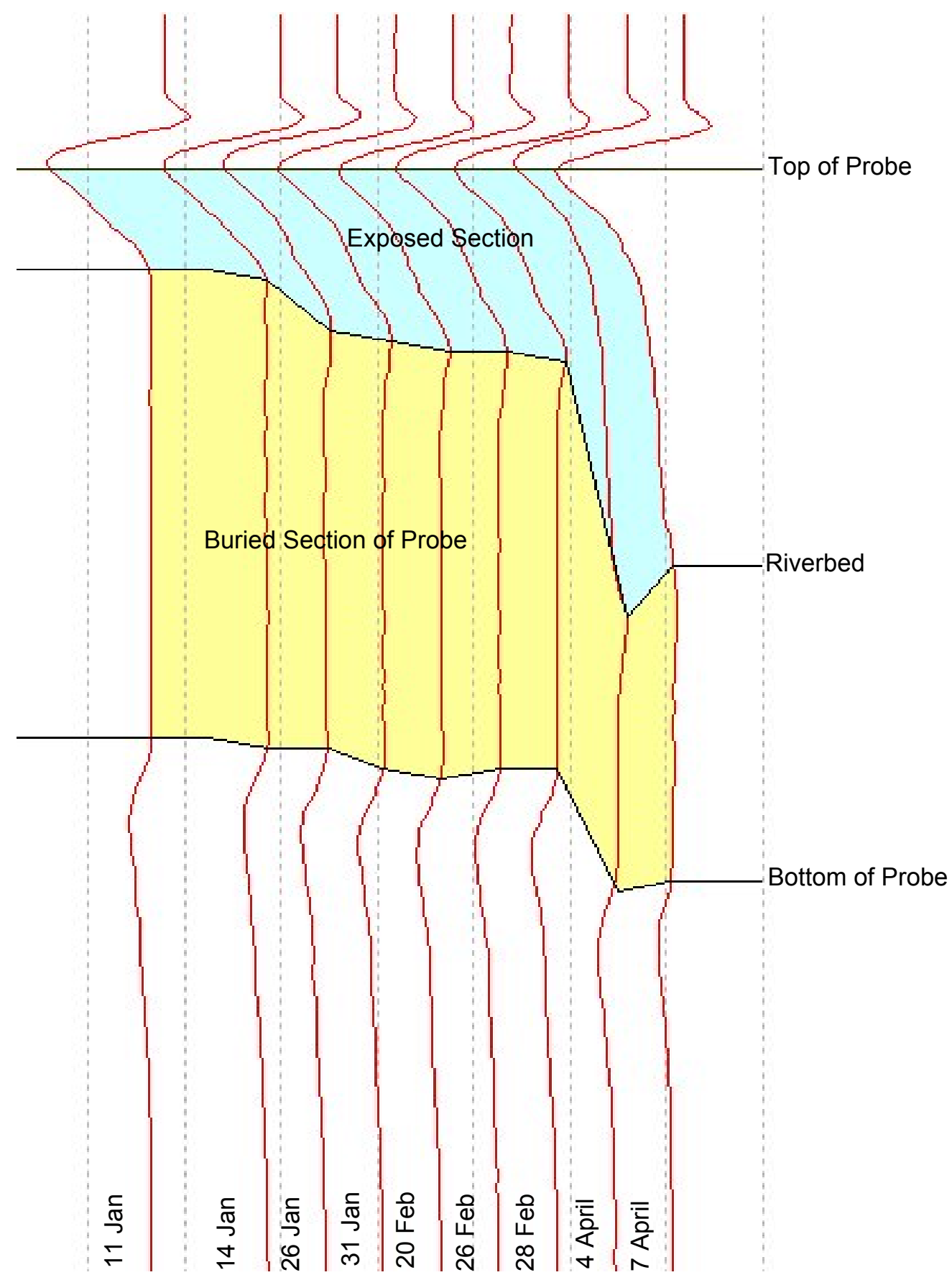

Figure 39. Waterfall plot of images from TDR 1 captured using the 1503. 


\section{SURVEY CONDITIONS}

The weather and flow conditions were conducive for conducting the bathymetric surveys, which could be carried out on the scheduled dates. Flow conditions in the reach essentially were in accord with the CWCP schedule for flow release from the Fort Peck Dam and are typical of the winter flow regime for the river (Fig. 40).

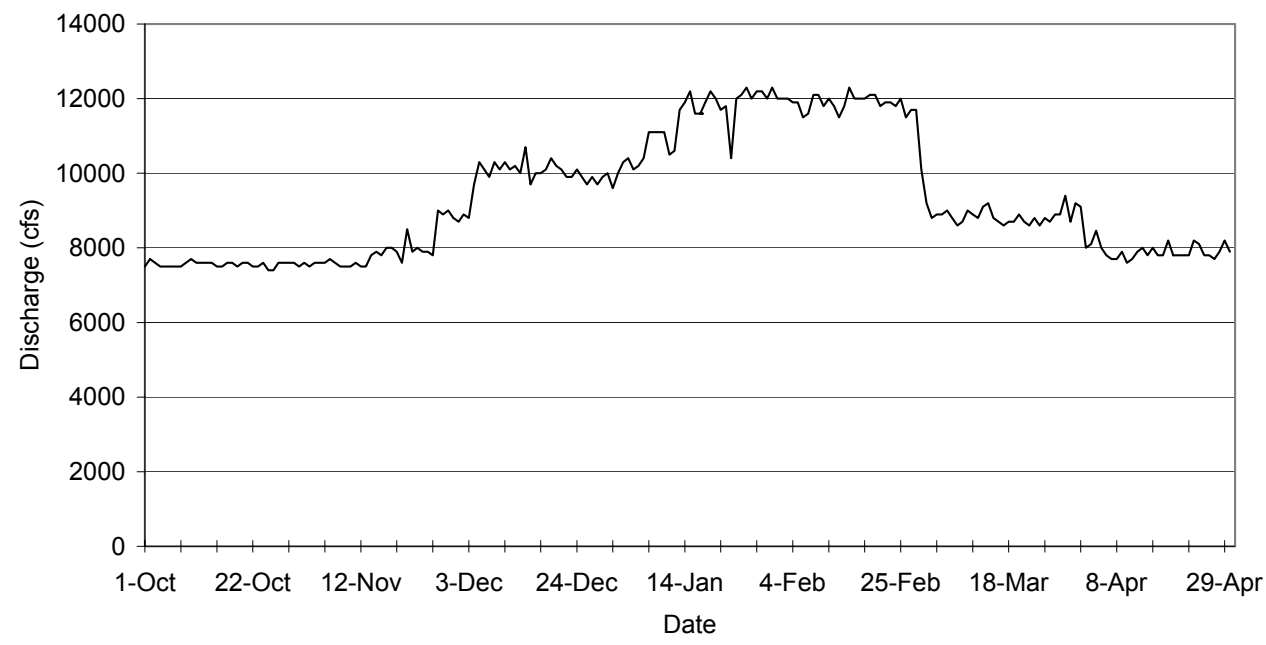

Figure 40. Discharge from the Fort Peck Dam, 1 October 1998 to 1 May 1999.

\section{Weather}

The winter of 1998-99 was relatively warm for the Fort Peck reach for northeast Montana. The accumulated total of freezing degree-days (AFDD) for March 1998 through March 1999 was about 1648. In contrast, March 1996 through March 1997 was one of the coldest periods, with 3060 AFDD.

Other factors that may have affected the river system include the relatively wet fall, which potentially increased the water table. The higher water table may have increased the gradient towards the river, with ramifications along the bank. Also, the snowfall was above normal, increasing the amount of water entering the system either as runoff or ground water during the spring thaw. Figure 41 shows the precipitation measured in the Culbertson area for September through December for 1980-1998.

Freeze-up occurred along the river during late December. At the Culbertson, Tveit-Johnson, and Vournas sites, it occurred on December 20. At the Mattelin and Pipal sites, it began on the evening of December 20 and was completed on 


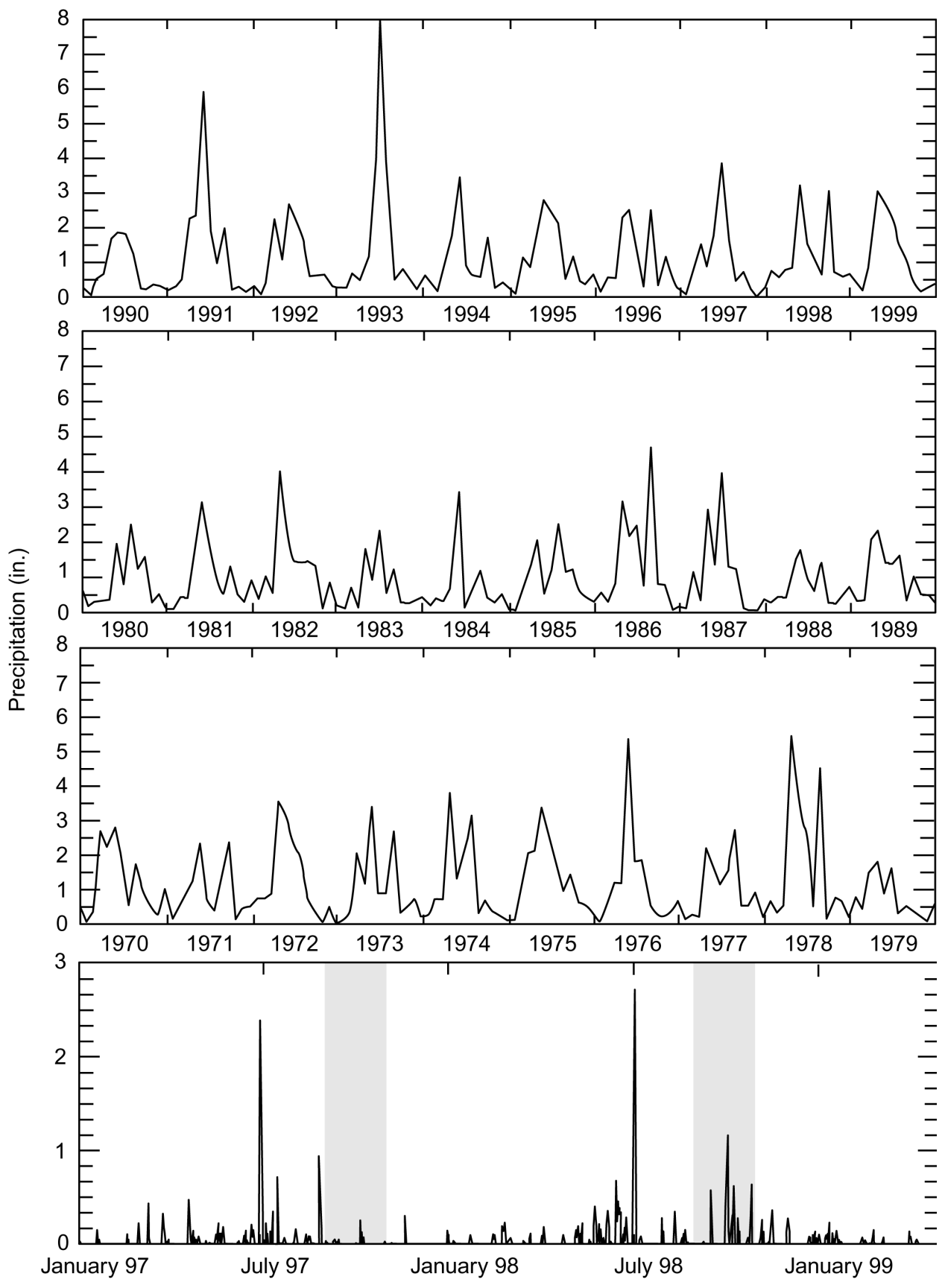

Figure 41. Average precipitation for the fall period of 1970 to 1999 and precipitation for January 1997 to January 1999, with the two fall periods highlighted. 
December 21. These freeze-up dates are later than normal, which is early December. At all the sites the ice cover formed primarily through accumulation of drifting frazil slush and pans and skim ice. An important part of freeze-up was the formation of border or bankfast ice along riverbanks. Bankfast ice congested the flow surface available for ice passage, especially in the wider subreaches where the river flowed through two or more subchannels, such as at the Culbertson site. At some locations (e.g., the Culbertson site and the upstream end of the Pipal site), ice did not completely cover the channel. At those locations, drifting ice bridged across the upstream end of a subchannel, leaving patches of open water. Under continued cold weather conditions, some of the patches eventually froze over. However, some areas with higher velocities remained open during the entire winter.

The ice cover broke up along the Fort Peck reach during late March. It had broken up about one month earlier at some upstream sites; for example, at the Pipal site the ice cover broke up in mid-February during a brief period when the air temperatures were close to $30^{\circ} \mathrm{F}$ and the warm water released from the dam progressed downstream, melting the ice cover. The ice conditions at 1400 on February 14 in the downstream reach of the Pipal site are shown in Figure 42. The warm water followed the thalweg, melting out the ice in the channel area. As channel area opened up, ice would break off the shoreline and migrate downstream. Similar breakup occurred at the other sites. Figure 43 is from the Culbertson camera at 0900 on March 17.

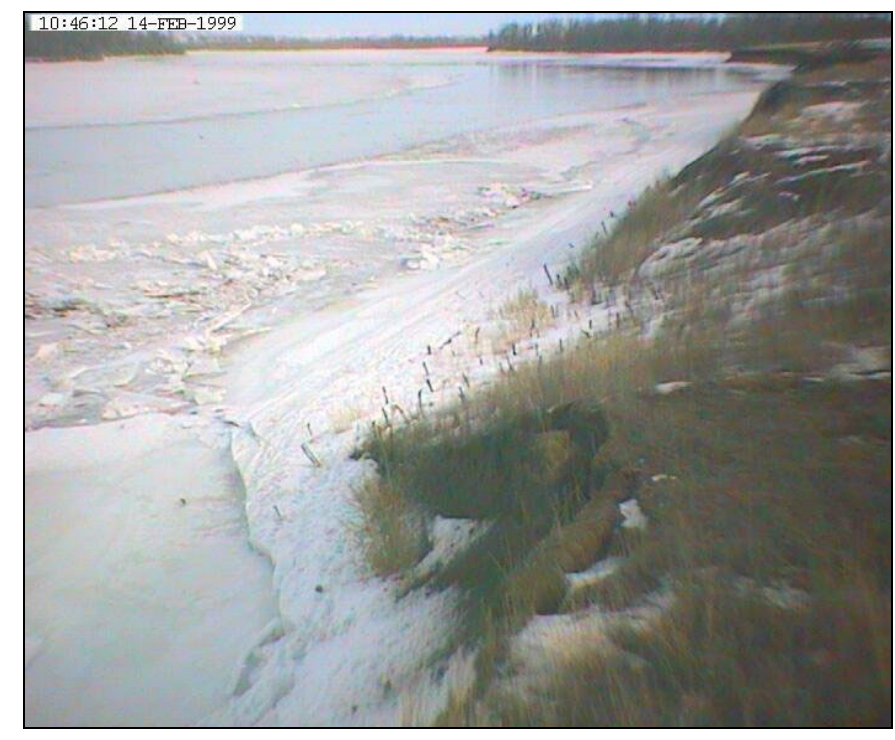

Figure 42. Early stage of breakup in the downstream reach of the Pipal site on 14 February 1999. 


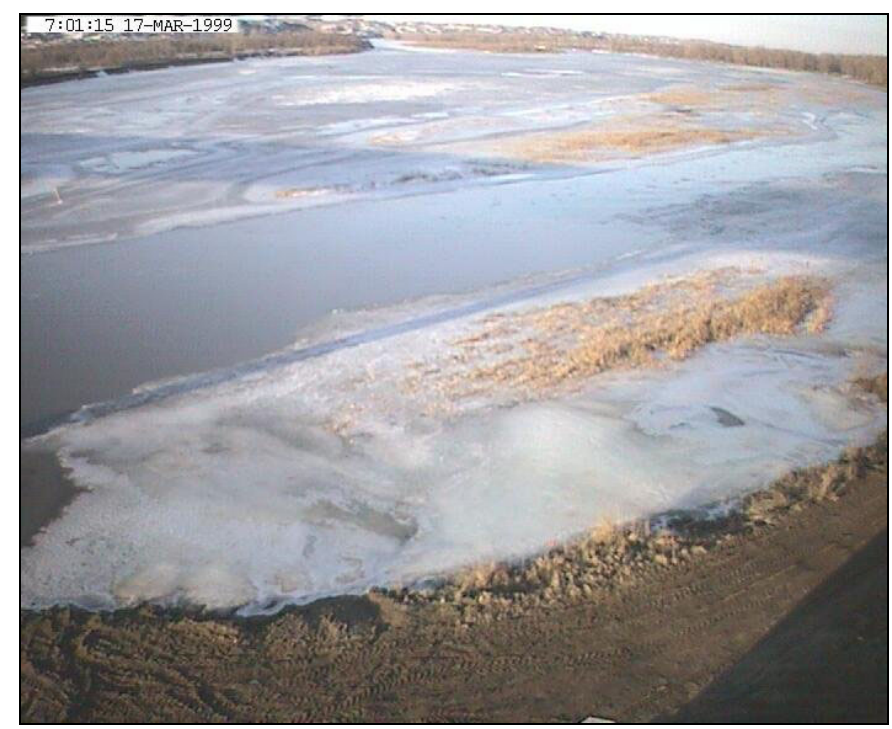

Figure 43. Ice conditions at the Culbertson site on 17 March 1999 in the early stages of breakup.

\section{Flow}

Ice cover formation alters the relationship between flow rate and flow stage, so it was not feasible to assess directly a continuous record of flow rate at each of the monitored sites. However, the record of flow rate released from Fort Peck Dam, located about 150 river miles upstream of the monitoring site at Culbertson water intake (RM 1621), indicates the flow rates at the sites because there is little additional inflow into the river over the monitored reach during winter. Figure 44 is a record of the daily average flow released from Fort Peck Dam from 1 October 1998 through 1 May 1999. Also indicated on Figure 44 are the dates when freeze-up and breakup occurred at the Pipal and Culbertson sites. The Fort Peck discharge was not affected by the ice cover on the river. Also, over each day the flow released from the dam was steady about the daily average flow rate, reducing the likelihood of water surges that could lead to fluctuations in the pore pressure and flexing of the ice along the bank.

In approximate terms, based on average flow velocities through the Fort Peck reach (Pokrefke et al. 1998), flow released from Fort Peck Dam would travel about 40-50 miles per day. At a rate of, say, 45 miles per day, flow changes at the Pipal and Culbertson sites on average would lag flow changes at Fort Peck Dam by 1.5 and 3 days, respectively. Haydon (1931) suggested that the flood peaks traveled the reach at a rate of 4-5 miles per hour, or about 80-100 miles per day. These estimates are useful in assessing actual water discharge at the 


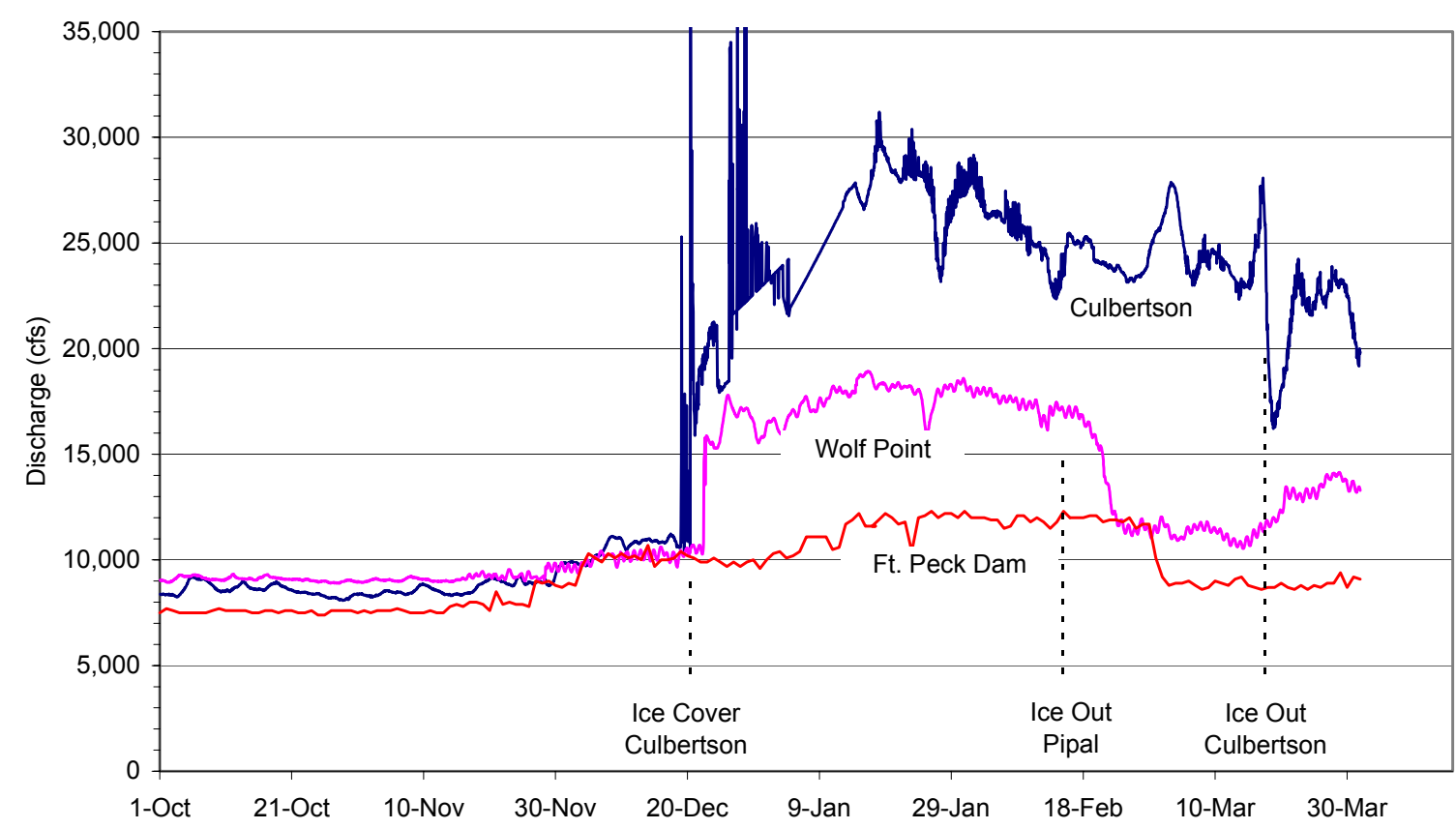

Figure 44. Discharge from the Fort Peck Dam with measurements from the Wolf Point and Culbertson gages.

survey sites; the USGS gages otherwise closest to the sites (Wolf Point and Culbertson) were ice-affected and could not be used to determine flow rate, but the provisional data from these gages are included in Figure 44.

The Fort Peck data in Figure 44 show that the flow rate in the river increased with the onset of winter, attained a peak that was sustained for almost two months during winter, and then decreased during late winter and into spring.

Freeze-up at the Culbertson and Pipal sites, which occurred on 20 and 21 December, respectively, coincided with river flows of about 10,000 cfs. Throughout much of January and February, flow at those sites was almost 12,000 cfs. During the melt-out and gradual breakup of the ice cover in the reach, the flow release from Fort Peck was on the order of 12,000 cfs. At the end of February and into the first few days of March, the flow rate dropped rapidly to less than $9,000 \mathrm{cfs}$. 


\section{FINDINGS AT SURVEY SITES}

\section{Culbertson site, RM 1620-1622}

Ice cover formation, as well as differences in ice cover thickness and roughness, dictated which of the two subchannels at this site became the primary thalweg during the winter season and possibly for the ensuing year. This process of thalweg switching appears from the survey to be a common occurrence. It likely contributes to the recurrent problem of sedimentation at the Culbertson water-supply pump site and at other pump sites along the Fort Peck reach (e.g., the Mattelin and Whitmer sites). The pump sites most troubled by sedimentation largely are situated in sites with two or more subchannels. We introduce the term "ice-triggered avulsion" to describe the process

\section{Observations}

The ice cover formed from pieces of drifting skim ice together with frazil ice pans and slush that floated downstream, collected, and froze as an accumulation cover during 20 December 1998. The air temperature on that day dropped to about $-10^{\circ} \mathrm{C}$. By 21 December the cover extended well upstream of the site and encompassed all the sites, although a few small open water patches remained. They eventually froze over several days later. As is evident from the USGS gage at Culbertson, the river's stage rose $3 \mathrm{ft}$ once the cover had formed.

The most evident influence of ice cover formation was a shift in the alignment of the river's main thalweg from the south subchannel to the north subchannel. Drifting ice accumulated first at, and then bridged across, the upstream end of the north subchannel. Over time a relatively smooth ice cover formed thermally on the remaining length of the north subchannel. The initial accumulation of ice at the upstream end of the north subchannel deflected a subsequent heavier drift of ice, which moved into and packed thicker in the south subchannel. Figure 45 was taken as the ice was thickening in the south channel and the ice was starting to arch across the entrance to the north channel. The sequence of photos in Figure 46 shows the site before ice cover formation, once the ice cover had formed, in mid-winter, during breakup, and after the ice cover had broken up and departed the site. The photographs show that, once the ice cover had departed, the north subchannel had enlarged at the expense of the south subchannel. A small, vegetated medial bar in the north subchannel was completely eroded, and a new medial bar had formed in the south subchannel.

The flow resistance of the south subchannel at the Culbertson site had apparently increased much more than did the flow resistance of the north subchannel. Consequently, as the regulated flow increased during winter, more flow passed 


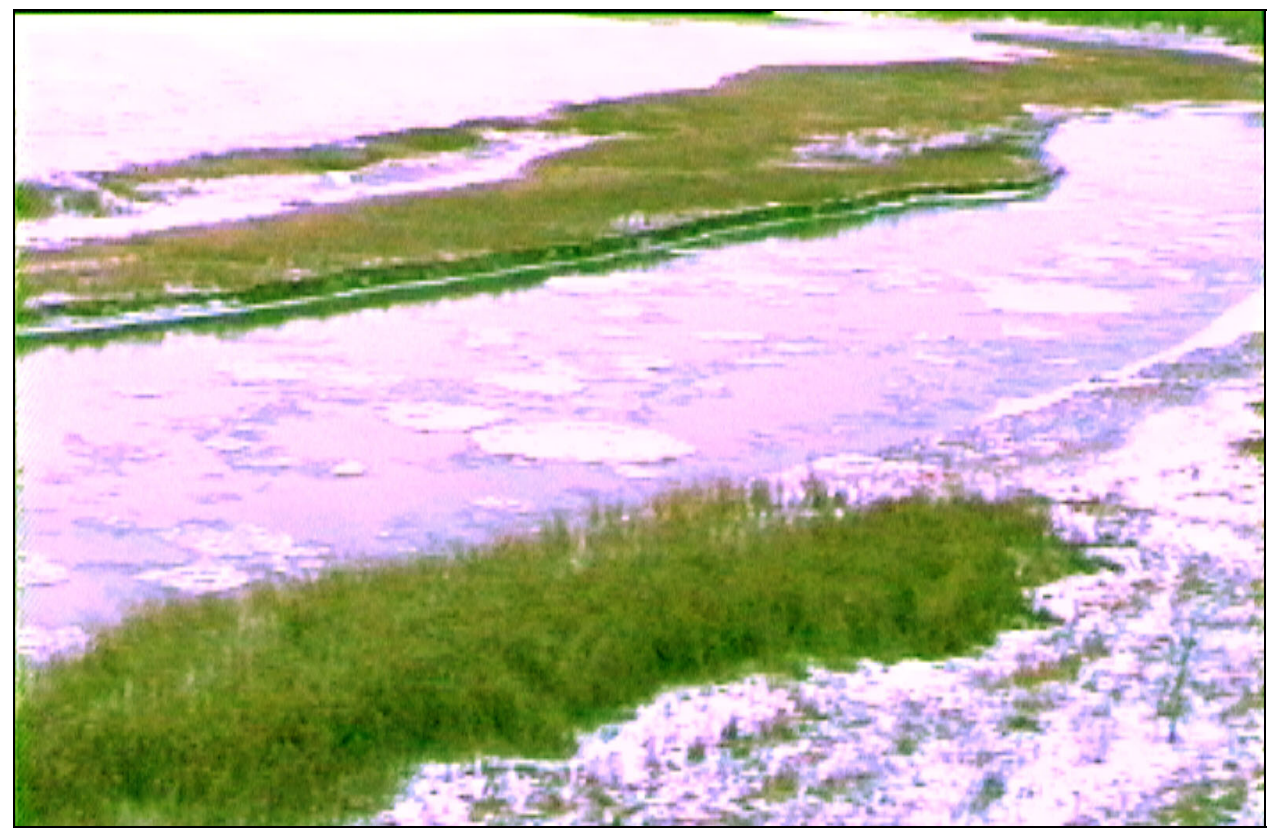

Figure 45. Culbertson site during freeze-up prior to the ice arching across the north channel (view from north bank with flow right to left).

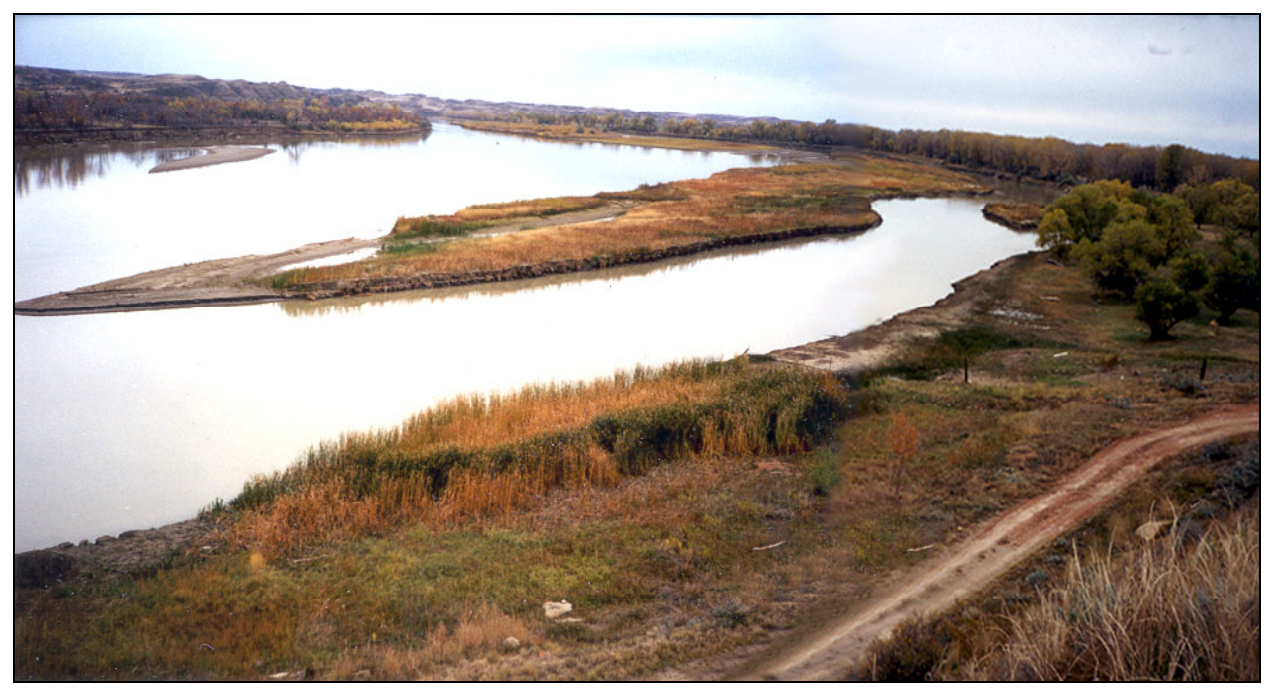

a. 14 October 1998 (view from the north bank with the flow from top to left side).

Figure 46. Culbertson site during the survey. 


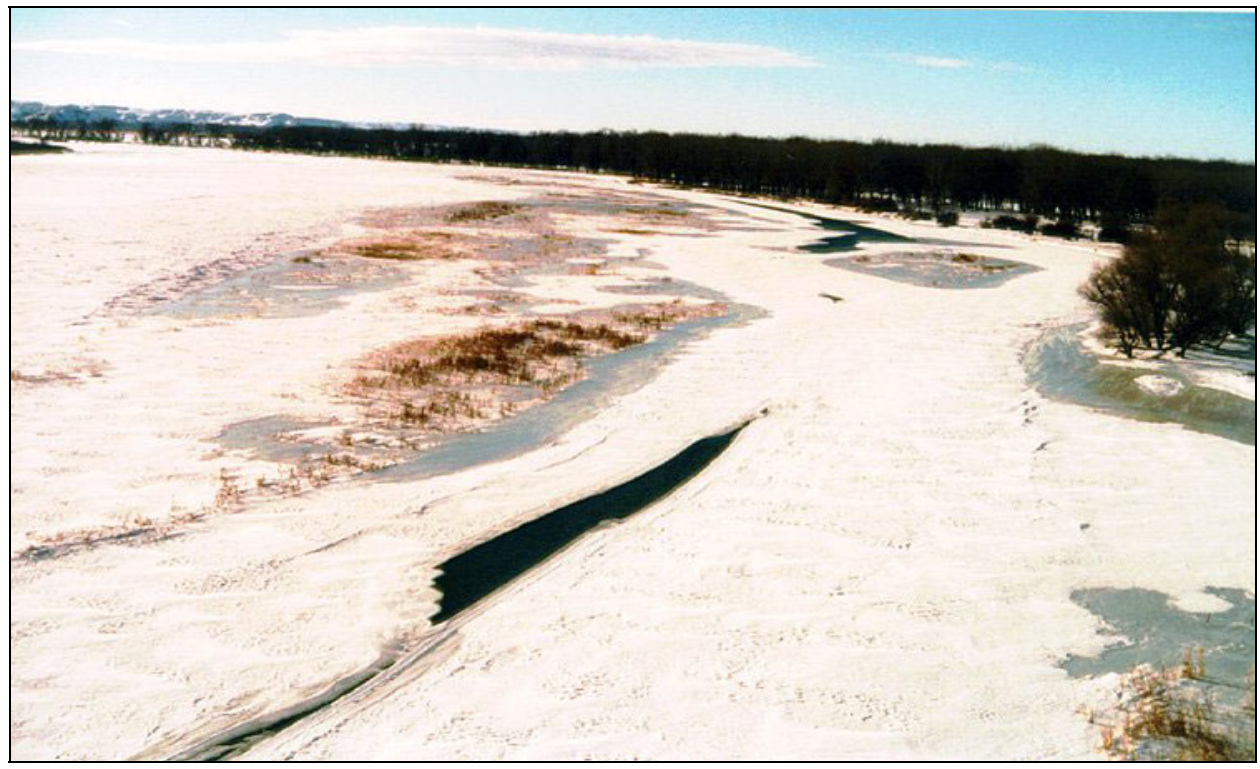

b. 26 January 1999 (view from the north end of the bridge with the flow from top to lower left).

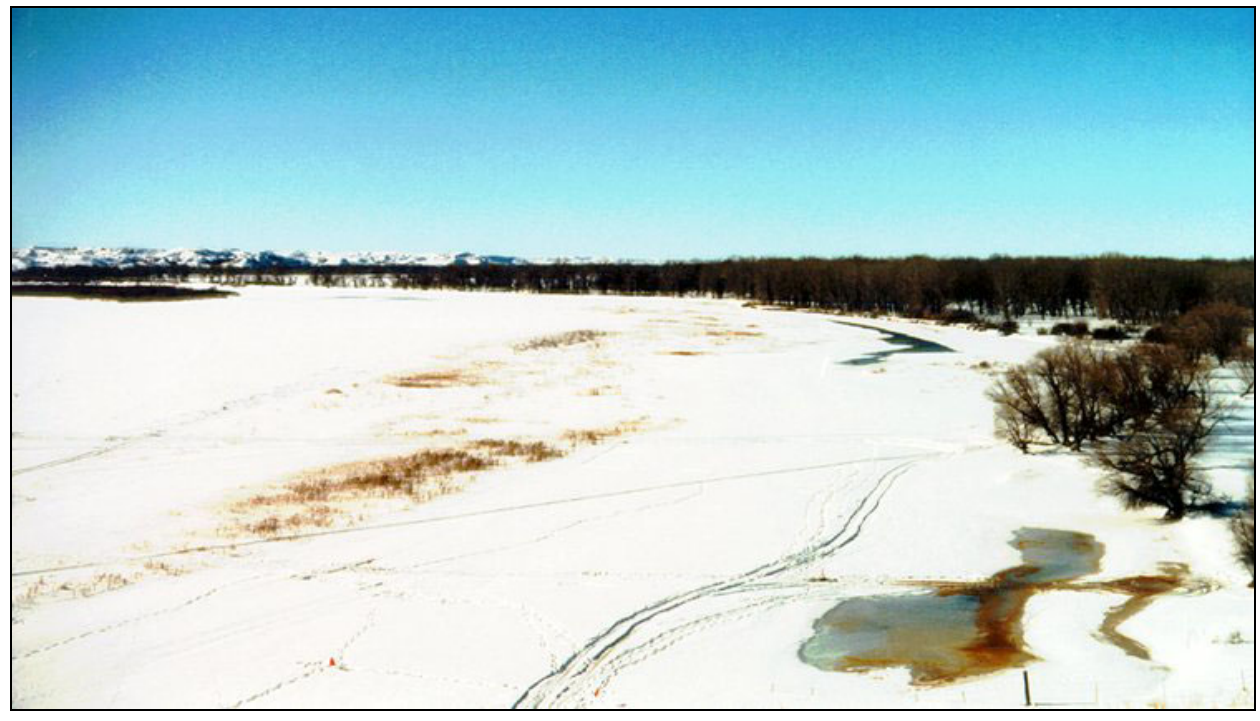

c. 23 February 1999 (view from the north end of the bridge with the flow from top to bottom).

Figure 46 (cont.). 


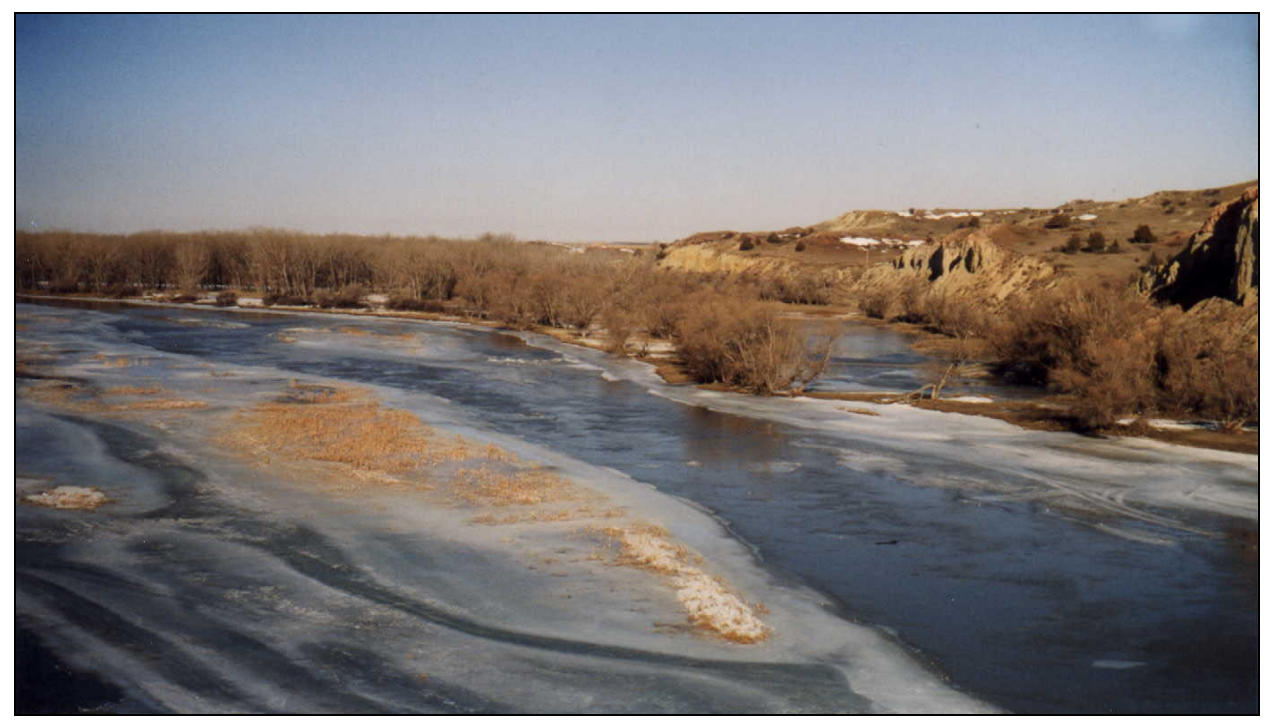

d. 17 March 1999 (view from the south end of the bridge with the flow from left to right).

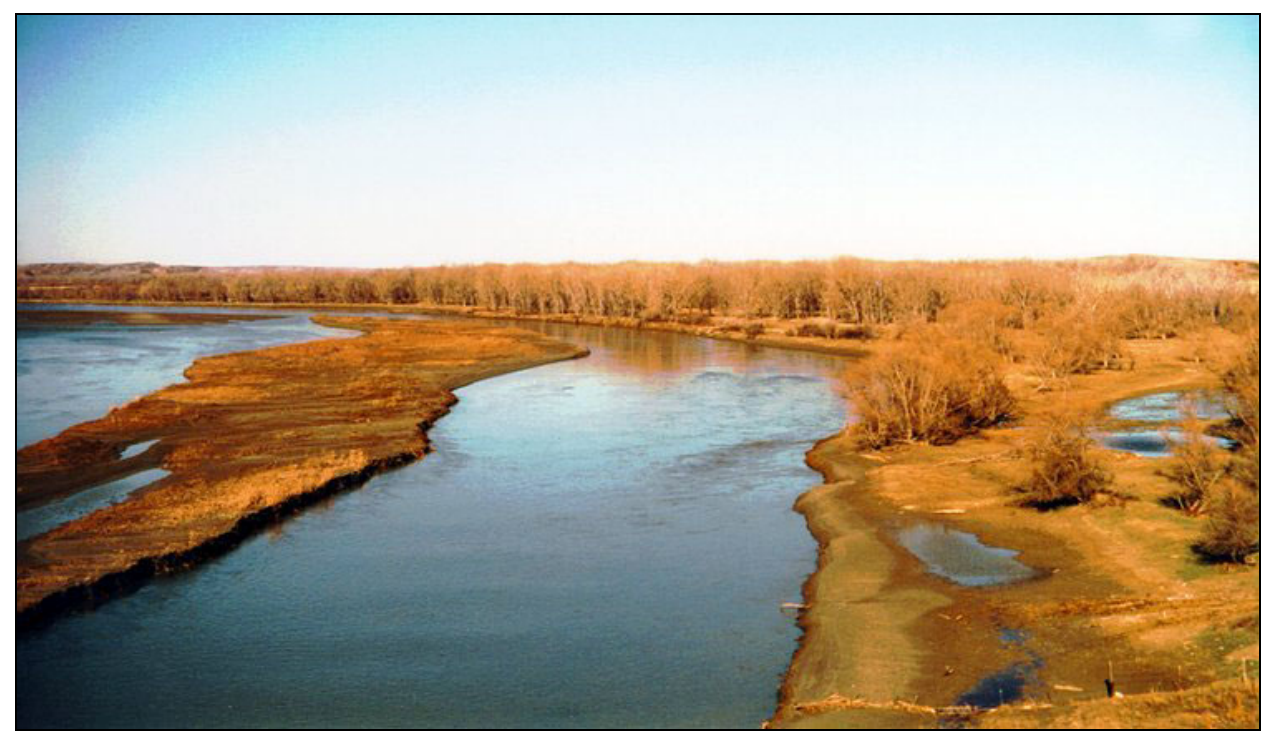

e. 4 April 41999 (view from the north end of the bridge with the flow top to bottom).

Figure 46 (cont.). Culbertson site during the survey. 
through the north subchannel than through the south subchannel. Eventually the flow area in the north subchannel enlarged by localized scour. In so doing, the flow undercut segments of the subchannel bank and the sides of the vegetated medial bar in the north subchannel. When the ice cover eventually broke up and flushed from the north subchannel, the vegetated bar washed out. The TDR measurements indicate that the channel was eroded to compensate for the greater roughness of the ice cover. The rate of erosion diminished as the channel re-established equilibrium.

\section{Ice cover thickness}

Because of how the ice cover formed, the cover thickness varied over the site. Over most of the study area, the cover was 16-20 in. thick during the January survey and thickened only slightly through the rest of the winter; it was 16-24 in. thick at the time of the February survey.

The cover was thinnest (about 8 in.) where the flow was deepest and the flow velocities were greatest; these locations typically were the last to freeze over, primarily along the thalweg in the north channel (Fig. 46b, c and Fig. 47 ). The cover was thickest where it formed as bankfast ice over the bar (up to 35 in.) between the two subchannels and around the bridge piers (about 40 in.) as ice was incrementally thickened by a cyclic flooding-freezing process.

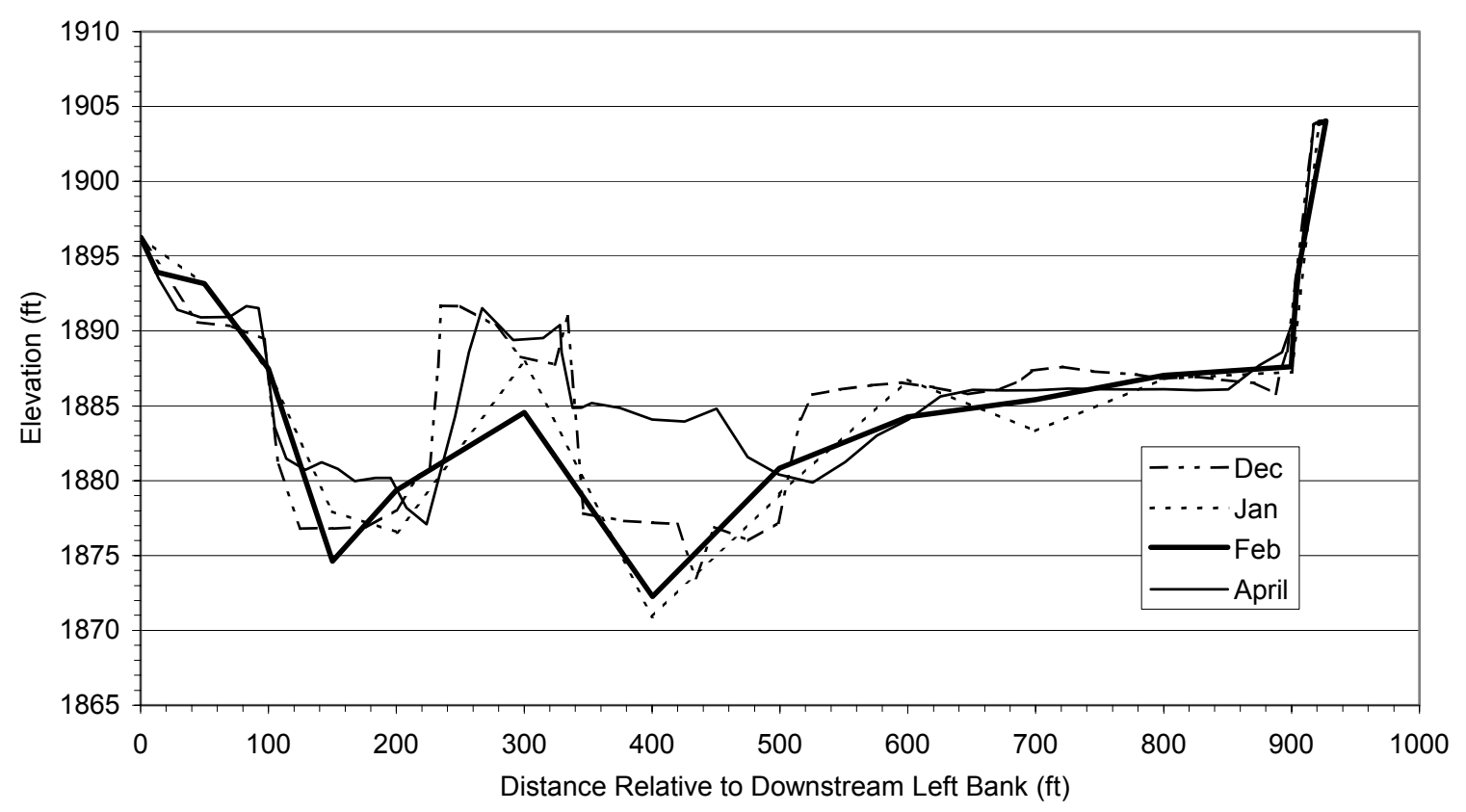

Figure 47. Bed profiles of cross sections at RM 1620.4. 


\section{Bed profiles}

The observed changes in channel conditions at the Culbertson site are evident in the bed profiles obtained from the surveys and the bathymetry contours. Figure 47 shows the bed profiles measured for the cross section at RM 1620.4 during the four survey periods.

Because ice cover formation around the head of the bars triggered a switch in the river's thalweg location, it would have been useful to survey additional cross sections farther upstream; the main changes in channel bathymetry probably initiated near the upstream end of the diagonal bars that divide the two subchannels. However, the survey cross sections do reveal some of the change, especially the bed lowering of the north subchannel at the upstream cross section surveyed (RM 1620.45). Also, the April and October bathymetry contours show how the thalweg switch to the north subchannel is reflected in the lower bed elevations of that subchannel.

A further important ice influence, however, occurred in the center of the site. A low point in the bed (RM 1620.4) deepened once the cover had formed over the site. The deepening section coincided with a thinner portion of ice cover. One interpretation is that the flow was concentrated toward the deeper section of the channel, since that section provided the least flow resistance. The flow velocity measurements support this interpretation; they show a sustained large unit discharge of water through the section. The TDR measurements indicate that sediment started to deposit in the vicinity of the probes shortly after ice cover breakup, and it is safe to assume that sediment was also being deposited in the deeper portion of the river. By the time of the April survey, the holes detected in February were backfilled and no longer evident.

Increased flow through the north subchannel scoured and lowered the bed along the upstream portion of that subchannel by about $5-6 \mathrm{ft}$ by the time of the January survey (RM 1620.45). The depth of scouring diminished downstream along the subchannel; for example, at RM 1620.35, no significant deepening of the bed is evident for the north subchannel. It is likely that the bed had already scoured down to a rock layer. A more detailed explanation of this variation is uncertain.

Reduced flow velocities in the south subchannel appear to have resulted in sediment deposition along much of that subchannel. Such sediment deposition would have further increased the flow resistance through the south subchannel. The amount of deposition was substantial - about $8 \mathrm{ft}$ along the south subchannel at RM 1620.45 (Fig. 47). By the April survey the entire subchannel had silted up and a second medial bar had formed (Fig. 46e). At some locations along the 
south channel, bed elevations had risen locally by as much as $15 \mathrm{ft}$ (cross section RM 1620.35).

The bed along the north subchannel remained in the lowered state through the February survey but had partially infilled by the time of the April survey. Several explanations can be offered for the partial recovery in bed elevation of the subchannel:

- Some sediment scoured from the upstream end of the subchannel may have deposited along the lower end of the subchannel as the subchannel widened and the flow velocities in it decreased;

- At the lower end of the medial bar separating the two subchannels, the rise in bed elevation of the south subchannel could have spilled sediment back into the lower end of the north subchannel;

- When open water conditions were re-established, the enlarged north subchannel may have drawn proportionally more bed load sediment than water into the south subchannel; the sediment transport capacity of the flow may not match the imposed bed load;

- The overall sediment load entering the river may have increased with the increase in snowmelt runoff and overall warming of the watershed during and after ice cover breakup; and

- Clumps of bank material from the collapsed riverbanks may have provided a source of sediment to be transported by the flow, and the open water velocities may have been insufficient to convey all the sediment through enlarged areas eroded while the ice cover was in place.

Clearly, evidence confirming these explanations is fragmentary and the factors themselves still are conjectural, requiring further investigation.

\section{Flow velocities}

The January and February velocity profiles shown in Figure 48 are from about the middle of the north channel at ice station $1+00$ with respect to the north bank. The plotted October and April open water velocity measurements are from the closest locations, which were 22 and $10 \mathrm{ft}$ respectively away from the location for the winter measurements. The excessive bending of the fiberglass rods used during the January survey prevented measuring the velocity in the unexpectedly deeper and faster water. 


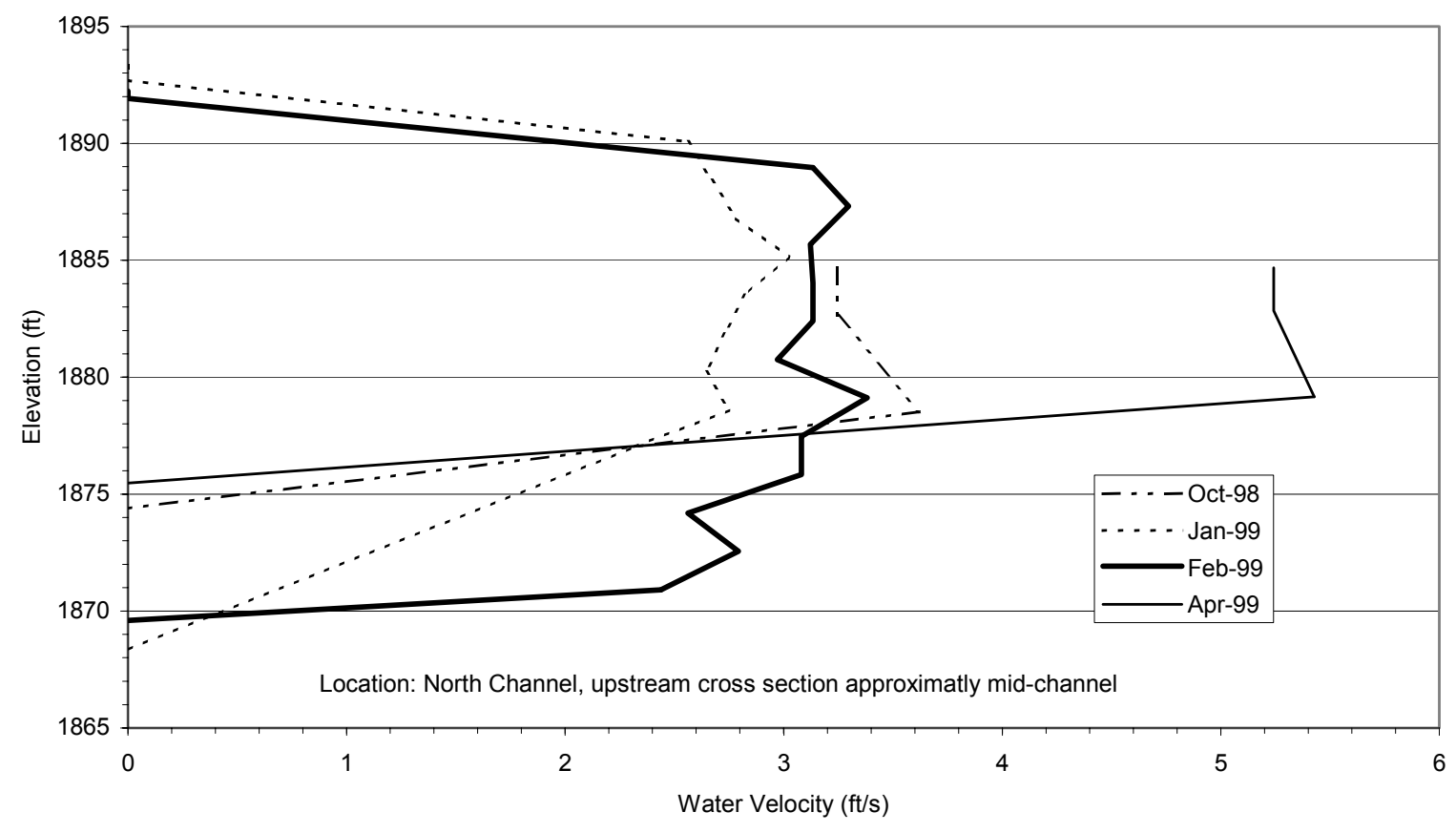

Figure 48. Velocity distributions at approximately the middle of the north channel on the upstream cross section (RM 1620.45, approximately station $1+00$ ).

\section{TDR measurements}

The TDR plots, the flow stage records for the Culbertson site, and the flow discharge records from Fort Peck Dam provide useful additional insight into the channel's response to ice cover formation, presence, and breakup at the site.

The images captured using the 1503 TDR on TDR 1, located on the north bank of the north channel, are shown in chronological order as a waterfall plot in Figure 49. The increased flow resistance produced by ice cover formation increased the flow stage and upset the system equilibrium so that the bed started to scour. Converting the image data from 11 January to engineering units using eq 6 indicates that $0.62 \mathrm{ft}$ of the probe was exposed (the top of the probe was approximately $0.2 \mathrm{ft}$ above the riverbed when it was installed on December 16). As the ice cover thickened, it became more rigid and fixed the cross-sectional area of flow. Increases in flow rate caused an overall increase in the bulk velocity of flow, thereby increasing the flow drag on the channel bed, which locally scoured the bed. Bed erosion continued until 31 January, when the converted measurements indicated that about $1 \mathrm{ft}$ of the probe had become exposed.

With time, as the cover thickened thermally, its underside became smoother, and flow resistance along the cover underside diminished. Combining this reduc- 


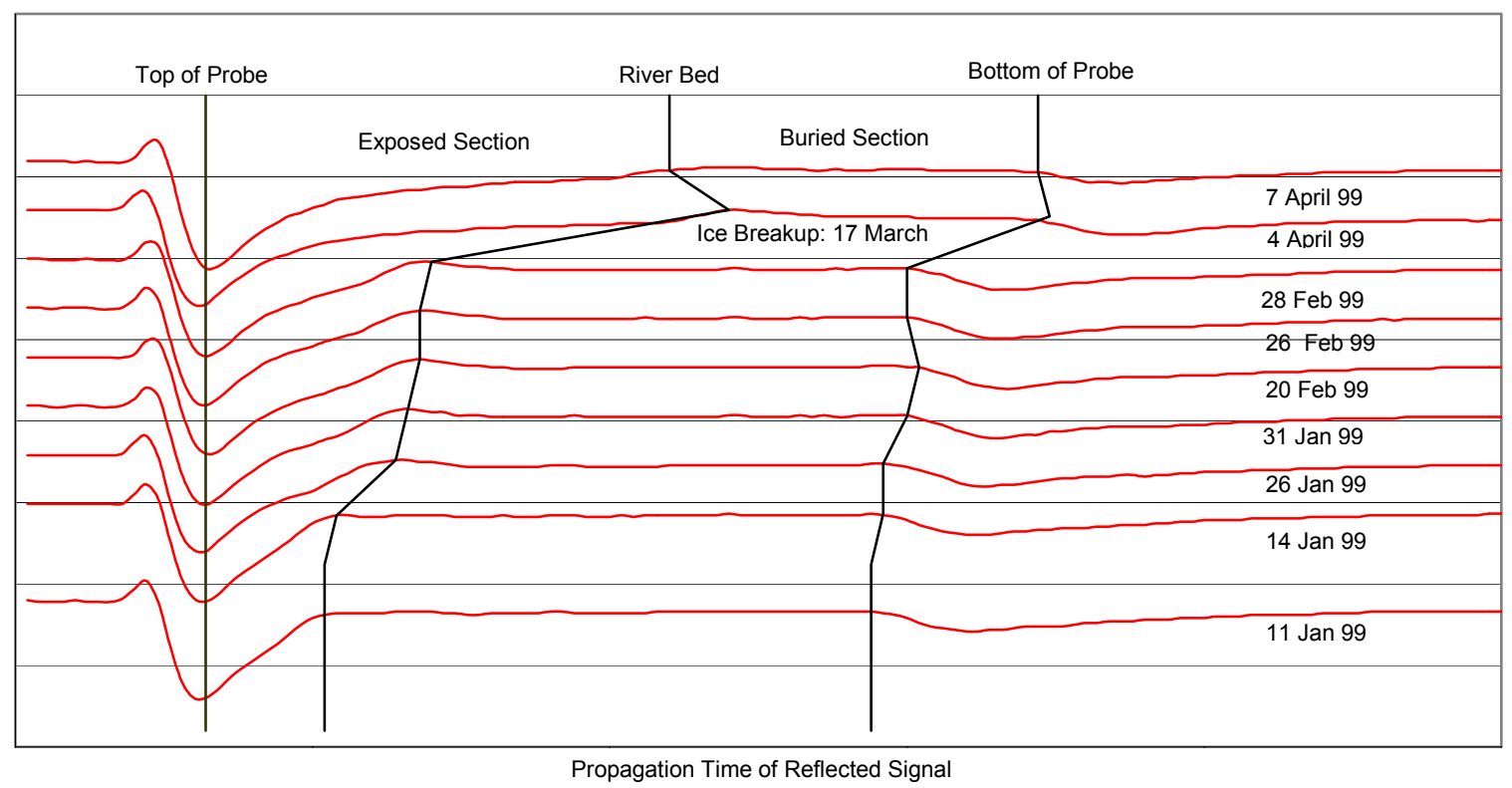

Figure 49. Bed elevation on the north bank of the north channel detected using TDR 1 and the 1503.

tion in drag with the increase in flow area due to enlargement of the channel caused a net reduction in the bulk velocity of flow. The rate of bed lowering also diminished, and a transitory bed equilibrium eventually prevailed. The TDR readings indicate that the bed elevation remained relatively unchanged during the period of 20-28 February, the time of the second survey.

Most of the ice cover at the Culbertson site broke up and departed the site on 17 March (Fig. 46d), leaving no bankfast ice along the channel banks. Ice covers typically break up because of an increase in stage caused by snowmelt and/or rain runoff, but the ice cover at Culbertson warmed, weakened in place, and either melted in place or broke off as a floe and floated downstream. A reading taken 17 days after the ice cover broke up revealed that $2.8 \mathrm{ft}$ of the probe remained exposed. We used eq 6 with the change of the inflection points on the 1503 images to determine the changes in elevation at all the TDR locations (Fig. 50).

The waterfall plot of the periodic 1502 images for TDR 1 (Fig. 51) indicates a trend similar to the one for the 1503 images; the inflection points drift to the left, stabilize, then suddenly move to the right, followed by a recovery to the left. Ice cover breakup occurred in this manner along the lower portion of the Fort Peck reach of the Missouri River. The signals from all the TDR probes indicate that the channel bed at the downstream end of the site remained stable until the 


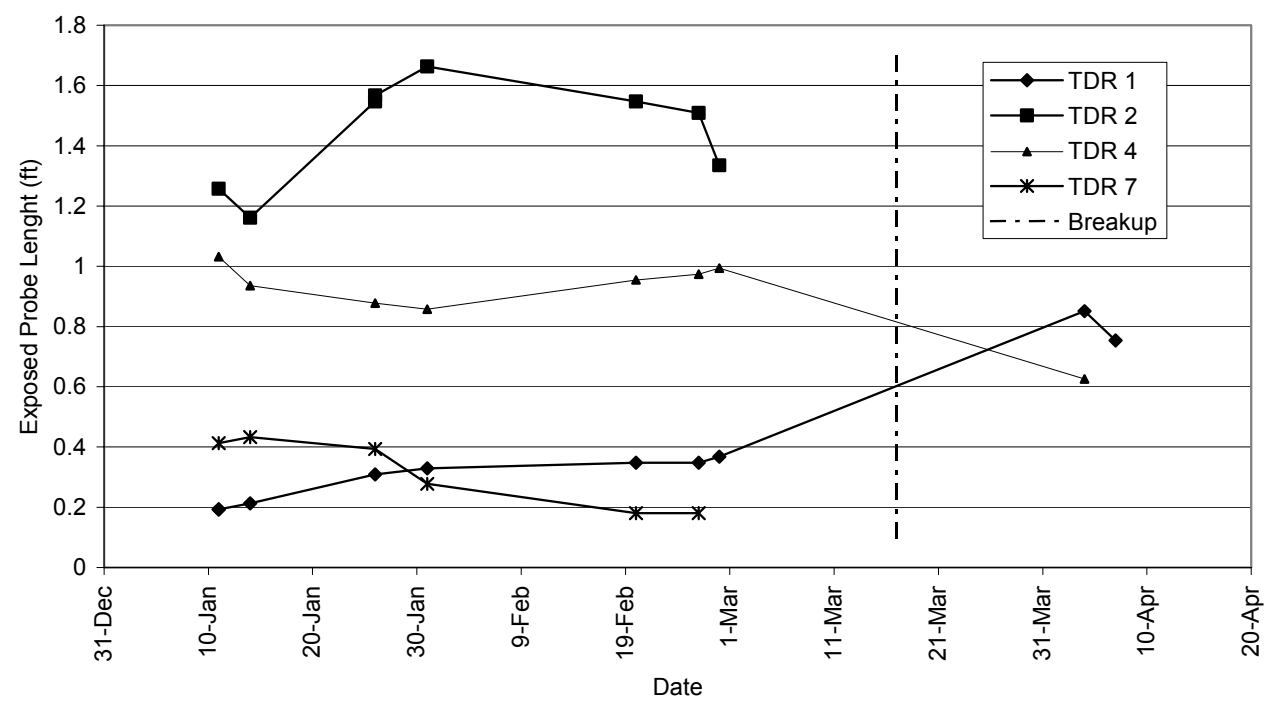

Figure 50. Bed elevations from the TDRs using the 1503.

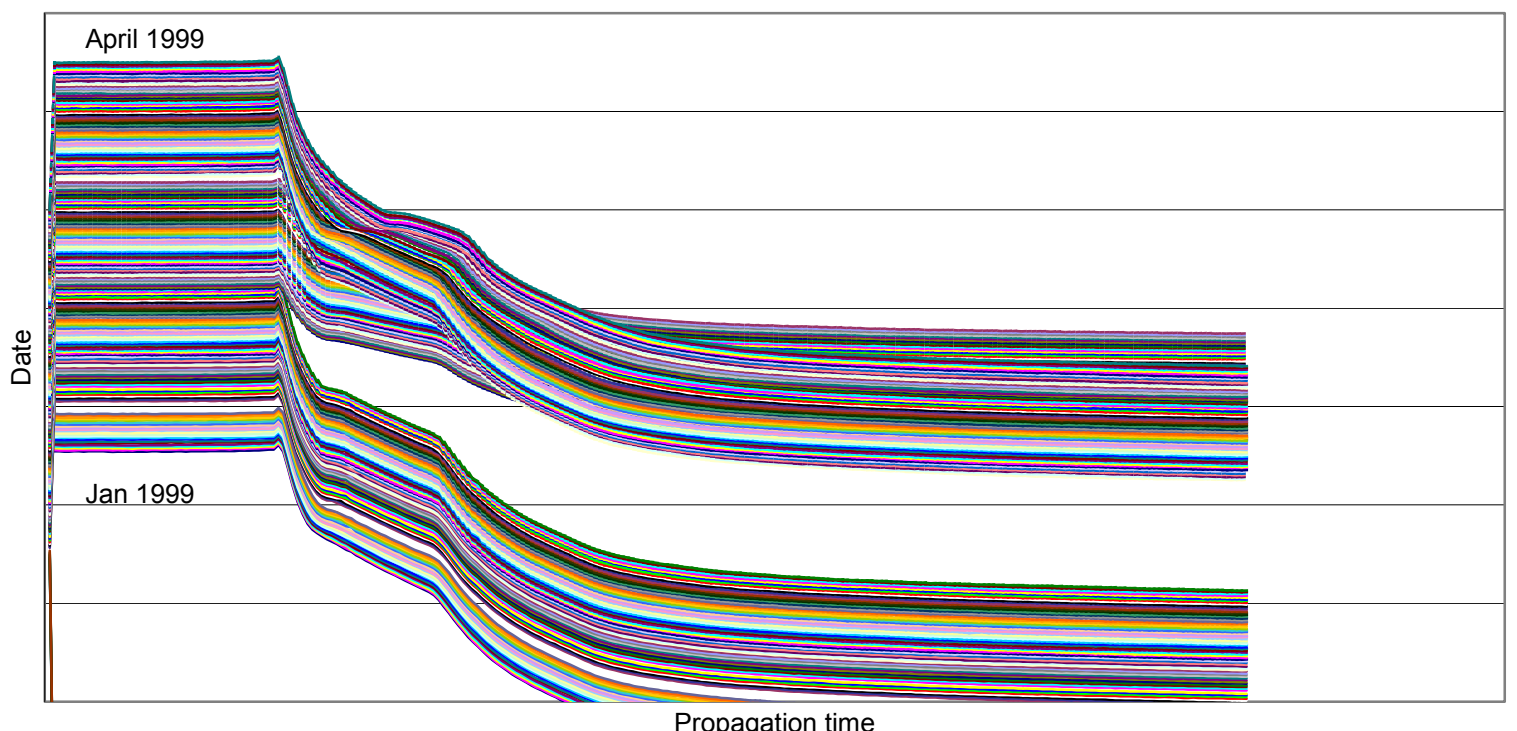

Figure 51. Bed level changes at TDR 1 using the 1502.

ice cover broke up; the same signal trends are evident on waterfall plots from both the 1502 and 1503 for all the other TDRs.

It is possible that some of the probes failed, despite the care taken in placing them. The coax cables could have developed leaks, which would have increased the apparent pulse propagation time, making the coax cable appear electrically 


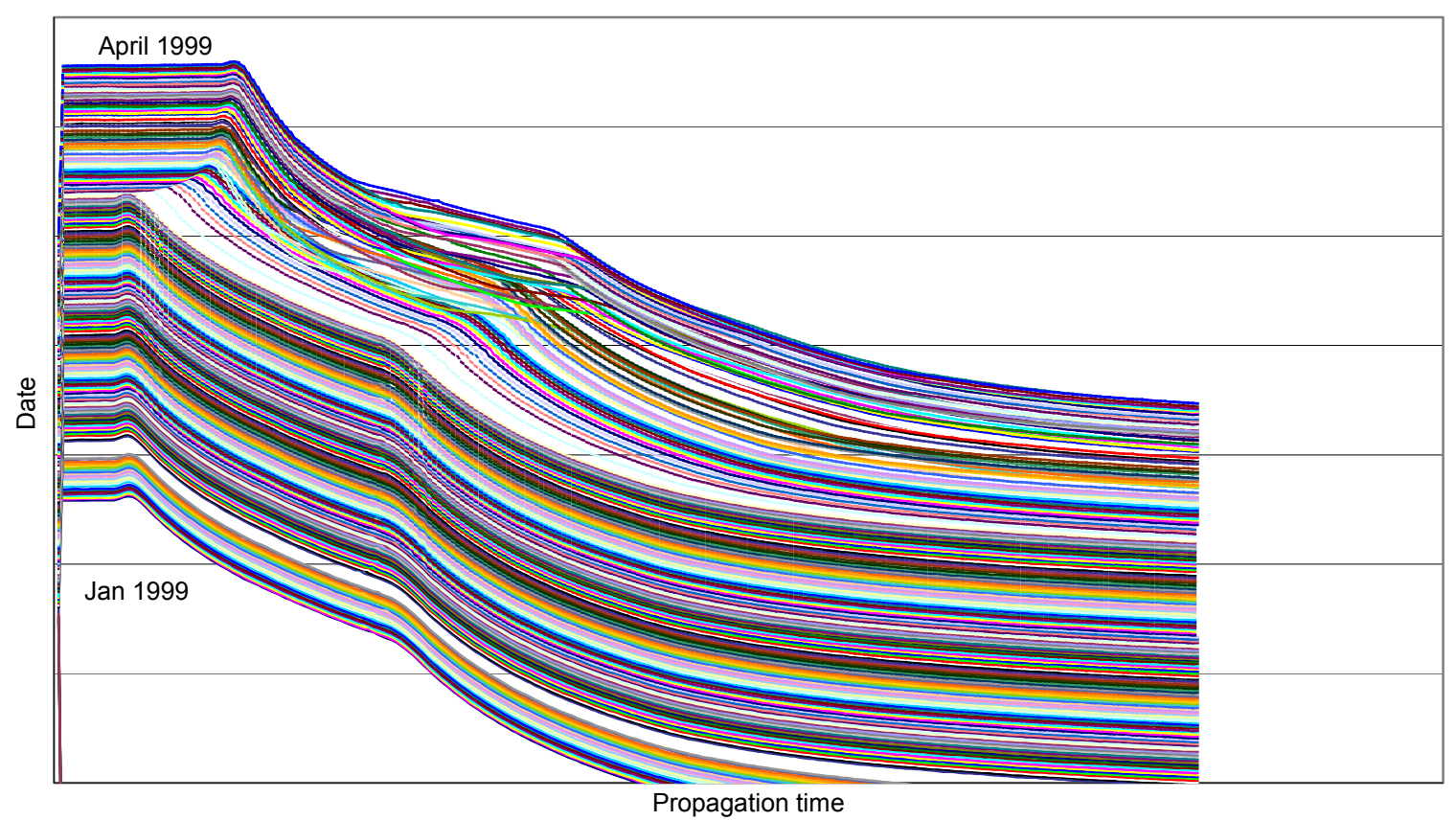

Figure 52. Bed level changes at TDR 3 using the 1503.

longer. In the data acquisition mode the Tektronix is adjusted to the beginning of the sample window using a pre-programmed electrical wire length, so an "electrically" longer cable would offset the probe image in the sampling window. This seems to have been the case for TDR 3, where the top of the waterfall plot drifts to the right during breakup (Fig. 52). For TDR 6 (Fig. 53) the inflection point representing the water-bed interface is missing from the images taken in March, yet electrically the probe was still operational. The connection at the top of the probes may have developed a leak, giving a very "noisy" return signal, as in TDR 7 (Fig. 54). The anchoring section of this probe was shortened, so the probe may have been pushed over and reburied. Though some of the probes eventually failed, the information they provided gave useful insights into the interaction between the ice cover and sediment movement. The lesson learned will be incorporated into future generations of the probe design.

\section{Discussion}

It is possible that a periodic cyclic shift occurs in the location of the main thalweg at the Culbertson site. The shift, triggered by ice cover formation, swings the dominant thalweg from the north subchannel to the south subchannel, then back again. Incomplete observations, historic photographs, and anecdotal accounts at this site and, for example, the Whitmer site (RM 1687) suggest that 


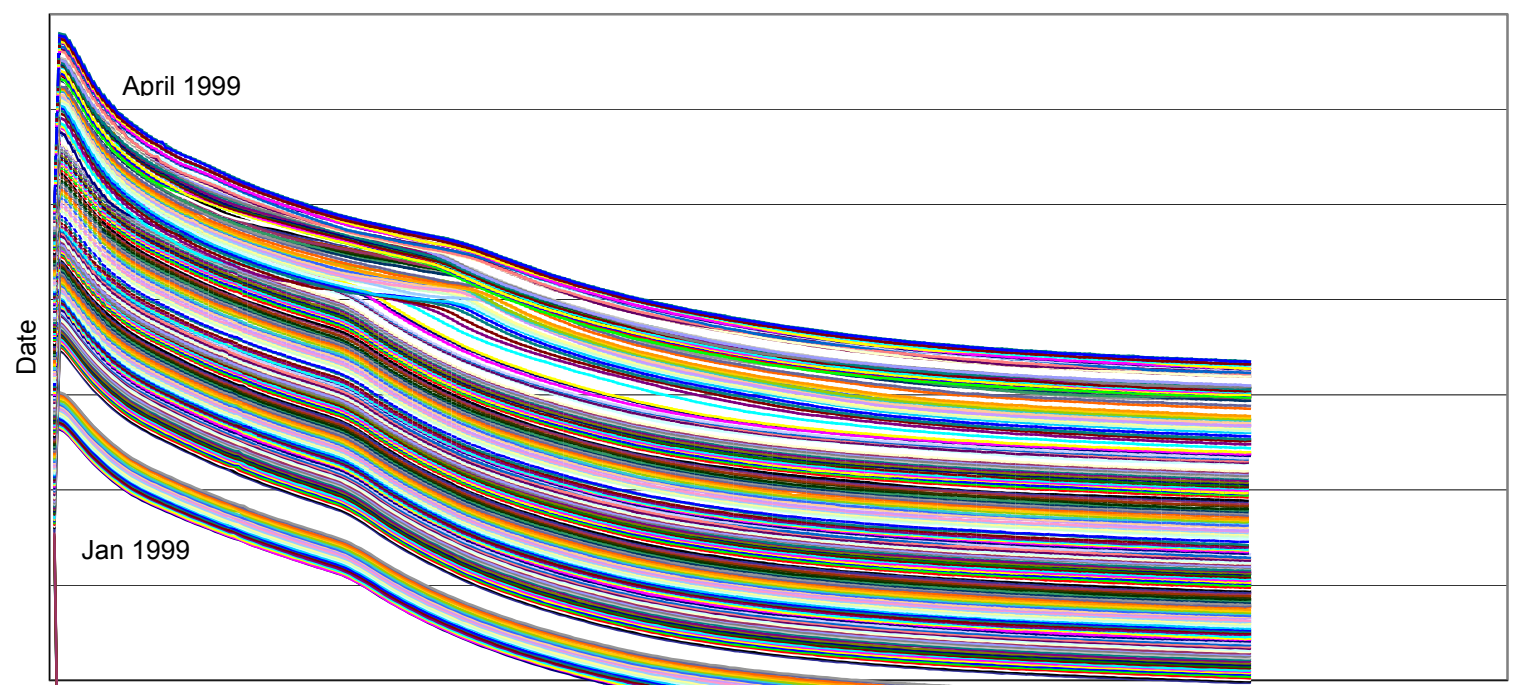

Propagation time

Figure 53. Bed level changes at TDR 6 using the 1503.

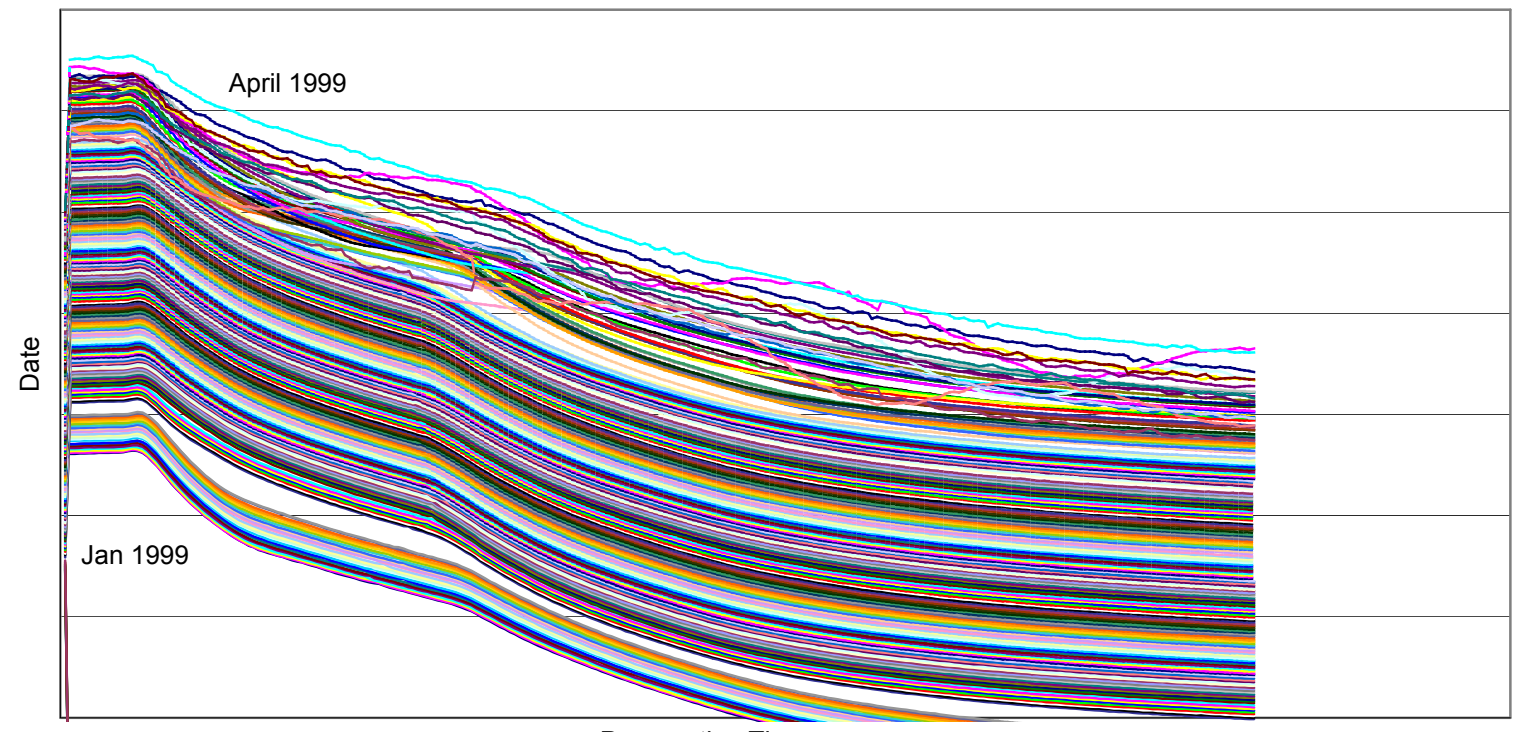

Propagation Time

Figure 54. Bed level changes at TDR 7 using the 1503.

thalweg switching is a recurrent process and that switches may take several winters to complete. Historical photographs indicate that the switching process may take about three years. 
Strictly speaking, subchannel switching comprises a stochastic dynamic process that may have a recurrence interval or be narrow-banded about a dominant period (e.g., a certain number of winters). The narrow band may be superimposed on a broad band because of the variability of flow conditions during a year or during ice cover formation, the severity of winter weather, or other factors, which may have a long-term effect.

A possible complicating factor in interpreting the bed profile changes is the presence of dunes. The profiles were developed from point measurements across each cross section. No measurements were made orthogonally to the cross sections. Such measurements would enable estimation of typical bed form heights. Nonetheless, the bed profile changes at the cross sections are concordant and do indicate consistent overall trends.

\section{Tveit-Johnson site, RM 1624-1626}

The Tveit-Johnson site was subject to multiple hydraulic and geomechanical influences of river ice, which dramatically accelerated erosion along a portion of the site's north bank and thereby hastened lateral shifting of the channel's single thalweg through the site. Besides the hydraulic influences of river ice at this site, the river ice also affected the bank's stability.

\section{Observations}

The Missouri River at this site forms a sinuous loop that is migrating downstream. The principal hydraulic influence of ice cover formation through the site is to aggravate the already unstable alignment of the river's thalweg relative to the north bank. The bank's migration is hastened because the river's thalweg is not aligned with the bank but sweeps across the riverbed and impinges against the north bank, as is evident in Figure 18, which shows the site during open water conditions. Figure 55 shows the site prior to ice cover formation, following freeze-up, during ice cover formation, and after ice cover breakup.

Observations suggest that river ice formation accelerates the downstream migration of the meander loop, apparently by concentrating the flow toward the apex of the loop's eroding outer bank. Flow velocities along the bank's toe are increased, as is erosion of bank toe material.

Additionally the ice cover structurally loaded the bank and likely influenced its freeze-thaw behavior by affecting the elevation of the water table in the bank. Before the January survey a segment of bank in the vicinity of the bend apex collapsed through the ice cover (Fig. 56). 


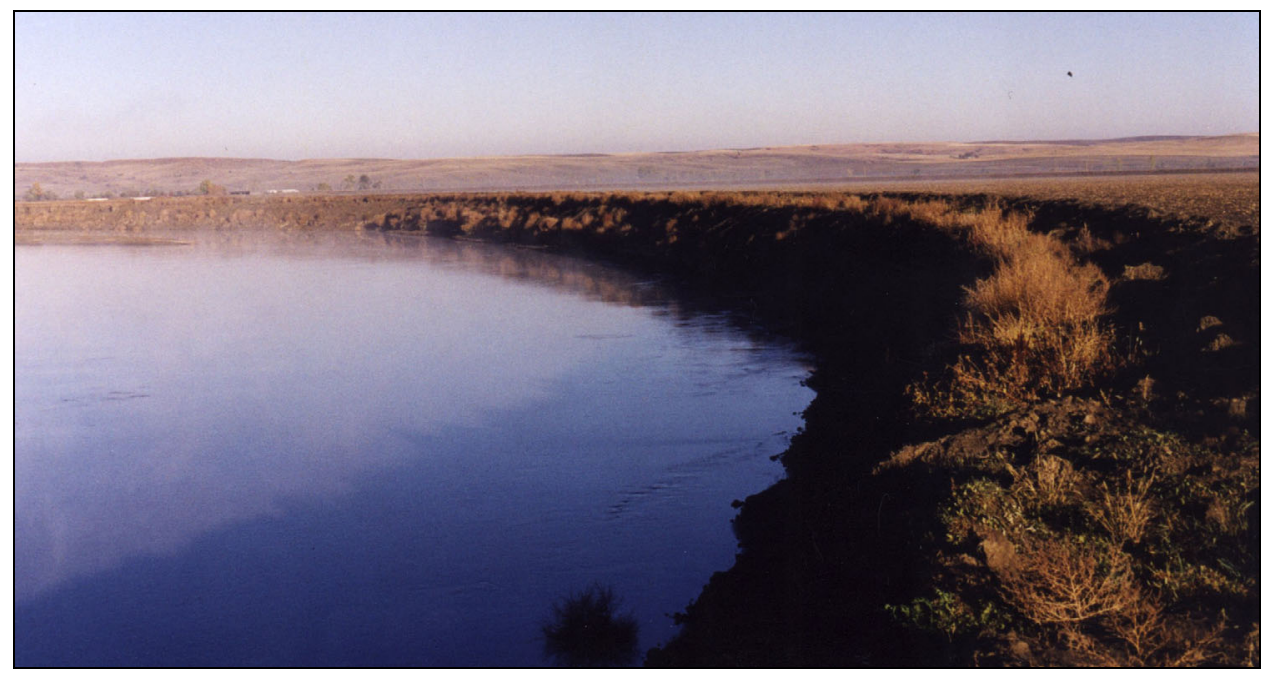

a. 14 October 1998 (view from the north bank with the flow from top to bottom).

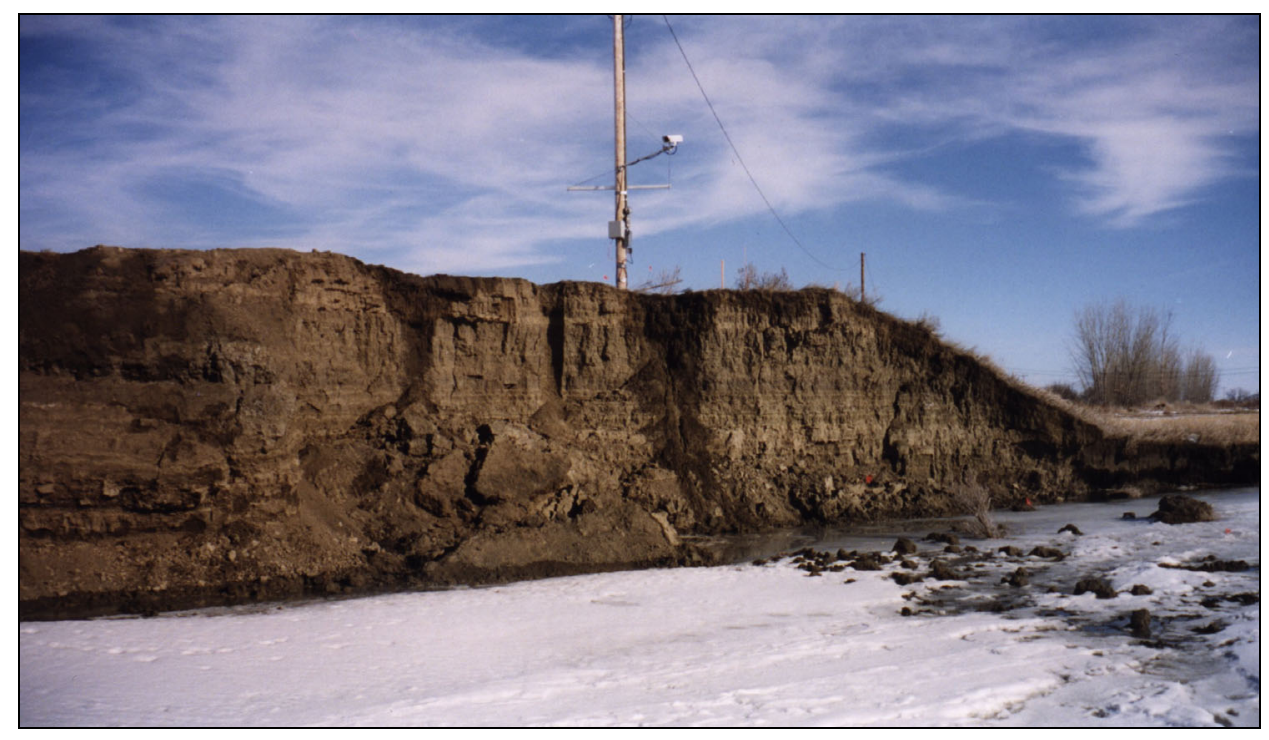

b. 26 January 1999 (view from the ice looking at the north bank with the flow from left to right).

Figure 55. Tveit-Johnson site (RM 1623-1624) during the survey. 


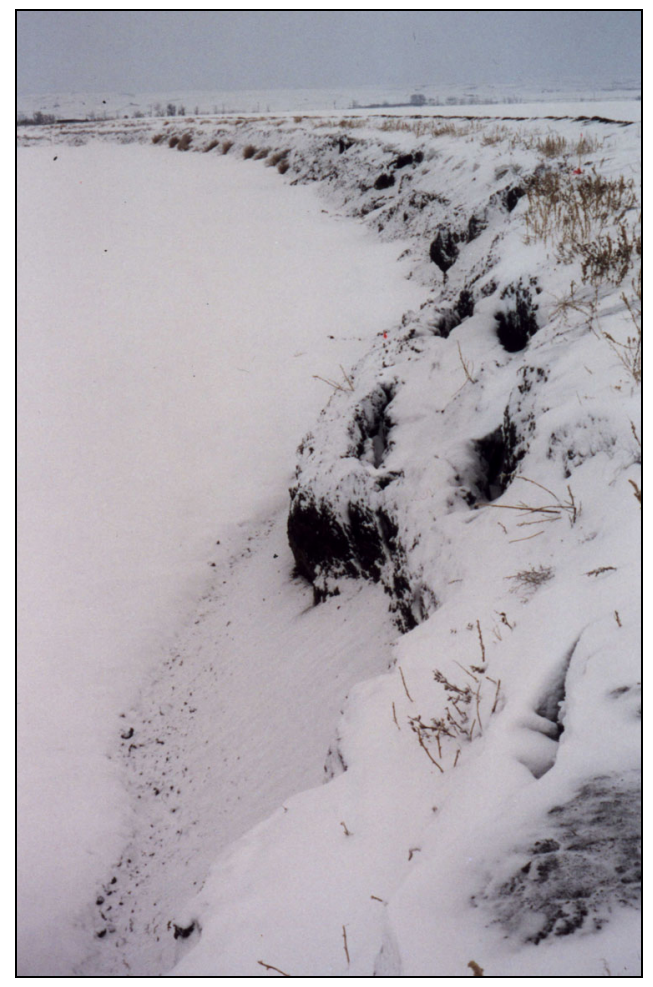

c. 21 February 1999 (looking at the north bank with the flow from top to bottom).

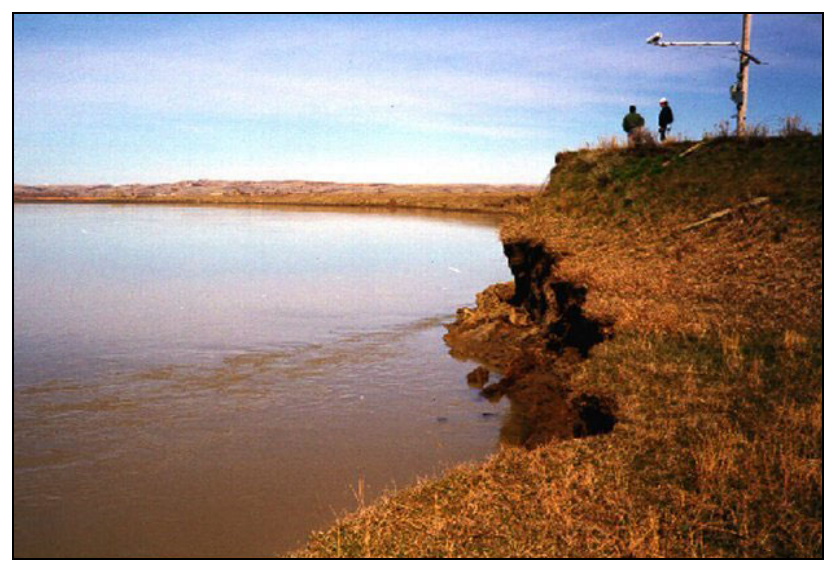

d. 4 April 1999 (view from the north bank with the flow from top to bottom).

Figure 55 (cont.). 


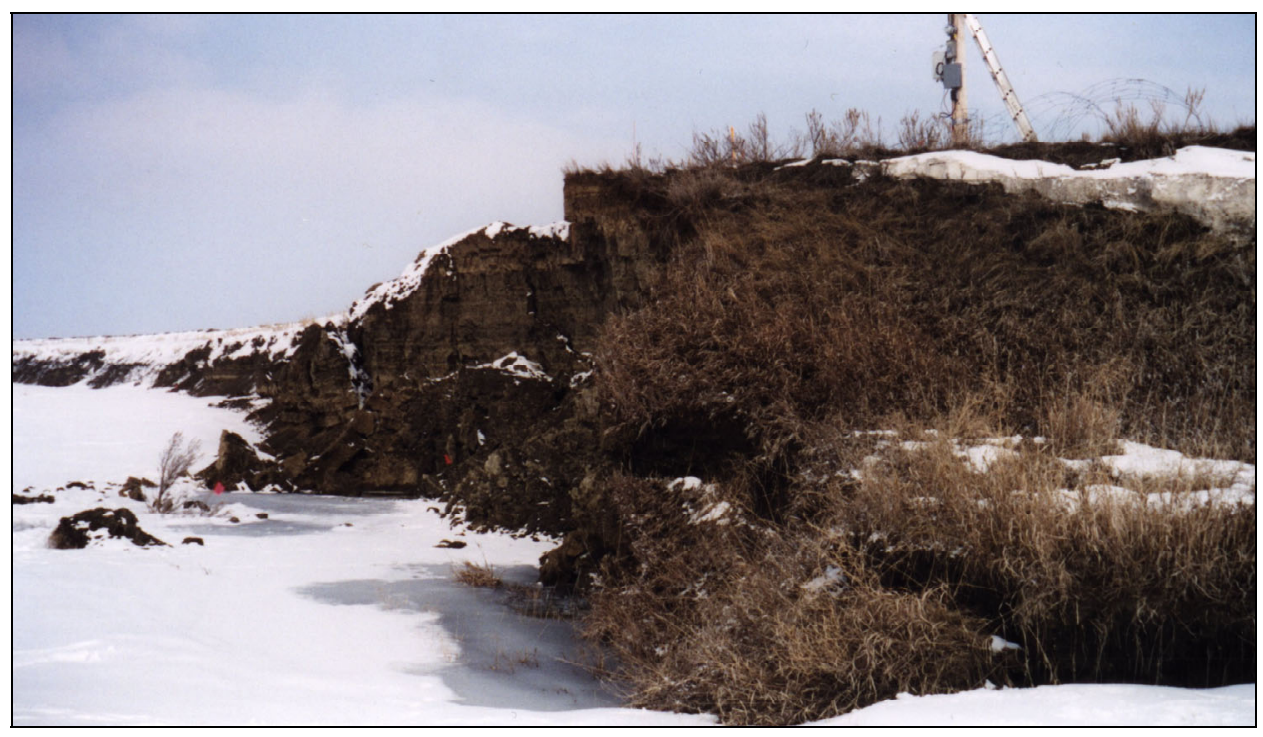

Figure 56. Collapsing north bank at RM 1623.

The observations from the Tveit-Johnson site dramatically showed how bank erosion can occur during winter conditions on flow-regulated rivers, as well as immediately after ice cover breakup. The combined hydraulic and geomechanical effects caused the bank, at the apex of the channel loop, to erode about $30 \mathrm{ft}$ during the monitoring period. The rate of bank erosion was such that the pole supporting the video camera had to be moved landward two times during the survey. Figure 57 illustrates the changes in bank alignment that occurred following breakup on March 17 to March 30. This severe bank erosion has been animated by assembling video images from the web camera at the site.

Bed profile measurements and elevation contour plots reveal that the thalweg deepened at the bank toe, reducing bank stability. Observations of bankfast ice indicated some of the stressing exerted by bankfast ice in response to changes in flow stage. Especially noticeable was a horizontal crack formed in the bank immediately above the bankfast ice (Fig. 58a). How the crack formed is not yet understood, but the separation resulted in the collapse of the bank (Fig. 58b).

\section{Ice cover thickness}

By the time of the January survey, the ice cover varied from about 16 to 24 in. thick over most of the site. It thickened further over the next month but not uniformly over the site. By February the greater part of the ice cover thickened to about 20-28 in. A central portion of the cover, however, thickened to almost 39 in. Since the location of the greatest ice thickness in February coincided with a 


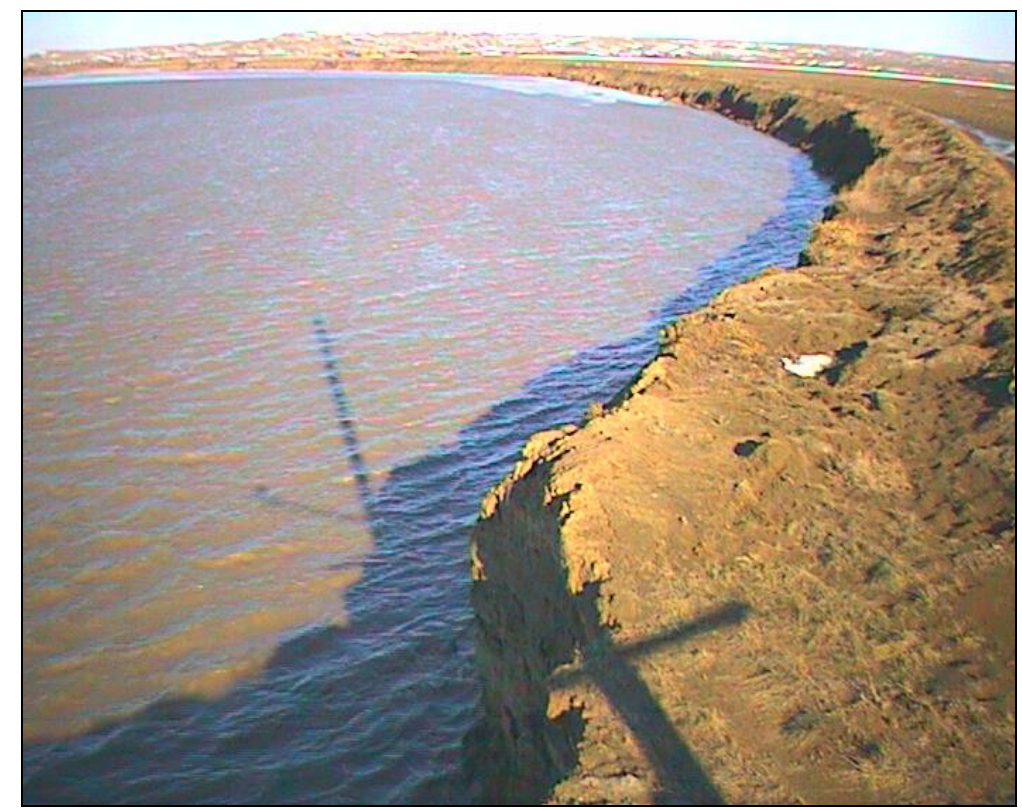

a. March 17, immediately following ice out (March 16).

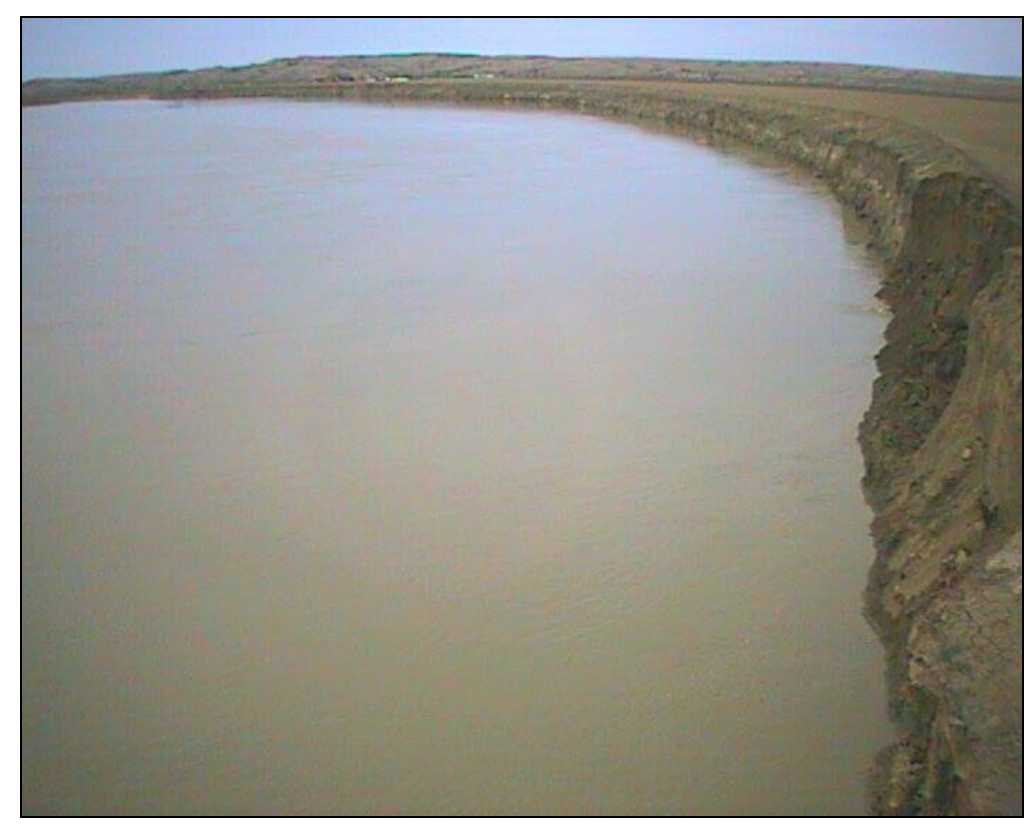

b. March 30, prior to relocating the camera pole.

Figure 57. Change in the north bank position following breakup. 


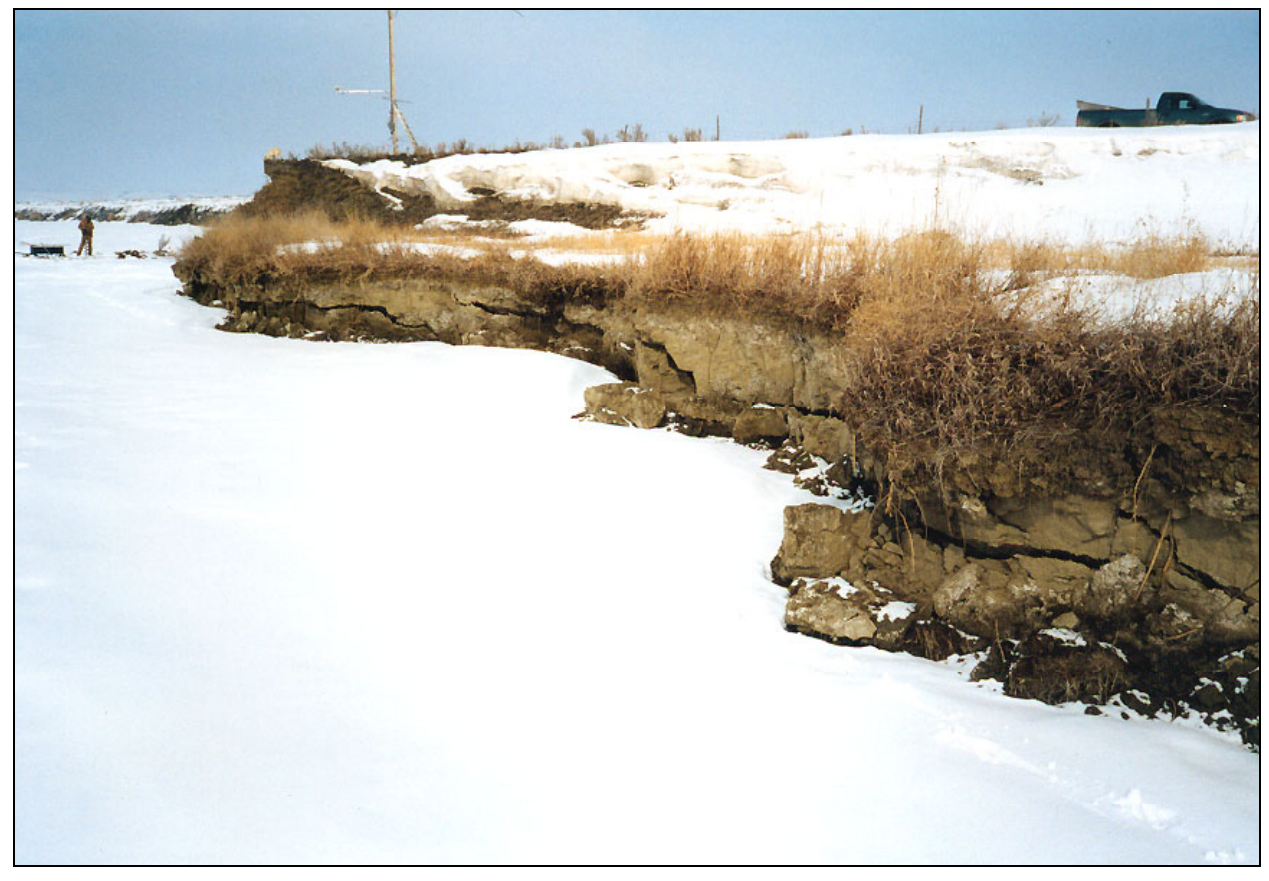

a. 26 January 1999.

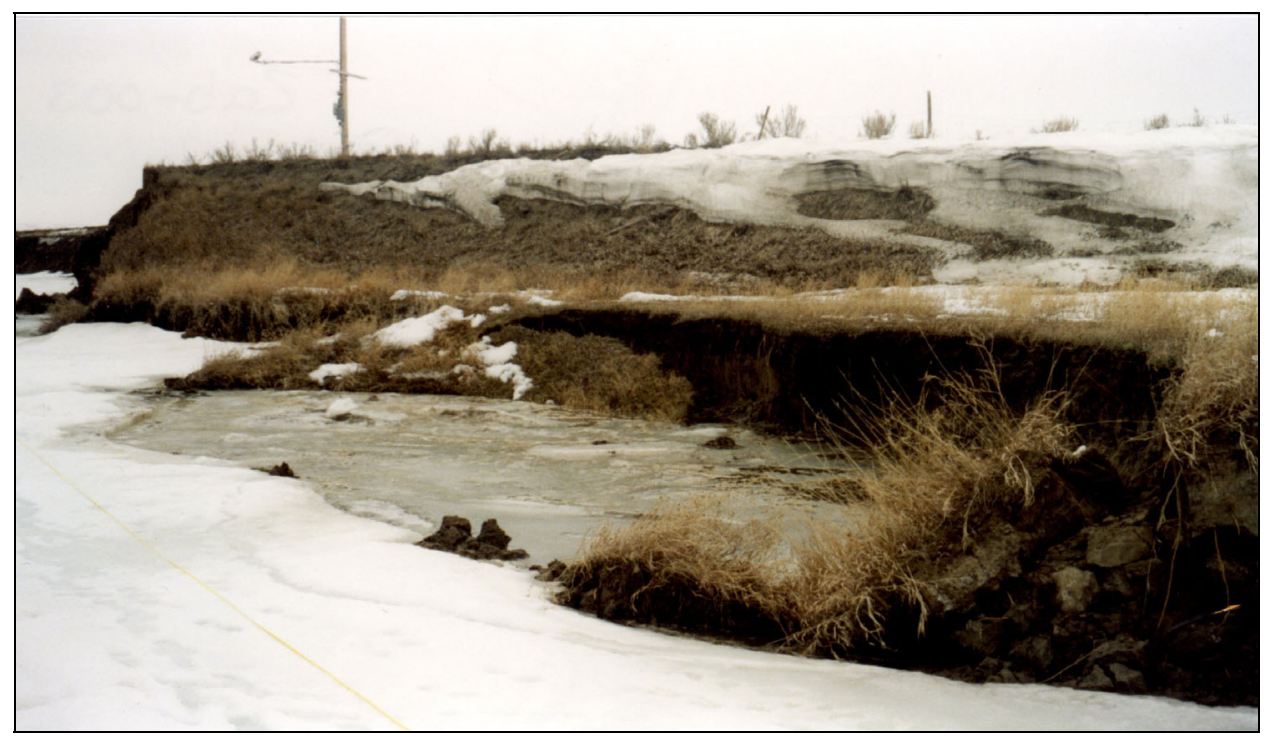

b. 22 February 1999.

Figure 58. Crack and ultimate riverbank failure above bankfast ice, RM 16231624, Tveit-Johnson site. 
location of thinner ice in January, it is likely that the greater thickening is attributable to under-cover accumulation of broken or frazil ice conveyed to the site. The frazil ice may have formed in open water areas upstream.

At several places along the bank between cross sections in the site, the ice cover was relatively thin, sometimes only a few inches thick where the ice cover had refrozen after sections of collapsed bank had broken through it.

The last image from the web camera on March 16 shows that the ice cover was intact but that water was beginning to ooze over the ice cover. The following morning the ice was gone (Fig. 57a).

\section{Bed profiles}

The bed profiles reveal that the bed lowered substantially along the thalweg when the site was ice-covered. The thalweg dropped about 5-6 ft in elevation between the October and the winter surveys, as is shown in Figure 59 for the cross section at RM 1623.97. Except for the downstream cross section (RM 1623.97), the bed elevation along the river's thalweg did not recover significantly after the ice cover broke up. The thalweg remained entrenched at those cross sections because of the downstream migration in the apex of the loop in the river. The migration would alter the approach alignment of the thalweg so that the flow continued to maintain the lowered bed level. At the downstream cross section, the thalweg bed elevation recovered almost to the prewinter elevation, but the thalweg widened. The recovery is likely attributable to the recent collapse of the

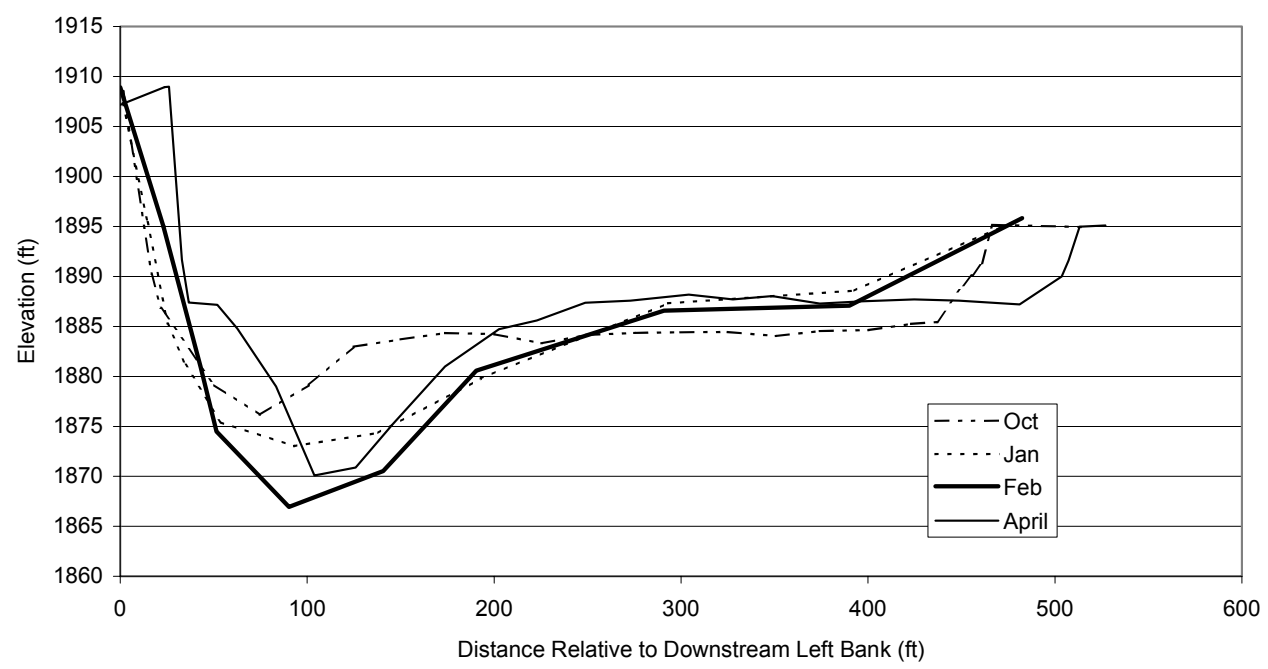

Figure 59. Bed profile cross sections at RM 1623.97. 
north bank along the site. With further flow the deposited sediment may eventually erode until the thalweg is lowered to the elevations reached during winter.

Away from the thalweg, the bed along the river's south side rose, typically by about $2-3 \mathrm{ft}$. This was likely caused by sediment deposition resulting from the reduced flow velocities through that portion of the river. The bed seems not to have eroded back to a lower elevation once the ice cover had broken up.

\section{Flow velocity}

A velocity profile about the middle of the channel at ice station $2+00$ with respect to the north bank is shown in Figure 60. The winter stations were repeatable in location, and the open water measurements were within a $15-\mathrm{ft}$ radius. But because they were not at precisely the same location, the open water measurements could have skewed the plot because of the dramatic changes of the bed elevation in the area.

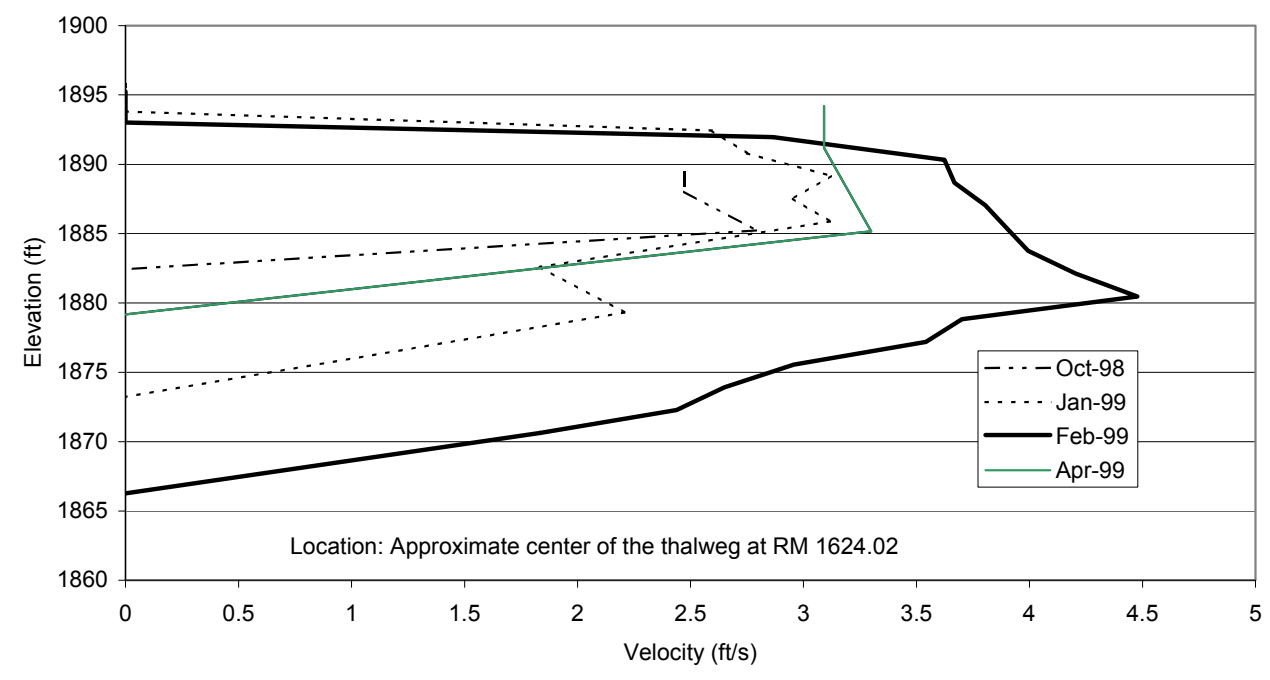

Figure 60. Velocity distributions at approximately mid-channel at RM 1624.02.

\section{Comments}

Of all the sites monitored, this site had by far the largest extent of channel shifting and bank erosion during, and immediately subsequent to, ice cover formation.

An interesting feature of riverbank behavior observed at this site was the gradual tilting of the face of the site's concave bank. As winter progressed, cracks along the bank top widened, and strips appeared to peel slowly from the 


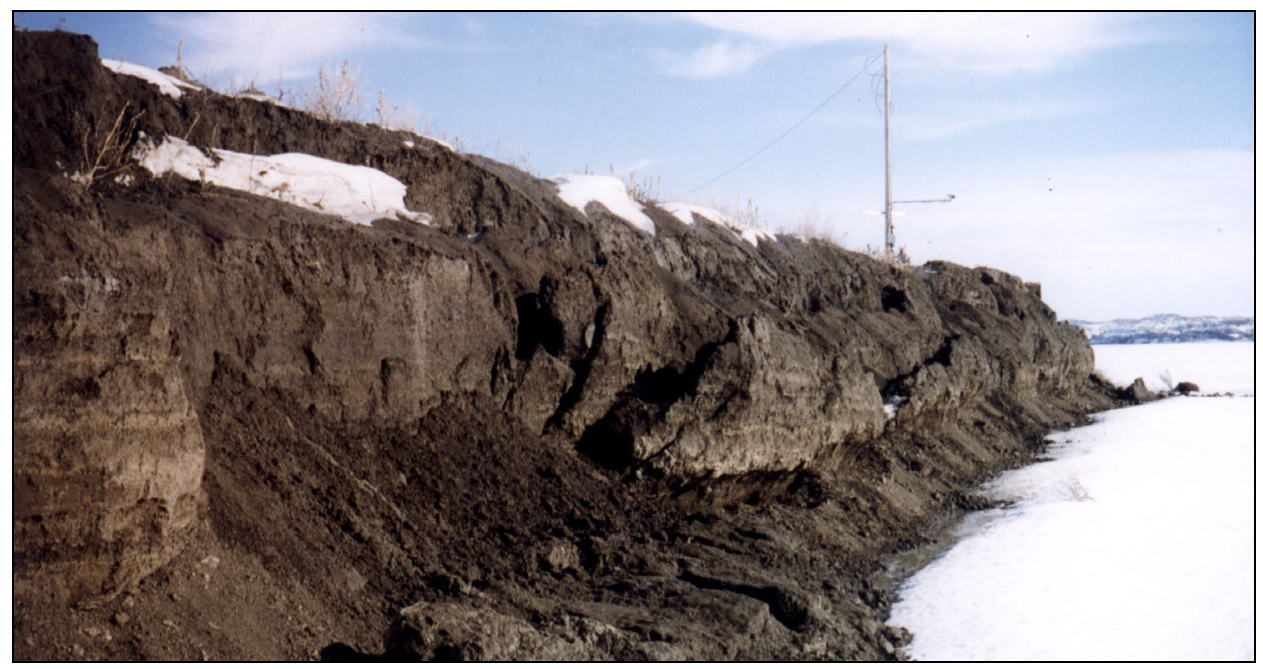

Figure 61. North riverbank gradually tilting and failing, RM 1623, 21 February 1999.

riverbank, overhanging the ice cover, as depicted in Figure 61. The cause of this deformation is unclear, but it may be a consequence of freeze-thaw action on the riverbank soil.

\section{Vournas site, RM 1631-1632}

The findings from this site are representative of ice formation impacts on a curved alluvial channel comprising a dominant single thalweg aligned along a steep outer bank, such as illustrated in Figure 20. The river has a much smaller subchannel along its inner bank. It was evident that river ice exerted pronounced hydraulic and geomechanical influences on the river channel at this site.

\section{Observations}

The two most evident influences of river ice at the survey cross sections of this site were the lowering of the riverbed along the outer bank and the development of a horizontal crack in the bank soil at the top of the bankfast ice. Both these influences were observed also at the Tveit-Johnson site.

Figure 62 shows the Vournas site before ice cover formation, following freeze-up, during ice cover formation, and shortly after breakup. Note how ice cover formation raised the flow stage through the site. The outer bank did not collapse while the ice cover was in place, at least not extensively. However, the bed profiles suggest that a localized bank failure may have occurred under the ice cover at the cross section at RM 1632.68. 


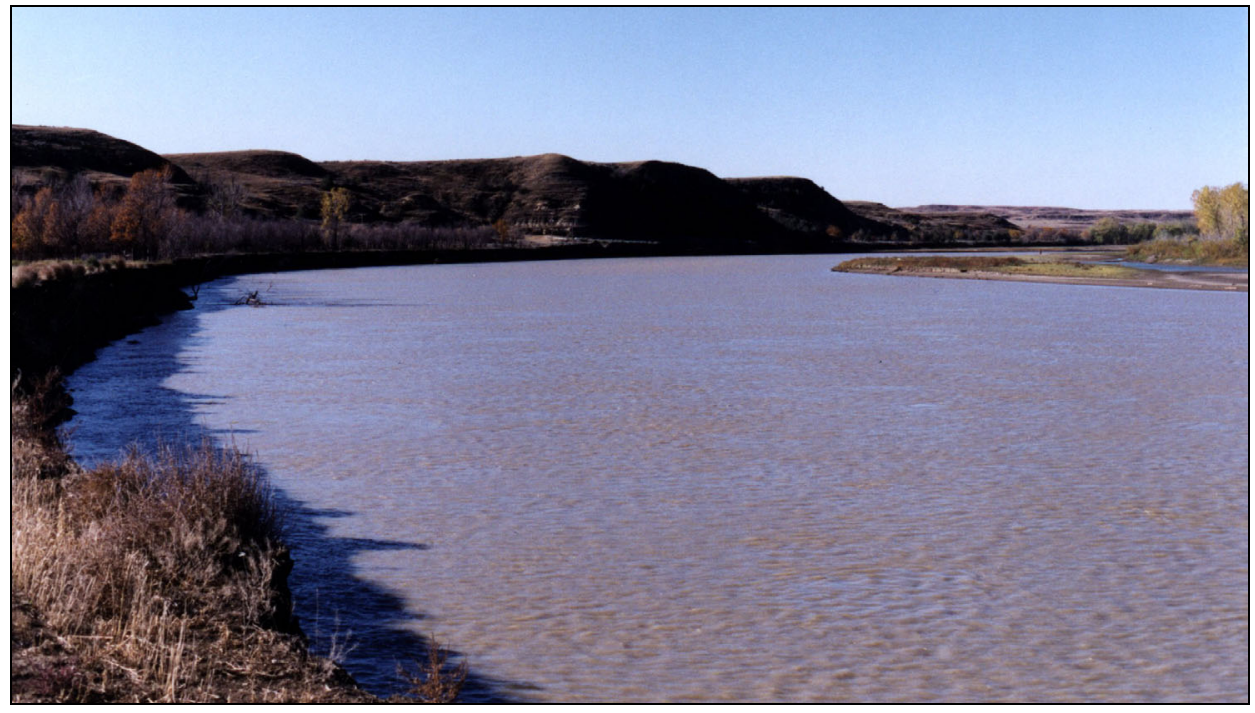

\section{a. 14 October 1998 (view from the south bank with the flow from top to bottom).}

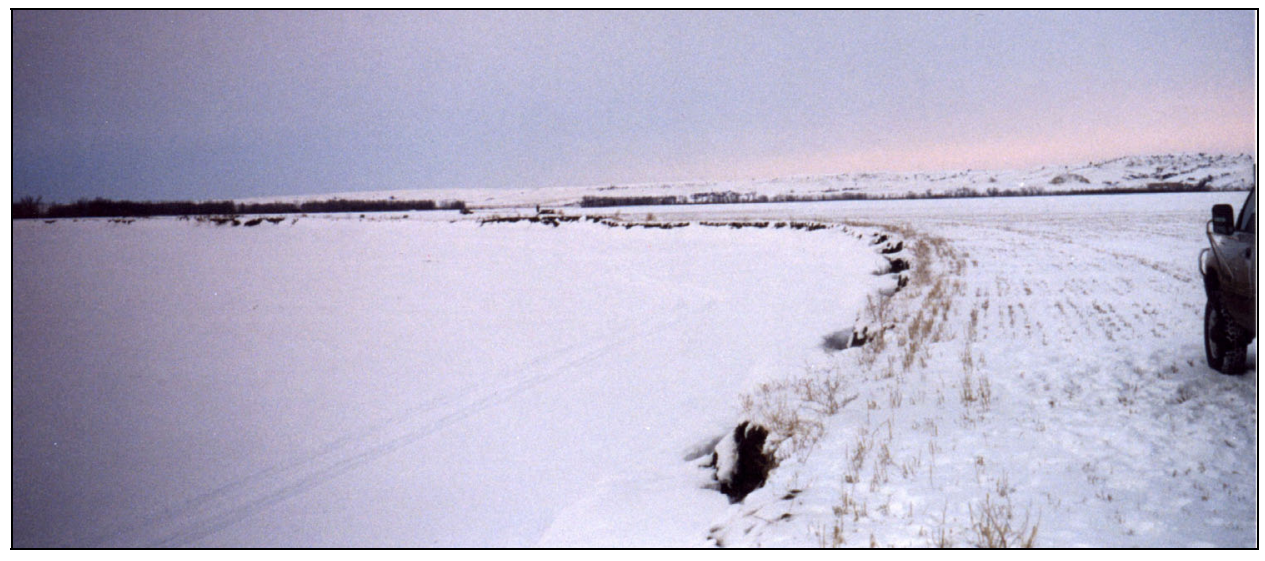

b. 26 January 1999 (view from the south bank with the flow from bottom to top).

Figure 62. Vournas site (RM 1631-1632) during the survey.

Cracks immediately above the bankfast ice were evident at locations where the bank was nearly vertical (e.g., at the cross section at RM 1632.55). Figure 63 shows the crack, which is essentially identical to the crack observed at the TveitJohnson site (Fig. 58). The view shown in Figure 63 is of a section of riverbank immediately below the trees in the foreground of Figure 62c. It appears that the bankfast ice was cantilevered from the channel's outer bank, pulling the crack 


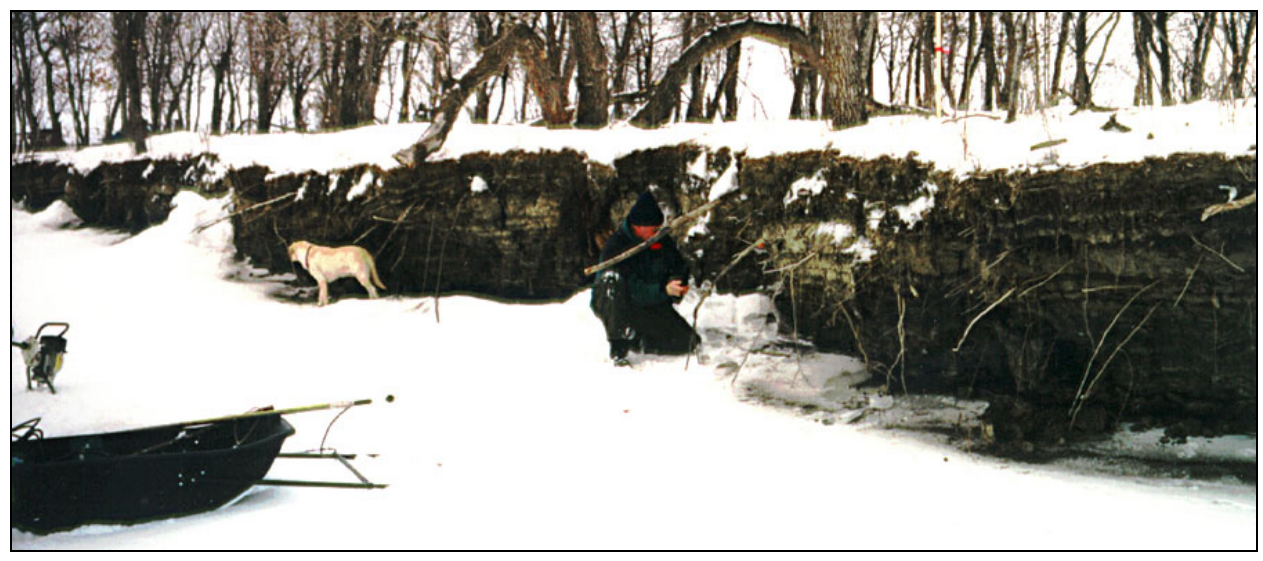

c. 23 February 1999 (view of the south bank from the ice with the flow from bottom right to top left).

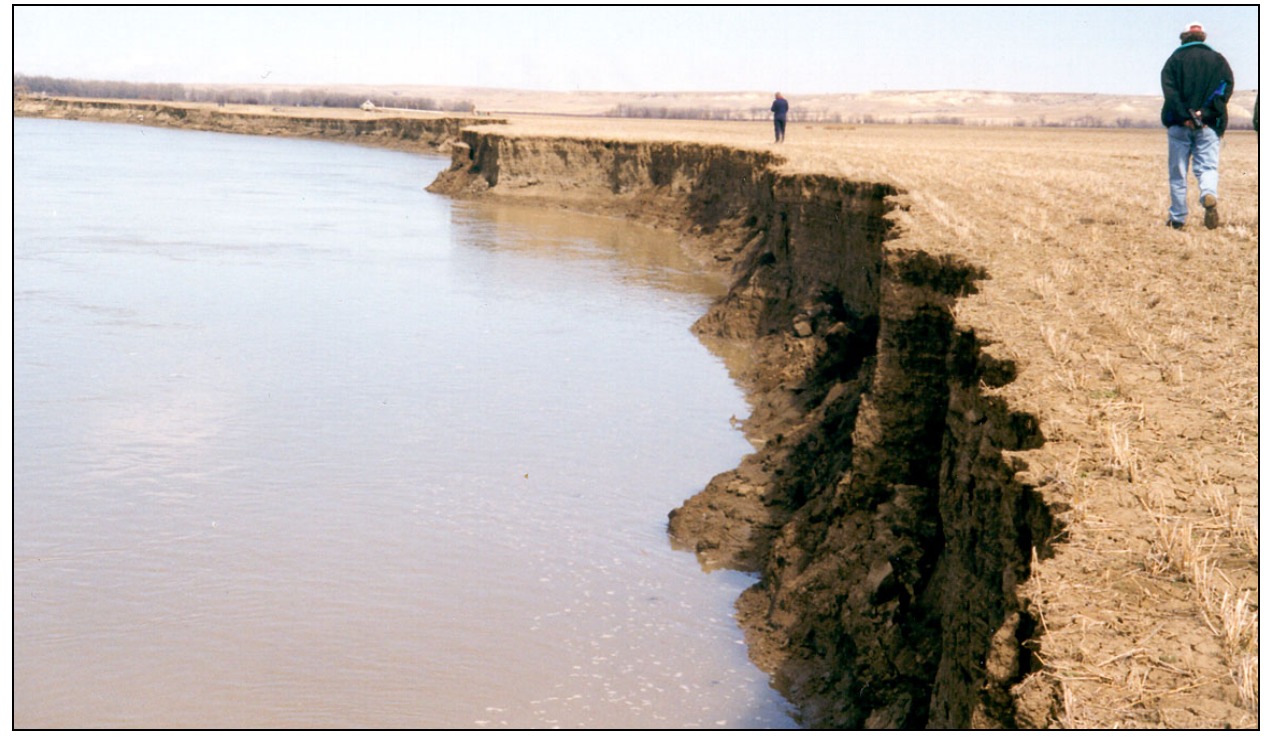

d. 4 April 1999 (view from the south bank with the flow from bottom to top).

Figure 62 (cont.).

open. It also is possible that flow may have undercut the bank and caused the crack. Ice cover formation did concentrate the flow along the outer bank of the bend and locally lower the bed elevation along the thalweg along the outer bank by about $3 \mathrm{ft}$, as indicated in the bed profiles. However, no direct evidence is available for this. The vertical rotation of the bankfast ice weakened the bank by developing a crack slightly above the ice line. 


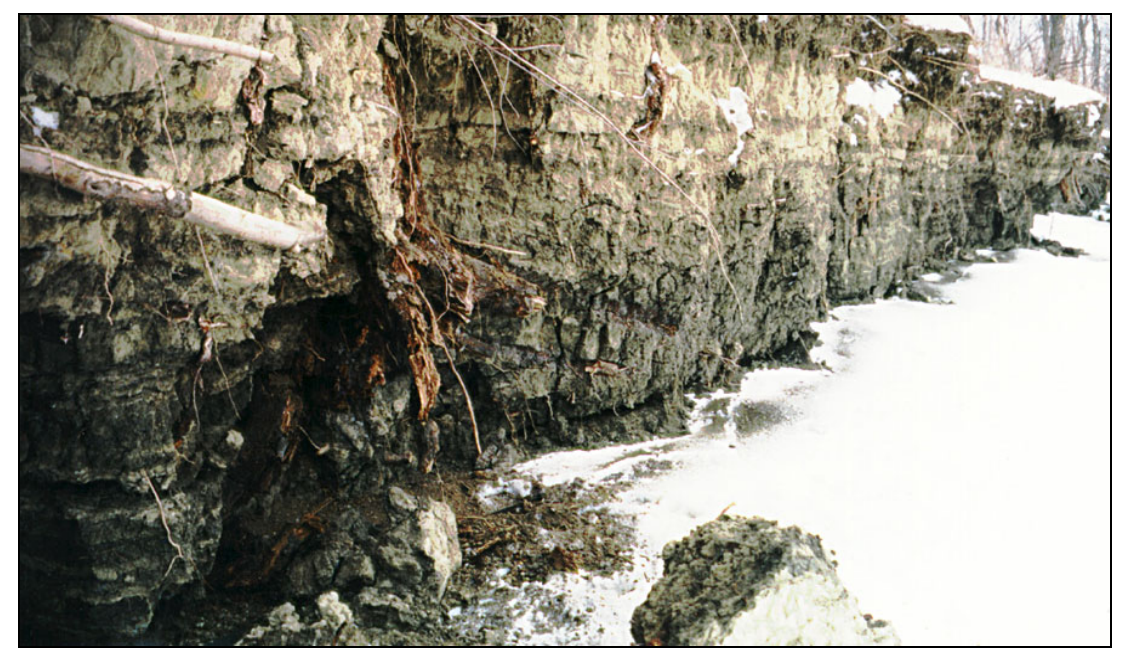

Figure 63. Crack development in the south riverbank at RM 1632.55.

The major instance of bank failure at the site occurred immediately after the ice cover broke up and was flushed from the site. As the flow elevation dropped, the combined effects of bed scour at the bank toe and weakening of the bank material caused the bank to recede about $3 \mathrm{ft}$ on average. As can be seen in Figure $62 \mathrm{~d}$, once the ice cover had departed, the riverbend had migrated farther downstream, so the flow impinged at an awkward angle against the bank.

\section{Ice cover thickness}

The ice cover formation progressed upstream through the site on December 21. As at the other sites, the cover was not uniformly thick but tended to be thinner where the flow velocity was greater. By the time of the January survey, the cover was 15-22 in. thick over most of the site, though only about $15 \mathrm{in}$. thick along the thalweg. At the upstream cross section, the cover was as little as 4 in. thick along the thalweg, indicating fairly recent closure. The greatest thickness of ice (28-32 in.) occurred in the middle of the site, perhaps reflecting an accumulation of frazil ice. By the time of the February survey, the cover thickness had become more uniform at about 20-23 in. A narrow band of thicker ice had developed along the outer bank of the bend at the upstream cross section (RM 1632.68).

\section{Bed profiles}

The main change evident in the bed profiles is a lowering of the bed along the toe of the outer bank of the riverbend. Figure 64 shows the bed profile changes along cross section at RM 1632.55, where the bed lowered about $3 \mathrm{ft}$ at 


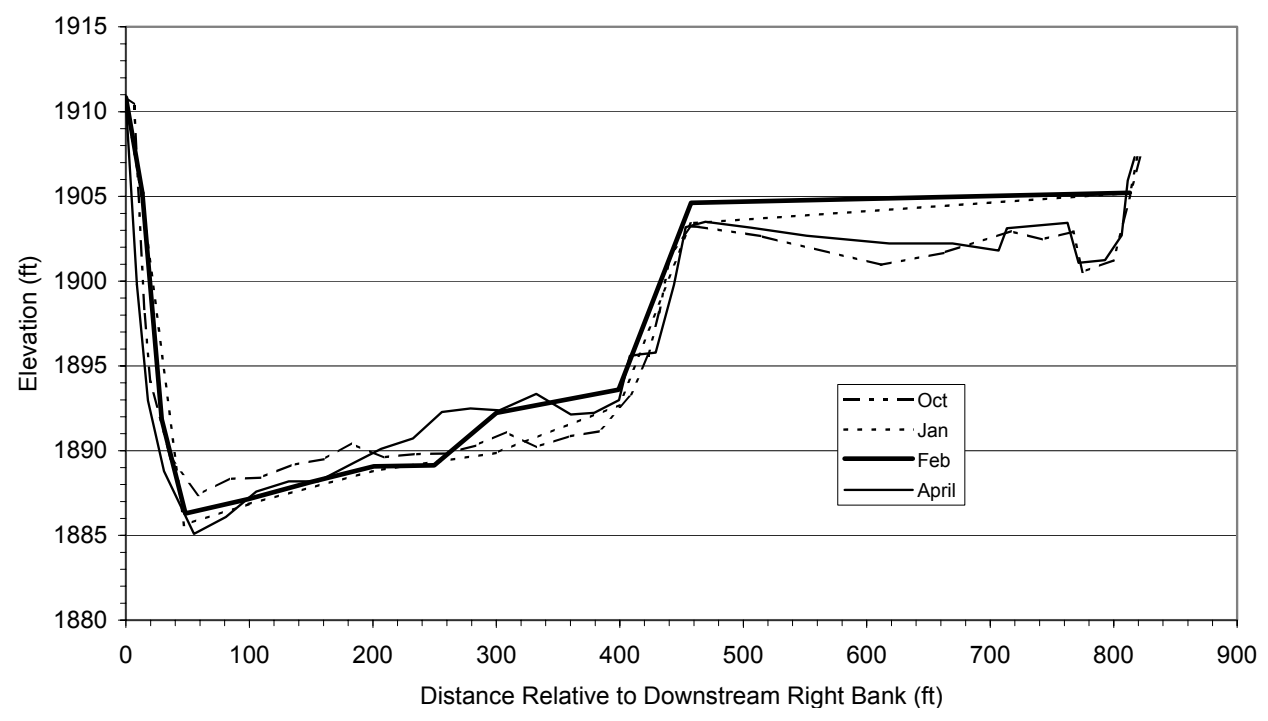

Figure 64. Bed profile cross sections at RM 1632.55.

the bank toe. The same lowering of bed elevation was measured at the other two cross sections, and all remained lowered once the ice cover had left the site.

The bed elevation along the river's inner bank altered during the survey. It apparently rose in elevation about $3 \mathrm{ft}$ at the three cross sections, then lowered during the winter. The cause is unclear, but it may be attributable to local shifts in the smaller subchannel along the site's inner bank.

\section{Flow velocities}

Figure 65 is a velocity profile from about the middle of the downstream cross section (RM 1632.55 station 2+00). Open water measurements were not taken during the survey in April.

\section{Comments}

The findings at this site concur with those observed at the Tveit-Johnson site in revealing the potentially severe combined hydraulic and geomechanical influences on the channel exerted by river ice. The combined influences led to bank collapse and the removal of collapsed bank material. The cracks observed in the bank at the connection of bankfast ice with the bank reflect both the influences and the need for further investigation. 


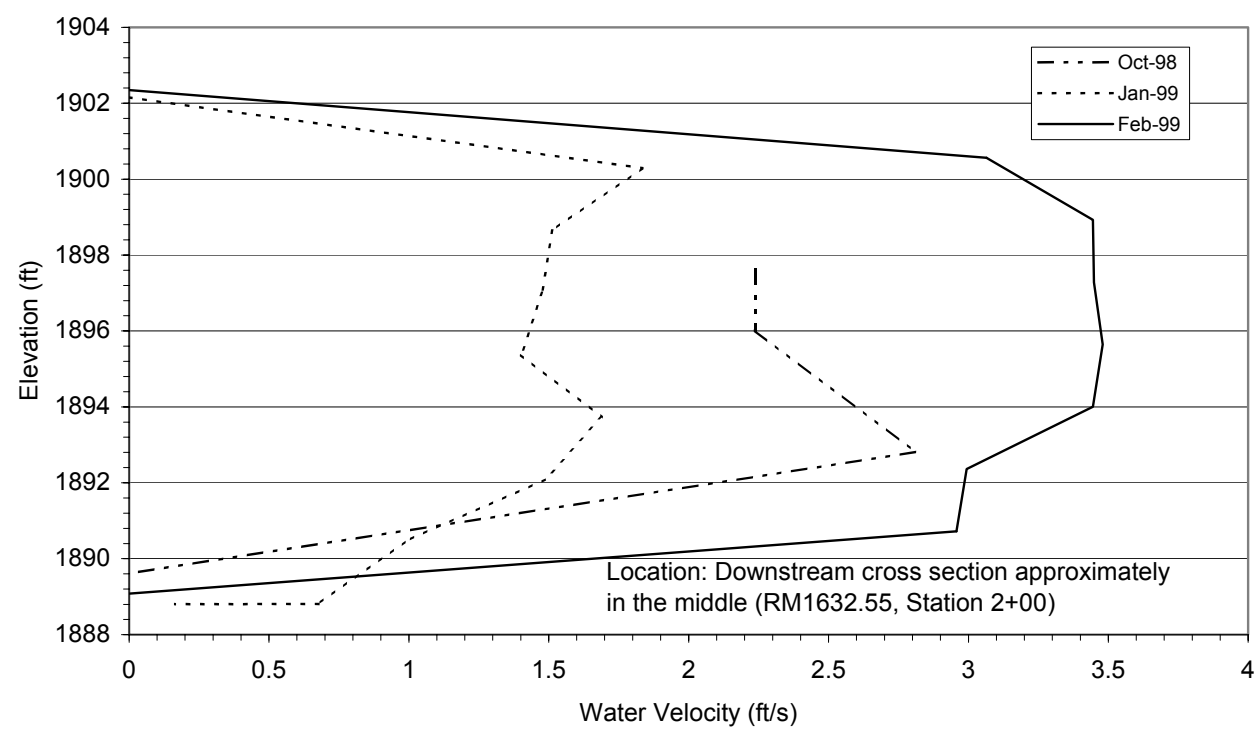

Figure 65. Velocity distributions about mid-channel downstream at cross section RM 1632.55 at approximately $200 \mathrm{ft}$ from the right bank.

\section{Mattelin site, RM 1645-1646}

The morphologic complexities of this site, in which the river flows through potentially three subchannels, appear to make the site especially sensitive to ice cover formation. The complexities also complicate interpretation of river ice influences because they make the site's response to ice formation dynamic and thereby difficult to monitor.

\section{Observations}

The main influences of river ice at this site are essentially the same as those observed at the Culbertson site; i.e., the way that an ice cover progresses upstream through the site substantially determines which of the site's several subchannels enlarges during winter and becomes the main thalweg. The Mattelin site, though, seems to be more dynamic than the Culbertson site, in that changes in subchannel size, bed elevation, and main thalweg alignment evidently happened quicker at the Mattelin site.

Figure 66 shows the Mattelin site before ice cover formation, following freeze-up, during ice cover formation, and shortly after breakup. It also shows how ice cover formation raised the flow stage through the site. Although cover progression through the site was not viewed directly (there was no video camera at this site), views of the site before, during, and after it became ice covered help 


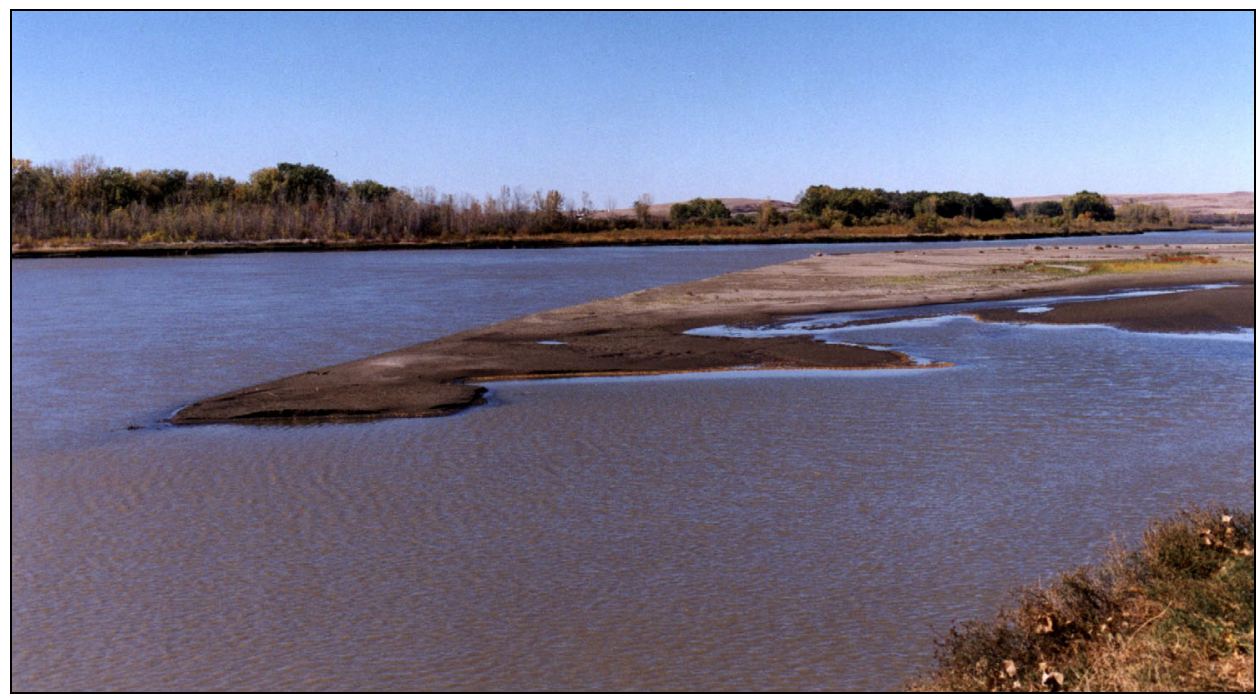

a. 14 October 1998 (view from the north bank with the flow from right to left).

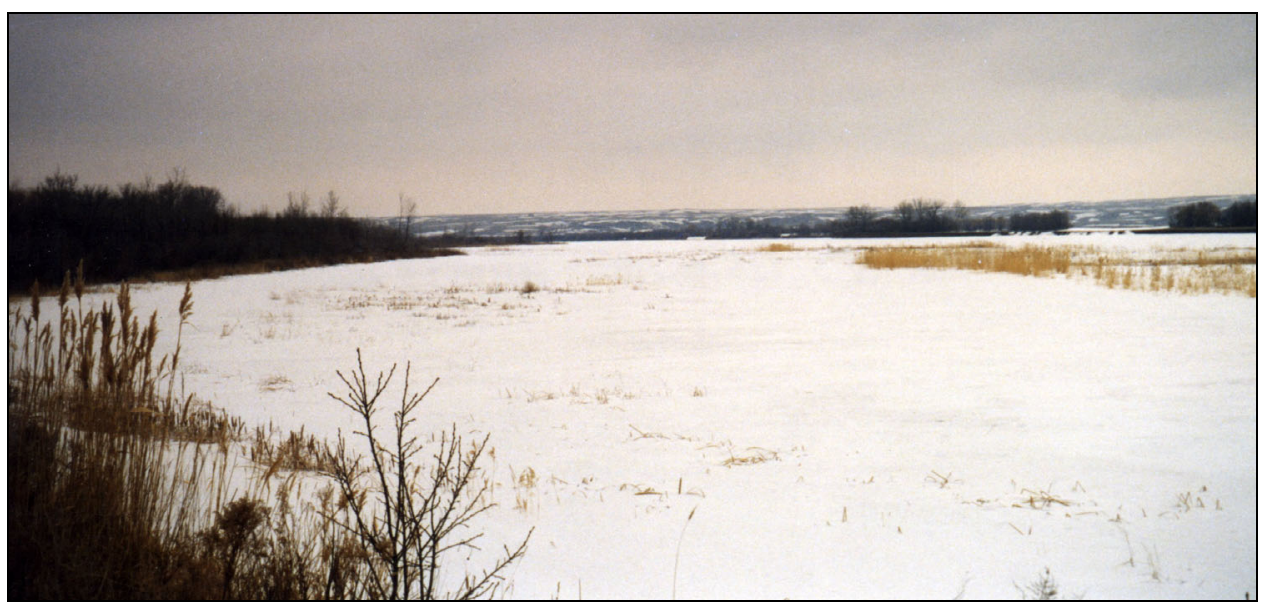

b. 26 January 1999 (view of the south bank with the flow from top to bottom).

Figure 66. Mattelin site (RM 1645-1647) during the survey.

illustrate the changes that occurred in subchannel size and alignment. The size of the extended and expanded south subchannel is especially evident from Figures $66 \mathrm{~b}$ and $\mathrm{c}$ from approximately the same location.

As explained in the site descriptions, the bulk of the river flow enters the site close to the site's south bank. The flow then crosses the site through three subchannels, exiting the site via two subchannels, the larger of which flows along 


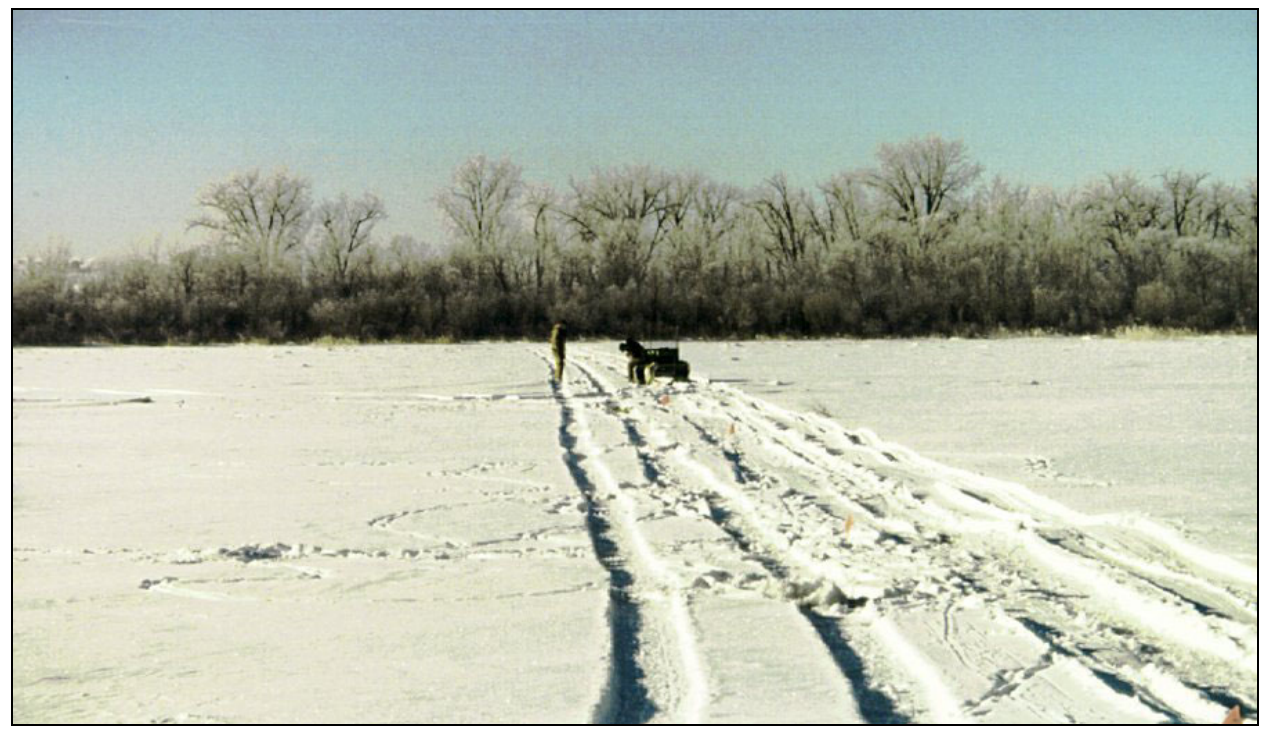

c. 23 February 1999 (view across the upstream survey alignment with the flow from right to left).

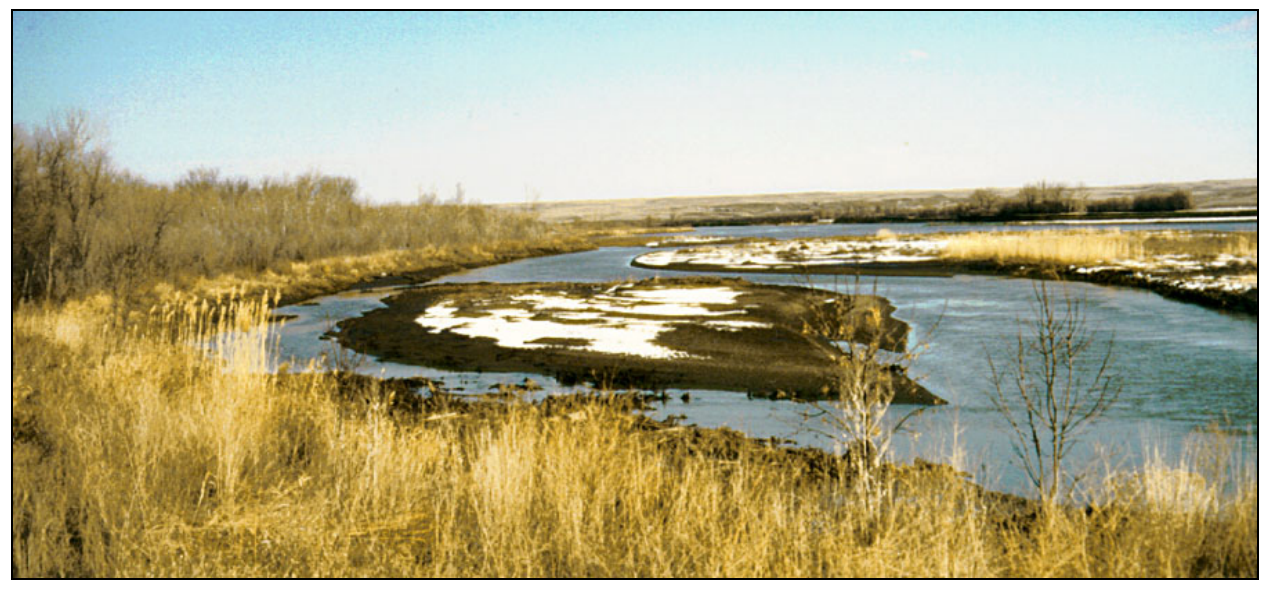

\section{d. 4 April 1999 (view of the south bank with the flow from top to bottom).}

Figure 66 (cont.). Mattelin site (RM 1645-1647) during the survey.

the southern half of the river, whereas a deeper, narrower flow passes along the north bank. When the ice cover progressed up through the site on 21 December, the ice cover first enveloped and virtually plugged the northernmost subchannel at the site's downstream end. Subsequently, as the cover progressed upstream, it occupied the middle subchannel. Eventually the southernmost subchannel, the deepest subchannel at the site's upstream end, became ice covered. The ice cover 
progression through the site affected the flow resistance through the subchannels, with the principal result that flow in the southernmost subchannel at the site's upstream end became directed farther along the south bank.

During its initial formation the ice cover froze to the low-lying bars in the middle of the site. As the flow stage increased at the site in response to increased flow release from Fort Peck Reservoir and increased flow resistance resulting from thickening of a fixed ice cover, the ice cover cracked around the bars, floated above the bars, then refroze over the bars. This change in ice cover elevation further altered the flow distribution through the site.

Ice cover thickness

The ice cover progressed upstream through the site during 20 and 21 December. It first covered the north subchannel, then eventually covered the other subchannels. By the time of the January survey, the ice cover varied in thickness from about 12 to 23 in. It was thickest (about 20-23 in.) over the north subchannel between the cross sections at RM 1646.72 and RM 1678. The cover was thinnest in the wake of a medial bar at the upstream cross section. The cover thickened between January and February, reaching about 20-24 in. thick over most of the site and 24-28 in. thick along the downstream cross section.

\section{Bed profiles}

The riverbed through the site actively adjusted up and down in elevation at each of the cross sections surveyed. However, the bed profiles taken together reveal only a disjointed image of the changes in subchannel size and alignment and inadequately reflect the dynamic nature of bed responses to cover formation and changes in flow rate. The bed profiles at RM 1646.78 (Fig. 67) show a variety of elevation changes, which, considered at any vertical transect, quickly become complex. Perhaps the changes are best interpreted as evidence of the significant amounts of bed sediment moved by flow under the ice cover.

The cross sections at RM 1646.84 were taken once the ice cover had formed at the site. It was decided that an intermediate cross section was needed to track the south subchannel. Measurements at RM 1648.84 revealed that the south subchannel had indeed enlarged subsequent to ice cover formation through the site. When the cover was present and immediately following breakup, the thalweg bed elevation dropped about $5 \mathrm{ft}$. 


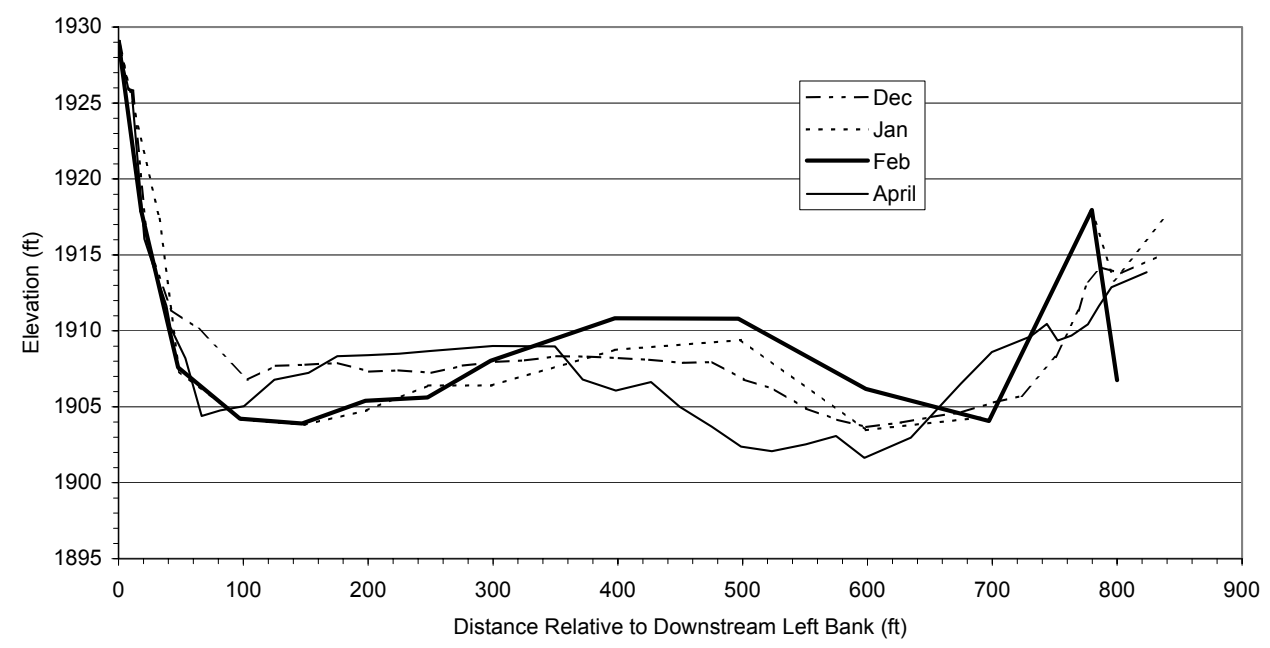

Figure 67. Bed profile cross sections at RM 1646.9.

\section{Flow velocities}

Variations in the velocity profile approximately midchannel of the upstream cross section are shown in Figure 68 (RM 1649.90 station 5+00). Velocity measurements were not taken during the open water survey in April.

\section{Comments}

The survey revealed important glimpses into the dynamic nature of ice cover interaction with the multiple subchannels of a sinuous-braided channel. However, this site also revealed the considerable extent to which ice cover effects on channel stability are inadequately understood.

The survey was only partially successful in detecting the ways in which river ice influences channel stability at the Mattelin site. As with the Culbertson site the major changes in bed profiles are related to the process by which the ice cover formed and progressed upstream through the site. The dynamic manner in which that process unfolded at the Mattelin site was difficult to monitor by means of intermittent bathymetric surveys of the site; site monitoring inevitably was fragmentary. Though the bed profiles are useful, an alternate approach to monitoring is required. For example, a useful alternative approach may be based on bathymetric surveys of the site before and after ice cover presence and on aerial photographs or video taken of the site as the ice cover forms.

Throughout the winter the exposed and partially vegetated face of the north bank of the site desiccated through freeze-thaw and sublimation, and spalled bank material fell onto the ice cover below (Fig. 69). This desiccation weakened the bank face, making it prone to erosion by ice and water. 


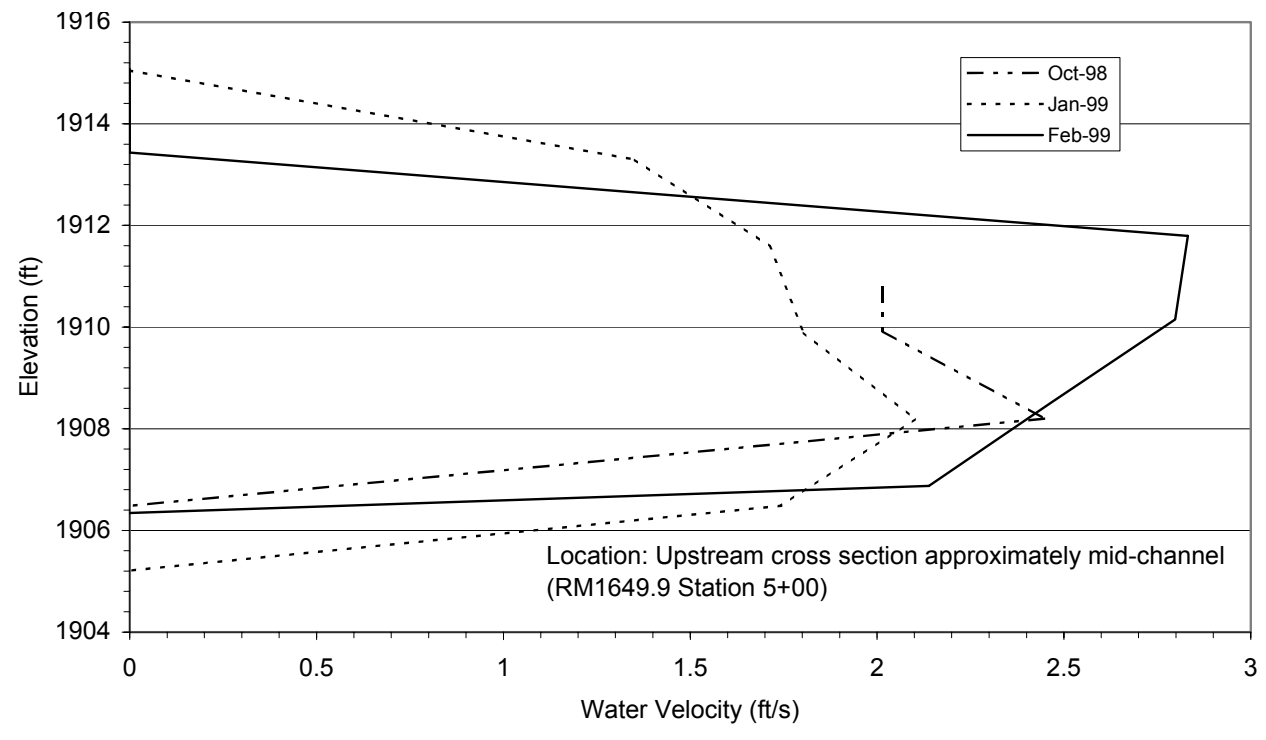

Figure 68. Velocity distributions at RM 1649.9 station 5+00.

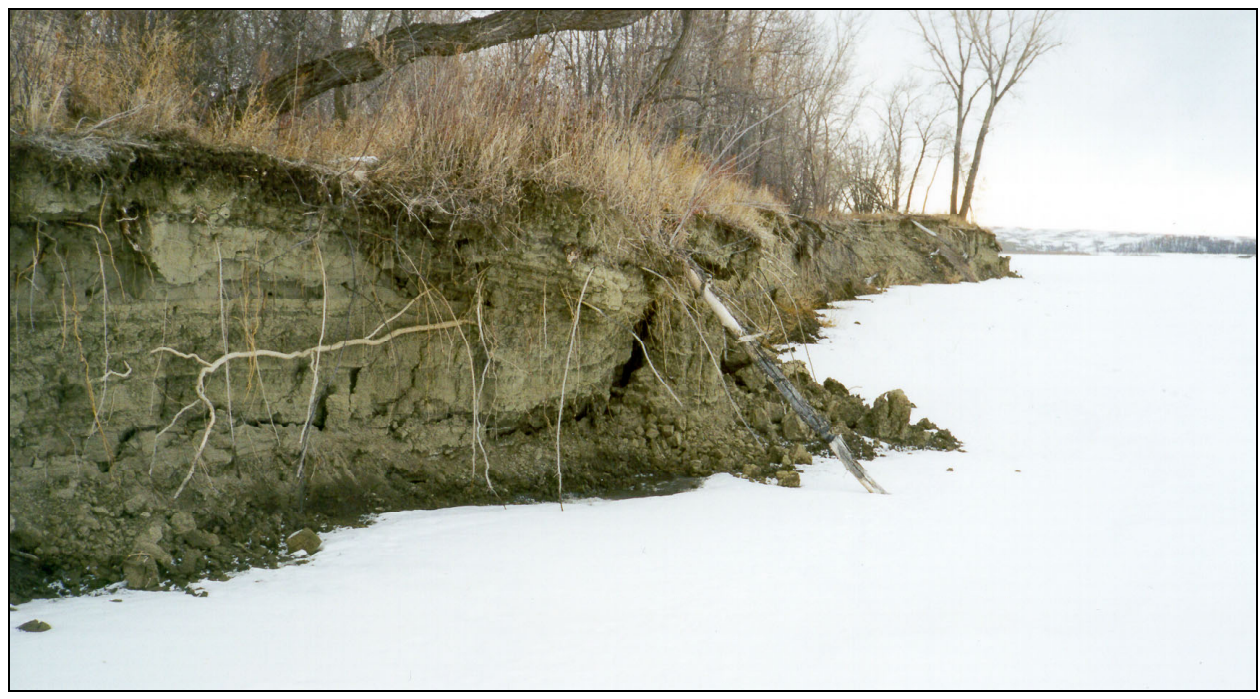

Figure 69. Soil spalling from the face of the north riverbank at RM 1646.

\section{Pipal site, RM 1716-1717}

Only three surveys were conducted at this site because the ice cover broke up before the second winter survey (scheduled for February 21) could be completed. By mid-February the ice cover upstream of about RM 1700 was patchy or nonexistent, partly because of the relatively mild weather during the 1998-99 winter. 
The findings from bed profiling and velocity measurement at this site essentially concur with the findings from the Tveit-Johnson and Vournas sites, both of which also comprised a curved alluvial channel aligned along a steep outer bank. As at those sites, the river ice evidently exerted pronounced hydraulic and geomechanical influences on the river channel at the Pipal site.

This site also provided tentative insights into ice cover effects on the performance of several channel and bank stabilization methods. Those insights are discussed later.

\section{Observations}

The ice cover formed on 21 December, largely as an accumulation of running frazil ice slush and pans. The river flow at the site was about 10,000 cfs, and the air temperature was about $-10^{\circ} \mathrm{C}$. The drifting ice slowed and congested between bankfast ice formed along riverbanks. The slowed ice accumulated at a front that propagated upstream in an irregular manner. The cover eventually did not completely cover the site. As it progressed upstream, it only partially formed around the medial bar at the upstream end of the channel; it did include a small area of the river in the lee of the bar, as Figure 70 shows. That patch of the river remained open throughout the winter. The resultant ice cover over the site was fairly rough.

Figure 71 shows the site before ice cover formation, while the site was ice covered, and after the ice cover broke up. The photos show how the additional flow resistance generated by the ice cover raised the flow stage. They also show the resultant shift in the outer bank and the channel thalweg alignment.

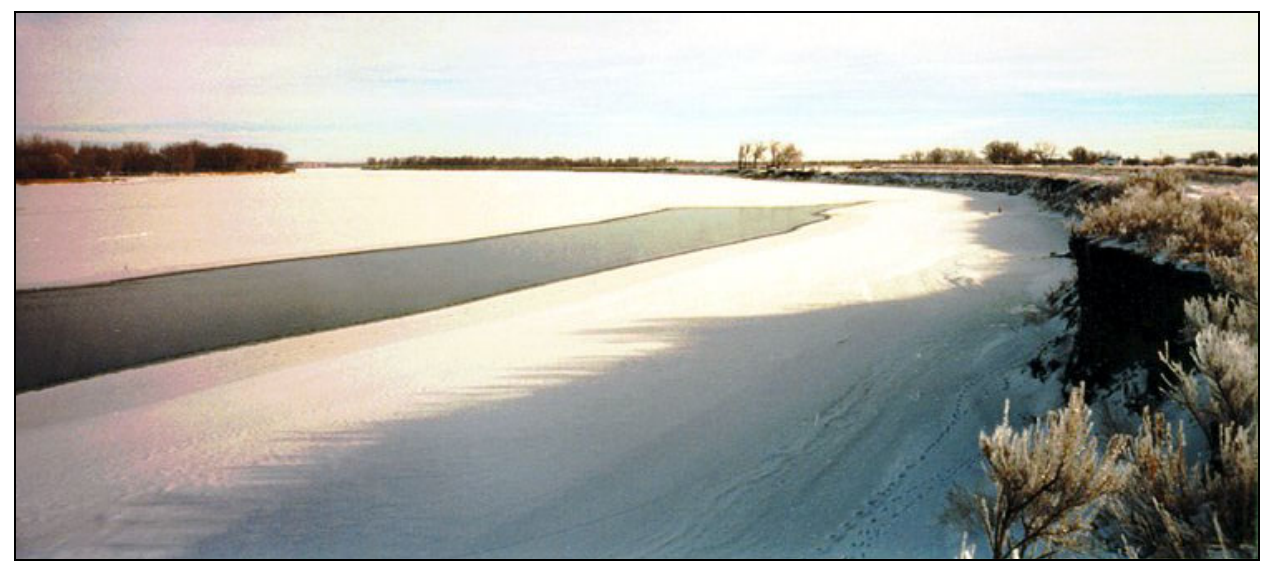

Figure 70. Open water area in the lee of a bar at RM 1716 (view of the south bank with the flow from left to right). 


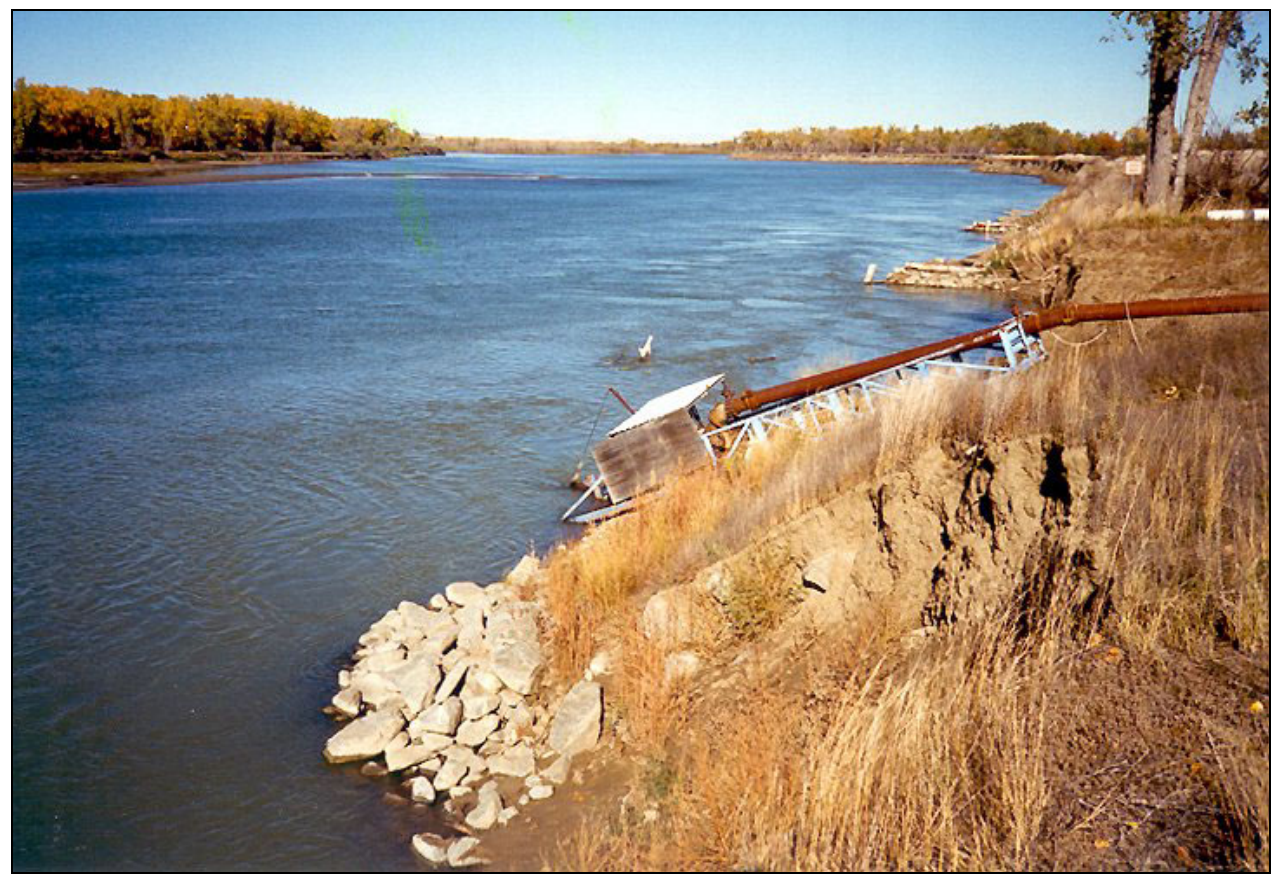

a. 14 October 1998 (view from the south bank with the flow from left to right).

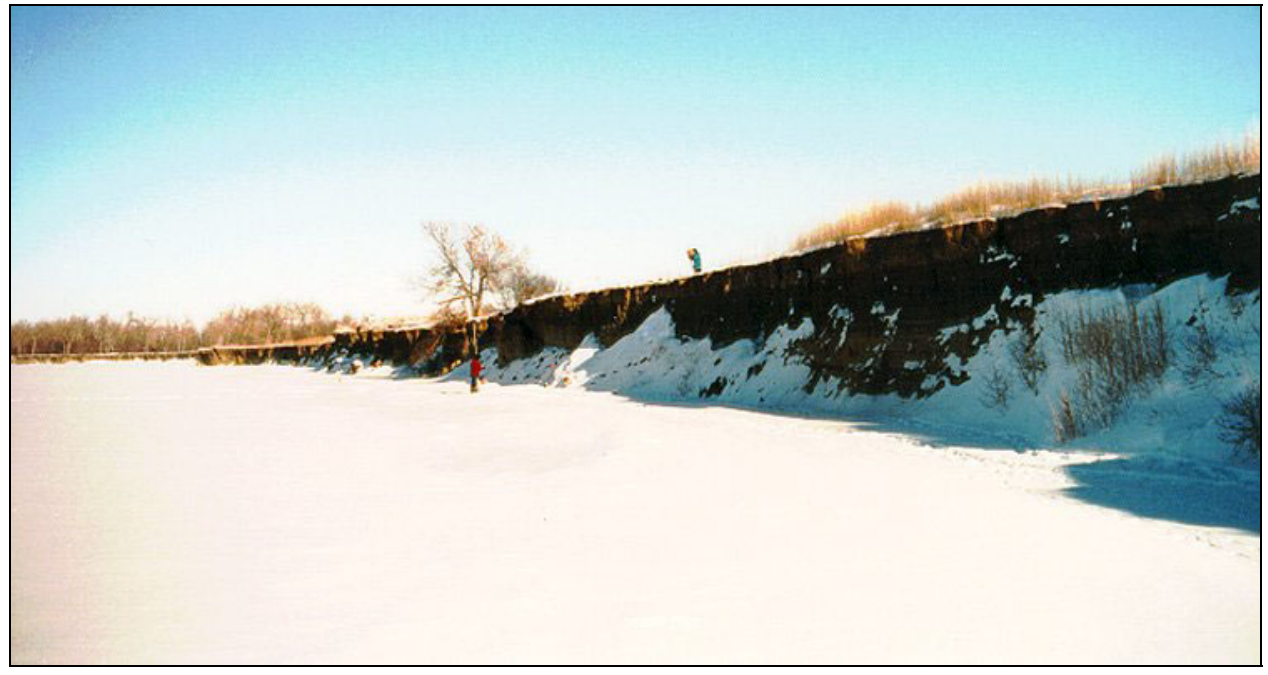

b. 26 January 1999 (view of the south bank from the ice with the flow from lower right to left).

Figure 71. Pipal site (RM 1715-1716) during the survey. 


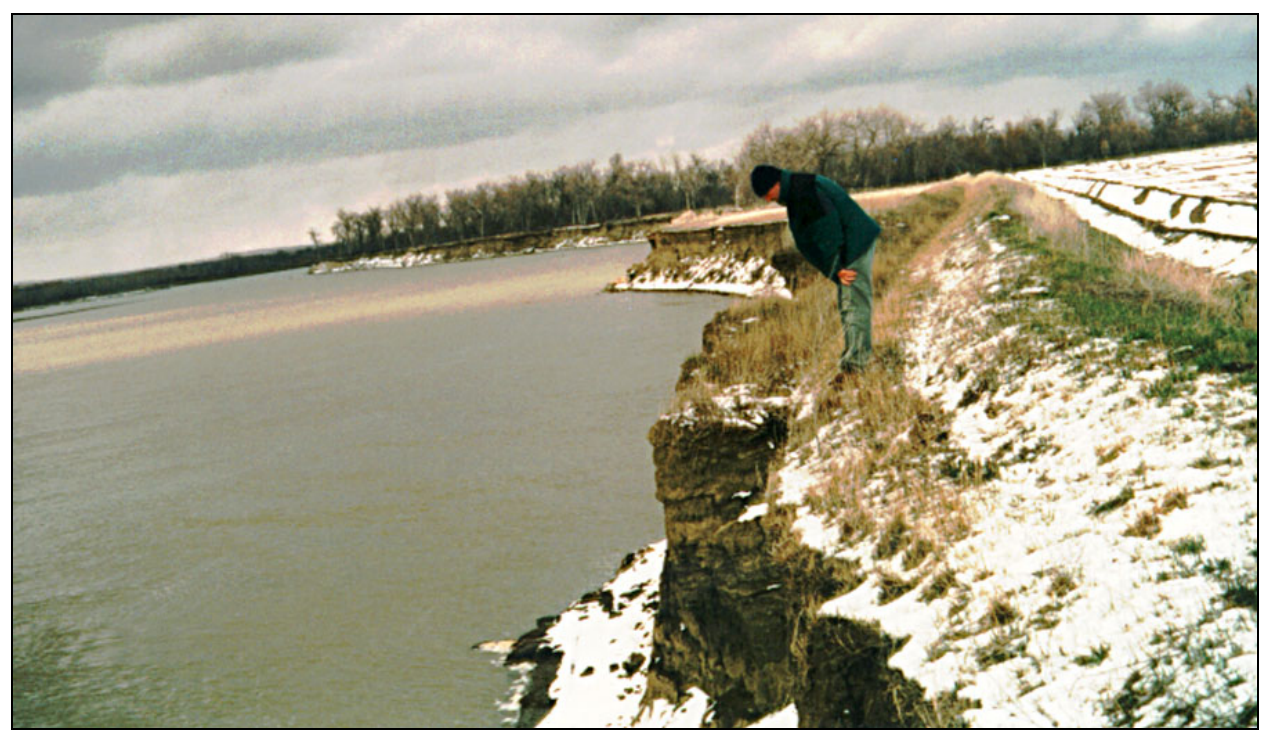

c. 4 April 1999 (view of the south bank with the flow from bottom to top).

Figure 71 (cont.). Pipal site (RM 1715-1716) during the survey.

The ice cover melted in place on the afternoon and evening of 14 February (Fig. 42), earlier than at the four downstream sites surveyed. Cover breakup, however, was accompanied by a major bank failure at the site. With the departure of the ice cover and lowering of the flow elevation, the combined effects of bed scour at the bank toe and bank material weakening caused the bank to recede about $3 \mathrm{ft}$ on average. As can be seen from the view shown in Figure 71c, once the ice cover had departed, the riverbend had migrated far enough downstream so that the flow impinged at an awkward angle against the bank.

\section{Ice cover thickness}

The cover thickness was variable over the site. At the time of the January survey, much of the cover was about 20-28 in. thick, with localized patches being almost $35 \mathrm{in}$. thick. The thinner locations coincided with the areas of deeper and faster flow and therefore where the cover formed last. No ice cover remained at the site by February 21.

\section{Bed profiles}

The bed profiles show an overall deepening of the thalweg along the toe of the outer bank of the riverbend. At the two upstream cross sections, though the larger part of the flow area deepened, the lowest bed elevation at the bank toe 


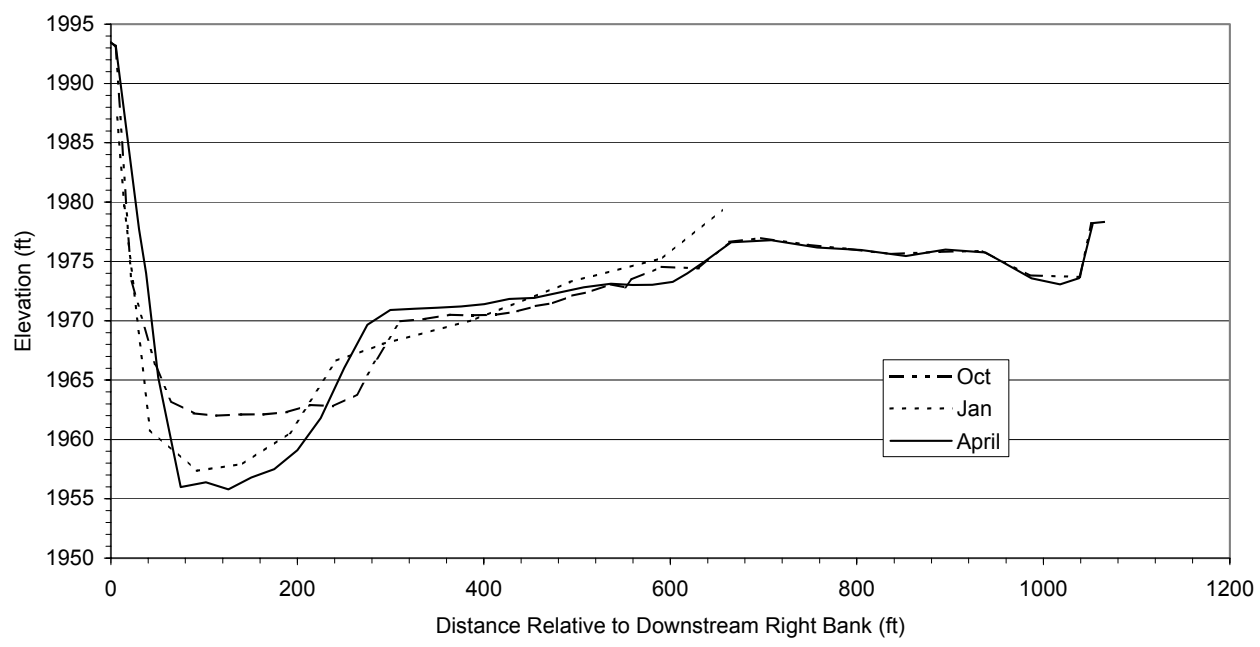

Figure 72. Bed profile cross sections at RM 1715.58.

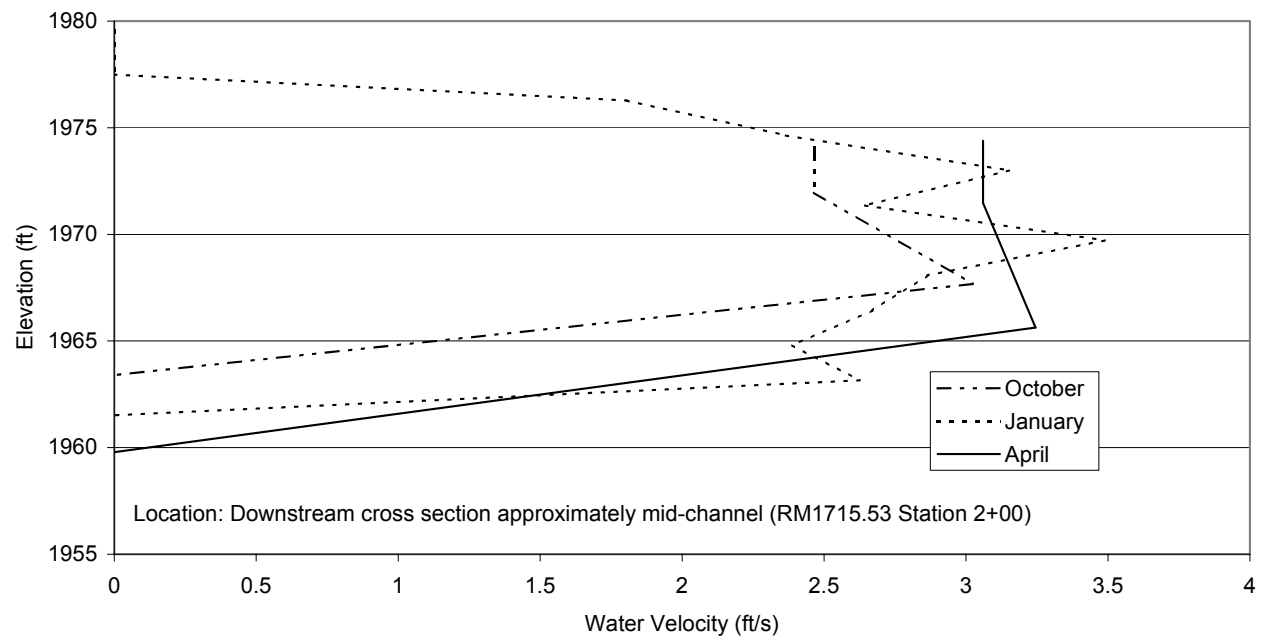

Figure $\mathbf{7 3 . ~ V e l o c i t y ~ d i s t r i b u t i o n s ~ a t ~ R M ~} 1715.53$ station 2+00.

rose. At the two downstream cross sections, the entire thalweg lowered by about 6-7 ft (Fig. 72). As at the Vournas site the bed elevation along the toe of the bank remained lowered once the ice cover had left the site.

\section{Flow velocities}

The maximum flow velocity of $4.6 \mathrm{ft} / \mathrm{s}$ was measured in the thalweg on the downstream cross section. The velocity vector was impinging towards the southern bank. Figure 73 is a velocity profile just off the south bank of the downstream cross section (RM 1715.53, station 2+00). 


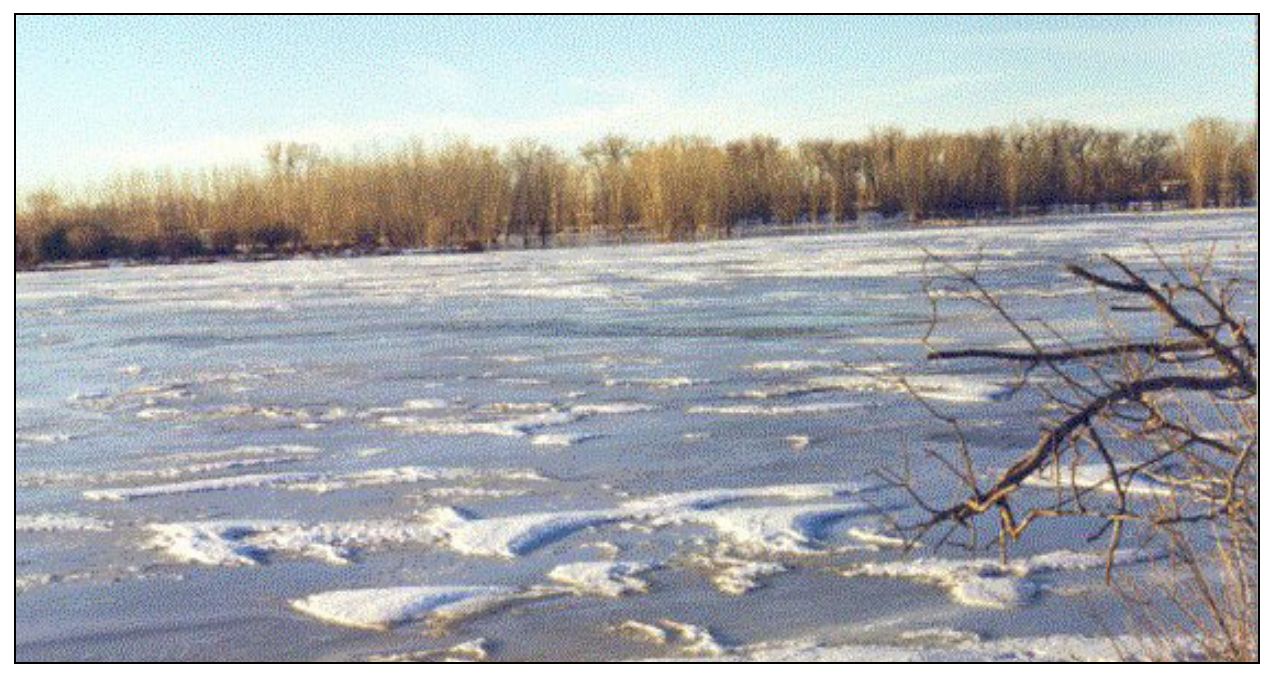

Figure 74. Water on ice at the Pipal site during the winter of 1994-95.

\section{Comments}

The ice cover did not remain in place at the Pipal site as long as it did at the other sites surveyed, but the reasons for this are unclear. One possibility is that the site is located toward the upstream end of the ice cover along the river. The site's proximity to Fort Peck Reservoir, the immediate source of warmer discharge water into the river, may also be a factor.

Ice covers on the Fort Peck reach typically begin forming at the downstream end of the reach and progress upstream. As they progress, they continuously increase flow resistance, create a backwater effect, and, with time, raise the flow stage when the flow rate is more or less steady in the river. The consequence is that ice cover formation produces a larger increase in flow stage at sites farther upstream. It can be argued, though it has yet to be confirmed, that sites farther upstream are less stable. Changes in flow released into the river from the reservoir cause greater changes in flow stage at the upstream end of the ice cover. In turn, the greater changes in flow stage exert greater stresses on the ice cover, with possible flooding of the ice sheet as seen in Figure 74.

With the milder temperatures, the warmer water released from the reservoir traveled a longer distance before the full water column was near freezing and ice could form.

Also, fluctuations in flow release from the reservoir attenuate with distance of flow along the river, especially when an ice cover is present, so sites closer to the reservoir experience greater fluctuations in peak flow rate and stage. Conse- 
quently the Pipal site may undergo larger changes in stage than do the sites downstream. This factor is partially borne out by a comparison of flow stage fluctuations at the USGS gages at Wolf Point and Culbertson (Fig. 44); the fluctuations in stage are slightly more peaky at the former gage location than at the latter.

\section{Observations on riverbank erosion at the survey sites}

Though the survey did not include measurements of riverbank properties or quantitative assessment of riverbank loads, stability, and erosion, it did provide an opportunity to observe riverbank conditions and to develop tentative descriptions of modes of ice-induced riverbank erosion.

Five mechanisms of bank erosion were observed that may be related or may be independent:

- Spalling and frittering, where small pieces of riverbank soil become detached from the riverbank face;

- Rotational sliding, where a mass of riverbank fails and slides along a circular failure plane;

- Vertical drop, where irregular blocks of undercut riverbank drop into the river;

- Toppling, where a strip of near-vertical riverbank tilts forward and topples into the river; and

- Bankface cracking, where a horizontal crack forms in the riverbank at an elevation just above the top of the bankfast ice.

\section{Spalling and frittering}

Throughout the survey period along all of the riverbanks, small pieces of soil became detached from the riverbank face. Such spalling and frittering is attributable to freeze-thaw and freeze-sublimation of soil in the riverbank face and contributed a more-or-less steady flow of soil onto the ice or into the water at the base of the slope (Fig. 75).

\section{Rotational sliding}

An example of rotational sliding occurred at the Pipal site (RM 1716), where a portion of riverbank protected by a hay bale revetment failed. That failure, depicted in Figure 76, is discussed later in this report. Rotational slides are common in banks formed of clayey soils (e.g., Lambe and Whitman 1979). 


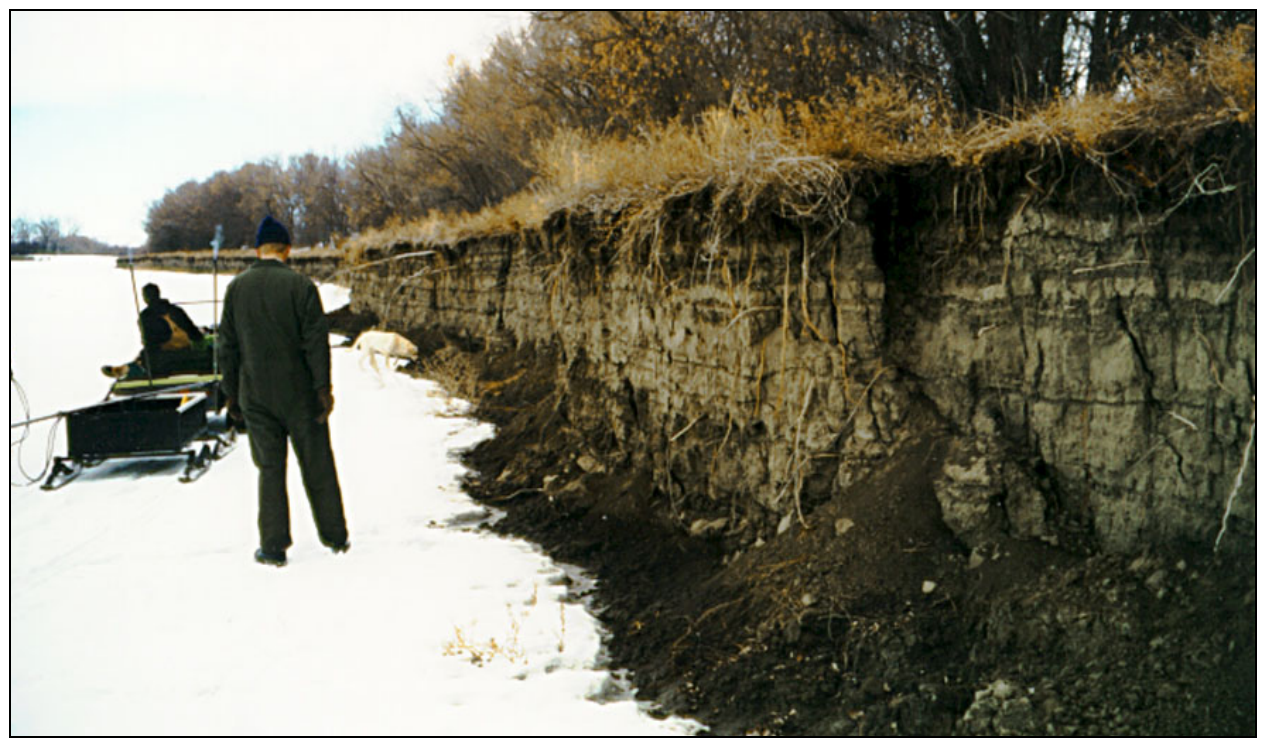

Figure 75. Failing soil along the bank.

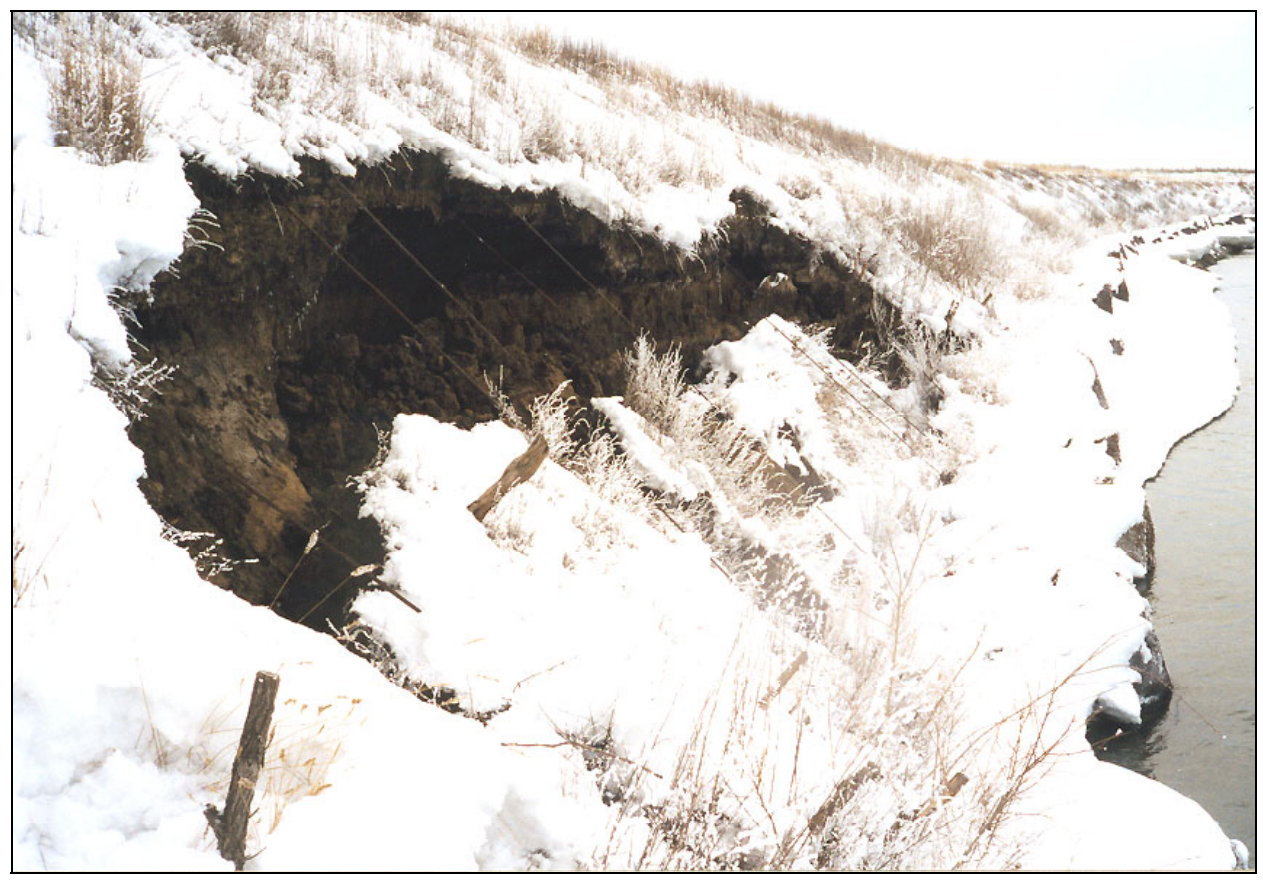

Figure 76. Riverbank slip at RM 1716. 


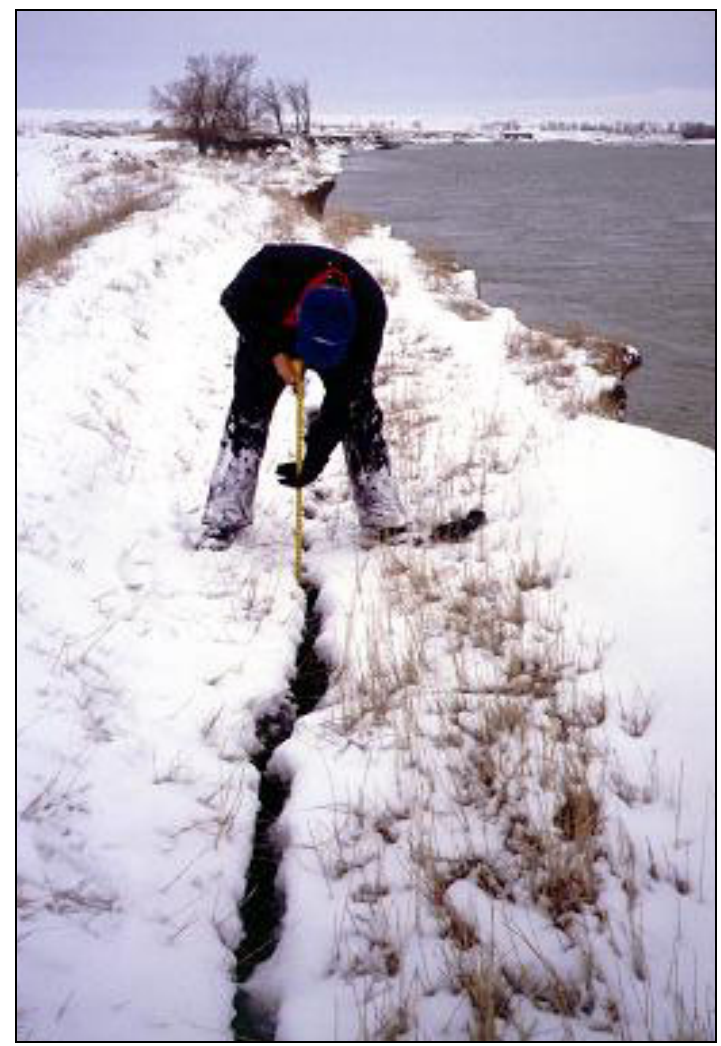

Figure 77. Crack in the riverbank soil at RM 1715.

\section{Vertical drop}

The extensive erosion along the unprotected downstream half of the Pipal site's concave bank occurred as a vertical drop, with chunks and blocks of riverbank soil dropping into the river. As is characteristic of this kind of failure, a lengthy and deep crack formed a short distance back from the crest of the riverbank (Fig. 77). The crack paralleled the face of the riverbank, sometimes being set back as much as about 6-10 ft from the riverbank face, and was approximately $50 \mathrm{ft}$ long and at least $8 \mathrm{ft}$ deep. Similar cracks, but closer to the riverbank face, were observed along the concave riverbank at the Tveit-Johnson and Vournas sites. The details of crack formation were not investigated during the survey. However, several processes evidently were at work.

In most unprotected locations at the Pipal site, for instance, the riverbank is almost vertical as well as high (about $20 \mathrm{ft}$ ), and in some locations the top of the riverbanks juts out from the riverbank. Given its weak soils (Simon et al. 1999), the riverbank is of marginal stability. In most locations the riverbank is formed of 
three layers (Simon et al. 1999). The base of the riverbank is formed in a layer of silty sand, of variable thickness but typically about $5 \mathrm{ft}$. Above that layer is a layer of clay, then an upper layer of fissured silty clay, about $8 \mathrm{ft}$ thick. At some locations along the base of the riverbank at the Pipal site, a layer of mudstone (locally termed Bearpaw shale) outcrops and is relatively resistant to erosion by flow. Variations in the response of each layer and the combined soil system to changes in river stage and to freeze-thaw effects likely play a role in the development of cracks along the top of the bank.

Once formed, the cracks enlarge throughout the winter. The inner walls of the cracks expose the bank top to freeze-thaw effects over a greater depth and likely accelerate weakening of the riverbank. Snow may also weaken the riverbank by accumulating in the cracks and eventually opening and eroding the inside of the crack as it melts. The flow of melting water into the soil pores would further weaken the riverbank by reducing values of the angle of internal resistance and cohesion of the soil layers comprising the riverbank.

Erosion of the sandy silt layer at the base of the riverbank reduces riverbank stability. Although the upper level of the riverbank may overhang its lower level, the riverbank did not show evidence of extensive undercutting. However, because the riverbank soil is weak and there is little vegetation at the riverbank top, extensive undercutting was not needed to destabilize the riverbank. The combined effects of flow erosion and freeze-thaw processes eventually caused blocks or strips of riverbank soil to calve from the riverbank, as is evident in Figure 78. The blocks fell to the riverbank toe, where they provided temporary toe protection until gradually being eroded by the flow (Fig. 79). In comparison the root systems of trees along the top of the riverbank at the Vournas site resulted in much more extensive undercutting of that riverbank (Fig. 80).

\section{Toppling}

This mode of bank failure occurred along a portion of the riverbank of the Tveit-Johnson site. Figure 81 shows how a strip of riverbank develops pronounced overhang curvature. With time during winter, the overhang progressively curls forward until the strip of riverbank fails and topples. Some portions of the riverbank failed while the ice cover was present. Most portions failed immediately after the ice cover broke up.

The north riverbank of the Tveit-Johnson site is steepened and heightened by the river-flow erosion of sediment along the toe of the riverbank. Like the riverbank along the downstream portion of the Pipal site, the riverbank at the TveitJohnson site developed cracks along the bank crest, though the cracks at the Tveit-Johnson site were closer to the face of the riverbank. Unlike at the Pipal 


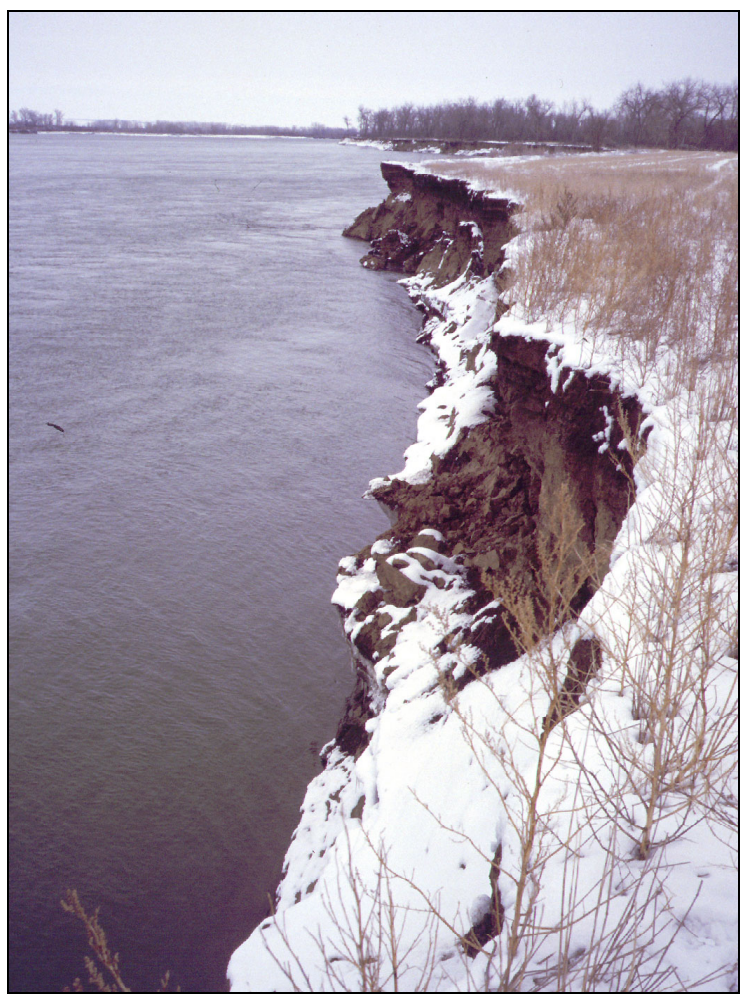

Figure 78. Eroded riverbank along RM 1715.

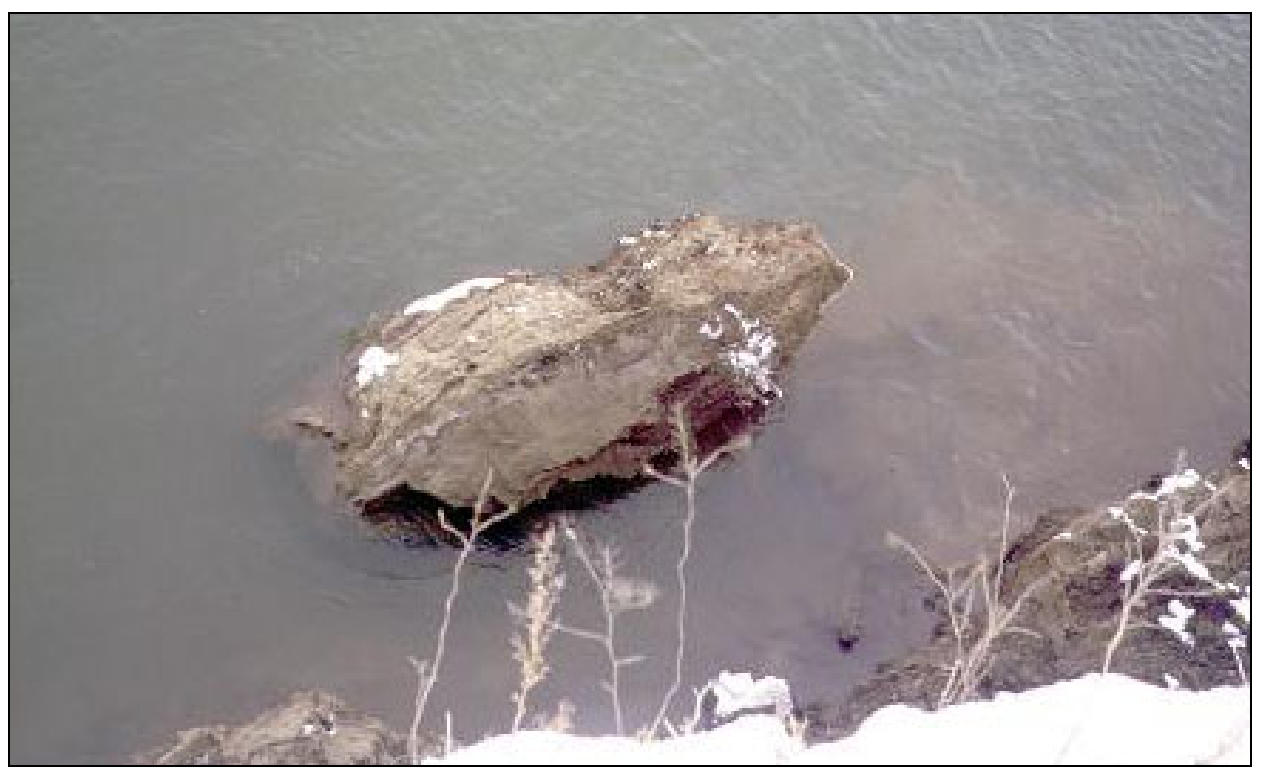

Figure 79. Fallen block of bank material at the riverbank toe. 


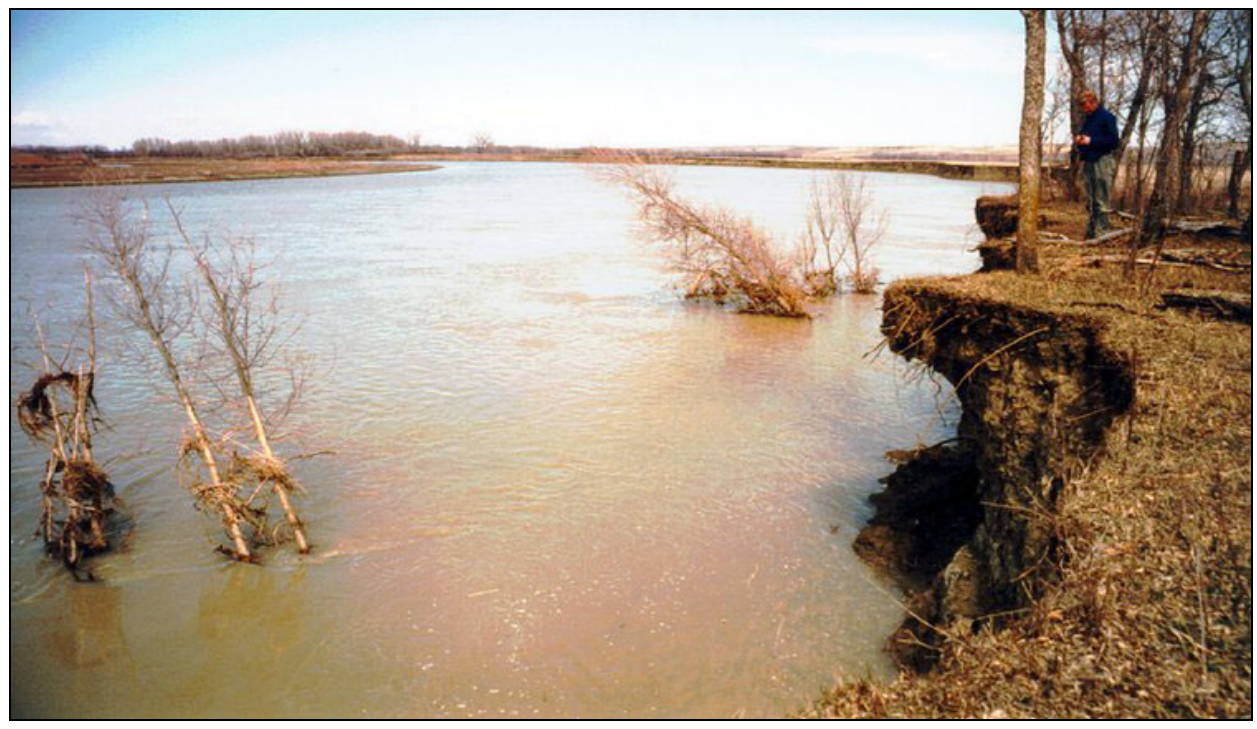

Figure 80. Extensive undercutting of the riverbank at RM 1632.

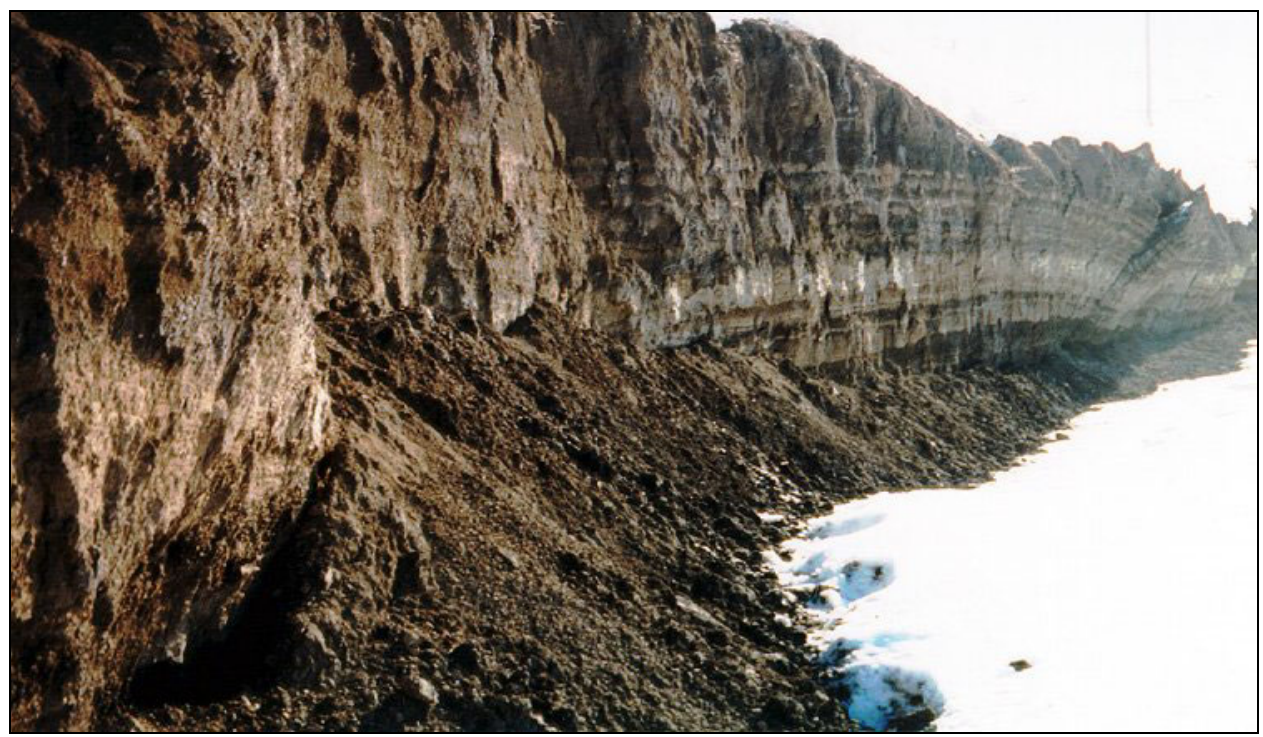

Figure 81. Toppling at the Tveit-Johnson site.

site, the eroding riverbank at the Tveit-Johnson site faces south, so it receives a substantial amount of direct insolation. The peculiar formation of a curled strip of riverbank is likely attributable to the frequent freeze-thaw cycles (or freeze and partial thaw cycles) that the bank undergoes. Such cycles may cause a slow, plastic deformation of the riverbank, giving the riverbank its curved form. 


\section{Bankface cracking}

As illustrated in Figures 58 and 63 for the Tveit-Johnson and Vournas sites, respectively, horizontal cracks appeared in the riverbank near the top of the bankfast ice. The cause of these cracks was not investigated during the survey. We surmised that the cracks developed from one or both of two causes:

- Undercutting of the riverbank by flow may have locally weakened the riverbank such that a lower segment of riverbank separated from an upper portion. The ice cover, however, continued to support the lower segment so that the segment did not collapse completely.

- Flexing of the ice cover exerted compressive and tensile stresses that eventually weakened and eventually cracked the riverbank.

The crack along the bankface did not appear to coincide with the boundary between layers of different bank sediments. The portion of riverbank with the cracked face eventually failed, as Figure 82 shows for the Tveit-Johnson site.

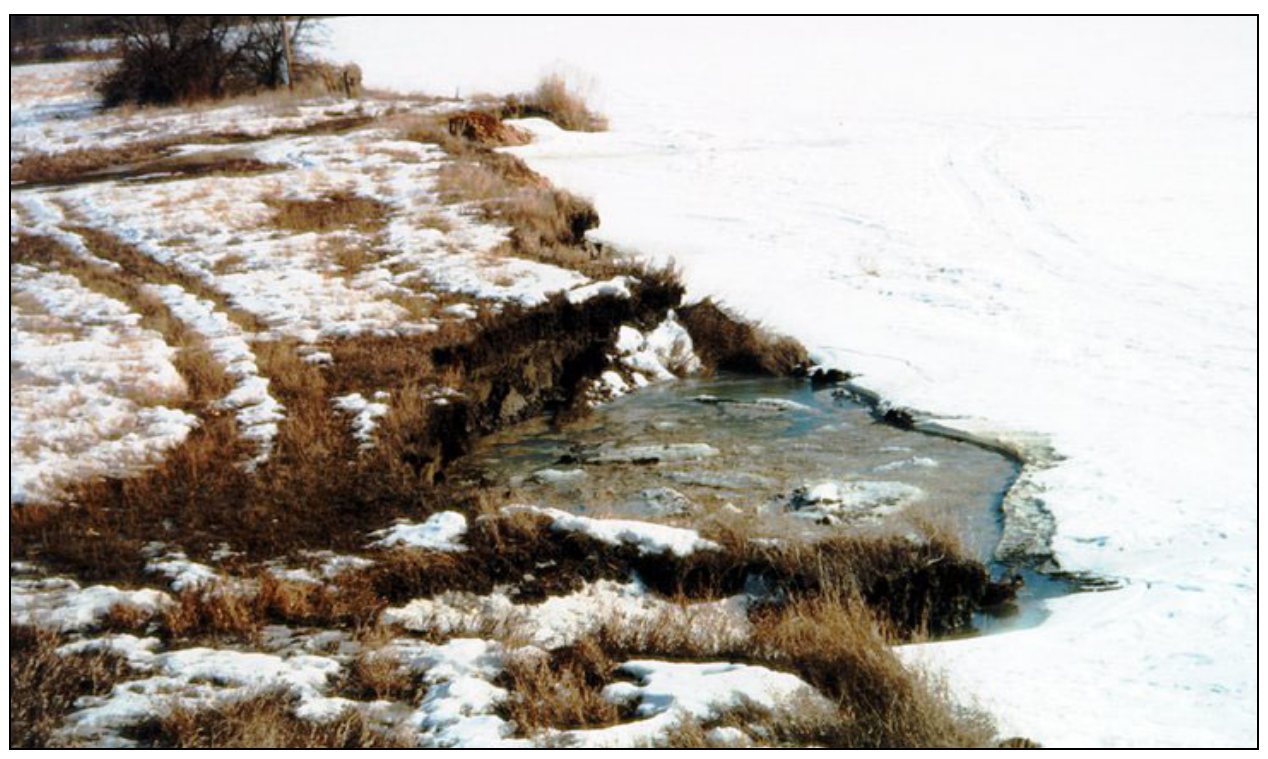

Figure 82. Bank collapse following the formation of horizontal cracks. 


\section{PERFORMANCE OF RIVERBANK STABILIZATION METHODS}

The survey of ice cover influences on channel stability at the Pipal site provided a unique opportunity to monitor the wintertime performance of several methods for riverbank stabilization implemented along the upstream half of the site's concave bend (Fig. 83). The stabilization methods were designed for open water conditions. Monitoring led to several useful insights as to how the methods work for rivers with morphologies similar to the Missouri River at the Pipal site.

The design considerations associated with each stabilization method are not considered in this report. They are documented in earlier publications (USACEOmaha 1997, 1998b, LaGrone and Remus 1998). The methods were implemented in part to address the specific concerns about severe bank erosion at the

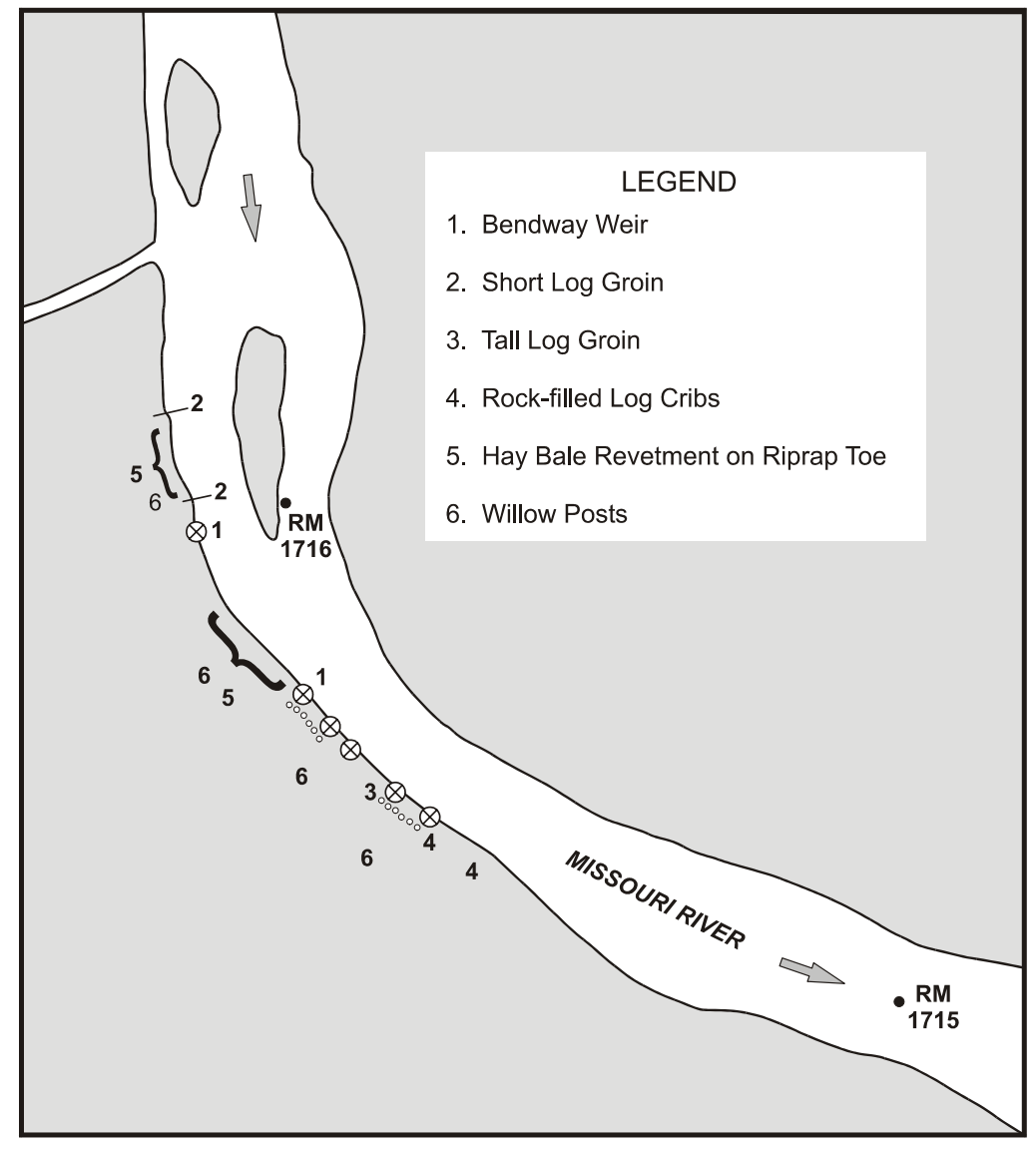

Figure 83. Locations of bank stabilization methods used at RM 1715-1716, Pipal site. 
Pipal site and in part as a trial of several potentially cost-effective techniques for riverbank stabilization. Mellema (1997) described the background of the stabilization methods and observations concerning the performance of each method under open water conditions. His report includes several appendices prepared by USACE-Omaha. LaGrone and Remus (1998) described the considerations in the design of the hay bale on riprap toe.

The following riverbank stabilization methods are implemented at the site (Fig. 84):

- Bendway weirs;

- Short log groins;

- Tall log groins;

- Rock-filled log cribs;

- Hay bale revetments on riprap toe; and

- Willow posts.

All the methods were installed in 1997 and therefore had undergone two winters at the time of the surveys.

The methods have worked reasonably well, given their trial nature. All but one method withstood ice cover formation during the winter of 1998-99, and there were a few deficiencies in a couple of the methods.

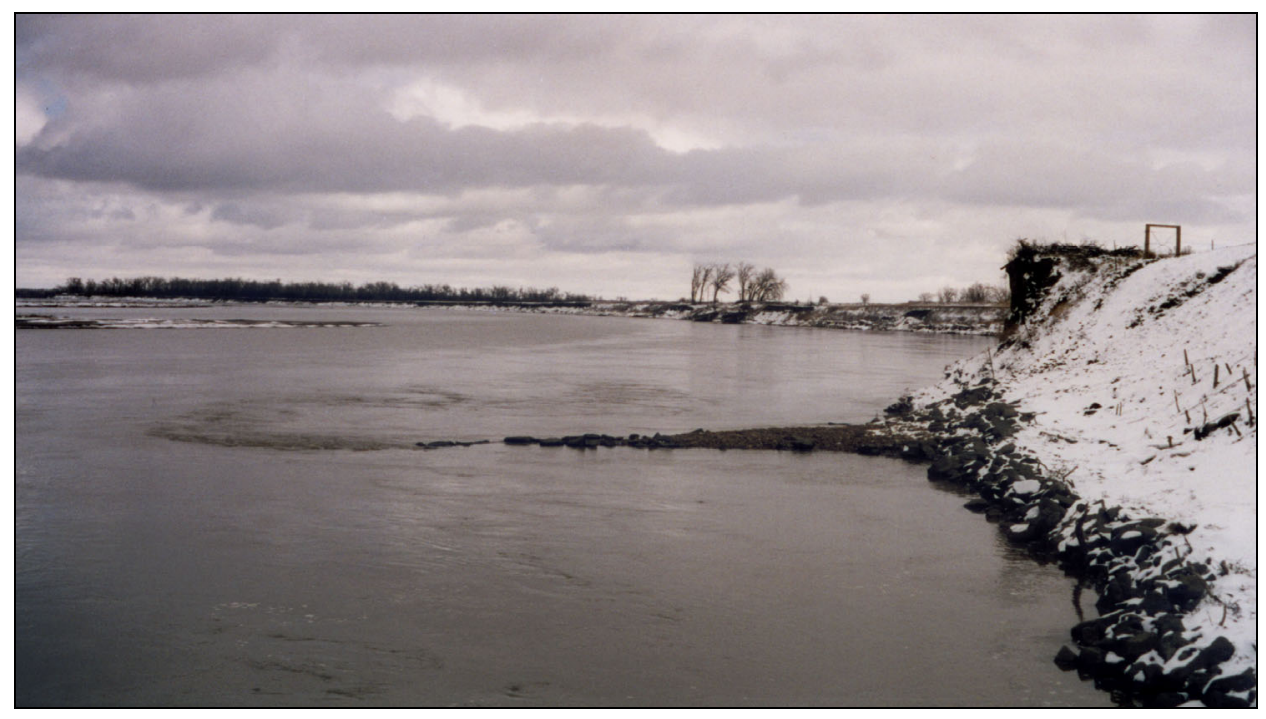

a. Bendway weir.

Figure 84. Bank stabilization methods. 


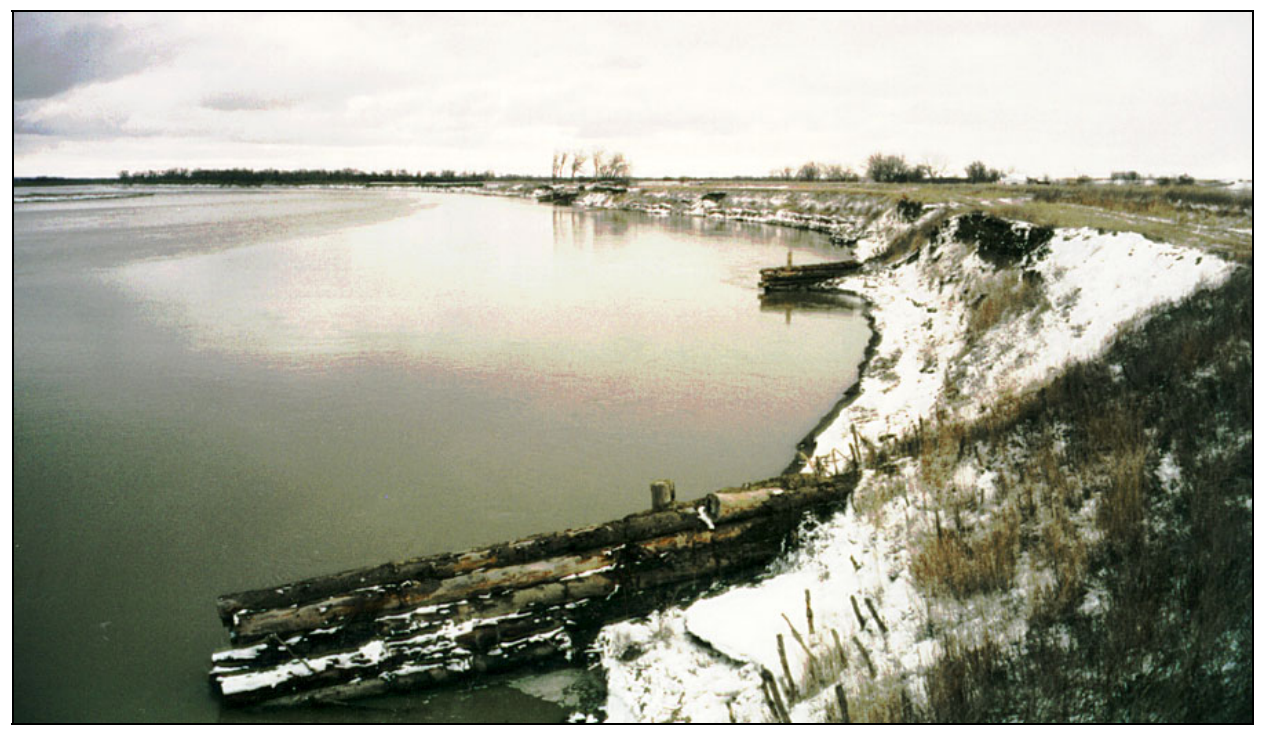

b. Short log groin.

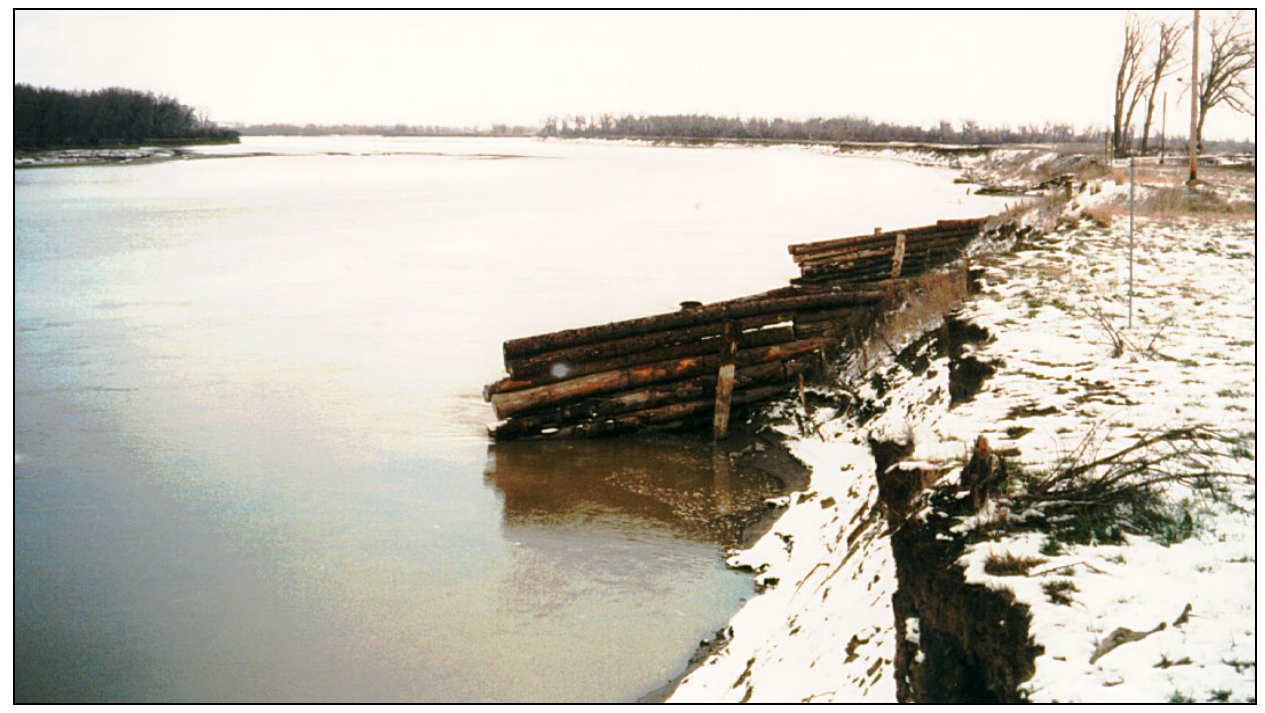

c. Tall log groin.

Figure 84 (cont.). Bank stabilization methods. 


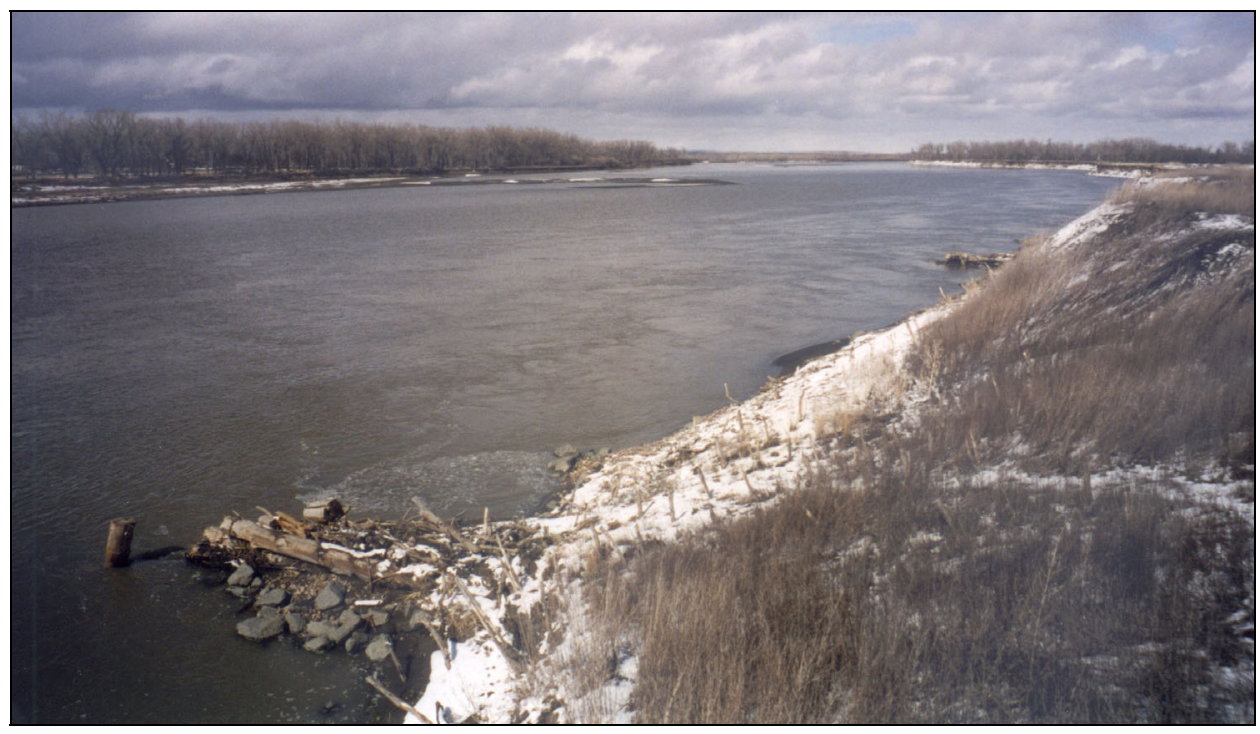

d. Rock-filled log cribs.

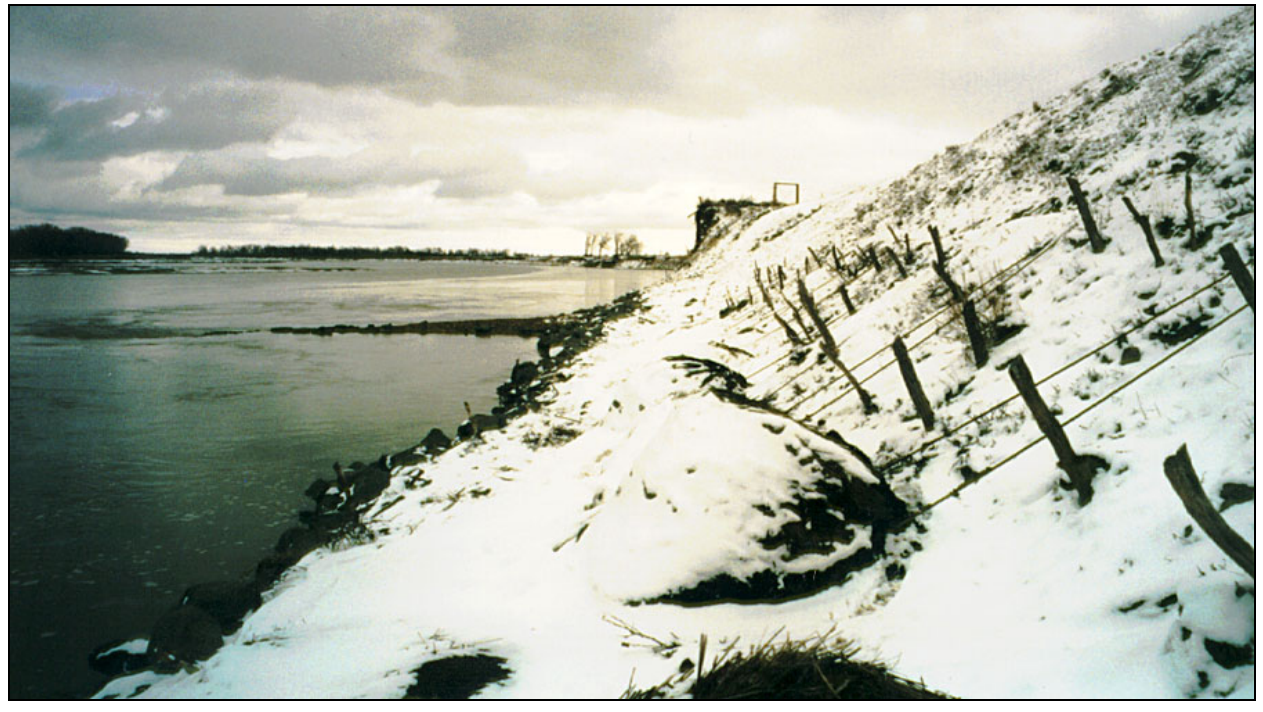

e. Hay bale revetment on riprap toe.

Figure 84 (cont.). 


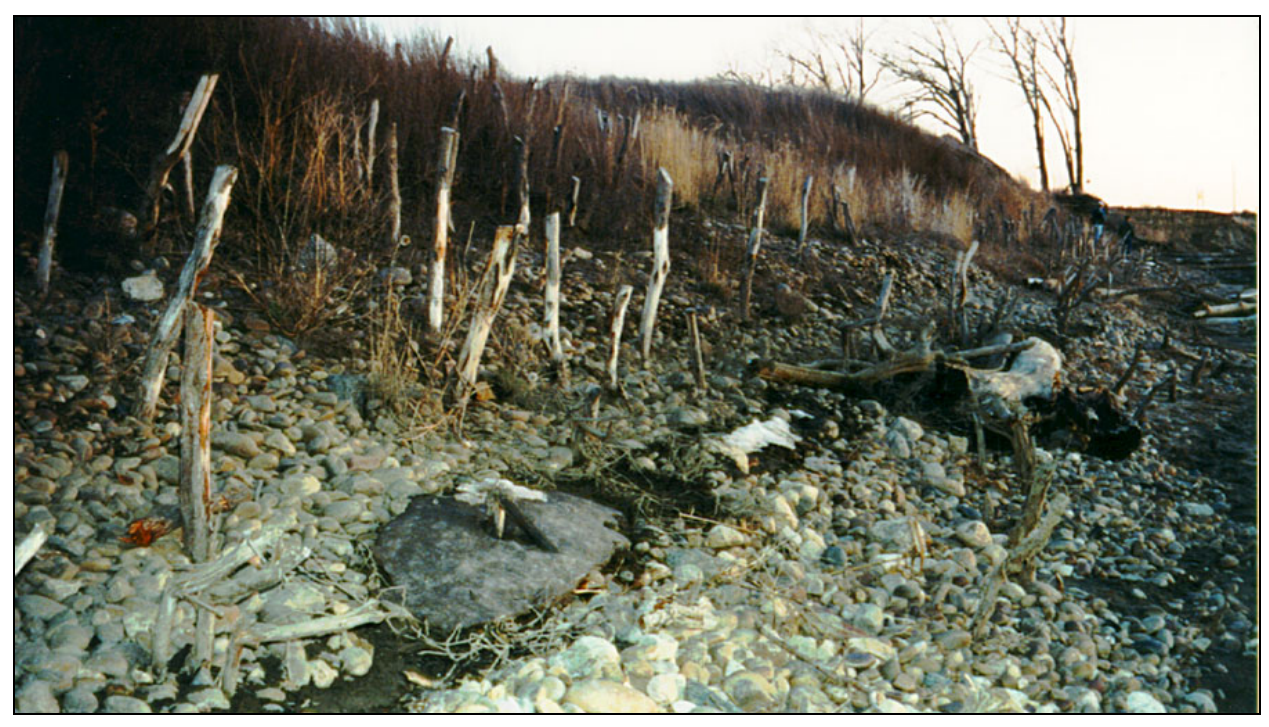

\section{f. Willow stakes for shore stabilization}

Figure 84 (cont.). Bank stabilization methods.

\section{Bendway weirs}

The two bendway weirs weathered the winter survey period apparently unscathed. Flows were of sufficiently large magnitude, and therefore flow stages were sufficiently high, that the weirs were submerged beneath the ice cover, though only by a maximum of a couple of feet (Fig. 85a). The bendway weirs appear not to have been significantly damaged when the ice cover broke up (Fig. $85 \mathrm{~b}$ ). River flows at the time of the photos in Figures 85a and 85b were 12,300 and $11,800 \mathrm{cfs}$, respectively.

Though the bendway weirs remained intact, the bank immediately upstream of bendway weir 2 suffered a local failure. A cuspate segment of the bank collapsed as a rotational slide, most likely doing so immediately after the ice cover broke up.

Although no flow velocity measurements were taken to document the flow patterns under the ice in the vicinity of the bendway weirs, it appears from observation of open water flow currents at the weirs that the weirs may have partially blocked flow along the bank. The bendway weirs would have caused the flow to make a sharp turn at the weir, locally increasing the flow velocities and turbulence along the bank. This may have led to localized scouring of the bed at the bank toe and thus contributed to the collapse of a portion of bank immediately upstream of bendway weir 2 . This is a prime concern associated with the use of 


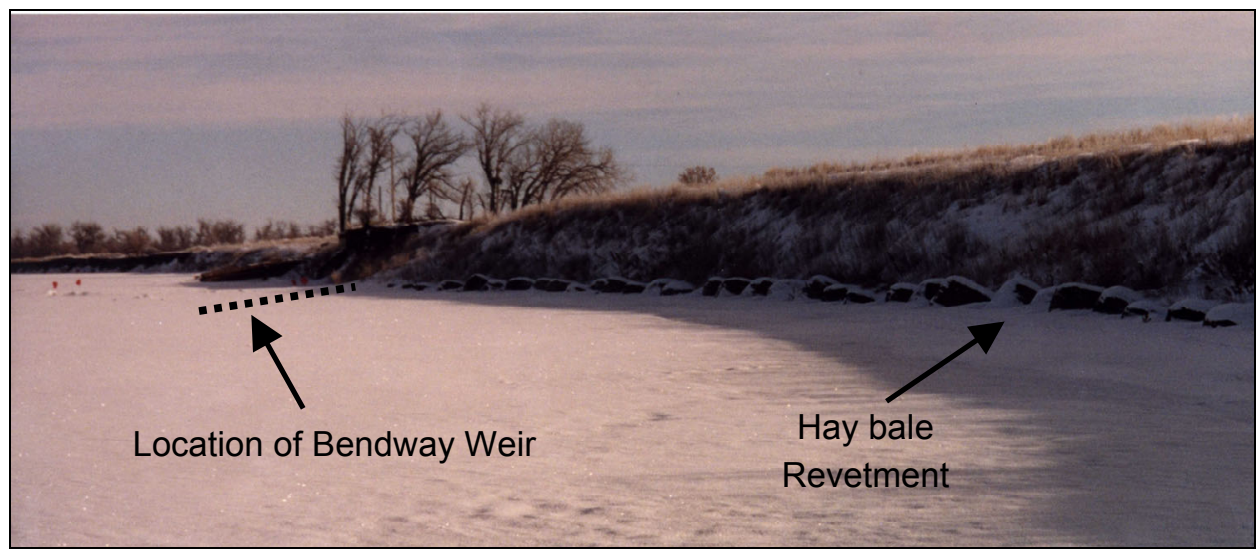

a. Ice cover on 26 January 1999 when the river flow was 12,300 cfs.

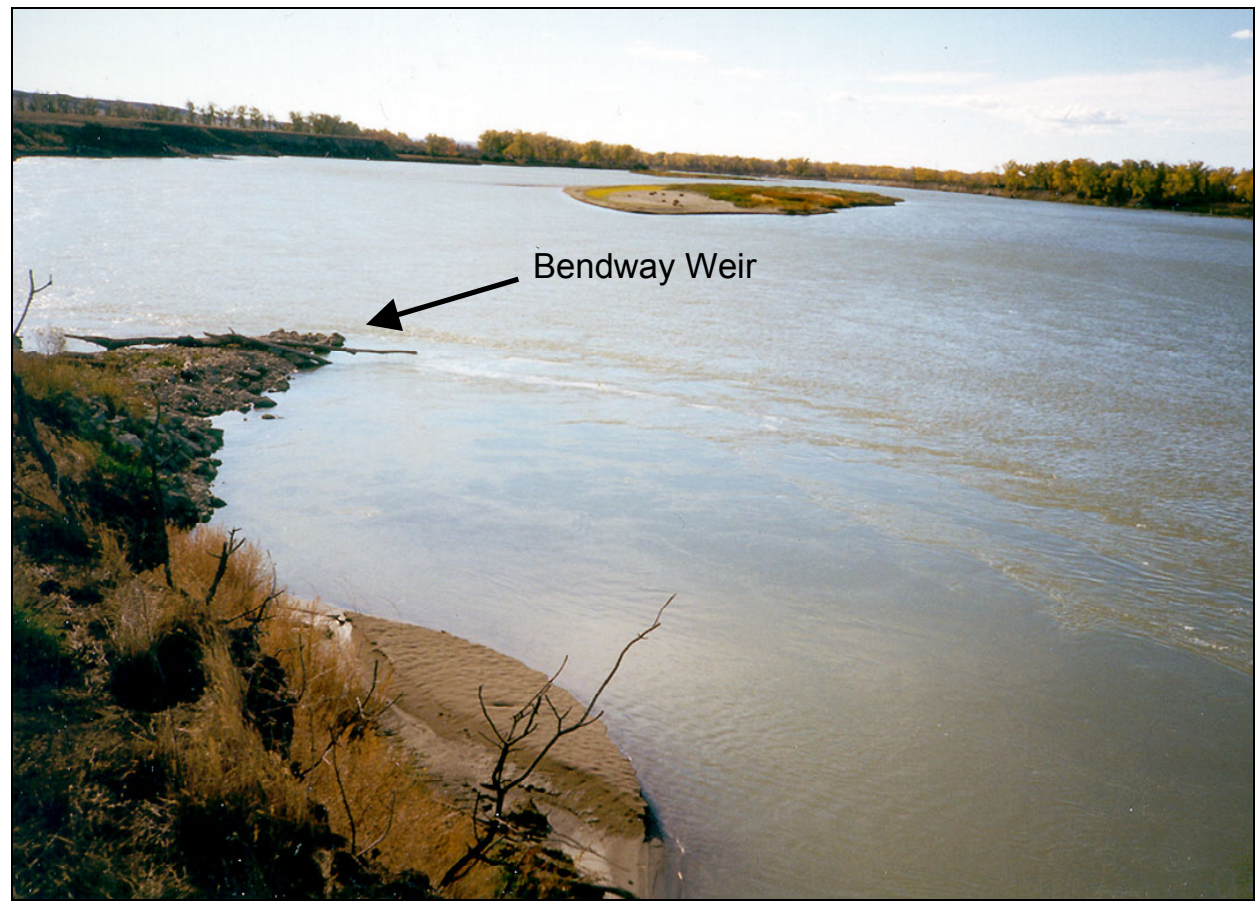

b. Site after the ice had departed, 21 February 1999 . The river flow was 11,800 cfs.

Figure 85. Bendway weir.

upstream-oriented groins (e.g., Haydon 1931, Schoklitsch 1937); the bendway weir, when not fully submerged or submerged to a shallow depth, essentially acts as an upstream-pointing groin. 
The underside of the ice cover was less than a couple of feet from the crest of the bendway weirs. Consequently flow over the bendway weir would have been constricted, diminishing its desired effect of turning flow away from a bank. Further investigation is needed to assess the usage of bendway weirs in icecovered flow.

\section{Short and tall log groins}

Two sets of log groins, differing in height and length, are installed at the Pipal site. Near the center of the site, the tall groins are almost to the top of the riverbank and extend farther out into the river than the short groins. At the upstream end of the site, the short groins are much lower and barely protruding above the ice cover.

The log groins froze into the bankfast ice that formed along the site's south bank. The groins, which are built from long logs, withstood the ice loads associated with the ice cover and appeared to have been undamaged when the cover broke up and departed the site. Figure 86 shows a tall log groin frozen into the cover and the same groin after breakup. Figure 87 shows a short log groin encased in ice on January, shortly after the ice cover had broken up. A hinge crack that generally parallels the shoreline allowed rotation between the stationary bankfast ice and the flexing channel without vertical displacement across the crack. The groins locally supported the ice cover, causing the shoreline crack to

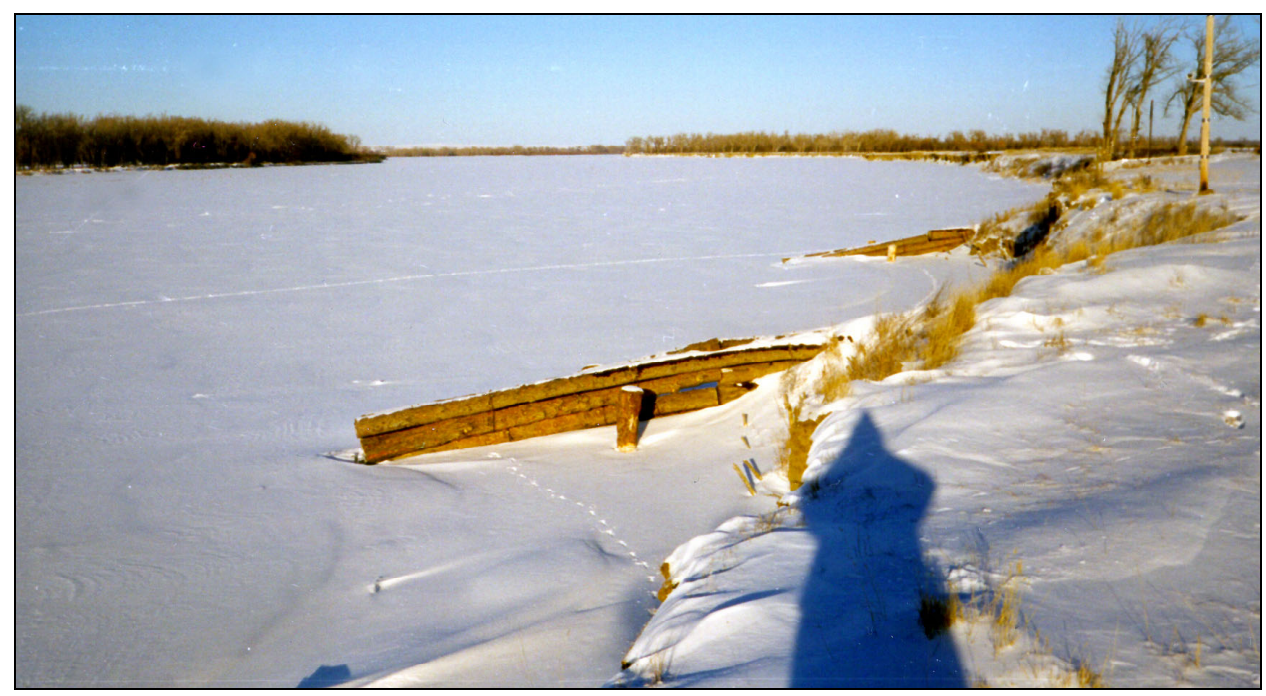

a. Frozen in ice, 26 January 1999.

Figure 86. Log groins. 


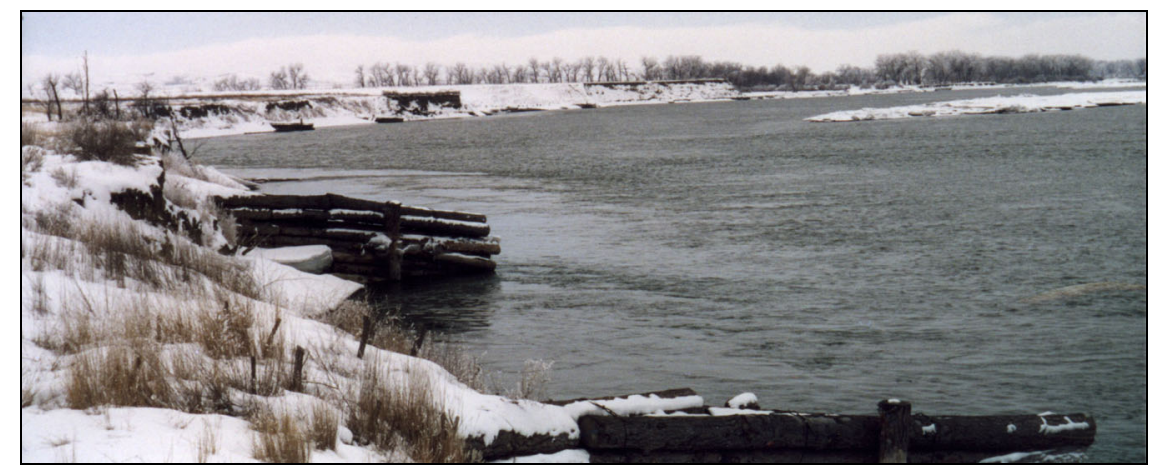

b. Following breakup.

Figure 86 (cont.). Log groins.

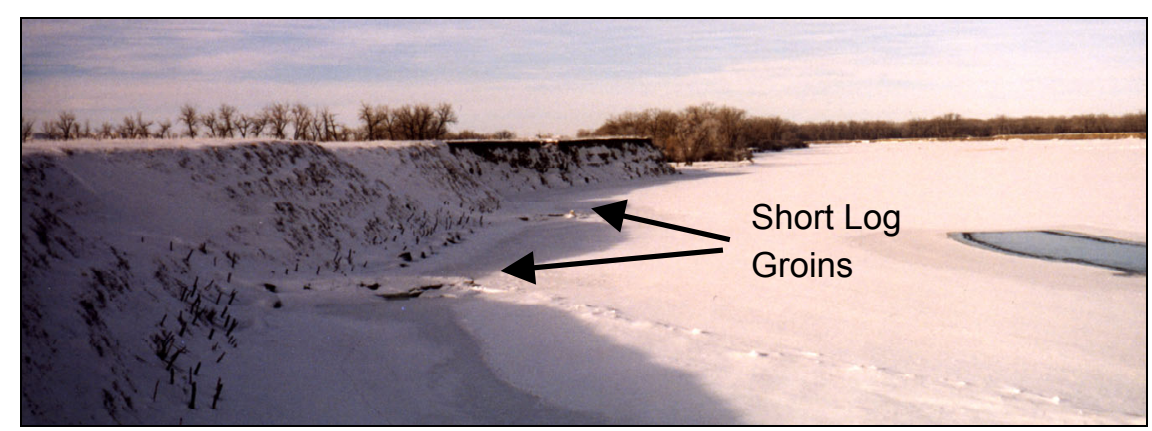

a. In the ice, January 1999.

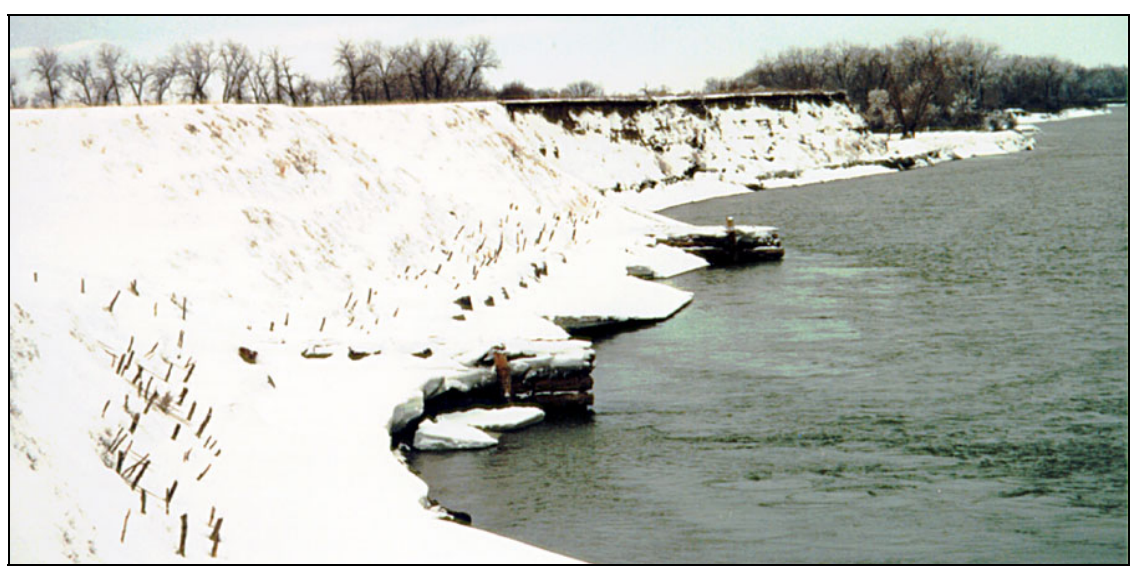

b. Following breakup, 21 February 1999.

Figure 87. Short groins. 


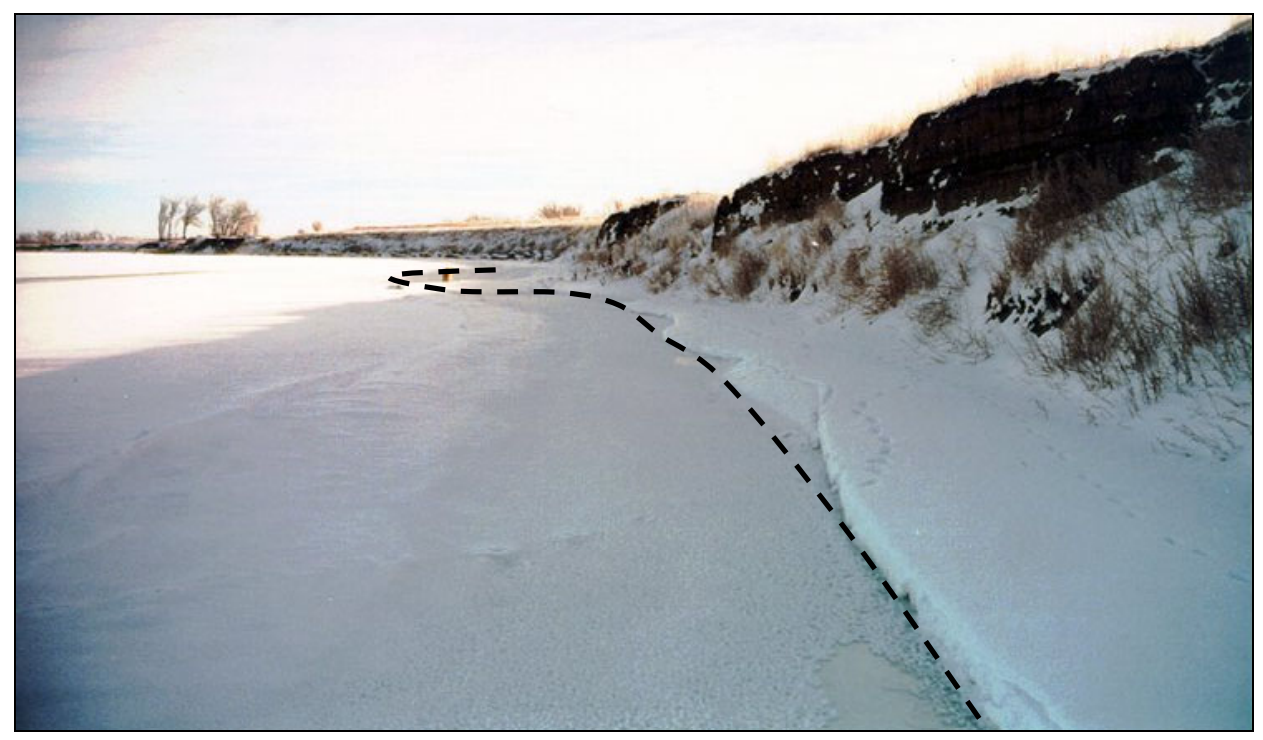

Figure 88. Short groin with relocated shoreline crack.

be relocated towards the channel and widening the margin of the bankfast ice. The dashed line in Figure 88 shows the relocated shoreline crack due to the short groins. The beneficial consequence of relocating is seen in Figure 87b, as the bankfast ice may have helped to protect the banks from damage during breakup. The taller log groins, which project farther out into the flow, relocated the shoreline crack farther away from shore, resulting in a wider band of bankfast ice. Following breakup, the water level dropped, and the wider bankfast ice was cantilevered from the shore. When the bank is steep, as at the Pipal site, a wider band of bankfast ice cantilevered from the bank exerts a larger load on the bank face as the supporting water level drops following break up. In approximate terms the load increases proportionally with the square of the width of the bankfast ice. As can be seen in Figure 89, the collapse of bankfast ice strips soil and vegetation from the face of the bank.

\section{Rock-filled log cribs}

The rock-filled log cribs, which are short, stout, and submerged well below the ice cover, appear to function effectively. Figure 90a shows the under-ice location of two cribs on 26 January 1999, with the relocated shoreline cracked designated. Figure $90 \mathrm{~b}$ shows a crib shortly after the ice cover had broken up. The crib structures suffered no damage attributable to ice, and the structures did not unduly increase the local width of bankfast ice. 


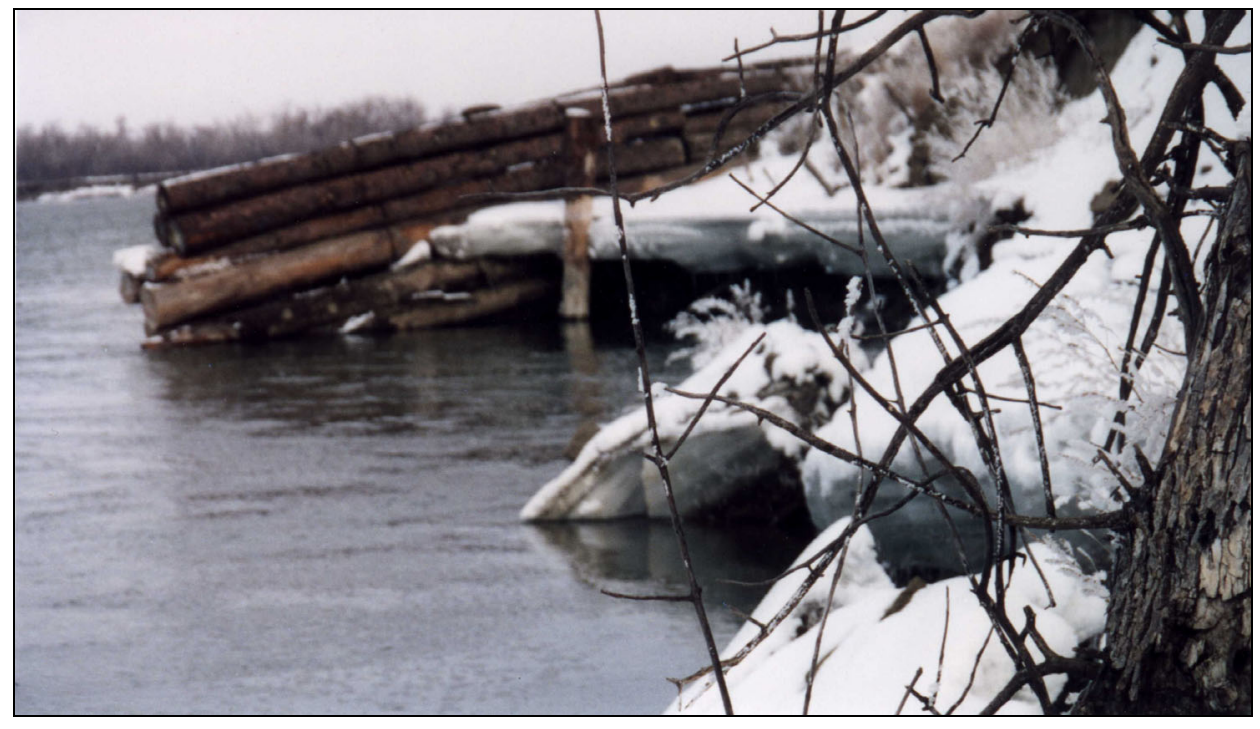

a. Ice attached to groin.

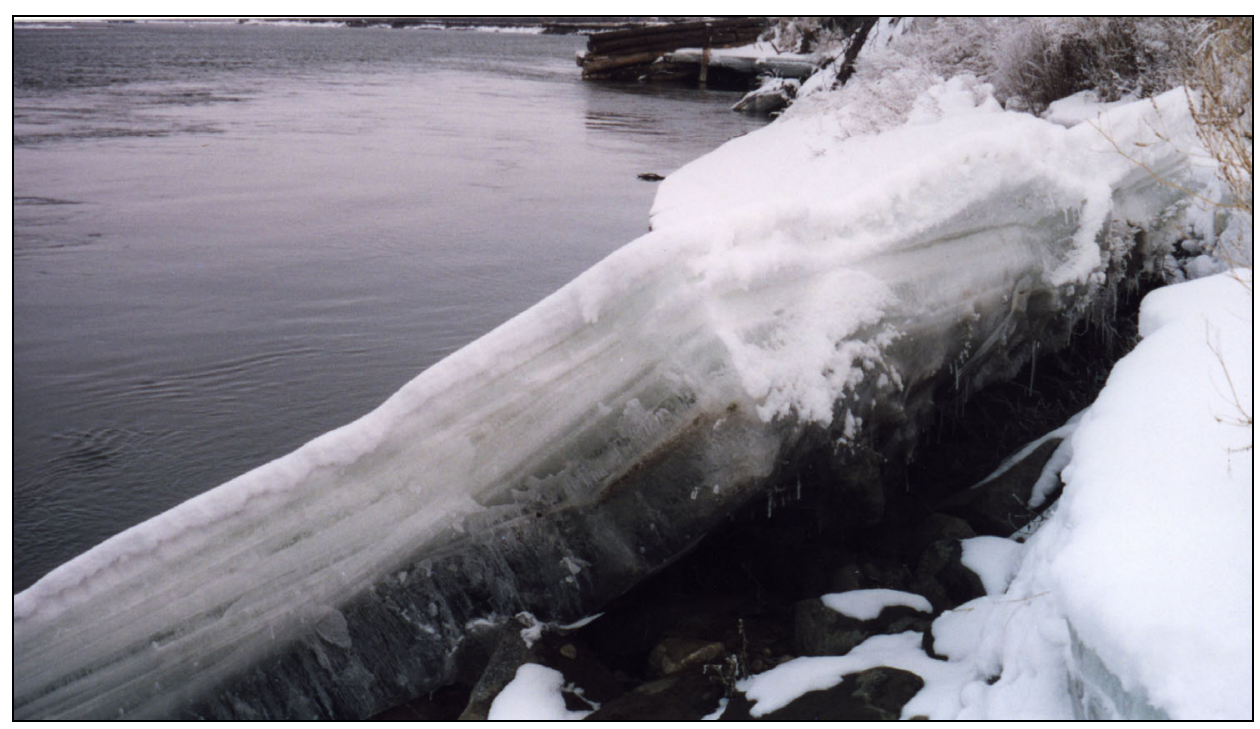

b. Ice block sliding down the embankment.

Figure 89. Tall log groin. 


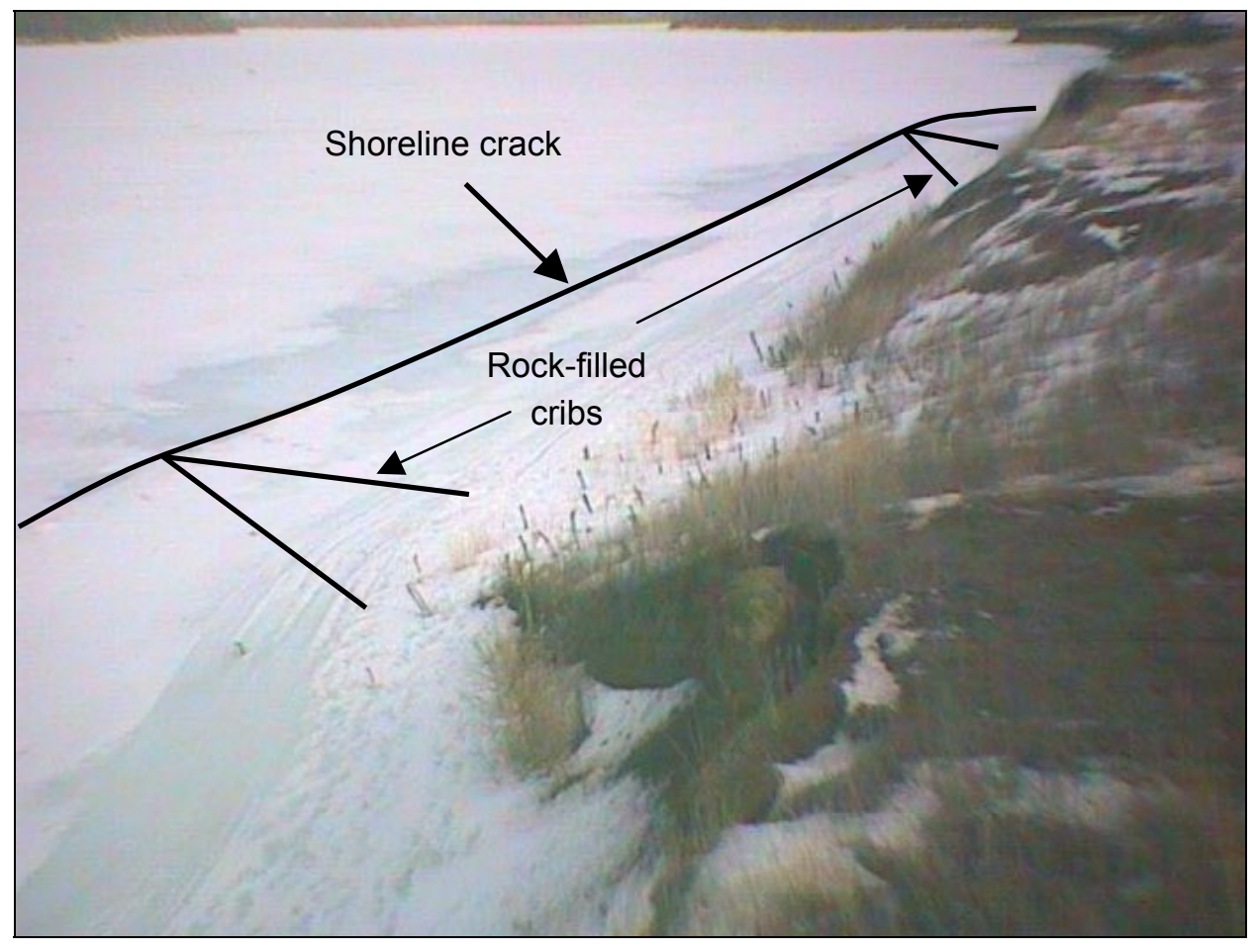

a. Frozen into the ice cover.

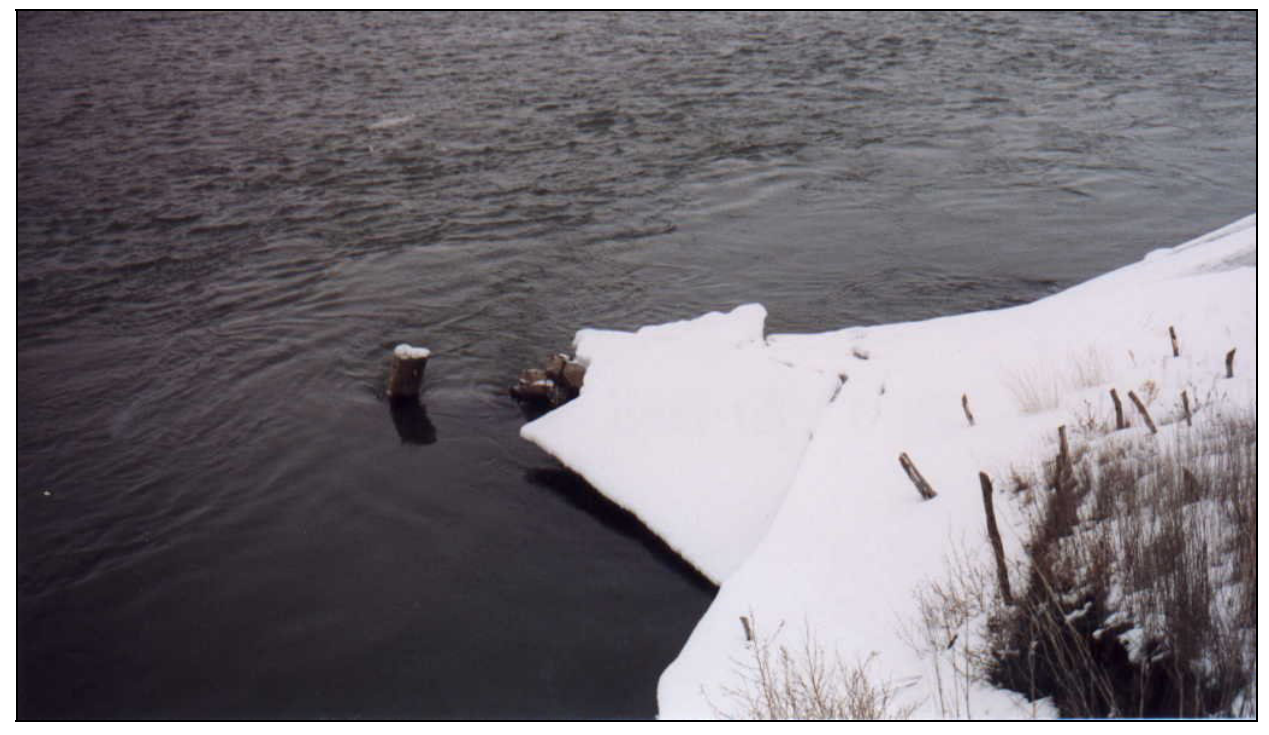

b. After ice breakup in February.

Figure 90. Log cribs. 


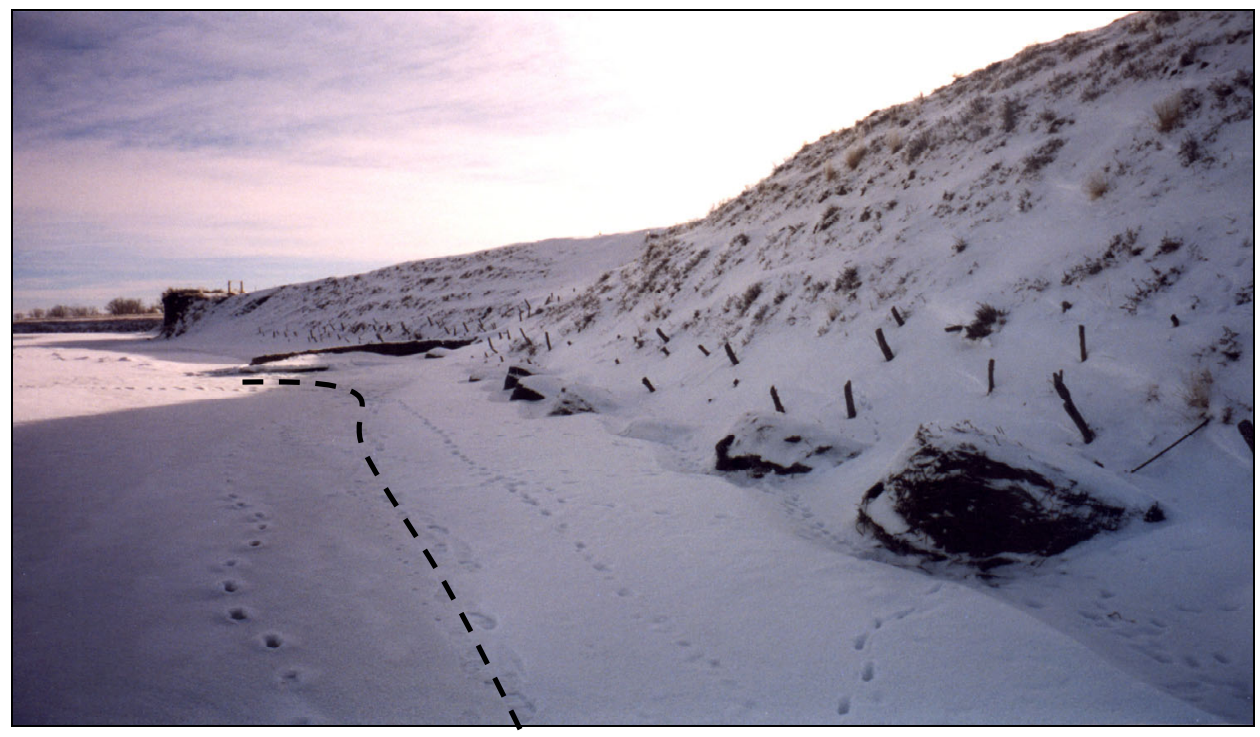

Figure 91. Hay bale revetment frozen into the ice cover.

\section{Hay bale revetments on riprap toe}

A segment of the bank protected by the hay bale revetment and its riprap toe failed. The segment is located immediately upstream of bendway weir 2 (Fig. $84 \mathrm{a}$ ), which may have played a role in the bank's collapse.

The elevation of the ice cover on 26 January 1999 was such that the cover formed around and into the hay bales, which were wrapped in a geotextile fabric (Fig. 91). The ice cover did not seem to have directly damaged the bales. It froze well into the bales, enveloping them. They, in turn, seem to provide a reasonably secure anchoring for the bankfast ice; the bales themselves are anchored to the bank top by means of steel cables. The crack delineating the outer extent of the bankfast ice was located outside the bales. The dashed line in Figure 91 shows the location of the shoreline crack.

Immediately upstream of the submerged weir, the flow at the bank toe seems to have undermined and removed the riprap protection placed beneath the bales and destabilized the bank. Once the ice cover broke up and no longer supported the bank, the bank failed in a more-or-less classic semicircular failure surface (Fig. 92).

The stone used to form the layer of riprap placed to protect the lower elevations and toe of the river bank is undersized for ice conditions. As Figure 93 illustrates, riprap stone could be plucked from the bank by bankfast ice as it rotated and collapsed from the bank immediately after the ice cover broke up. As 


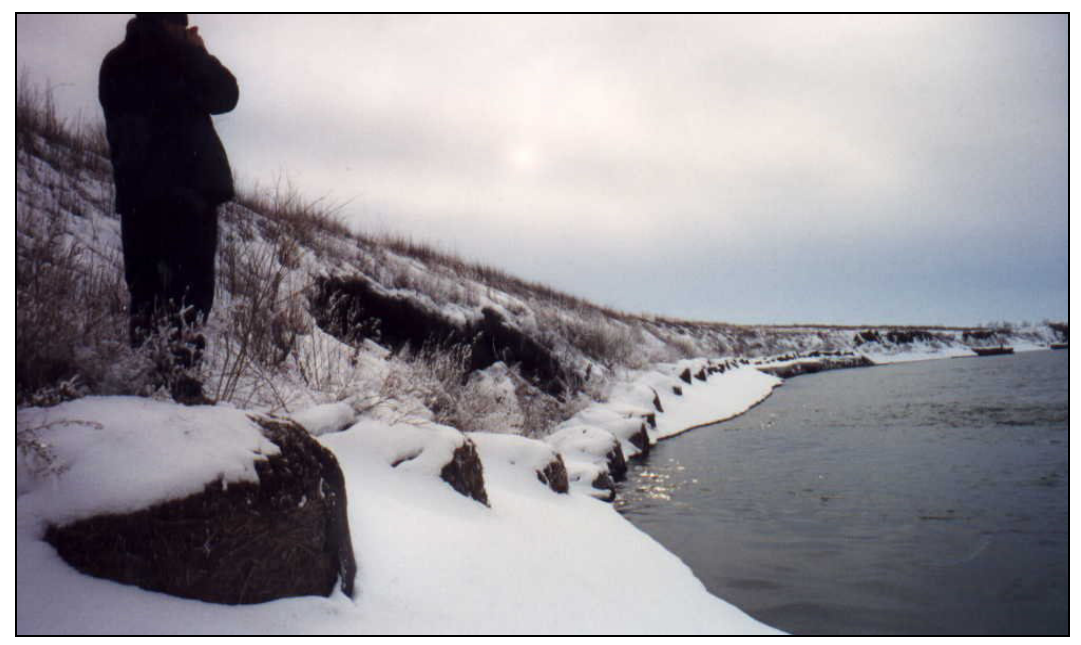

Figure 92. Collapsed section of bank near the hay bale revetment following ice out in February.

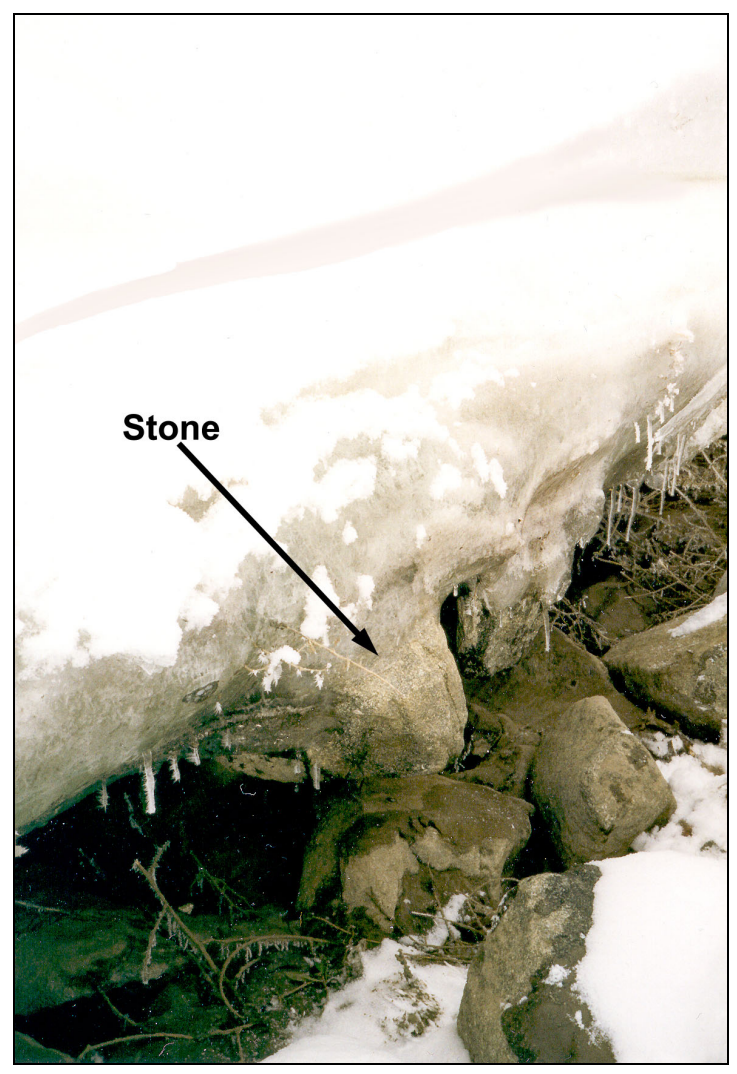

Figure 93. Riprap being plucked by bankfast ice. 


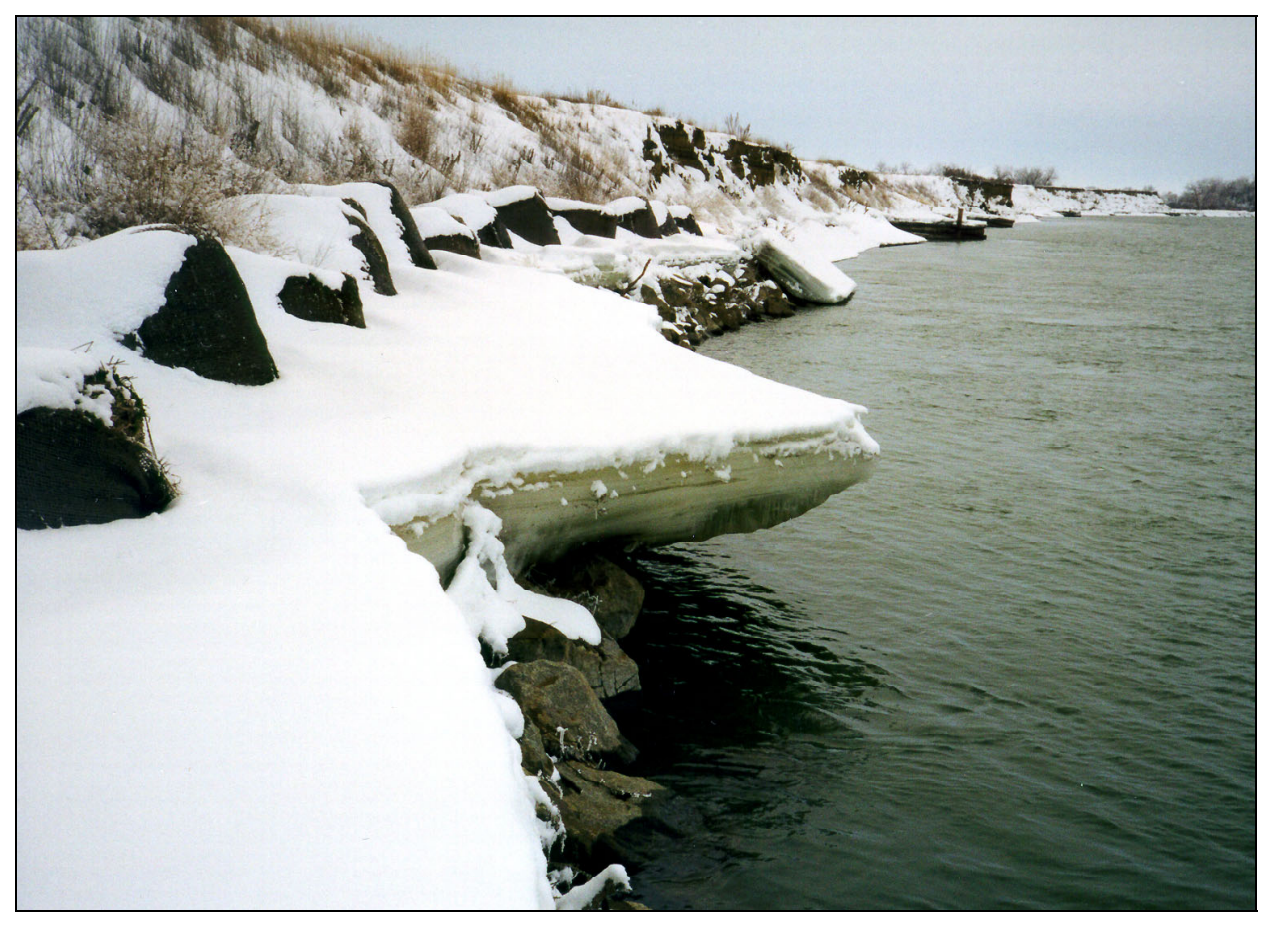

Figure 94. Shorefast ice along riprap beaches.

a rule of thumb (e.g., Wuebben 1995), riprap subject to ice plucking or ice impact should comprise stones of a diameter equal to 2.5 times the thickness of the ice sheet. Large gravel stone, with diameters in the range of 2-6 in., was used for control of upper bank erosion, and cobbles with diameters in the range of 6-30 in. were placed for controlling erosion of the bank toe (USACE-Omaha 1997). Where the riprap beach was wider, it supported the landfast ice (foreground of Fig. 94); where it was narrow, the unsupported ice blocks rotated and slid down the beach (background of Fig. 94) as the water receded following breakup.

\section{Willow posts}

We could tell little about the performance of the willow posts. It appeared, at the time of the survey, that most of the willow posts had not become established as young trees, but the reasons for this are not known. It was observed, though, that collapsing bankfast ice pulled out some willow posts (Fig. 95).

\section{Discussion}

Several inferences regarding the wintertime performance of riverbank stabilization methods can be drawn from the observations made at the Pipal site. 


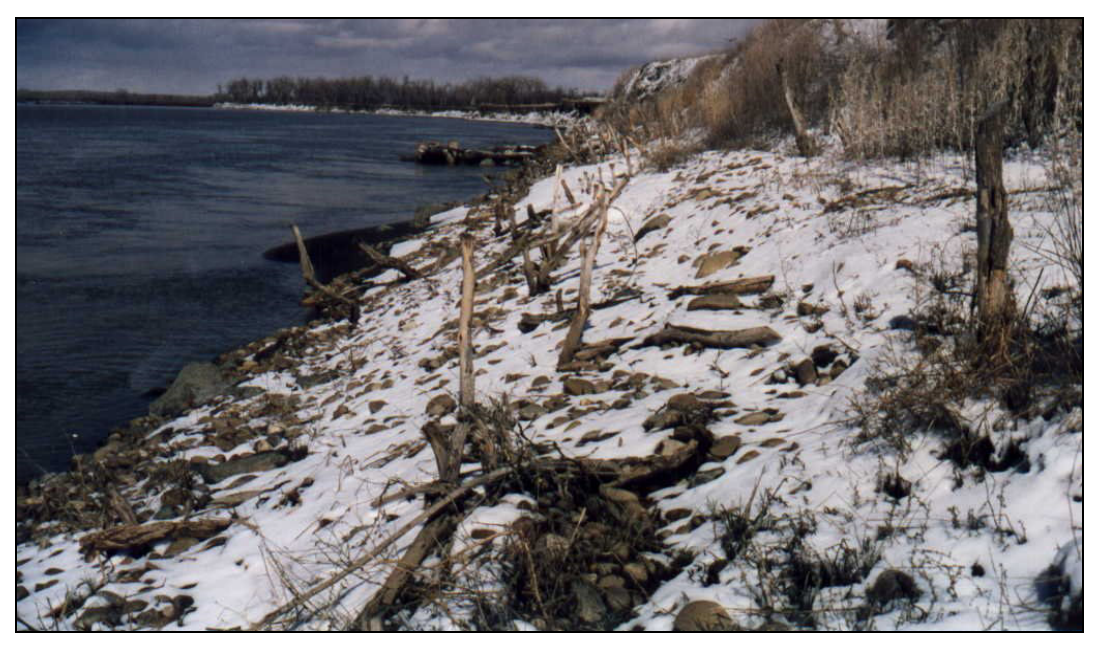

Figure 95. Failed willow post.

Observations at the Pipal site suggest that stabilization structures should not protrude into the river farther than the usual width of bankfast ice at the bank the structures are required to protect. Compared to open water conditions, shorter and closer-spaced structures are preferable for use in ice-covered flows. Structures longer than the normal bankfast ice width move the shoreline crack towards the channel, widening the bankfast ice and potentially loading banks excessively. Bankfast ice between and near the timber groins was significantly wider than elsewhere at the site. When the river was ice covered, the bankfast ice formed a floating membrane attached to the groins and the bank. When the ice cover broke up and the flow stage subsided, large slabs of bankfast ice collapsed, damaging the banks and vegetation along the banks (Fig. 96).

Ice cover formation may adversely alter the flow field around structures placed to locally modify flow near a riverbank. The ice cover that formed over the bendway weirs and long groins appears to have negated their intended action by concentrating the flow locally toward the bank rather than away from the bank. This may have contributed to the collapse of a section of bank protected by riprap and hay bales.

Riprap stone must be sized, and riprap slope configured, to withstand bankfast ice collapse, not just impact by moving ice. At some locations along the protected bank, riprap stones were plucked from the bank by collapsed bank ice. The choice of the upper elevation of riprap stone placement should take into account the probable elevation of the ice cover. To prevent riprap plucking by ice, it may be necessary to place larger riprap stone at that elevation. Similarly, willow posts should be located above the usual elevation of the ice cover, because the cover may damage or remove posts placed below that elevation. 


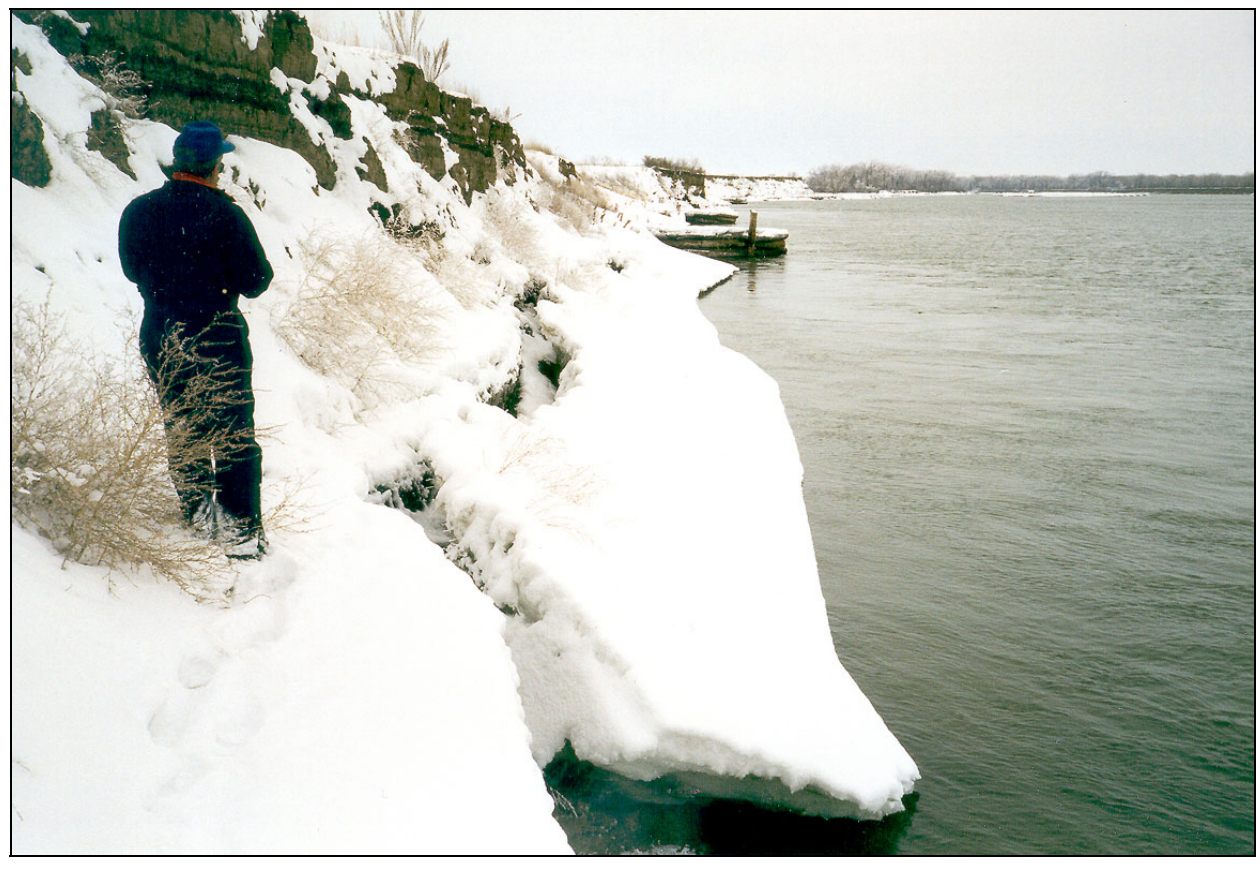

a. Unsupported ice block.

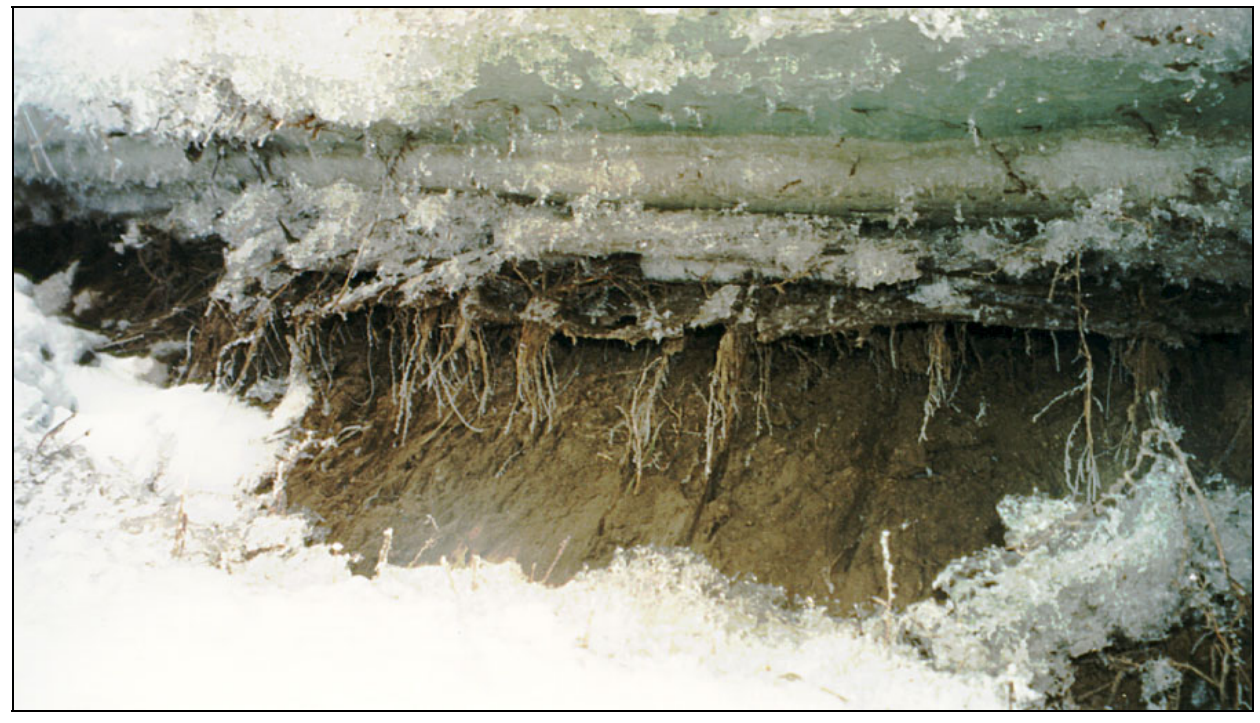

b. Block pulling root structures of entrapped vegetation.

Figure 96. Ice blocks sliding offshore. 


\section{GENERAL OBSERVATIONS}

This study showed that river ice formation can influence the channel bathymetry along the Fort Peck reach of the Missouri River. The findings are of use both for understanding wintertime channel processes occurring in the Fort Peck reach and other alluvial channel rivers and for designing and conducting diverse engineering activities.

The river ice influences identified are complex. They can be characterized usefully in terms of hydraulic and geotechnical influences on channel stability. Hydraulic influences pertain to the flow resistance performance of the channel, whereas geotechnical influences pertain to the channel bank loading and strength. By themselves, neither hydraulic nor geotechnical influences substantially destabilize the river; local ephemeral adjustments occur, which may reverse themselves. However, in combination, hydraulic and geotechnical influences can locally destabilize the river.

\section{Hydraulic influences of river ice}

The survey findings show that river ice likely exerts the following hydraulic influences $(\mathrm{H})$ on channel bathymetry along the Fort Peck reach of the Missouri River:

H1. Where the river flows in a single bend (e.g., the Vournas and Pipal sites), ice cover formation promoted outward shifting of the channel thalweg and downstream migration of the bend. It did so by altering the cross-channel distribution of resistance so as to concentrate flow toward the bend's outer bank. The concentrated flow scoured the channel bed along the outer bank of a bend, increasing bank steepness and height and occasionally undercutting the bank. If the bank failed, the channel thalweg shifted toward the outer bank and downstream. The process is illustrated in Figure 97.

$\mathrm{H} 2$. Where the river flows in two (or sometimes three) subchannels, ice cover formation can trigger a switch of the principal thalweg from one subchannel to the other (as happened at the Culbertson and Mattelin sites). When a rougher ice cover formed in one subchannel, the cover partially diverted the flow from that subchannel to the subchannel with the smoother ice cover. The subchannel with the smoother ice cover then enlarged, while the rougher-covered subchannel shrank. Survey observations suggest that thalweg switching is a recurrent process and that switches may take several winters to complete. Strictly speaking, such switching is a stochastic dynamic process that may be narrow-banded about a dominant period (e.g., a certain number of winters). It also may be broad-banded because of several factors (e.g., dependency on geometry upstream of the reach, 

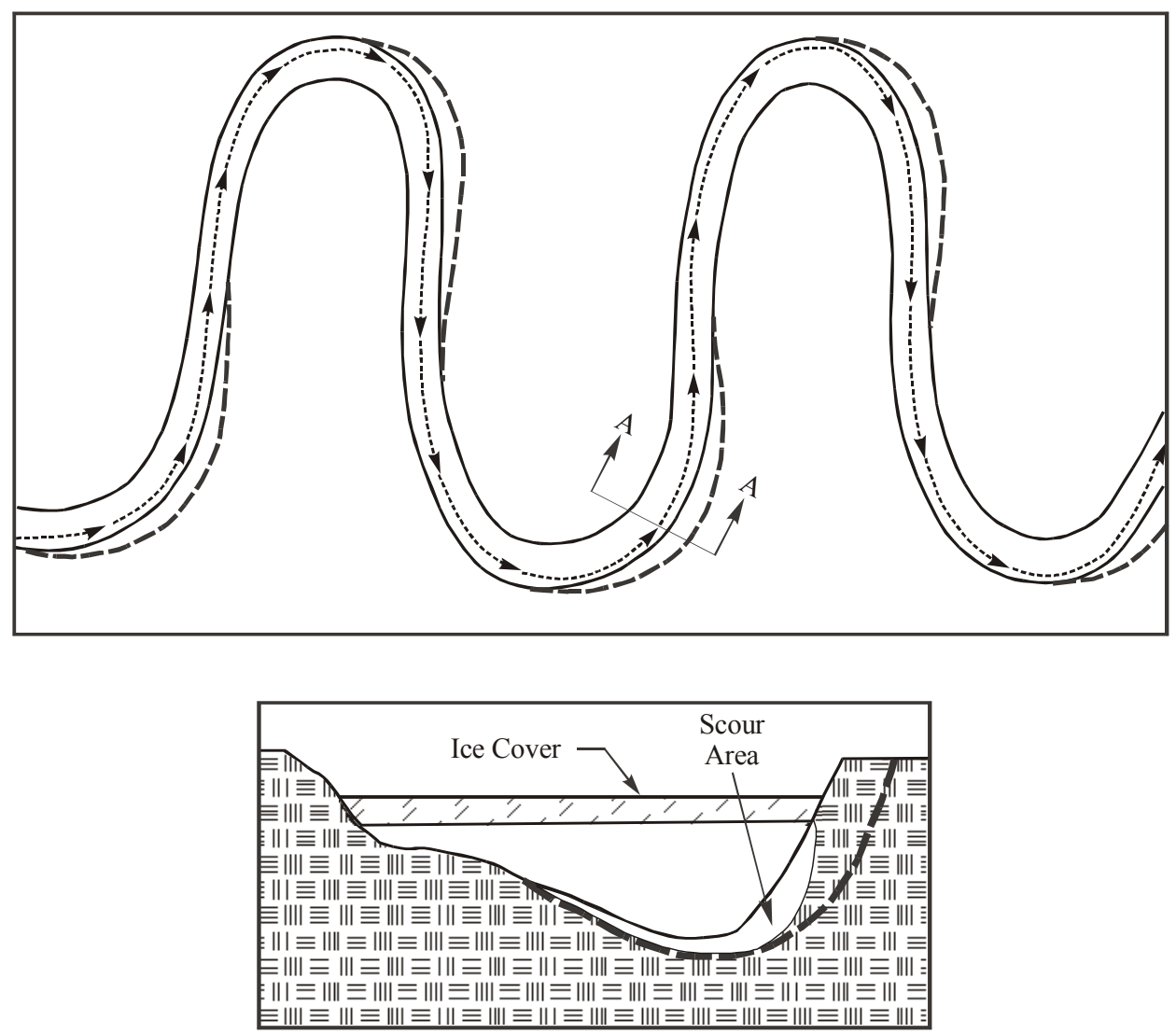

SECTION A-A

Figure 97. Ice cover concentration of flow toward the outer bank of a bend, which accelerates bed scour along the bank toe, bank erosion, and downstream migration of the bend.

changes in the variability of flow conditions during a year or during ice cover formation). This process is illustrated in Figure 98.

H3. Ice covers appeared to concentrate the flow towards the deeper locations of the river, and the concentrated flow further deepened the already deep locations. Shortly after ice cover breakup, the deepened locations in-filled partially with sediment. This process likely reflects the old river-engineering adage that depth attracts flow.

H4. An ice cover anchored to a riverbank fixes the cross-sectional area of the flow. Consequently, when the flow discharge increases, flow velocities under the ice increase and the riverbed may initially scour so as to increase the crosssectional area. As the area increases, flow velocities decrease, so the flow and sediment movement beneath the ice cover adjust to a new equilibrium. An ice 


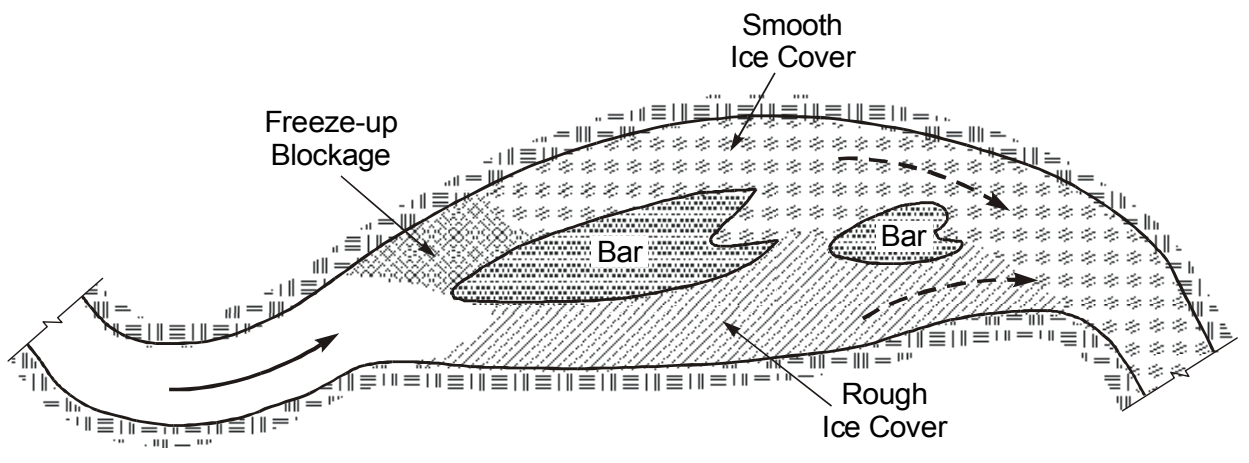

a. A relatively short initial accumulation of drifting ice in the upper subchannel may divert ice into the lower subchannel, which then becomes extensively enveloped by a rough ice cover. Meanwhile, the upper subchannel freezes over with a smooth ice cover or may remain partially open. The greater flow resistance in the lower subchannel causes the flow to favor the upper subchannel, which then enlarges.

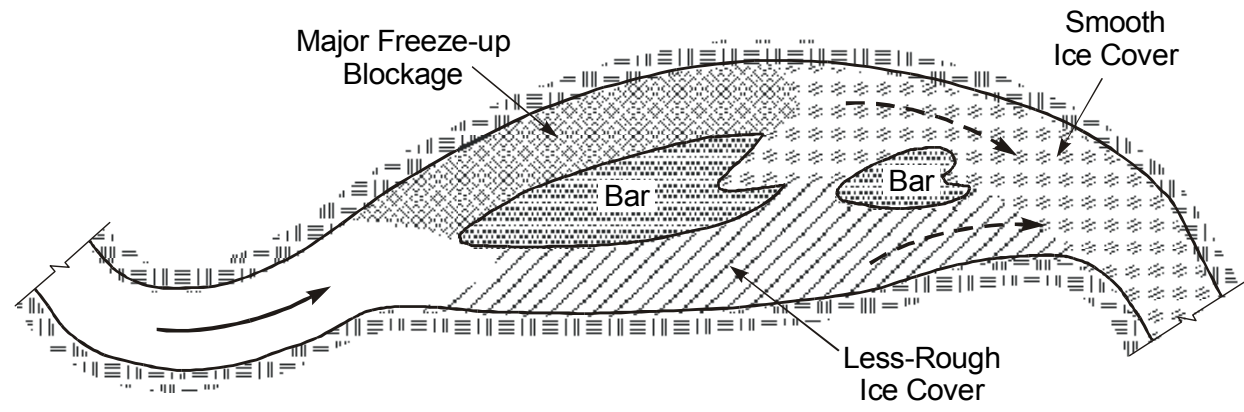

b. A relatively long initial accumulation of drifting ice in the upper subchannel may divert ice and flow into the lower subchannel, which then becomes extensively enveloped by a less-rough ice cover. The greater flow resistance in the upper subchannel causes the flow to favor the lower subchannel, which then enlarges.

Figure 98. Two scenarios for how ice cover formation in a sinuous-braided channel may alter the location of the major subchannel.

cover can become anchored to the riverbank during steady flow and especially cold weather. During ice cover breakup the cross-sectional area of flow is oversized for open water flow conditions. Sediment deposition then more-or-less re-establishes the open water cross-sectional area.

Several additional hydraulic processes were identified as being theoretically possible, and indeed they may have been underway along the entire Fort Peck 
reach. However, evidence for them was not readily apparent among the survey's data and observations. In particular, the following processes likely influenced channel stability:

H5. By reducing the sediment transport capacity of a reach, a free-floating ice cover redistributes bed sediment along the channel. River ice may accentuate erosion locally, but an ice cover reduces the channel's overall capacity to convey the eroded sediment a significant distance from the erosion location. Consequently bars can develop in response to flow conditions under river ice but be washed out shortly after the cover breaks up. In places where a significant load of bed sediment enters a long reach, river ice may cause mild aggradation of the channel it covers.

H6. By imposing additional flow resistance, a free-floating ice cover diminishes the effective gradient of flow energy available for sediment transport and alluvial channel shaping. Consequently cover formation can alter the alignment of the channel's thalweg, especially for sinuous-braided channels.

Bathymetry measurements provide data confirming processes $\mathrm{H} 1$ through H3. Data from the TDR probes indicate that process H4 occurred. Additional qualitative evidence for process $\mathrm{H} 4$ exists in the form of observations of bankfast-ice conditions and a photograph of water flowing over the ice cover at the Pipal site (RM 1716) in the winter of 1994-95 (Fig. 74). At present, only qualitative evidence exists for process $\mathrm{H} 5$ in the form of observations of bars exposed after ice cover breakup. Process H6 likely did not substantially affect the channel because it is so slow.

\section{Geotechnical influences of river ice}

River ice may exert several geotechnical influences $(G)$ on the riverbanks of alluvial channels. The following influences were observed during the survey:

G1. Flow stage changes rotated bankfast ice and thereby locally weakened the adjoining bank material.

G2. Collapsed bankfast ice wrenched and dislodged bank material and bank vegetation.

G3. River ice formation and the attendant rise in river stage may have raised levels of pore water pressure in the banks, potentially weakening the banks, especially when a rapid drawdown of river stage occurred following ice cover breakup.

G4. Elevated water levels in the river affected the freeze-thaw stressing of bank material. 
These influences weaken the bank's resistance to scour, and they increase the local supply of sediment to the channel. Figure 14 illustrates the first two influences, which may have been factors at the Tveit-Johnson and Vournas sites. The last two geotechnical influences were likely at work, but they were not monitored during the present survey. None have been well studied.

Channel bank freezing is closely linked to bankfast ice formation along a channel. The details of the relationship are unclear, however. The factors involved are the bank condition (material, vegetation, snow, etc.), the relative elevations of the water table and the flow stage, and the temperatures of the groundwater and the river water. Bankfast ice weakening of banks is particularly significant for steep banks, which typically contain sufficient clay to allow them to maintain a steep slope.

\section{Combined impact of hydraulic and geotechnical influences}

Evidence from the survey suggests that a single hydraulic or geotechnical effect of river ice may disturb a channel but not necessarily destabilize it. However, the combined impact of hydraulic and geotechnical influences may be destabilizing. A switch in thalweg alignment or a bank failure alone may not destabilize a channel. Eventually the thalweg may switch back to more or less its prior condition. Besides, a single ice influence may be damped or possibly constrained. For instance, the flow concentration along a thalweg may be damped by an increase in bed resistance resulting from an increase in bedform size, and bank erosion may be damped as the bank slope consequently flattens. Moreover, the collapse of a high bank that deposits a large mass of sediment into the channel, or the exposure of scour-resistant strata (e.g., a clay layer, hardpan, or rock outcrop), may locally constrain thalweg shifting or entrenchment.

Not surprisingly the survey supports the conclusion that the channel morphology impacts of river ice are more severe for channels whose morphology already is less stable under conditions of open water flow. Sinuous-point-bar, sinuous-braided, and braided alluvial channels are especially prone to river ice impact, especially if they have steep banks formed of fine and partially cohesive sediments. The principal thalweg of such channels usually lies close to the outer banks of bends, and the banks themselves are prone to border ice loading, lack of vegetation cover (typical of eroding banks), and freeze-thaw weakening. Figure 99 depicts the susceptibility of banks in such channels, which are typical of the Fort Peck reach during winter. The thalweg lies close to the bank, such that the flow continually erodes the bank toe, keeping the bank steep and possibly undercutting the bank. Frost penetration deepens as cracks develop in the bank, and the water table is held relatively high. The channel becomes destabilized and shifts. 


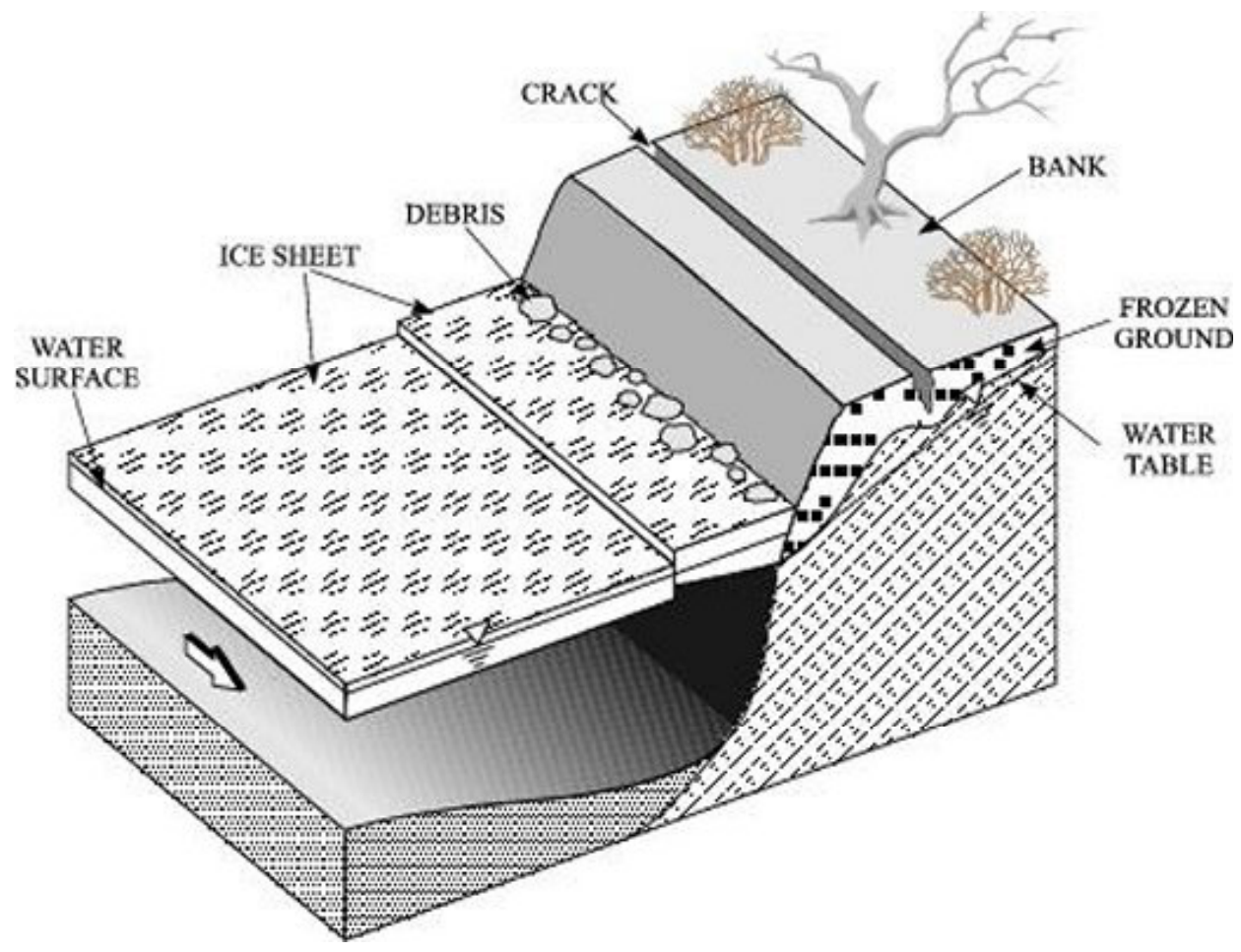

Figure 99. Methods by which hydraulic influences (e.g., thalweg shift and bank toe erosion), together with geomechanical influences (e.g., freeze-thaw weakening, seepage pressures, and bankfast ice loading), may weaken and erode channel banks, resulting in continual channel destabilization.

Survey findings do not indicate that the problem of pump site sedimentation is directly related to bank erosion upstream of a pump site. The two problems are direct, but separate, consequences of the effects of river ice. 


\section{CONCLUSIONS AND FURTHER ISSUES}

The conclusions are limited to observations made during the winter of 199899 , which was relatively mild. The extensive survey provided preliminary evidence into several ways by which river ice formation likely influences channel bathymetry, with possible impacts on channel stability along the Fort Peck reach of the Missouri River. However, the influences are complex and sensitive to the flow discharge and ambient temperature while an ice cover develops through the reach. They can be characterized in terms of hydraulic and geotechnical influences. Hydraulic influences pertain to the flow resistance performance of the channel, whereas geotechnical influences pertain to the channel bank loading and strength. By themselves, neither hydraulic nor geotechnical influences permanently alter channel bathymetry; local, ephemeral adjustments occur, which may reverse themselves. However, in combination, hydraulic and geotechnical influences may destabilize the river locally.

\section{River ice influences}

River ice exerts the following hydraulic influences on channel bathymetry along the Fort Peck reach of the Missouri River.

Where the river flows in a single bend (such as at the Tveit-Johnson, Vournas, and Pipal sites), ice cover formation promoted outward shifting of the channel thalweg and downstream migration of the bend by altering the cross-channel distribution of resistance so as to concentrate the flow toward the bend's outer bank.

- Where the river flows in two (or sometimes three) subchannels, ice cover formation can trigger a switch of the principal thalweg from one subchannel to the other (such as at the Culbertson and Mattelin sites). When a rougher ice cover formed in one subchannel, the cover partially diverted flow from that subchannel to the subchannel with the smoother ice cover. The subchannel with the smoother ice cover then enlarged, while the rougher-covered subchannel shrank. Survey observations suggest that thalweg switching is a recurrent process and that switches may take several winters to complete. Strictly speaking, such switching comprises a stochastic dynamic process that may be narrow-banded about a dominant period (e.g., a certain number of winters). It also may be broad-banded due to the several factors (e.g., variability of flow conditions during a year or during ice cover formation).

- By constricting flow, a rigid floating ice cover may locally scour the riverbed. This process may occur during steady flow under especially 
cold winter weather in which an ice cover becomes rigidly bonded to each bank.

River ice may exert several geotechnical influences on the banks of alluvial channels. Two influences were observed during this survey:

- Flow stage changes rotated the bankfast ice and thereby locally weakened the bank material at the root of the bankfast ice.

- Collapsed bankfast ice wrenched and dislodged bank material and bank vegetation.

Two other significant geotechnical influences were likely at work, but they were not monitored during this survey:

- River ice formation and the attendant rise in river stage may have raised the pore water pressure in the banks, potentially weakening the banks, especially when a rapid drawdown of river stage occurred when the ice cover broke up.

- The elevated river stage may have affected the freeze-thaw stressing of bank material.

These influences weaken bank resistance to scour, and they increase the local supply of sediment to the channel. The details of the relationship between bankfast ice and bank freezing are unclear, however. The relationship depends on the bank condition (material, vegetation, snow, etc.), the relative elevations of water table and flow stage, and the temperatures of the groundwater and river water.

Evidence from the survey suggests that a single hydraulic or geotechnical effect of river ice may disturb a channel but not necessarily destabilize it. However, the combined impact of hydraulic and geotechnical influences may be destabilizing. A switch in thalweg alignment or a bank failure alone may not destabilize a channel. Eventually the thalweg may switch back to more or less its prior condition. Besides, a single ice influence may be damped or possibly constrained. For instance, the flow concentration along a thalweg may be damped by an increase in bed resistance resulting from an increase in bedform size, and bank erosion may be damped as the bank slope consequently flattens. Moreover the collapse of a high bank that deposits a large mass of sediment into the channel, or the exposure of scour-resistant strata (e.g., a clay layer, hardpan, or rock outcrop), may locally constrain thalweg shifting or entrenchment.

Not surprisingly the survey supports the conclusion that the channel morphology impacts of river ice are more severe for channels whose morphology already is less stable under conditions of open water flow. Sinuous-point-bar, sinuous-braided, and braided alluvial channels are especially prone to river ice impact, especially if they have steep banks formed of fine and partially cohesive 
sediments. The principal thalweg of such channels usually lies close to the outer banks of bends, and the banks themselves are prone to border ice loading, lack of vegetation cover (typical of eroding banks), and freeze-thaw weakening. The thalweg lies close to the bank, such that the flow continually erodes the bank toe, keeping the bank steep and possibly undercutting the bank. Frost penetration deepens as cracks develop in the bank, and the water table is held relatively high. The channel becomes destabilized and shifts.

Survey findings indicate that the problem of pump site sedimentation is not directly related to bank erosion upstream of a pump site. The two problems are direct, but separate, consequences of the effects of river ice on channel stability.

\section{Instrumentation performance}

The survey showed mixed results in instrument performance. The web cameras were immensely useful as a means of almost continuous monitoring of ice and flow stage conditions at sites. They provided an inexpensive and reliable way to monitor the selected sites.

The TDR measurements of the bed elevation under ice confirm the utility of TDR technology for recording how ice cover formation, presence, and breakup accumulations affect local bed elevations. At the Culbertson site the TDR provided continuous records of scour or local bed elevation. This information was useful for relating changes in channel bathymetry to changes in flow and ice cover formation. For example, the TDR data indicate that ice cover formation led to an initial increase in bed erosion with consequent lowering of the channel bed. The bed likely eroded until the equilibrium elevation was re-established. The bed remained stable until the increase in flow or the transition zone from open water to an ice cover disrupted the velocity profiles. Following breakup, redeposition of sediment occurred.

The ground-penetrating radar proved to be overly sensitive to water salinity in the river, though the salinity level of the river was higher than expected for inland rivers. This result may indicate a limit for the further use of radar for bed profiling in midwestern rivers.

Large depths hampered measurements of flow depth and velocity at some survey locations. The rod technique was useful for most depths, but at depths greater than about $20 \mathrm{ft}$, flexure and vibration of the rod may have affected some of the measurements. 


\section{Issues for further investigation}

The numerous observations and extensive data obtained from the survey led to preliminary conclusions about the processes by which river ice formation influences alluvial channel stability along the Fort Peck reach of the Missouri River. The preliminary conclusions also indicate issues requiring further investigation:

- At sites where the river flows in several subchannels around large alluvial bars, it appears that an interactive relationship develops between ice cover formation and subchannel size. This interaction (or set of interactions) has never been studied before. To better understand what happens, it is necessary to monitor more closely ice formation and channel conditions, especially at the upstream ends of bars that separate the subchannels. A further survey should pay close attention to the progression of ice cover formation through the Culbertson, Mattelin, and possibly Whitmer sites (RM 1620, RM 1647, and RM 1687, respectively).

- The survey suggests that ice-triggered switching of thalweg location occurs at locations with multiple subchannels and that the switching may be a narrow-banded stochastic process about a period of three to four years. In addition to studying the processes causing thalweg switching, the periodicity of switching should be investigated. This is important in the planning of engineering activities. River-ice-induced switches in thalweg alignment at one location can have significant consequences for downstream locations, especially if a switch is accompanied by substantial bank erosion. Existing engineering structures (e.g., water intakes and bridge foundations) have been built without awareness of channel switching. Similar concerns exist for other reaches of the Missouri River and other rivers (e.g., the Platte and Yellowstone Rivers).

- Riverbank stability should be investigated for the combined influences of river ice formation. There is considerable practical interest in monitoring bank material conditions (extent of soil freezing, pore-water pressures, etc.) in conjunction with ice conditions at one site along the Fort Peck reach. A convenient and useful study site would be the Tveit-Johnson site.

- The process by which bankfast ice grows into banks, loads banks, and eventually collapses needs to be investigated.

- Design guidelines for channel and bank stabilization structures (and techniques) need to be modified to account for river ice influences. It is evident from the Pipal site that structures designed on the basis of open 
water conditions may produce adverse effects in conditions of icecovered flow. The river ice influences described in this report have consequences for engineering activities along the Fort Peck reach, other reaches of the Missouri River, and alluvial channels in general:

- River ice formation adversely affects the performance of channel and bank stabilization structures, as well as possibly damaging such structures;

- Switches in dominant thalweg location may cause sediment accumulation at riverside water intakes;

- Bank erosion, together with a switch in dominant thalweg location, may create potentially severe local scour at bridge piers and abutments.

An overall issue in need for further investigation is the influence of flow regulation on ice cover formation, cover stability, and cover breakup, and how flow regulation influences channel bathymetry. Once the contributing processes are better understood, it may be possible to carry out a broader study aimed at this issue. 


\section{LITERATURE CITED}

Andersland, O., and Anderson, D.M. (ed.) (1990) Geotechnical Engineering for Cold Regions. New York: McGraw Hill.

Lower Missouri River Coordinated Resource Management Group (CRM) (1996) Richland, Roosevelt, Valley and McCone Counties, Montana., Sept. 2327. Unpublished site assessments. CRM, 508 6th East Ave., Culbertson, Montana 59218.

Chamberlain, E.J. (1981) Frost susceptibility of soil: Review of index tests. Monograph 81-2, U.S. Army Cold Regions Research and Engineering Laboratory, Hanover, New Hampshire.

Doyle, P.F. (1988) Damage from a sudden river ice breakup. Canadian Journal of Civil Engineering, 15: 609-615.

Dupre, W.R., and R. Thompson (1979) The Yukon Delta: A model for deltaic sedimentation in an ice-dominated environment. Proceedings of the 11th Annual Offshore Technology Conference, p. 657-664.

Eardley, A.J. (1938) Yukon channel shifting. Bulletin of the Geological Society of America, 49: 343-358.

Gatto, L.W. (1988) Techniques for measuring reservoir bank erosion. Special Report 88-3, U.S. Army Cold Regions Research and Engineering Laboratory, Hanover, New Hampshire.

Gatto, L.W. (1995) Soil freeze-thaw effects on bank erodibility and stability. Special Report 95-24, U.S. Army Cold Regions Research and Engineering Laboratory, Hanover, New Hampshire.

Harlan, R.L., and J.F. Nixon (1978) Ground thermal regime. Section 3 in Geotechnical Engineering for Cold Regions (Andersland and Anderson, ed.). New York: McGraw Hill.

Hamelin, L.-E. (1979) The Bechevnik: A river bank feature from Siberia. The Musk Ox, 25: 70-72.

Haydon, G.C. (1931) The Missouri River and its improvements. Technical Report, U.S. War Department, Corps of Engineers, Missouri River Division, Kansas City District. Reprinted by Office of the Chief of Engineers, Washington, D.C., 1947.

Hopkins, W.B., and J.R. Tilstra (1996) Availability of ground water from the alluvium along the Missouri River in northeastern Montana. Hydrologic Investigation Atlas, Report HA-0224, U.S. Geological Survey, Reston, Virginia. 
Kellerhals, R., and M. Church (1980) Comment on "Effects of channel enlargement by river ice processes on bankfull discharge in Alberta, Canada," by Smith, D.G. Water Resources Research, 16 (6): 1131-1134.

LaGrone, D.L., and J.I. Remus (1998) Nontraditional erosion control projects constructed on the Missouri River. Proceedings of the ASCE Conference on Water Resources Engineering, Memphis, p. 399-404.

Lambe, T.W., and R.V. Whitman (1979) Soil Mechanics. New York: John Wiley and Sons.

Lawson, D.E. (1983) Erosion of perennially frozen streambanks. CRREL Report 83-29, U.S. Army Cold Regions Research and Engineering Laboratory, Hanover, New Hampshire.

Lawson, D.E. (1985) Erosion of northern reservoir shores: Analysis and application of pertinent literature. Monograph 85-1, U.S. Army Cold Regions Research and Engineering Laboratory, Hanover, New Hampshire.

Mackay, D.K., D.A. Sherstone, and K.C. Arnold (1974) Channel ice effects and surface water velocities from aerial photography of Mackenzie River breakup. In Hydrological Aspects of Northern Pipeline Development, Report No. $74-$ 12. Task Force on Northern Oil Development, Environmental-Social Program, Northern Pipelines, Saskatoon, Saskatchewan.

Marusenko, Ya.I. (1956) The action of ice on river banks. Priroda, 45 (12): 9193.

Mellema, W.J. (1997) An evaluation of streambank erosion control projects along the upper Missouri River. Technical Report submitted to U.S. Army Corps of Engineers, Omaha District.

Neill, C.R. (1976) Scour holes in a wandering gravel river. Proceedings of the Symposium on Inland Waterways for Navigation, Flood Control, and Water Diversions, $3^{\text {rd }}$ Annual Conf. of ASCE Waterways, Harbors and Coastal Engineering Division, New York, p. 1301-1317.

Pokrefke, T., D.A. Abraham, P.H. Hoffman, W.A. Thomas, S.E. Darby, and C.R. Thorne (1998) Cumulative erosion impacts analysis for the Missouri River master water control manual review and update study. Technical Report CHL98-7, U.S. Army Waterways Experiment Station, Vicksburg, Mississippi.

Prowse, T.D. (in press). River ice ecology. In River Ice (H.T. Shen, ed.), IAHR.

Reid, J.R. (1985) Bank-erosion processes in a cool-temperate environment, Orwell Lake, Minnesota. Geological Society of America Bulletin, 96 (6): 781792. 
Schoklitsch, A. (1937) Hydraulic Structures. New York: American Society of Civil Engineers.

Sellman, P.V., A.J. Delaney, and S.A. Arcone (1992) Sub-bottom surveying in lakes with ground-penetrating radar. CRREL Report 92-8, U.S. Army Cold Regions Research and Engineering Laboratory, Hanover, New Hampshire.

Simon, A., F.D. Shields, R. Ettema, C. Alonso, M. Marshall-Garsjo, A. Curini, and L. Steffen (1999) Channel erosion on the Missouri River, Montana, between Fort Peck Dam and the North Dakota border. Technical Report, USDAAgricultural Research Service, National Sedimentation Laboratory, Oxford, Mississippi.

Smith, D.G. (1979) Effects of channel enlargement by river ice processes on bankfull discharge in Alberta, Canada. Water Resources Research, 15 (2): $469-$ 475 .

Uunila, L.S. (1997) Effects of river ice on bank morphology and riparian vegetation along the Peace River, Clayhurst to Fort Vermilion. Proceedings of the 9th Workshop on River Ice, Fredericton, New Brunswick, p. 315-334.

USACE (1933) Report on Missouri River and Tributaries. House Document 238, 308 Report, Congressional Documents, 73rd Congress, Second Session, 1933-34, U.S. Government Printing Office, Washington, D.C.

USACE-Omaha (1945) Report on retrogression observations, Missouri River downstream of Fort Peck Dam. Technical Report, U.S. Army Corps of Engineers, Omaha District.

USACE-Omaha (1952) Report on degradation observations, Missouri River downstream of Fort Peck Dam. Technical Report, U.S. Army Corps of Engineers, Omaha District.

USACE-Omaha (1983) Missouri River, Fort Peck Dam to Williston, Aerial Mosaic.

USACE-Omaha (1986) Missouri River streambank erosion study: Fort Peck Dam, Montana, to the Yellowstone River, North Dakota. Technical Report (project No. C15074), U.S. Army Corps of Engineers, Omaha District.

USACE-Omaha (1996) Culbertson, Aerial Mosaic.

USACE-Omaha (1990) Aggradation, degradation, and water quality conditions: Missouri River mainstem reservoir system. Technical Report, River and Reservoir Engineering Section, Hydrologic Engineering Branch, U.S. Army Corps of Engineers, Omaha District. 
USACE-Omaha (1997) Section 33 non-traditional bank stabilization projects, North Dakota and Montana: Design and construction lessons learned. Technical Report, U.S. Army Corps of Engineers, Omaha District.

USACE-Omaha (1998a) Erosion sites along the Missouri River in Montana. Letter Report, September, U.S. Army Corps of Engineers, Omaha District.

USACE-Omaha (1998b) Section 33 non-traditional bank stabilization projects, North Dakota and Montana: Performance review. Technical Report, U.S. Army Corps of Engineers, Omaha District.

Wei, T.C. (1997) Downstream channel and sediment trends study. Technical report prepared for U.S. Army Corps of Engineers, Omaha District, by Midwest International Inc.

Williams, G.P., and M.G. Wolman (1984) Downstream effects of dams on alluvial rivers. Professional Paper 1286, U.S. Geological Survey, Washington, D.C.

Wuebben, J.L. (1988) A preliminary study of scour under an ice jam. Proceedings of the 5th Workshop on Hydraulics of River Ice/Ice Jams, Winnipeg, Manitoba, p. 177-190.

Wuebben, J.L. (1995) Ice effects on riprap. Chapter 31 in River, Coastal and Shoreline Protection: Erosion Control Using Riprap and Armourstone (C.R. Thorne, S. Abt, S.T. Barends, and K.W. Pilarczyk, ed.). New York: John Wiley and Sons.

Wuebben, J.L., and J.J. Gagnon (1995) Ice jam flooding on the Missouri River near Williston, North Dakota. CRREL Report 95-19, U.S. Army Cold Regions Research and Engineering Laboratory, Hanover, New Hampshire.

Yankielun, N.E., M.G. Ferrick, and P.B. Weyrick (1993) Development of an airborne MMW FM-CW radar for mapping river ice. CRREL Report 93-1, U.S. Army Cold Regions Research and Engineering Laboratory, Hanover, New Hampshire.

Yankielun, N.E., and L.J. Zabilansky (1998) Innovative instrumentation techniques for detecting and measuring effects of sediment scour under ice. Proceedings of the ASCE Water 98 Conference, Memphis, Tennessee.

Yankielun, N.E., and L.J. Zabilansky (1999) Laboratory investigation of time domain reflectometry system for monitoring bridge scour. ASCE Journal of Hydraulic Engineering, 125 (12): 1279-1284. 


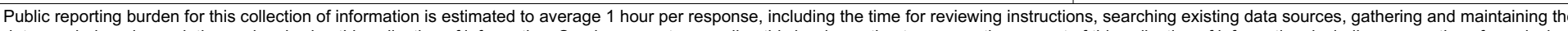

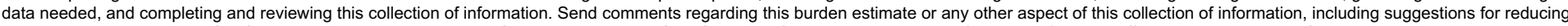

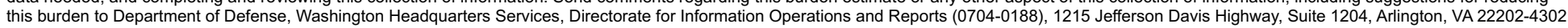

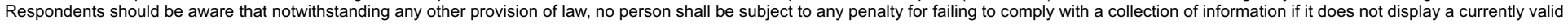
OMB control number. PLEASE DO NOT RETURN YOUR FORM TO THE ABOVE ADDRESS.
1. REPORT DATE (DD-MM-YY)
2. REPORT TYPE
3. DATES COVERED (From - To)

September 2002

Technical Report

4. TITLE AND SUBTITLE

Survey of River Ice Influences on

Channel Bathymetry Along the Fort Peck

Reach of the Missouri River, Winter 1998-1999

5a. CONTRACT NUMBER

5b. GRANT NUMBER

5c. PROGRAM ELEMENT NUMBER

6. AUTHOR(S)

5d. PROJECT NUMBER

Leonard J. Zabilansky, Robert Ettema, James Wuebben, and

Norbert E. Yankielun

5e. TASK NUMBER

5f. WORK UNIT NUMBER

7. PERFORMING ORGANIZATION NAME(S) AND ADDRESS(ES)

8. PERFORMING ORGANIZATION REPORT

NUMBER

U.S. Army Engineer Research and Development Center

Cold Regions Research and Engineering Laboratory

72 Lyme Road

ERDC/CRREL TR-02-14

Hanover, NH 03755-1290

9. SPONSORING/MONITORING AGENCY NAME(S) AND ADDRESS(ES)

10. SPONSOR / MONITOR'S ACRONYM(S)

Omaha District

U.S. Army Corps of Engineers

11. SPONSOR / MONITOR'S REPORT NUMBER(S)

\section{DISTRIBUTION / AVAILABILITY STATEMENT}

Approved for public release; distribution is unlimited.

Available from NTIS, Springfield, Virginia 22161.

\section{SUPPLEMENTARY NOTES}

\section{ABSTRACT}

This report documents the findings of a comprehensive survey that investigated the extent to which river ice influences channel bathymetry along the Fort Peck reach of the Missouri River. The Fort Peck reach stretches about 170 miles from Fort Peck Dam, Montana, to Lake Sakakawea, North Dakota. The reach comprises a channel of alluvial sinuous-braided morphology historically known for its shifting thalweg and erosion-prone banks. The survey, which entailed extensive monitoring and detailed measurements of channel bathymetry, ice conditions, and flow velocity distribution, was conducted at five sites during the winter of 1998-99. The observations and data, though still preliminary and incomplete, indicate fundamental processes whereby river ice formation may influence channel bathymetry along the Fort Peck reach, as well as other flow-regulated, alluvial-channel rivers. Prior to the survey, the river ice processes had only been conceptualized but not documented. The results provide evidence that ice cover formation can trigger shifts in the channel thalweg location and can exacerbate riverbank erosion. The observations and data provide insights for operating Fort Peck Reservoir, as well as for engineering activities in the Fort Peck reach of the Missouri River. More generally, they indicate which riverbank stabilization structures likely work better in winter conditions, where riverside water intakes might best be located, and the effects of ice formation on local channel morphology at bridge crossings. The information also has significance for dredging work. The conclusions are based on measurements made during the 1998-99 winter season on the Fort Peck reach, when the hydraulic and ice conditions were unique during the time of the measurements. Further work is needed to confirm the processes and to understand the short- and long-term interactions between the variables influencing the bank-ice-sediment system.

\begin{tabular}{|c|c|c|c|c|c|}
\hline 15. SUBJECT TERMS & \multicolumn{2}{|c|}{$\begin{array}{l}\text { Bathymetry } \\
\text { Missouri River }\end{array}$} & $\begin{array}{l}\text { Riverbank erosion } \\
\text { River ice }\end{array}$ & & \\
\hline \multicolumn{3}{|c|}{ 16. SECURITY CLASSIFICATION OF: } & 17. LIMITATION OF & 18. NUMBER & 19a. NAME OF RESPONSIBLE PERSON \\
\hline a. REPORT & b. ABSTRACT & c. THIS PAGE & & & 19b. TELEPHONE NUMBER (include area code) \\
\hline $\mathrm{U}$ & $\mathrm{U}$ & $\mathrm{U}$ & $\mathrm{U}$ & 151 & \\
\hline
\end{tabular}




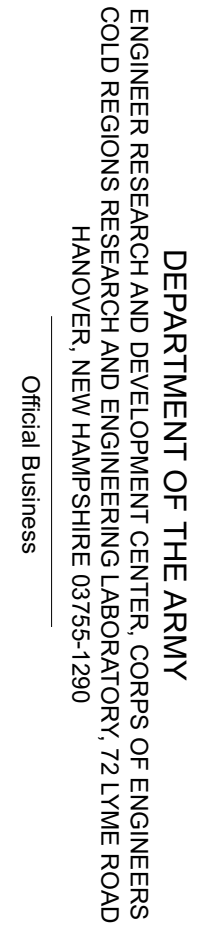

